\title{
"TODOS UNIDOS TRIUNFAREMOS"
}

Las interacciones de las organizaciones subnacionales del peronismo platense (2011 y 2017)

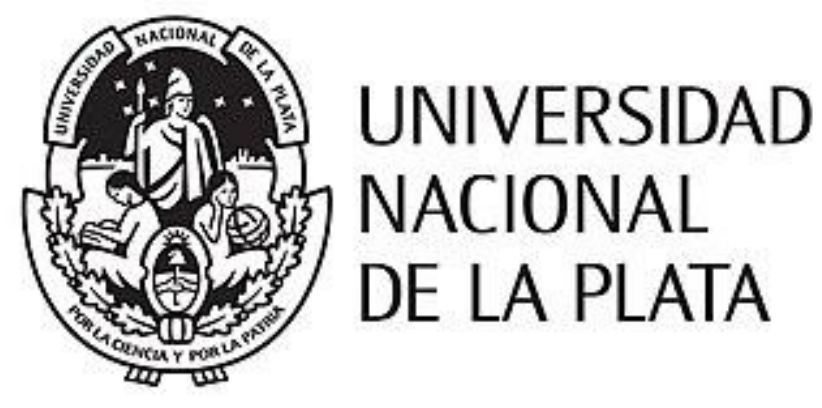

Tesis para optar por el título de Doctor en Ciencias Sociales

Autor: Dell’Unti Juan Cristóbal

FaHCE-IdIHCS-UNLP

Director: Retamozo Martín

$05 / 11 / 2019$ 
A la lleana y a través de ella a la familia, sanguínea y ensamblada.

Porque el amor no se anda con nimiedades. 
La siguiente investigación se propuso analizar las formas de construcción de la unidad política del peronismo platense durante los años 2011 y 2017. El objetivo de la misma fue el de poder comprender las lógicas de representación, cooperación y disputa de las organizaciones subnacionales de esta fuerza política, en pos de aportar al análisis de la organización interna del peronismo, en particular, y del sistema de partidos políticos argentino en general. La hipótesis que guio el estudio sostuvo que, a nivel municipal, el peronismo presenta diferentes modos de construcción de la representación política distinguibles tanto por su relación con las élites extra-locales, los marcos de alianzas internos y la construcción de un modo de inserción en el espacio identitario. Finalmente, para la comprensión de estos fenómenos, la investigación se focalizó en los procesos electorales, bajo la propuesta de que los mismos implican una cristalización contingente de los procesos políticos.

Palabras claves: Peronismo, organización subnacional, movimiento partidario, lógicas de representación política, estrategia electoral, identidad política. 


\section{Agradecimientos:}

La presente tesis no hubiera sido posible sin la ayuda y el acompañamiento de un conjunto amplio de personas e instituciones. En primer lugar quisiera agradecer a las autoridades de la FaHCE-UNLP, como así también del IdIHCS, lugares donde pude trabajar y desarrollar la investigación. También es importante agradecer al CONICET que me permitió contar con una beca de finalización de tesis, que fue muy importante para poder reinsertarme en el circuito del doctorado. A las autoridades del Liceo Víctor Mercante que también me apoyaron en mi retorno de México. Agradecer a las autoridades de la carrera de Posgrado de la FaHCE, como así también a los y las docentes que leyeron los avances de este trabajo y realizaron comentarios importantes en los talleres de Tesis I y II. También quisiera agradecer a mi director de tesis, Martín Retamozo, con quien vengo trabajando desde hace varios años y sin el cual nada de esto hubiera sido posible.

Del universo de personas que me acompañaron, apoyaron, leyeron y comentaron, muchas de las cuales no están vinculadas necesariamente a la academia, quisiera agradecer a mi familia en especial por el apoyo. A Jorge, Emilio, Germán, Mario, Ernesto, Candela, Facundo, Julio, Ricardo, Eduardo. A mis compañeros y compañeras de la Facultad y del departamento de Filosofía. A todos y todas, muchas gracias. 


\section{Índice}

"TODOS UNIDOS TRIUNFAREMOS"

Las interacciones de las organizaciones subnacionales del peronismo platense (2011 y

2017)

Índice 5

Introducción: "un peronismo, dos peronismos, muchos peronismos" ................................. 10

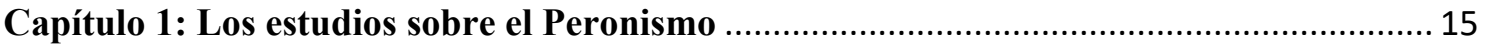

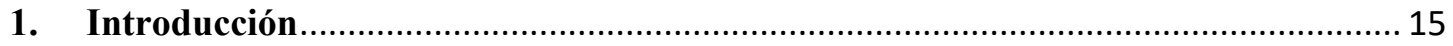

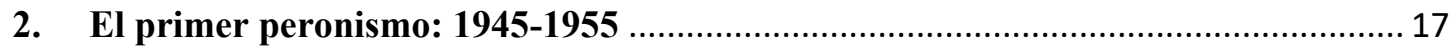

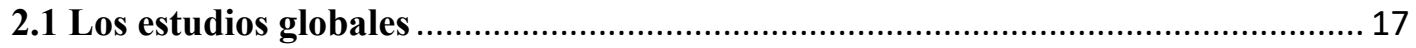

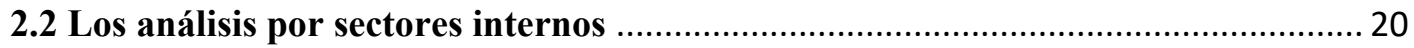

3. El peronismo de la resistencia, al retorno de Perón: 1955-1976 .............................. 24

3.1 Los estudios de la resistencia en la clase obrera …................................................ 25

3.2 Los estudios de la resistencia en las organizaciones armadas ................................ 27

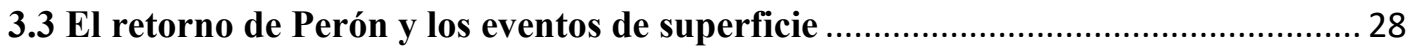

4. El peronismo de los años 80: crisis de identidad y reconstrucción partidaria.......... 29

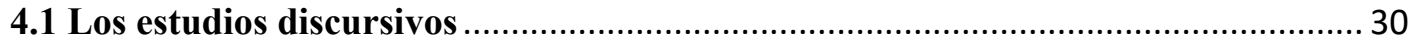

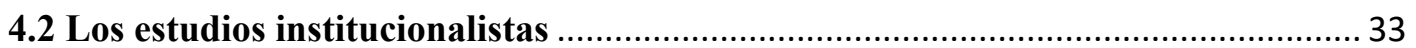

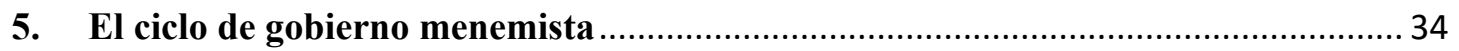

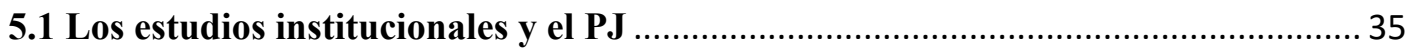

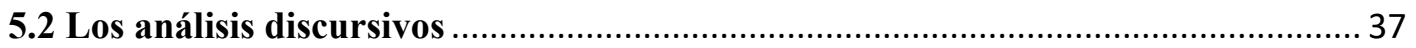

6. El ciclo de poder del Kirchnerismo y la aparición del Frente Para la Victoria....... 39

6.1 Los estudios situados bajo la égida de la continuidad ............................................... 39

6.1.1 Breve discusión sobre el clientelismo ......................................................... 40

6.2 Los estudios críticos y la matriz movimentista ........................................................ 42

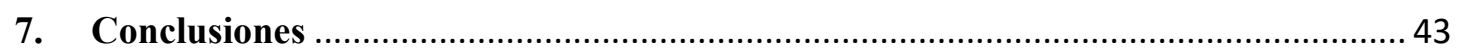

Capítulo 2: Marco Teórico y Consideraciones Metodológicas ................................................ 45

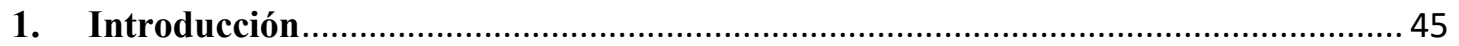

2. Marco conceptual: supuestos y conceptos centrales............................................. 45

3. Categorías, dimensiones y observables................................................................ 52

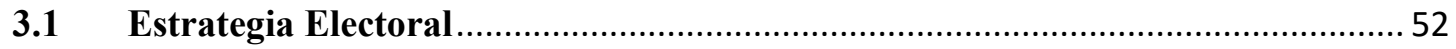

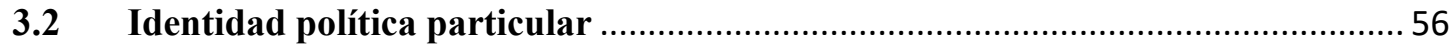

4. Consideraciones metodológicas y recorte temporal …............................................... 58

4.1 Algunas consideraciones sobre las reglas electorales ..........................................6 60

4.1.1 Consideraciones sobre las boletas electorales ............................................. 61

4.2 Consideraciones sobre el diseño institucional provincial y local.......................... 63 
Capítulo 3: El peronismo platense y las elecciones del 2011: división, anticipación y acumulación diferenciada

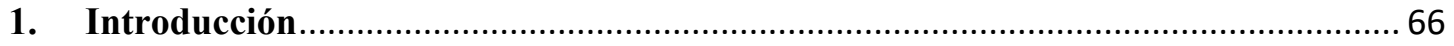

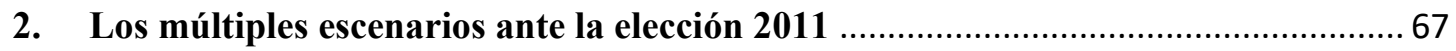

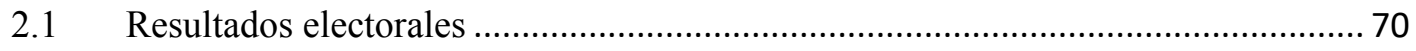

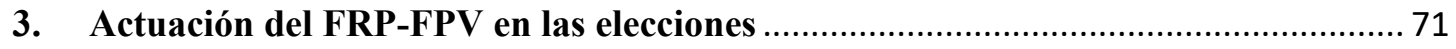

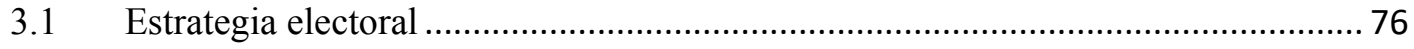

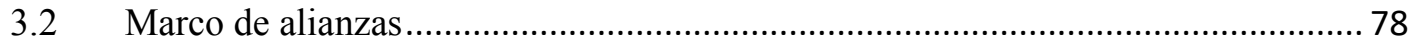

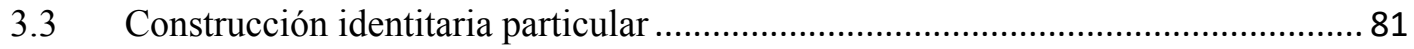

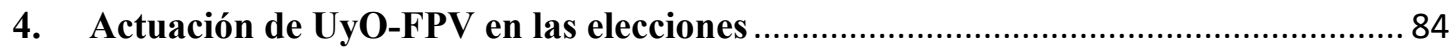

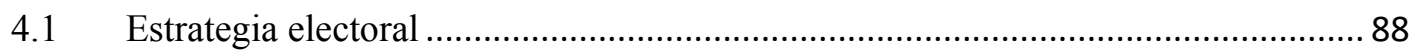

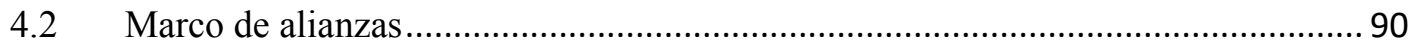

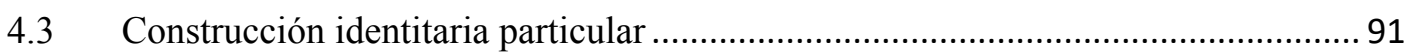

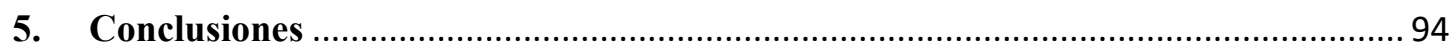

Capítulo 4: Las elecciones del 2013: disputa, inundación y asignación diferencial de

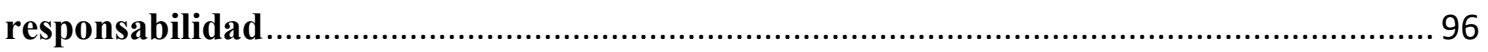

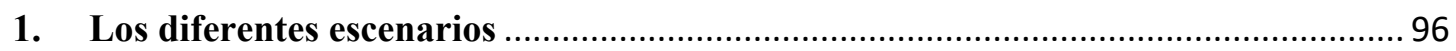

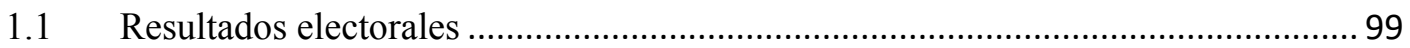

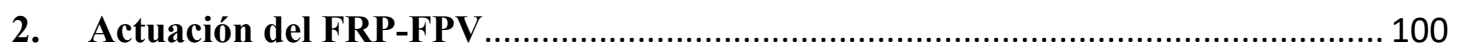

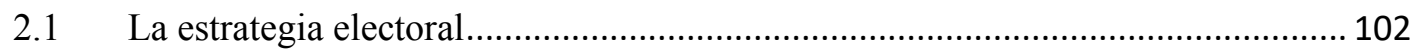

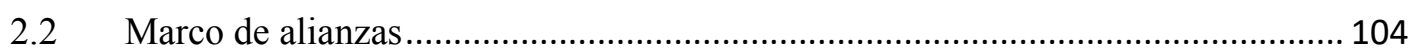

2.3 Construcción identitaria particular ................................................................. 107

3. Actuación de UyO en las elecciones del 2013 ........................................................ 110

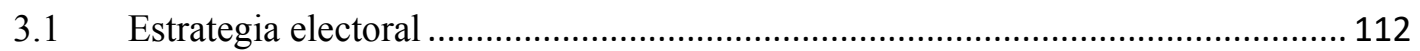

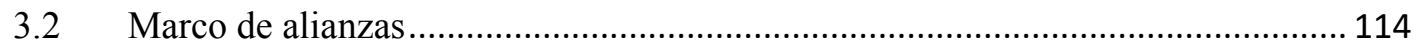

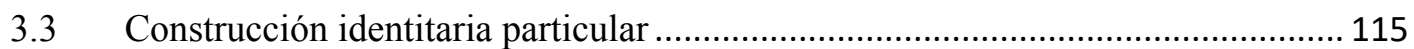

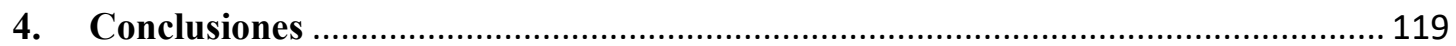

Capítulo 5: Las elecciones del 2015: Cierre del ciclo político y reconfiguraciones ............ 120

1. Los múltiples escenarios ante las elecciones del 2015 ........................................... 120

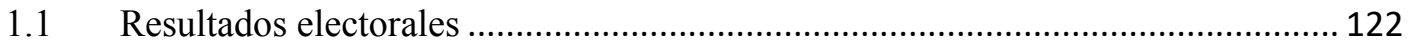

2. Actuación del FRP-FPV ante las primarias del 2015 _......................................... 123

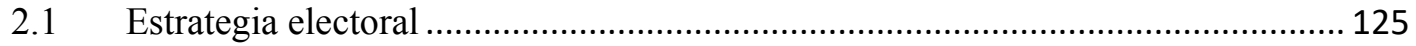

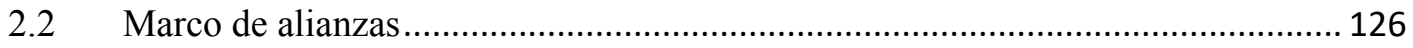

2.3 Construcción identitaria particular ................................................................. 129

3. Actuación de UyO ante las primarias del 2015 ..................................................... 132 


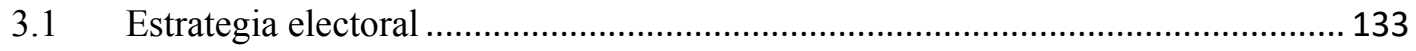

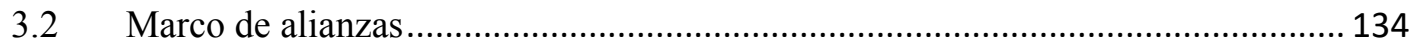

3.3 Construcción identitaria particular .................................................................. 137

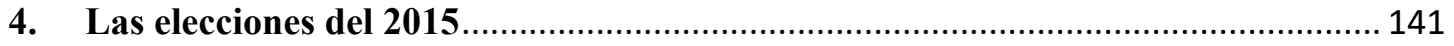

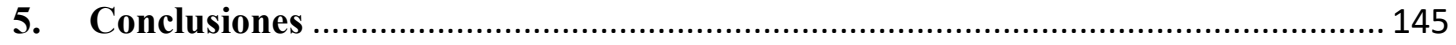

Capítulo 6: El día después: nuevas agrupaciones y cambio del escenario local ................. 147

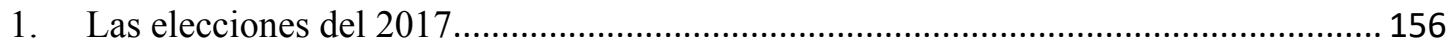

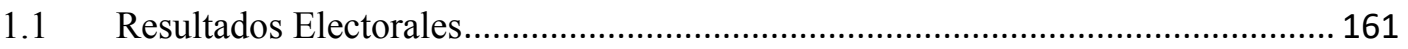

2. Actuación de Unidad Ciudadana ante las elecciones del 2017 ..................................... 162

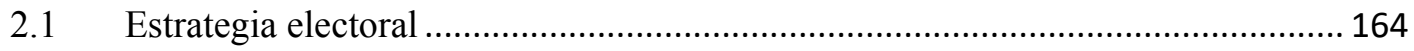

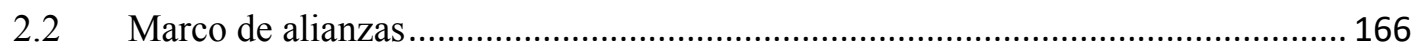

2.3 Construcción identitaria particular ...................................................................... 168

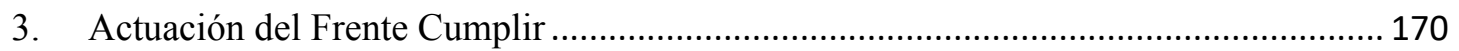

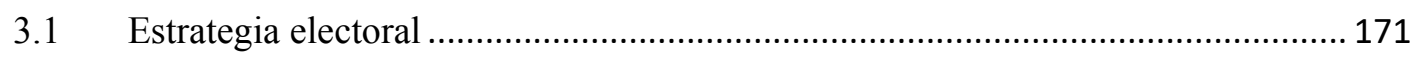

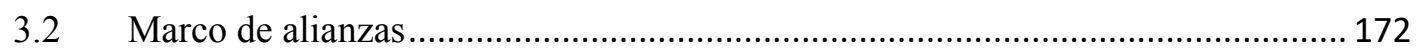

3.3 Construcción Identitaria Particular..................................................................... 174

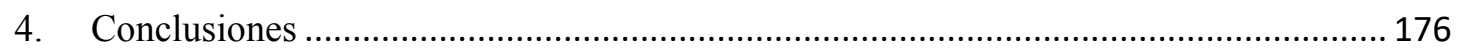

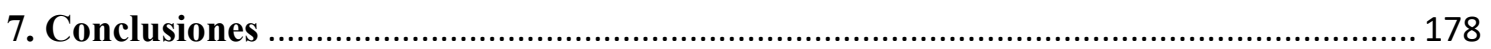

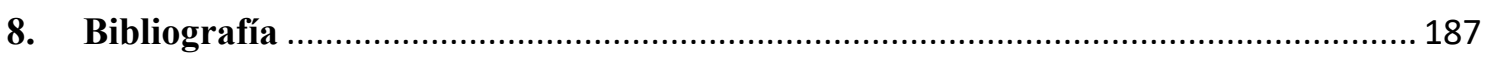

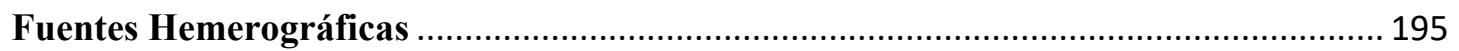

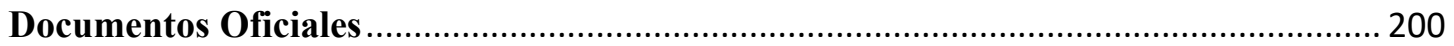

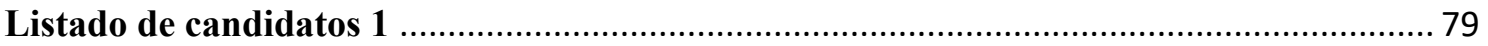

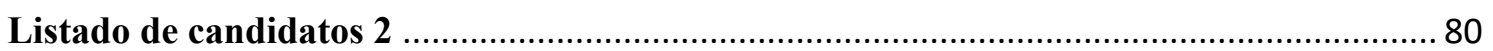

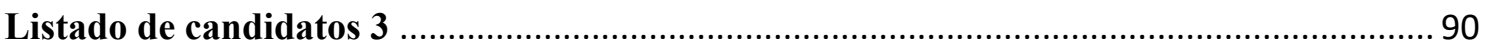

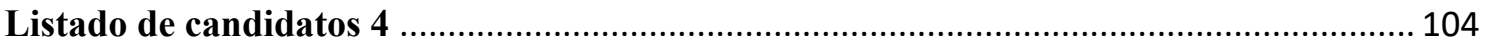

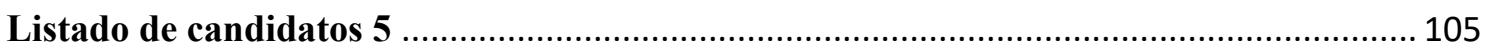

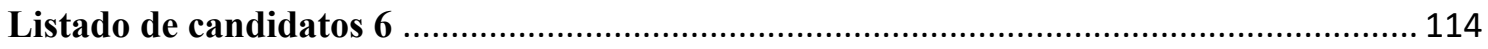

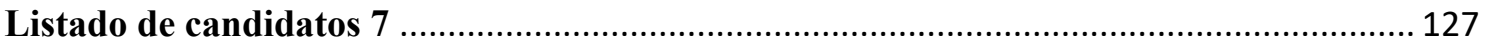

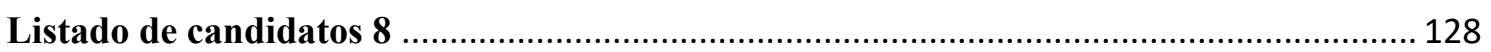

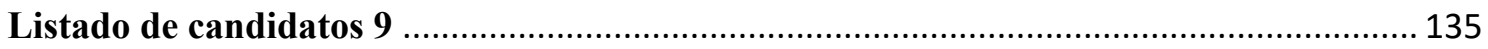

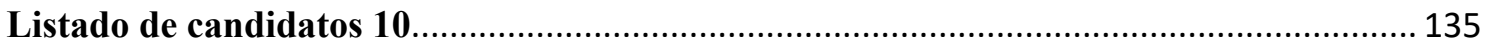

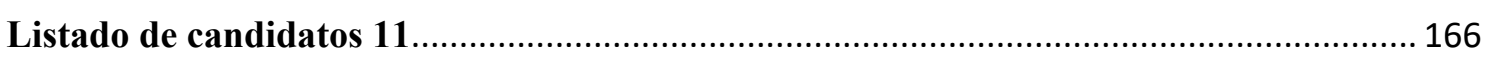

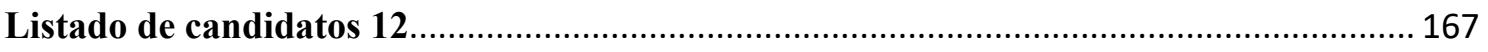

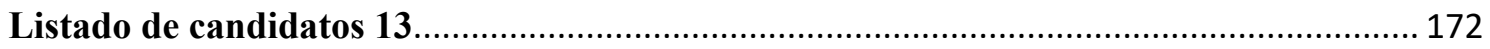

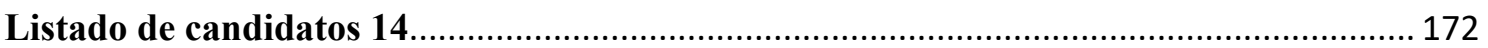

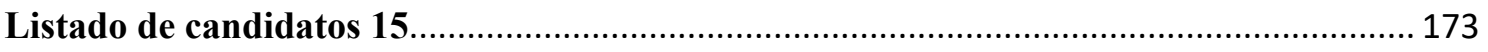

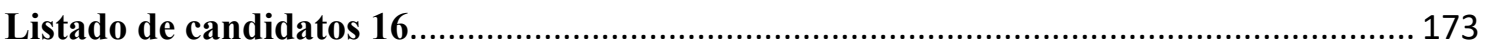




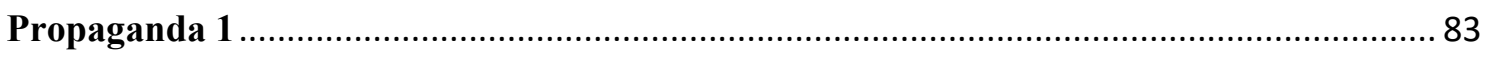

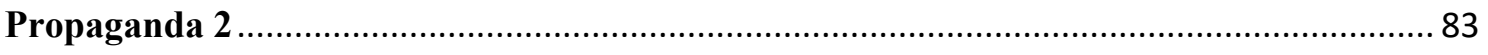

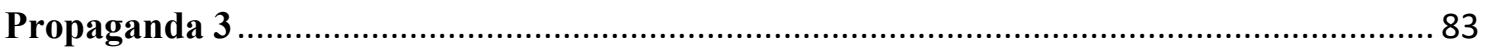

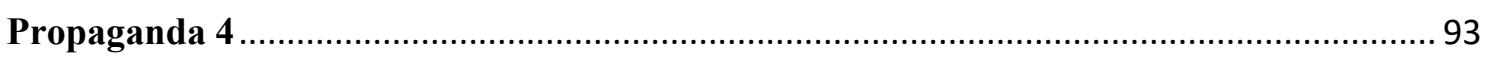

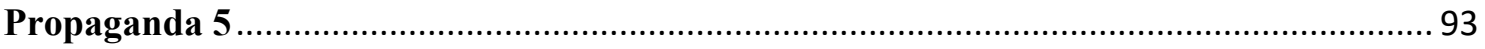

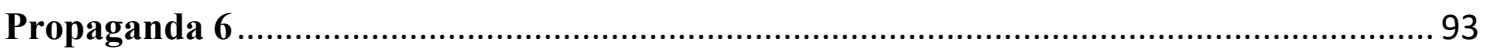

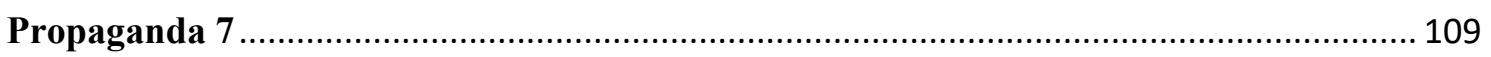

Propaganda 8

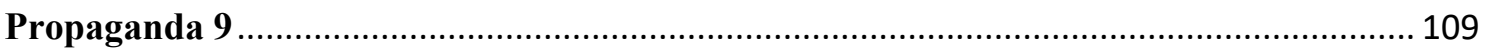

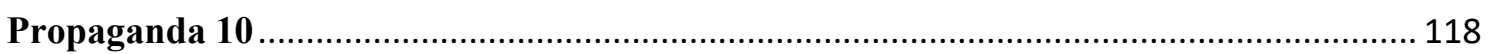

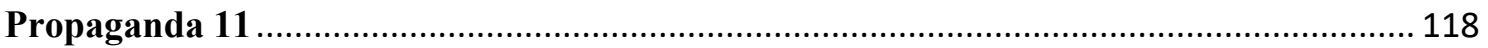

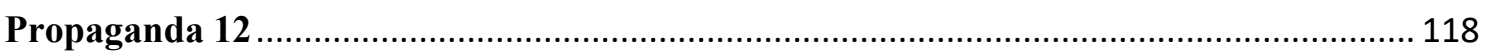

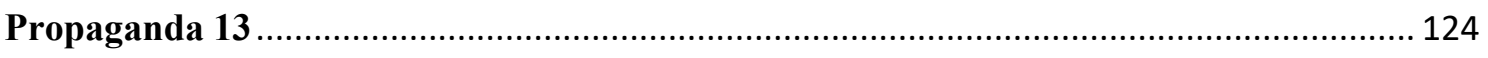

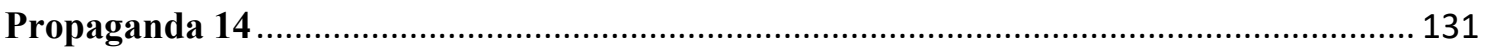

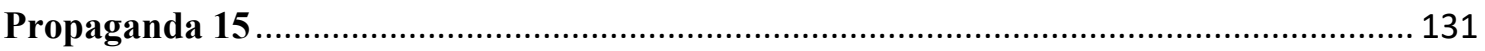

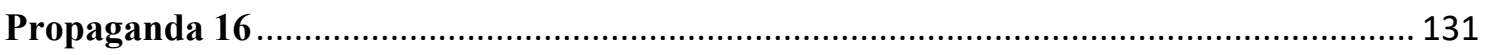

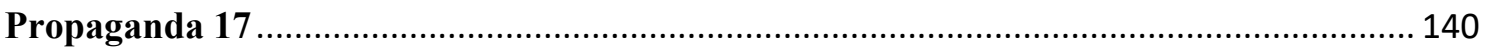

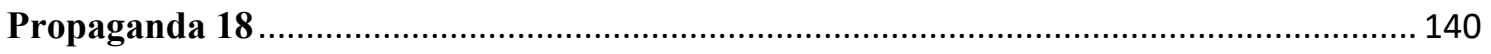

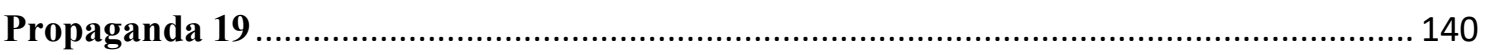

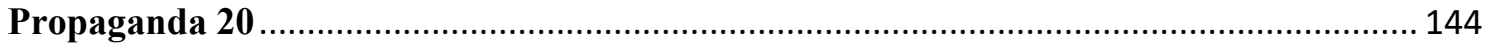

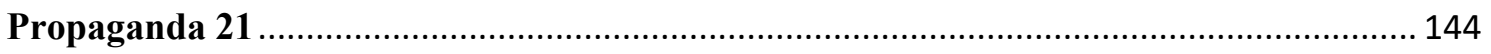

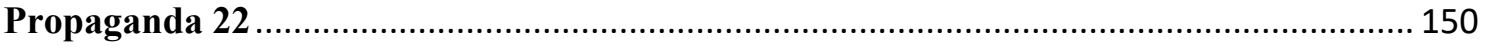

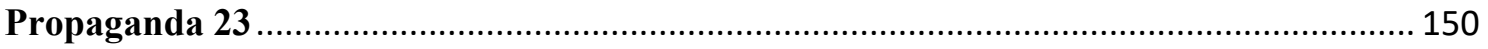

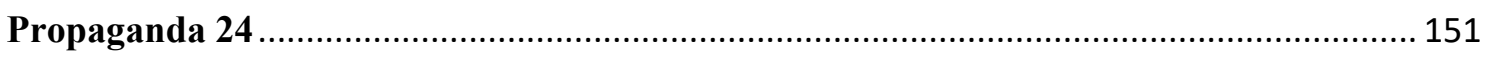

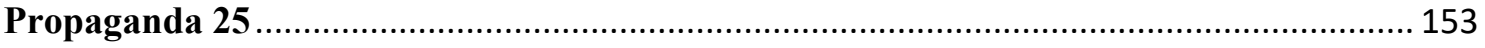

Propaganda 26

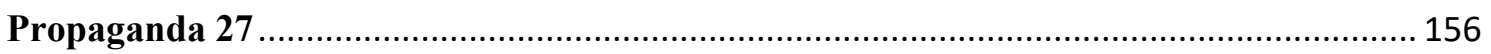

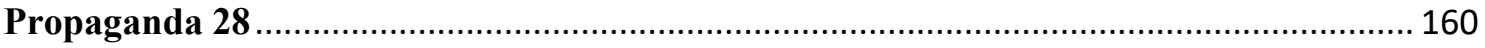

Propaganda 29

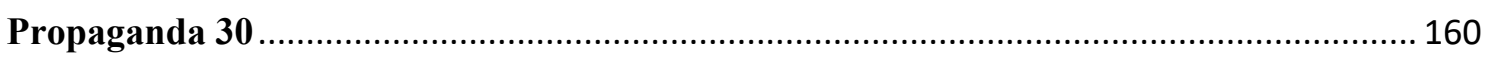

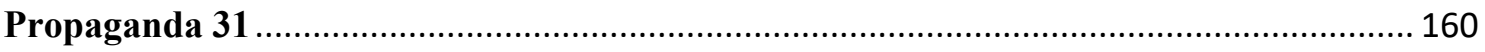

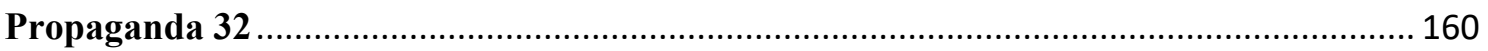

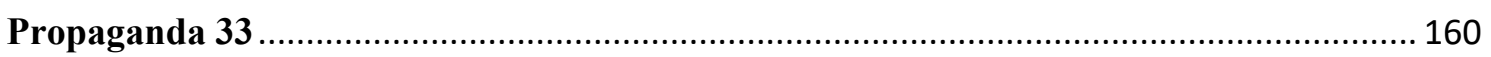

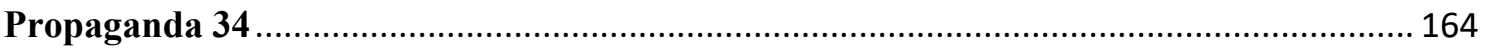

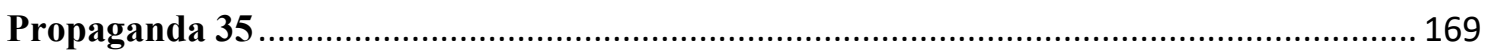

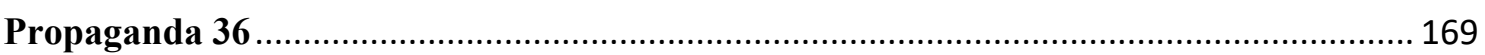

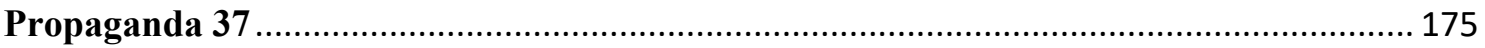

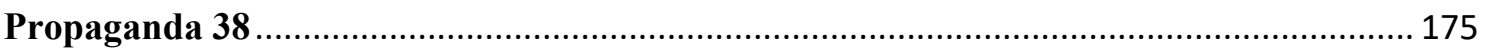

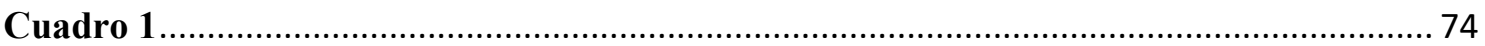

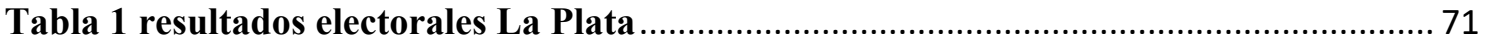

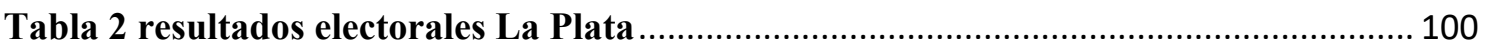




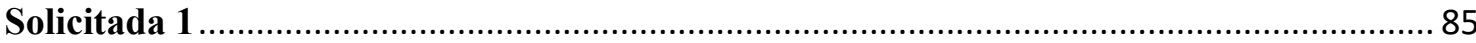

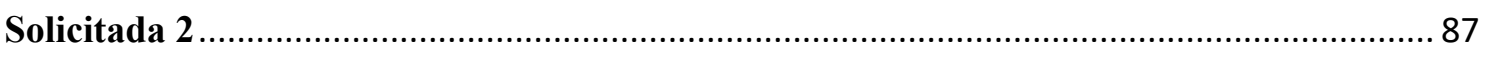

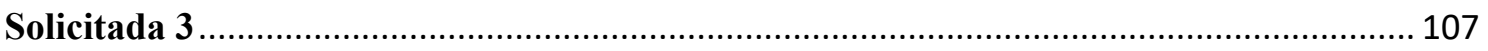

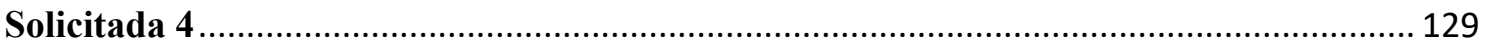

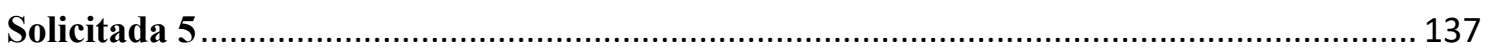

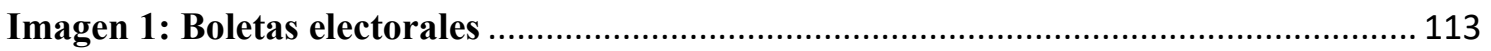

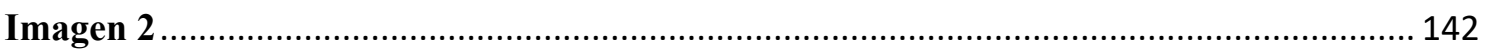




\section{Introducción: "un peronismo, dos peronismos, muchos peronismos"}

“...no podemos sorprendernos de que ser peronista sea, en una medida muy evidente, preguntarse qué es ser peronista."

Horacio Gonzalez

El peronismo es hoy el enigma político argentino más desafiante para su estudio. Cargado de una historia con múltiples etapas, liderazgos, programas y adscripciones, esta fuerza política mantiene su obstinación de rehuirle a la tranquilidad que otorga la previsibilidad de lo reiterado. Con la reinvención como práctica habitual, el peronismo transcurre sin perturbarse demasiado por el hecho de no contar con una única respuesta a la pregunta sobre lo que incluye su propia constitución. Ciertamente el problema de estudiar una fuerza política masiva que a lo largo de su historia atravesó tan distintos escenarios, estriba más en los eventos que parecen desbordar los sistemas clasificatorios que en otra cosa. Así, la cuestión de si es un partido, un movimiento o un frente electoral, conforman tópicos reincidentes de las investigaciones en tanto ninguna categoría pareciera lograr dibujar suficientemente el contorno de esta fuerza. Frente a esto la multicitada frase: "Peronistas somos todos" que sostuvo Perón en una entrevista de la que no quedan registros pero si muchos recuerdos, agregó al problema una universalidad desconcertante. Sin embargo no es solo su reinvención lo que vuelve problemático su estudio. También sería posible remarcar fenómenos como los de crecimiento organizacional descentralizado, su multiplicidad de narrativas identitarias o los permanentes fenómenos de disputas internas los cuales, contra esa fórmula universalista, parecieran descomponer al peronismo en un conjunto interminable de grupos, corrientes y posiciones políticas.

La presente tesis es el resultado de la investigación sobre las formas de organización interna del peronismo en la ciudad de La Plata durante el período 2011- 2017. El objetivo de la misma consistió en explicar los procesos de unidad electoral que lograron articular un conjunto diverso y diferenciado de organizaciones locales. Formas de participación que desde modos antagónicos configuraron un discurso público, un modo de disputa electoral y un tipo de negociación con sus élites nacionales y provinciales.

El argumento que se expone durante toda la investigación sostiene que en el análisis de 
las interacciones entre los actores subnacionales del peronismo, es posible advertir márgenes de autonomía que exigen un análisis específico y no derivado de las decisiones de las élites nacionales. Basados en las estrategias electorales y los usos de diferentes capitales políticos, estos mismos actores entablan negociaciones con las élites nacionales y provinciales de su misma fuerza, que les permiten trazar una trayectoria articulada y asimétrica en sus propios distritos. Simultáneamente, estas mismas construcciones, al interior del distrito, implican marcos de alianzas con una diversidad de agrupaciones, que se encuentran en permanente tensión $\mathrm{y}$ establecen un equilibrio fluctuante entre momentos de mayor solidez y momentos de elevados índices de competencia interna. Todo lo cual permite concebir la unidad organizativa como una consecuencia y no una causa, que en el marco de la coyuntura histórica en la que se encuentra inserta, resulta circunstancial y contingente.

Ahora bien, en el marco de un sistema democrático presidencialista como el argentino, en el que se ha marcado reiteradamente por los estudios de partidos su baja institucionalización, la discusión sobre la organización interna de los partidos políticos fundamentalmente los grandes partidos como el PJ o la UCR- deviene en una discusión central para comprender los arreglos ad hoc que se generan y con los que los mismos suplen la baja incidencia de las rutinas institucionales. En este contexto, el PJ constituye un caso de estudio paradigmático en tanto en reiteradas ocasiones ha logrado articular un desarrollo extensivo masivo y una estabilización gubernamental en sus períodos al frente del gobierno -cualquiera sea el nivel del Estado. Todo esto, combinado con una alta capacidad de interpretación y subsecuente trasformación interna, de las variables ambientales. O dicho en otras palabras, el peronismo, sin dejar de ser el partido de masas más extendido del sistema democrático argentino, ha sido muchos peronismos a lo largo de su historia. Esta capacidad de variación -adaptación- observada por muchos estudios, ha sido explicada generalmente desde la observación de los ciclos de gobierno realizados a nivel nacional, apelando al supuesto de la verticalidad descendente como clave heurística para concluir que gracias a la síntesis operada a ese nivel, el resto de la organización se movería simétricamente en los niveles subnacionales. Sin embargo, con la aparición de los estudios extra-céntricos, este supuesto ha caído en crisis, no solo porque se pudo observar que las disputas internas no cesaron aun cuando se instauró un ciclo de gobierno nacional, sino que, fundamentalmente, si se opera un descentramiento del eje nacional, se visualizó una multiplicación de forma significativa de lo que se puede 
denominar como peronismos. De esta manera, además de los contrastantes ciclos políticos que el peronismo protagonizó a nivel nacional, al interior de los mismos, fue posible encontrar la cohabitación de una multiplicidad de experiencias diferentes, en las Provincias, y más abajo también en las Intendencias. Al respecto y como ejemplo, valga el detenerse en la variación de las estrategias de alianzas que se pudieron observar en toda la historia del peronismo en los diferentes niveles estatales disputados.

¿Cómo es que una fuerza política de masas logra establecer la estabilidad interna necesaria para ganar elecciones y gobernar el Estado, cuando no presenta ni un comando centralizado, ni conjunto de reglas claras? ¿Cómo puede mantenerse unida una fuerza con frecuentes fenómenos de disputa interna? Estas preguntas animaron la presente investigación, que se inscribe, además, en el conjunto de investigaciones que intentar responderlas desde una perspectiva local. Consideramos que este desplazamiento de la perspectiva de estudios, lejos de limitar el acceso a fenómenos importantes para la lógica organizativa -sea esta cual fuere- permite un estudio con mayor profundidad desde el cual se aporte a la comprensión de las formas de negociación que las élites nacionales entablan con los sectores subnacionales para llevar adelante sus proyectos.

Además de realizar un estudio sobre la organización del peronismo "desde abajo", es decir, desde una perspectiva municipal, el mismo se centró sobre los eventos electorales habida cuenta de que los mismos permiten capturar un momento - una regularidad- de lo que se ha denominado como la fluidez, desde los cuales poder establecer comparaciones, reconocer los desplazamientos y ubicar las trayectorias. Claramente la temporalidad de un proceso electoral no se agota en las campañas. Antes de las fechas institucionales estipuladas y luego de los recuentos electorales finales, los y las actoras componen un juego de expectativas y posiciones por el que van trazando tendencias que luego se consolidan en la arena pública. Esta selección temporal, forma parte de un conjunto de decisiones metodológicas más amplias que aun cuando serán expuestas y explicadas a continuación, merecen ser nombradas para aportar a la claridad del desarrollo. Ciertamente el devenir organizativo de una fuerza política no se agota ni en un lapso temporal definido -los procesos electorales- ni en un único territorio -la ciudad de La Plata. No obstante, el estudio enmarcado en estos dos recortes permitió profundizar el análisis de las interacciones por sobre la tentación de abarcar fenómenos más extendidos en el tiempo. Así también fue sorprendente para nosotros la escasa bibliografía existente sobre esta temática en particular focalizada en el distrito de La Plata, capital de la 
Provincia más importante del país. Esta investigación busca aportar también en este punto.

Por último, es importante recolocar el desafío que significó para esta investigación la selección de datos. El peronismo en tanto objeto de estudio, parece una maquinaria de producción de información casi inabarcable. Gran parte de su protagonismo en la escena pública, en todos los niveles, está sustentada en esta capacidad de construir un flujo de datos -internos o externos- que ocupan la mayor parte de las agendas trasformando el debate inter-partidario casi en un soliloquio. Dicho sea de paso, este flujo de datos se ve complejizado por la cantidad y variabilidad de discursos que grupos internos presentan.

\subsection{Estructura de la Tesis}

En lo que sigue, la tesis se compone de 6 capítulos más las conclusiones. El primero de los capítulos se aboca a la presentación de las diferentes investigaciones realizadas sobre la organización del peronismo. Habida cuenta que esta bibliografía resulta abundante y en constante crecimiento, se optó por estructurar las discusiones según un criterio que permitiera capturar las especificidades de las discusiones analíticas. Para ello, se han ordenado las investigaciones en función del período histórico que las mismas presentan como objeto de estudio. Esto resulta en un conjunto de 6 apartados que recorre casi en su totalidad la trayectoria del peronismo. Al interior de estos apartados, además, se ha organizado la literatura en función de dos ejes: el cronológico de las investigaciones, tratando de mostrar como evolucionaron las concepciones de la forma de organización en cada época; y un eje de matriz analítica, distinguiendo entre investigaciones que se estructuraban sobre una clave institucionalista y otras sobre una clave identitaria.

En el segundo capítulo se presentará el marco teórico de la investigación, así como también la estrategia metodológica adoptada. Se presentarán y discutirán los conceptos de objetivos políticos e identidad, así como las categorías de ellos derivadas, centrales para la presente investigación. También se expondrán las decisiones metodológicas en torno al recorte temporal, los criterios de selección de agrupaciones, las fuentes de información utilizadas y algunas consideraciones importantes sobre las reglas electorales vigentes, las boletas de votación y los “juegos” políticos que ambas permiten a los actores.

Los siguientes 4 capítulos son los denominados empíricos, donde se expone y analiza la información surgida de la aplicación de las variables a los diferentes eventos electorales. 
Teniendo en cuenta que cada elección implicó interacciones específicas entre los actores, se optó por diferenciar la presentación en distintos capítulos, intentando poder obtener mayores niveles de profundidad en la exposición de las trayectorias. Así como la compulsa democrática no se agota el día de la elección, sino que implica también a las campañas electorales e incluso los momentos anteriores en la disputa interna por la definición de los representantes a ocupar los cargos en las listas, tampoco implican una cesura hacia adelante. Por tanto, se optó en cada capítulo por establecer las continuidades entre los procesos electorales a partir de una presentación de la coyuntura política y de los diferentes escenarios que se estructuraron. También se han incorporado al interior de cada capítulo, los datos necesarios para comprender las trayectorias de los actores, siempre con una debida advertencia.

Finalmente se presentarán las conclusiones generales de la tesis. En las mismas se repondrán las lógicas de representación que operaron al interior del peronismo platense durante estos años y se analizará sus vínculos tanto de cara a las élites extra locales como a la ciudadanía. La formalización del análisis de los datos empíricos permitirá, en este capítulo abordar una mirada más general de las tensiones internas de la organización. 


\section{Capítulo 1: Los estudios sobre el Peronismo}

\section{Introducción}

El presente capítulo conforma una revisión de las investigaciones sobre las formas organizativas internas que adoptó el partido Justicialista ${ }^{1}$ a lo largo de su historia. Aun cuando este tópico conforma sólo un aspecto parcial de los diferentes abordajes de estudio que se han realizado en torno a esta fuerza política, la multiplicidad de discusiones sobre las formas en las que se estructura este partido de masas evidencia la dificultad de la aprehensión del tema. Sea bajo la categoría de populismo, movimiento, partido o coalición de gobierno, diferentes categorías se han ensayado para intentar encuadrar en una explicación esta experiencia que, al menos en esta dimensión, muestra bajos niveles de institucionalización. Atendiendo las diferentes líneas de trabajo que concurren en los análisis de este campo de estudios -el de partidos políticos en general y el del peronismo en particular- se han tomado algunas decisiones metodológicas en vistas de organizar tanto las discusiones teóricas y de relevar las tendencias analíticas existentes.

En primer lugar, la bibliografía se organizó tomando como criterio el período histórico del peronismo propuesto por los mismos trabajos aquí referidos ${ }^{2}$. Esta decisión permitió reunir en un mismo apartado diversas interpretaciones y organizar las discusiones a partir de sus dimensiones epistemológicas y argumentativas de modo más claro. Además, también ayudó a visibilizar como fueron emergiendo nuevos interrogantes ${ }^{3}$ en los analistas que complejizaron algunas consideraciones instaladas desde los denominados estudios clásicos (De Ipola, 1989). Como se podrá observar, para cada período la

\footnotetext{
${ }^{1}$ Tanto "Peronismo" como "Partido Justicialista" (PJ) son utilizados frecuentemente como sinónimos aun cuando remiten a campos analíticos distintos: el primero a un problema de identidad política y el segundo a una discusión sobre partidos políticos. En este trabajo se mantiene la sinonimia salvo casos de necesaria diferenciación (ver infra nota 47).

2 Cabe destacar que también resulta controversial la periodización del peronismo. Así, por ejemplo, Sidicaro (2008) ajusta los períodos sólo a los momentos en el que el peronismo fue gobierno y obtiene 3 momentos. Horowicz (1986) construye 4 momentos diferentes del peronismo (el análisis sólo llega hasta el año 1983), basado en el criterio de la forma organizativa que este presentó. Teniendo presente los diversos estudios aquí reunidos, en el presente capítulo se establecen 5 períodos alcanzando hasta el ciclo de poder del kirchnerismo.

${ }^{3}$ Respecto a estas discusiones sobre la perspectiva de análisis y las claves heurísticas para comprender los diferentes momentos del Peronismo, es interesante tomar como ejemplo el texto de Acha y Quiroga (2009) referido a los análisis historiográficos sobre el primer período -1943-1955- donde los autores recuperan el fenómeno de la aparición de nuevos interrogantes producto de los acontecimientos históricos contemporáneos vividos por los investigadores.
} 
tendencia en la evolución de las investigaciones parece haber sido la misma: el desplazamiento del foco de estudios que, descentrándose de la figura presidencial -o de la ausencia de la misma-, fue interesándose por los grupos o actores subnacionales mostrando como la vida interna de la organización partidaria fue rica en discusiones y problemáticas que exigían a las figuras nacionales el establecimiento de diferentes mecanismos de contención e integración. Como se podrá observar dicho desplazamiento también se observó para los análisis de casos recientes, donde la posibilidad de contar con más fuentes de información primaria, permitió capturar a los investigadores casos municipales de diferentes provincias del país.

En segundo lugar, y de forma superpuesto al punto anterior, la bibliografía se organizó con un criterio epistemológico que permitió diferenciar, para los períodos donde fue posible observar, entre estudios de corte identitaristas y de corte institucionalistas. Esta segunda decisión buscó poner en diálogo dos tradiciones de investigación que abordan el problema organizativo acentuando diferentes fenómenos y eventos. Si bien no es el objetivo del presente capítulo lograr extraer un balance del cruce de estas perspectivas, si se intenta recuperar elementos de ambas tradiciones que permiten profundizar la propia investigación.

Por último, es necesario referir a una discusión que atraviesa todo el presente capítulo y que se encuentra a la base de muchas investigaciones: teniendo en cuenta los cambios y vaivenes que este partido atravesó a lo largo de su historia ¿tiene sentido postular la unidad del objeto de estudio? $\mathrm{O}$ en otras palabras ¿el peronismo se trata de una o de múltiples fuerzas políticas? Esta controversia atraviesa al conjunto de la literatura especializada dividiendo aguas: así, de un lado se encuentran las posturas que apuestan a suponer la univocidad del objeto analizado a partir de la selección de alguna variable a lo largo del tiempo: la figura del líder, la promesa ${ }^{4}$, la imbricación con el movimiento obrero, son algunos de los elementos -entre muchos otros- que se eligen para argumentar sobre la existencia de un conjunto de prácticas coherentes (medianamente) identificables a lo largo del tiempo. Por otro lado, algunas posturas de tipo nominalistas tienden a destacar los elementos o rasgos específicos que este partido adoptó en cada época ${ }^{5}$,

\footnotetext{
${ }^{4}$ Esta por ejemplo es una de las características que menciona Sigal como estructurales del peronismo (2008).

${ }^{5}$ Desde una perspectiva antropológica en la que se pretende desarticular la noción de carisma como clave heurística, Balbi sostiene la imposibilidad de capturar la unidad del objeto de estudio: "Un buen punto de partida sería, tal vez, asumir simplemente que en tanto objeto real el peronismo no existe" (2009: 160)
} 
fundadas en una matriz de análisis sincrónica por la que se multiplican -quizás de forma exponencial- las discontinuidades. Siguiendo esta división, el resultado que se obtiene es el de la existencia de diferentes peronismos, en los cuales la variable de "adaptación al entorno" o coyuntura histórica política del país, prevalece sobre las referencias a fenómenos trasversales a dichos períodos. Queda a la vista que la virtud de esta postura es la de ganar en especificidad de análisis de cada período, mientras que el problema irresoluble que afrenta es justamente la imposibilidad de establecer una lectura global de la organización del partido; de forma exactamente inversa, lo mismo ocurre con la primera tendencia arriba descrita. Nuestra propuesta, entonces, es la de intentar situarse en medio de ambas direcciones, considerando que de esta forma será posible establecer un mapeo de la evolución en las preguntas y respuestas que las investigaciones han desarrollado.

\section{El primer peronismo: 1945-1955}

Los estudios sobre la organización interna del primer peronismo conforman un campo vivo de controversias y revisiones. Además de contener las investigaciones que dieron origen al análisis de la organización peronista, también se presentan para este período conceptos que fungieron como claves heurísticas para las investigaciones de otros períodos. Las discusiones para este apartado se han organizado intentando mostrar cómo se fueron desarticulando en las investigaciones algunas hipótesis sobre la no organización interna de esta fuerza política ${ }^{6}$.

\subsection{Los estudios globales}

Es la obra de Gino Germani, caracterizada como de "apertura" de los estudios sobre el peronismo $^{7}$, la que propone una categoría para explicar la organización de esta fuerza:

\footnotetext{
${ }^{6}$ Como lo señala Palacio: “En primer lugar, nadie puede negar que el revisionismo implacable del que está siendo objeto el primer peronismo es, a todas luces, saludable. Es evidente que la imagen de un Estado compacto, una coalición gobernante sin fisuras ni contradicciones, de una verticalidad absoluta del movimiento peronista y de un control casi perfecto del territorio nacional, era producto tanto del discurso que el peronismo forjó sobre sí mismo y lugar en la historia argentina, como de cierta historiografía tradicional. [...] Los nuevos trabajos se están encargando de desmantelar ese constructo como tal." (Palacio, 2010: 264)

7 Tomamos este punto de partida porque, como muestra De Ipola, resulta quizás la primera formulación no panfletaria -a favor o en contra- de las investigaciones sobre el peronismo (De Ípola, 1989: 331)
} 
movimiento populista o movimiento nacional popular (1965: 231). Si bien este autor no desarrolló in extenso las particularidades organizativas que se derivan de esta forma de construcción política, por medio de algunas definiciones es posible advertir ciertos elementos de los que otras interpretaciones se hicieron eco. En primer lugar la noción de movimiento se diferencia de la noción de partido político (Germani, 1973a: 446), en tanto el dato central es la relación directa o inmediata entre el líder y las multitudes ${ }^{8}$. No se trata de un desconocimiento de parte del autor de las estructuras organizativas que el peronismo se dio en sus primeros años sino que, en el marco de su análisis, esta relación vertical descendente subsume todos los demás aspectos al punto de que no resultan relevantes -incluso se podría sostener que resulta casi inexistente- los mecanismos propios de un partido como las reglas de funcionamiento, los mecanismos de democracia interna o un programa de definiciones ideológicas claramente identificables. Las dos claves heurísticas que fungen como condición de posibilidad de este tipo de organización son el carisma del líder y las condiciones sociopolíticas en las que se encontraba la clase obrera en la argentina de los años 40. La noción de carisma ${ }^{9}$ tal y como la expresa el autor, asemeja la experiencia del liderazgo a los modelos fascistas europeos ${ }^{10}$-aunque con profundas diferencias en las prácticas concretas- y sentará las bases para una forma de comprensión de la acción de liderazgo político al interior del peronismo que se extenderá, con sus variaciones, tras la muerte de Perón. Por el lado de las condiciones socio políticas, Germani sostiene en repetidas ocasiones la falta de mecanismos de integración (1973b) de carácter democrático para el acceso a derechos por parte de los trabajadores ${ }^{11}$. Esta situación, sumada al estado de movilización en la que los obreros se encontraban y, además, la conocida tesis de los valores psicosociales -proclives al

\footnotetext{
${ }^{8}$ En este sentido, la caracterización del "17 de Octubre" y de la disolución del partido laborista ordenada posteriormente Perón, conforman dos situaciones para Germani que expresan este vínculo político de inmediatez entre el líder y las bases (Germani, 1973a: 483).

${ }^{9}$ La utilización de este concepto remite a cierta raíz weberiana (Weber, 2008: 711) realzando en la misma una interpretación que privilegia una cierta característica demagógica.

${ }^{10}$ Germani nunca dejó de considerar al peronismo como un movimiento nacional popular (Germani, 1973a: 446) de carácter autoritario, sin embargo esto no le impidió diferenciar entre experiencias históricas: "La realidad subyacente era otra y escapa a nuestros propósitos analizarla aquí; lo que si interesa es examinar más detenidamente de qué manera el peronismo logró el apoyo sincero de la vastos sectores populares (y ello en agudo contraste con los fascismos europeos), y cuál es el verdadero significado que debe asignársele" (Germani, 1965: 243).

${ }^{11}$ Como dato interesante de la práctica política, Germani no considera que el apoyo de la clase trabajadora a Perón se debió por beneficios materiales, sino porque esta, al encontrar en el peronismo un cauce para las movilizaciones, adquirió un grado de conciencia de su capacidad de imponer condiciones para obtener derechos (Germani, 1965: 249).
} 
caudillismo- que presentaba un vasto conjunto de trabajadores ${ }^{12}$ provenientes de la migración interna iniciada en 1930, conformaron una plataforma para la articulación ${ }^{13}$ de una fuerza política que impulsó un proceso de modernización.

Otra lectura de la forma organizativa del peronismo en términos de populismo ${ }^{14}$, es la que presentó Di Tella (1973) en la que resaltó algunas características que la distinguen de la propuesta germaniana: por un lado, el populismo se presenta como una coalición anti status quo y resulta un fenómeno característico principalmente de países emergentes o poco desarrollados (1973: 47). En tanto coalición implica sectores de diversas clases sociales, entre ellos y principalmente, de la élite económica y política, pero también de sectores populares en estado de movilización. La falta de mecanismos de movilidad ascendente, en algunos sectores de la burguesía, empuja a estos a confrontar con el sistema político económico. En el caso del peronismo, Di Tella, agregó una característica adicional la cual implica la existencia de una élite minoritaria que será quién dirija los desarrollos de la coalición y una extensa penetración en los sectores obreros (1973: 78).

Si bien estas perspectivas globales permitieron visualizar las condiciones sistémicas que actuaron como condición de posibilidad del surgimiento del peronismo, rápidamente mostraron falencias explicativas para dar cuenta de la masividad que esta fuerza obtuvo en todo el país, como así también de un vasto conjunto de decisiones que se tomaron y que respondieron a problemas organizativos que resultaban de la incorporación de diversos sectores a la arena política ${ }^{15}$. En este sentido cabe destacar el viraje de los trabajos que, posteriormente, se dedicaron a comprender la construcción del partido

\footnotetext{
${ }^{12}$ El autor matizará esta tesis (Germani, 1967; 159) luego de las críticas de los valores psicosociales hacia un factor de "cultura política" (Germani, 1973a: 51).

${ }^{13}$ La relación entre valores y racionalidad de este argumento será un tópico largamente revisitado por otros análisis ya que, si bien la articulación de clase con un gobierno autoritario no corresponde con una respuesta "racional" -como si sería el camino de la democracia para el acceso a derechos-, el autor sostuvo que no existían otras alternativas (Germani, 1967: 251).

${ }^{14}$ Existe una amplia literatura enfocada en debatir los alcances explicativos del concepto de populismo. En general esta noción se encuentra muy ligada a una modulación particular de una práctica de gobierno. La vaguedad en su capacidad de señalar referentes empíricos homogéneos, sin embargo, produjo una crisis en la estructura epistemológica del concepto (Viguera, 1993). Otra perspectiva muy diferente es la que se observa en la conocida obra de Laclau, donde se la transforma en la expresión de la lógica política (2006).

${ }^{15}$ Por citar un caso que tuvo repercusión en todo el sistema político partidario: la ley 13.645 de Reglamentación de los partidos políticos, sancionada en 1949 -mismo año de la reforma constitucionalimpactó en todo el sistema político y sus motivos fueron largamente discutidas. La postura de Mackinnon al respecto sitúa los mismos como derivados de los problemas internos de esta fuerza: Por nuestra parte, nos parece que con independencia de sus objetivos ulteriores, la nueva normativa estaba dirigida a controlar a los grupos internos separatistas y a desalentar el surgimiento de partidos peronistas paralelos. (Mackinnon; 2002: 148).
} 
peronista -o coalición de gobierno- en sus diferentes variables, abriendo el campo de análisis a los actores subnacionales.

\section{$\underline{2.2 \text { Los análisis por sectores internos }}$}

Aún con sus actuales reformulaciones, el predominio de la variable de la verticalidad como forma preponderante de la organización política comenzó a mostrar falencias explicativas rápidamente. Las primeras críticas aparecieron en torno a la revisión de la composición de la clase trabajadora en este período histórico. La investigación de Murmis y Portantiero (1971) dio cuenta de la importancia de las mediaciones que significaron las estructuras sindicales en la construcción del vínculo entre el líder y las masas -como así también el rol del Estado-. El argumento central de estos autores proponía que los sindicatos se articularon bajo el proyecto político peronista de forma racional, y ofrecía como evidencia empírica de sustentación un análisis de los datos del ciclo de protesta que la clase obrera organizada había producido en la Argentina con anterioridad a la existencia de esta fuerza política y que habían encontrado eco estatal recién cuando Perón asumió la Secretaría de Trabajo en 1943. La obra de James (1990) también recuperó la importancia de los sindicatos y su acción de mediación entre la clase obrera y la figura de Perón agregando, en la reconstrucción histórica, las diferencias de posturas al interior de la dirigencia sindical ${ }^{16}$. Además, la investigación de James introdujo la variable de la construcción identitaria (1990: 56) como parte de la composición de la fuerza política.

El texto de Juan Carlos Torre (2011) sobre la vieja guardia sindical, presentó la virtud de dar cuenta de la fundación y del recorrido histórico del partido laborista ${ }^{17}$-desde ahora P.L.-, y las tensiones al interior de la primera coalición gobernante del peronismo desde la perspectiva de los trabajadores ${ }^{18}$. La investigación del autor permitió visualizar: en

\footnotetext{
${ }^{16}$ La reconstrucción de la jornada del 17 de octubre de 1945 que propuso James, desde la perspectiva de un sector gremial ligado a los frigoríficos de Berisso, aportó un conjunto de elementos a la perspectiva histórica por los cuales fue posible advertir que la lógica de la articulación política entre estos sectores no resultó mecánicamente construida de arriba para abajo, ya que las segundas líneas de la dirigencia sindical jugaron papeles importantes y condicionaron a los dirigentes de la primera línea.

${ }^{17}$ Es menester recordar que fue esta estructura, creada pocos días después del evento del 17 de Octubre de 1945, la que utilizó Perón como herramienta electoral para presentarse a los comicios de Febrero de 1946, aunque en términos políticos se presentó como una coalición de fuerzas (Torre; 2011: 181)

18 Recordamos que la coalición que conformó el peronismo en esta primera etapa se compuso de trabajadores -enrolados principalmente en el laborismo-, sectores que rompieron con el Partido de la Unión Cívica Radical -Junta renovadora-, sectores del viejo partido Conservador y en menor medida, militantes que salieron de las filas de los partidos de izquierda. Posteriormente se incorporará el Partido Peronista Femenino y con ello las mujeres como actores del sistema político.
} 
primer lugar, que el vínculo de origen del P.L. con la jornada del "17 de Octubre" fue fundamental para comprender la centralidad que obtuvo la capacidad de movilización a nivel nacional -estructura de organización y coordinación- en tanto que recurso principal en el salto a la arena política por parte de los trabajadores ${ }^{19}$. En segundo lugar, que la forma de organización interna del P.L., que se correspondía con el modelo del partido Laborista inglés, no fue suficiente para suplir las desventajas que los actores gremiales tuvieron -frente a los otros actores del peronismo de tradición estrictamente partidariaen su intento de asumir los roles de dirigentes políticos ${ }^{20}$. Por último, el hecho de la sobrevida de estos actores al interior del peronismo aún luego de la orden de disolución partidaria realizada por Perón, dotaron de diferencias específicas al peronismo en comparación con experiencias similares como el varguismo en Brasil.

Otro conjunto de estudios se centró en la forma que adquirió la incorporación de las mujeres como sujetos de derechos a la arena política ${ }^{21}$. Debe tenerse en cuenta que las mujeres participaban de las movilizaciones obreras y partidarias -y en el caso del peronismo, tuvieron una fuerte participación en la campaña de 1946- pero en tanto sector social se encontraban vetadas de ocupar cualquier cargo electivo y la mayor parte de los cargos directivos. Su salto a la política se produce durante el primer gobierno peronista $\mathrm{y}$, si bien existen datos de diversos partidos que presentaron mujeres en sus listas de candidatos en las elecciones de 1949, es al interior de esta fuerza política (el peronismo) que se produjo una experiencia significativamente interesante al constituirse el Partido Peronista Femenino -desde ahora PPF-. Zaremberg (2009) realizó un extenso análisis mostrando la forma de estructuración que vehiculizó la participación de las mujeres en esta fuerza. Por medio del análisis de grafos, la autora logró reconstruir las redes que

\footnotetext{
${ }^{19}$ En palabras de Torre sobre el resultado del 17 de Octubre: "una movilización obrera articulada desde los sindicatos, capaz de ejercer un peso propio y en función de objetivos de clase sobre la escena política. El nuevo ciclo que habrá de comenzar entre los indiscutibles vencedores de octubre se caracterizará así, por una relación de interdependencia, en la cual tanto Perón como los dirigentes sindicales serán consientes de la necesidad de apoyo mutuo para el logro de sus fines" (Torre; 2011: 177). El argumento de Torre señala que la importancia de la movilización del 17 se tradujo inmediatamente en un recurso político por el cual los sindicatos pulsearon en las disputas internas del peronismo por lugares y capacidad de conducción.

${ }^{20}$ Según el autor, la estrategia de los militantes del PL. de aliarse con cuadros conservadores que se pasaban a las filas del peronismo, terminó por resultarles más un problema que una virtud al momento de la disputa de cargos.

${ }^{21}$ La ley 13.010 que permitió el acceso al voto femenino y a la posibilidad de que las mujeres ocuparan cargos de gestión, se promulgó para 1947 y si bien existía en el país una larga lucha de sectores feministas para conseguir este derecho, existe un cierto consenso sobre la gravitación de la figura de Eva Perón en el impulso de la aprobación de dicha norma (Valle Benthencourt, 2014: 82).
} 
estructuraban las relaciones organizativas de la acción militante del PPF obteniendo un gran despliegue en todo el territorio ${ }^{22}$. La construcción de Unidades Básicas Femeninas, el desarrollo de acciones propias del PPF coordinadas a nivel nacional y una organización de cargos internos que se replicaba en cada lugar, daban cuenta de la constitución de una estructura de movilización que le permitía a estas nuevas actoras obtener un espacio considerable en las listas de candidatos ${ }^{23}$.

El profundo trabajo realizado por Carolina Barry (2009), también dirigido sobre la conformación del PPF, señaló tanto sus características de penetración territorial como también el hecho de haber consistido en, quizás, la primera experiencia de organización partidaria con altos niveles de cohesión interna. Su estructura le permitía la generación de actividades y directivas desde un centro que controlaba y coordinaba el desarrollo de la periferia, esto es, la conformación de las unidades locales ${ }^{24}$. El rol de Eva Duarte de Perón, líder del PPF, cumplió un rol gravitante en esta experiencia asegurando la verticalidad y la lealtad a Perón como destinatario de las acción política de este partido presentaba capacidad de selección y veto de las delegadas regionales, como también funcionaba como vehículo de obtención de recursos por fuera de los estipulados en las normas de funcionamiento cotidianas-. Cabe destacar la sobrevida de esta fuerza tras la muerte de Eva, como así también de manera posterior a la orden del nivel nacional de la fusión de todas las identidades que conformaban la coalición dominante en un solo partido político. El PPF perduró tanto por su eficacia en la capacidad de movilización social, como también por su extensión territorial unificada a nivel nacional.

El texto de Mackinnon (2002) desde una mirada más global de la conformación del Partido Peronista -aun cuando sólo alcanza hasta 1950- resultó esclarecedor en cuanto sitúo en términos de devenir histórico las relaciones de poder al interior del mismo. La tesis central que sostuvo la autora afirmaba que durante estos años la organización del

\footnotetext{
22 La rápida expansión territorial del PPF se logró conjugando una característica inclusiva en términos de incorporación de mujeres (bajo el lema "donde hay una necesidad hay un derecho") y una fuerte impronta horizontal en la estrategia de base: con ello se quiere hacer referencia a la existencia de redes no jerárquicas (las conformadas en torno a las redes vecinales de base) que estaban conectadas a la red principal jerárquica del partido (Zaremberg, 2009: 225). Estas redes, además, constituían canales paraestatales de transmisión de recursos.

${ }^{23}$ Para el caso de las diputadas el número para 1952 era de 26, pasando a 39 en 1955 -ocupando el 22,8\% de la cámara baja-, mientras que en el caso de las senadoras pasaron en el mismo período de 6 a 8 -22,2 $\%$ del total- (Zaremberg, 2009: 222).

${ }^{24}$ También sobre las "unidades básicas" como espacios organizativos particulares de generación de participación política vale citar el texto de Quiroga (2008).
} 
partido osciló entre dos polos organizativos o lógicas de construcción diametralmente opuestos: uno de carácter democrático, según el cual los problemas y tensiones sectoriales se resolvían -o al menos se intentaban resolver- en los mismos ámbitos locales donde se originaban; y una lógica de construcción de tipo carismática ${ }^{25}$ por la cual los conflictos comenzaron a resolverse a partir de las decisiones de la cúpula nacional -envestida por la figura del Líder o del Consejo Superior del Partido- que fue cobrando protagonismo con el paso de los años -y la impotencia de la lógica democrática. En este sentido, al focalizarse en torno al desarrollo evolutivo de la organización, la investigación logró mostrar que las categorías usualmente destinadas a caracterizar un partido, en este caso, podían comprenderse como tendencias que lograban imponerse o retrocedían en vistas a una efectividad obtenida en la capacidad de asegurar la unidad sobre las tensiones. Además de confrontar con las posturas de tipo genetistas, el análisis en términos de devenir permitió reabrir la discusión en torno al liderazgo como clave heurística ${ }^{26}$, ya que fue posible observar que la función del Perón al interior de su propia fuerza, no se encontraba predeterminada sino que, por el contrario, fue modificándose ${ }^{27}$.

Por último, también vale citar los trabajos que se estructuraron en función de recuperar las formas de inserción político territorial del peronismo a escalas provinciales o locales. La compilaciones de Tcach y Marcor (2003 y 2013) en el que se reúnen diferentes investigaciones sobre la construcción del peronismo en el interior del país, resultaron también obras centrales para comprender como se estructuro la organización política a nivel nacional en esta etapa. Enmarcadas en el conjunto de investigaciones denominadas como extracéntricas (Tcach, 2002), estos estudios dieron cuenta de las acciones de los cuadros políticos en diferentes provincias tanto en casos individuales como también por medio de su participación en corrientes internas que en algunos casos llegaron a contar con un despliegue territorial de nivel nacional, contando con el hecho que estos mismos

\footnotetext{
${ }^{25}$ Una crítica interesante y complementaria al texto de Mackinnon, lo realizó Balbi (2007) en su análisis de la noción de Lealtad. El argumento del autor era que la noción de carisma que utilizó la autora no alcanzó a mostrar las contingencias históricas por las que este polo de agregación -o si se prefiere de resolución de tensiones intra-partidarias- terminó imponiéndose progresivamente.

26 "...ha quedado de manifiesto que en los años formativos del Partido Peronista, hasta principios de1950 [...], el lugar de Perón en la organización no era tan ubicuo ni tan central como se ha sostenido y, sobre todo, que no fue un lugar fijo y determinado desde el principio, sino que más bien se desplazó al compás de la dinámica de los conflictos internos que la atravesaban." (Mackinnon, 2002: 175).

${ }^{27}$ También en un corte político se encuentran los trabajos de Rein (2008) y sus compilaciones (2014) sobre los dirigentes que acompañaron a Perón en los primeros años, denominados como "segunda línea". Esta idea de las líneas dirigenciales generó otros análisis como los de Salomón (2011) en torno a la "tercera línea" en donde se busca recuperar las trayectorias de los dirigentes locales.
} 
actores, solían obtener recursos ${ }^{28}$ que utilizaban como capital para promover sus posiciones, de forma autónoma a la conducción nacional.

El registro de los fenómenos de disputas locales y las resoluciones que se tomaron desde el nivel nacional del partido -en muchos casos llegando a la intervención ${ }^{29}$ de las seccionales- mostró claramente que, aún en el momento de mayor exposición y legitimidad de la figura de Perón, las relaciones intra-partidarias fueron de negociación. En estos análisis comenzó a visualizarse la existencia de mecanismos y diversas estrategias orientadas a asegurar la unidad de la fuerza -todo el problema radicaba en lograr subsumir las disputas sin caer en rupturas sectoriales- Ciertamente la relación vertical descendente en la toma de decisiones no desaparecía a medida que se profundizaban los estudios de los fenómenos de disputa en el interior del país ${ }^{30}$, pero lejos de ser un dato de la realidad, comenzó a ser un problema a explicar. En esta misma línea de análisis cabe resaltar el trabajo de Aelo (2006) sobre la organización del Peronismo en la Provincia de Buenos Aires cruzando las tensiones organizativas con la aparición de distintas elites de conducción provinciales al interior de la fuerza. En la mirada de este autor, la construcción organizacional del partido de masas en la provincia atravesó tensiones propias del proceso de incorporación de nuevos cuadros militantes que lograban tener propia inserción en el electorado y reclamaban para sí mayores niveles de espacios de decisión.

\section{El peronismo de la resistencia, al retorno de Perón: 1955-1976}

Con el golpe de estado de 1955, el exilio de Perón y la ilegalidad del partido, comenzó una etapa completamente diferente de esta fuerza y con ello un desplazamiento de las investigaciones. Es en este período el momento más complejo para continuar la pregunta por la organización del peronismo, tanto por su proscripción del sistema de partidos, como

\footnotetext{
${ }^{28}$ Con recursos no nos referimos únicamente a cuestiones de dinero, sino también organizativos -por ejemplo los sindicatos- o de legitimidad en ese territorio por trayectoria política -por ejemplo los sectores que provenían de las rupturas con el radicalismo- entre otros.

${ }^{29}$ Sólo por citar un caso, las investigaciones sobre la construcción del partido peronista en Salta implicó para 1950 una intervención por parte del sector nacional por fuertes disputas de sectores que no lograban acuerdos (Correa y Quintana, 2013: 191 y ss.) En el caso de Salta, pero también en Santiago del Estero, en Tucumán, como en otras provincias las disputas internas llegaron a tal grado en algunos casos que terminaron incluso con el desplazamiento de representantes locales.

30 "El peronismo en las provincias, contó en su haber momentos e instancias de mayor horizontalidad en las formas de participación política, pero estuvo muy lejos de tener capacidad para lograr que sus distintas fuerzas internas estuvieran "representadas» en el Consejo Superior." (Tcach y Marcor; 2013: 13).
} 
también por su gravitación, aún de forma ausente, en la percepción de las organizaciones cívico militares: en tanto el peronismo fue una suerte de huella de una organización que supo hegemonizar la política argentina, su imposibilidad de expresarse en la superficie del sistema político derivó en la aparición de nuevas organizaciones que, con lógicas propias de construcción, devinieron trascendentes en la disputa por el retorno de Perón ${ }^{31}$. La paradoja a comprender, que supone toda la literatura que investigó esta etapa, es el hecho de que existió organización -aún como un equilibrio de fuerza de diferentes sectores- sin comando central y por fuera de toda estructura estatal ${ }^{32}$. Esta situación empujó a las investigaciones a tomar diferentes caminos: así un conjunto de trabajos que recabó la forma de organización del peronismo en torno a la clase obrera-considerando a esta como el espacio central sobre el que se recostó la resistencia. Otro grupo de estudios trabajó la conformación de las organizaciones de jóvenes las cuales, nacidas hacia finales de la década del 60, muchas de ellas terminaron aportando a los ejércitos populares revolucionarios peronistas - principalmente Montoneros, aunque también existieron otras organizaciones-. La revisión de la literatura de esta etapa es importante para comprender los eventos tras el retorno del peronismo al gobierno en 1973 y las particularidades que en dicho momento se expresaron.

\section{$\underline{\text { 3.1 Los estudios de la resistencia en la clase obrera }}$}

Por el lado de las investigaciones dedicadas a la resistencia peronista desde las organizaciones de la clase obrera, Melon Pirro (2009) estudió la construcción de la resistencia peronista en los primeros años (hasta las elecciones de 1957), alternando entre un estudio del comportamiento de los sectores sindicales con la discusión en torno a los denominados partidos neo-peronistas surgidos hacia 1957 y su infructífera performance electoral. Cabe destacar de esta investigación el dato de la posición "débil" en la que se encontraba Perón en los años del exilio (ibidem: 253) que limitaba cualquier posibilidad

\footnotetext{
${ }^{31}$ Como señala Laclau, la demanda por el retorno del Perón operó como un significante vacío por el que se construyó una equivalencia de demandas -trabajo, libertad sindical, mejores condiciones de vida, etc.que posibilitaron el proceso de movilización popular (2006: 269).

32 Las consecutivas elecciones de su representante en el país, realizadas por Perón desde el exilio, generó un conjunto importante de literatura que intentó explicar la supervivencia del peronismo adscribiendo una posición de enunciación fuerte al líder. No nos detendremos en revisar estos.
} 
de ordenar el conjunto de acciones y actores que construyeron la resistencia ${ }^{33}$.

En diferentes abordajes se señala la imposibilidad de construir en los primeros años de la resistencia una estructura coordinada y centralizada que presente niveles de rutinización ${ }^{34}$. Si bien figuras como las de Jhon William Cooke ${ }^{35}$, designado por Perón como su representante, intentaron dirigir las acciones, finalmente tuvieron escasa capacidad de estructurar un espacio conjunto ${ }^{36}$.

El estudio de James, ya citado, refiere a los lugares de trabajo como espacios de resistencia ${ }^{37}$ y a la construcción de diversas estrategias de articulación realizadas por los sindicatos: la Ruptura entre la CGT -que se encontraba intervenida por el régimen militar o gobernada por sectores antiperonistas- y la aparición de las 62 Organizaciones, permitió observar la infructuosa estrategia militar de "desperonizar a la clase obrera". Del mismo modo, el análisis de la figura y rol de Vandor como dirigente sindical que proponía un "peronismo sin Perón"38 y la aceptación de una postura dialoguista con el régimen (1990: 220) permitió comprender como se construyó la lectura posterior de los grupos revolucionarios que confrontarían con los sectores gremiales por la conducción del peronismo $^{39}$.

\footnotetext{
${ }^{33}$ La debilidad en esta perspectiva remite al conjunto de limitaciones materiales que enfrentaba Perón. Por otro lado, la situación de conducción carismática, para Melon Pirro, se sostenía en términos de posición de arbitraje entre los diversos grupos (2009: 258).

${ }^{34}$ Para un análisis en términos de rutinización y organización partidaria véase Levitsky, 2005: 52-59.

${ }^{35}$ Existe una amplia literatura sobre la figura de Cooke y su intercambio epistolar con Perón. Por citar sólo algunos textos: Recalde, 2009; Feinmann, 1974.

${ }^{36}$ Melon Pirro sintetizó esta etapa de la siguiente forma: Es posible reconocer pues en el periodo la presencia de varios "peronismos paralelos" o, más concretamente, de varios factores que coexisten y que constituyen, en el mejor de los casos, redes de poder fluidas y capaces de maximizar beneficios a partir de las oportunidades que se les presentan, pero no de sumar esfuerzos y/o agregar intereses a favor de la acumulación de una fuente de poder político alternativo. $(2009,258)$

${ }^{37}$ La resistencia de los primeros años incluyó desde huelgas a medidas más extremas como la colocación de explosivos y acciones de guerrilla urbana -aunque muy incipiente: "En esos años [1956 a 1968] el sabotaje formaba parte integrante de las luchas obreras. Era poco menos que inimaginable una disputa laboral intensa sin el concomitante estallido de bombas e incendios" (James, 1990: 120). Es interesante notar que las huelgas se hicieron incluso a expensas de las estrategias que los sectores de la dirigencia sindical desplegaban.

${ }^{38}$ Augusto Vandor, provenía del sindicato metalúrgico y llegó a ser electo Secretario General de la CGT (Confederación General del Trabajo). Es conocido el enfrentamiento entre Perón y Vandor teniendo como escenario las elecciones de Mendoza de 1966 en la que los candidatos del primero vencieron al segundo y con esto se produjo la clausura del proyecto de una organización neoperonista que tuviera otro líder (James, 1990: 248)

39 “A esa joven generación la realidad del peronismo al promediar la década 1960-70 le parecía bastante clara: era un movimiento que incorporaba las tendencias antiimperialistas y anticapitalistas de las masas argentinas, pero movimiento dominado por una burocracia sindical que había sumergido profundamente y sofocado esos anhelos." (James, 1990: 281)
} 


\section{$\underline{\text { 3.2 Los estudios de la resistencia en las organizaciones armadas }}$}

Los estudios sobre organizaciones peronistas de extracción no sindical conforman un voluminoso cuerpo de estudios e incluyen un conjunto de discusiones que hasta hoy día no se han saldado. Más allá de las divergencias en torno a su origen (Eidelman, 2004), lo cierto es que para mediados de los años 60 comienza a emerger una gran cantidad de agrupaciones -la mayoría de ellas con un perfil de izquierda nacional, aunque también existieron grupos de derecha- que presentarán al menos dos particularidades: una forma de organización centrada en un nuevo tipo de militancia política ${ }^{40}$ de carácter social, y un devenir radicalizado producto del crecimiento de los grados de violencia represiva por

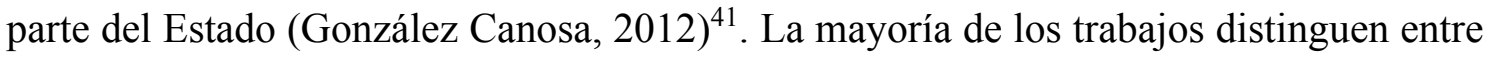
organizaciones de carácter político y organizaciones de carácter militar revolucionarias. De las primeras, es menester resaltar que los estudios reivindican la acción territorial construcción de redes sociales en barrios periféricos (Satta, 2015), como también la centrada en ámbitos educativos (Dip, 2012) que luego se irá expandiendo, hacia la década de los 70, a espacios laborales, fundamentalmente en sectores de trabajadores estatales (Tocho, 2014 y 2015). De las organizaciones político-militares se marcará la distinción entre organizaciones de superficie en las cuales se producían los reclutamientos y las milicias que presentaban una forma de estructuración jerarquizadas con un fuerte mando central (Bozza, 2001; Stavale, 2012)

Las investigaciones en tono a este período de resistencia peronista se desplazaron de lecturas más globales hacia trabajos más específicos centrados en territorios más delimitados. De esta forma, comenzaron a emerger en los análisis la territorialidad municipal de los espacios locales como una tercera dimensión de análisis que se articuló con los eventos y lecturas a nivel nacional y provincial (González, 2012; Robles, 2011). Esto se debe en parte a que la generación de nuevas prácticas políticas ${ }^{42}$-como la acción

\footnotetext{
${ }^{40}$ Como sostiene Robles: "La acumulación de fuerzas a través de la acción política en el barrio fue entonces el motivo que estructuró la estrategia de la JP desde mediados de los '60." (2008: 18).

${ }^{41}$ Como dato contextual para comprender la progresiva radicalización de la práctica política, es importante rescatar el concepto de "empate hegemónico" entre los sectores del campo popular y la clase propietaria de los medios de producción (Svampa y Martuccelli, 1997: 32) que impedía la aplicación en profundidad de los programas de ajuste económico y, con ello, elevaba las acciones represivas de los gobiernos de facto.

${ }^{42}$ La originalidad de estas nuevas prácticas, o su comprensión en términos de tradición política, podría discutirse si se tiene en cuenta el accionar que ya se marcó para la primera etapa del peronismo por parte del PPF.
} 
en barrios periféricos- se extenderá hasta la actualidad como forma de desarrollo territorial. Pero también es posible sostener como otro motivo que incitó las investigaciones de este tipo en que la capilaridad social que tuvieron estas organizaciones, su penetración en diferentes ámbitos, implicó espacios de fricción con otras organizaciones del movimiento peronista centralmente con las de derecha (Abattista y Tocho, 2012).

\section{$\underline{3.3 \text { El retorno de Perón y los eventos de superficie }}$}

Con el agotamiento del régimen político del dictador Lanusse y el llamado a elecciones para el año 1972, las organizaciones se vieron frente a la necesidad de asumir la institucionalización como proceso político (Pucciarelli, 1999:13). El caso del Partido Justicialista conformó, quizás, uno de los más complejos ya que el camino al proceso electoral implicaba la reaparición en el escenario después de 18 años de proscripción, y además, contando con el agregado no menor de contener un recambio generacional -y de agrupaciones internas- muy significativo. El peronismo, en tanto que identidad política, transitó en este tiempo un proceso de actualización sumamente tensionado entre la posibilidad del retorno al país de la figura de Perón y con ello su capacidad de centralizar la toma de decisiones (De Riz; 1987); la posibilidad de acceder nuevamente al control estatal y por ende de tramitar las demandas corporativas de cada sector ${ }^{43} \mathrm{y}$, por último, la recodificación del capital político acumulado por diversas organizaciones internas durante la proscripción -sea este en la organización sindical, en las organizaciones armadas, en las redes políticas, lealtad a la figura de Perón, etc.- a una escala valorativa que les propiciara un equivalente en el posicionamiento al interior de la organización partidaria $^{44}$. Estos tres procesos simultáneos se desarrollaron durante un período que abarca desde el llamado a elecciones hasta, por lo menos, la muerte de Perón en 1974 y el posterior ${ }^{45}-\mathrm{y}$ trágicamente conocido- decreto de aniquilamiento de la subversión. Pero

\footnotetext{
43 El peronismo se presentó a las elecciones de 1973 con la coalición denominada FREJULI (Frente Justicialista de Liberación Nacional) con la fórmula Cámpora/Solano Lima. Posteriormente a su victoria electoral, dicho presidente renunció y se convocaron a nuevos comicios en los que se presentó la fórmula Perón-(Isabel) Perón en septiembre de dicho año. Un análisis de este período y de la coalición gobernante se encuentra en Di Tella, (1983).

${ }^{44}$ Sobre el proceso de institucionalización de los miembros de La Tendencia Peronista para las elecciones de 1973 ver Lenci (1999)

45 Para un análisis de las actividades de La Tendencia al interior del Gobierno de Bidegain ver Tocho (2015), Para un análisis de la cultura política de las organizaciones vinculadas a la derecha peronista como Concentración Nacional Universitaria o Juventud Sindical, ver Besoky (2016), también Carnagui (2010).
} 
es entre los años 1972 y 1973 donde se puede observar con mayor precisión. Un interesante análisis de la reorganización del partido a nivel provincial se encuentra en las investigaciones de Ladeuix (2008) donde se evidencian que los actores locales y provinciales que habían transitado el denominado período de la "resistencia" exigieron un proceso de negociación con la figura de Perón que tuvo resultados dispares en los diferentes municipios de la provincia.

El análisis de Altamirano sobre la izquierda peronista en clave identitaria, por el que relee la alianza entre clase trabajadora y sectores medios como una búsqueda de convergencia entre socialismo y nación (Altamirano, 2001: 79); encuentra en el evento de Ezeiza y en la famosa Plaza de Mayo ${ }^{46}$ (ibidem, 121 y ss.), dos indicadores de la empresa altamente conflictiva (con visos de imposible) que resultó el intento de organización y apaciguamiento de líneas internas opuestas entre sí.

\section{El peronismo de los años 80: crisis de identidad y reconstrucción partidaria}

Con la caída de la dictadura militar a principios de los 80 el partido Justicialista -desde ahora $\mathrm{PJ}^{47}$ - se enfrentó a las primeras elecciones ejecutivas nacionales luego de la muerte de Perón. Si bien este período sea quizás comparativamente menos trabajado por la literatura científica, es quizás uno de los más interesantes en términos organizacionales. Dos grandes líneas de investigación se focalizaron en esta etapa para desplegar estudios que alcanzan hasta acontecimientos de finales de siglo: por un lado se estructuró una matriz de tipo discursiva que hizo foco en los aspectos identitarios por los cuales se comprendió al peronismo como un campo vasto de actores y tendencias. Por otro lado, con una impronta de carácter institucionalista emergieron trabajos focalizados en la reorganización del peronismo en términos partidarios, su vinculación con el sistema

\footnotetext{
${ }^{46}$ El acontecimiento de Ezeiza -nombre del distrito donde se encuentra el aeropuerto más importante del país- fue el enfrentamiento armado entre distintas fracciones del peronismo (aunque principalmente perpetrado por los grupos armados de derecha o proto-facistas) en el acto organizado para el recibimiento de Perón en su retorno del exilio, el 20 de Julio de 1973. El evento de Plaza de Mayo, fue la discusión pública ocurrida en un acto del 1 de Mayo de 1974, entre Perón -que se encontraba dando un discurso- y sectores vinculados a la Juventud Peronista -más precisamente a Montoneros. Dicho acto fue famoso porque frente a las consignas azuzadas desde el público, el presidente los expulsó del acto con la frase "estúpidos imberbes".

47 La introducción de esta nominación para el peronismo es conflictiva, ya que desde el primer período había sido un pedido del mismo Perón el que se denomine Partido Justicialista al movimiento (Mackinnon; 2002). Sin embargo, la decisión de incorporarlo recién en éste período acuerda con la postura de Mustapic (2002) en el que responde a la necesidad de otorgarle mayores niveles de especificidad a una etapa signada por la ausencia del líder carismático.
} 
democrático y las transformaciones en los sujetos interpelados por esta fuerza. El problema que sobrevoló a todas las lecturas sobre el PJ en este período es el de la ausencia del líder y la adaptación a estas circunstancias.

\section{$\underline{4.1 \text { Los estudios discursivos }}$}

La bibliografía que acentúa los trabajos de identidad en este período, partió de analizar cómo se procesó al interior del peronismo la experiencia de la dictadura militar. De esta forma, algunos análisis dieron cuenta de cómo, con el retorno democrático y la salida de la clandestinidad, resurgieron las tensiones entre grupos existentes en la década del 70 aunque contando con la singularidad de que el clivaje derecha/izquierda ahora se superpuso con el de gremialistas/políticos que fue propio de la primera etapa del peronismo. Ferrari advirtió sobre esta situación al investigar las "condiciones de posibilidad" de la construcción de nuevas dirigencias en el PJ para las primeras elecciones de 1983. El hecho de que fueran los sindicatos, tanto a nivel nacional como, particularmente, en la Provincia de Buenos Aires, quienes se encontraron con una mayor capacidad de articular un liderazgo al interior de la fuerza al contar con estructuras organizativas propias y el recurso de la recuperación de la tradición del movimiento obrero como columna vertebral del peronismo, confluyó -acompañado de actos violentos en la resolución de las discusiones- en la consolidación de una dirigencia de corte tradicional $^{48}$ (Ferrari; 2009:124). La derrota electoral frente a la Unión Cívica Radical funcionó como el catalizador de la aparición de una corriente renovadora al interior del PJ que terminó por desplazar dichos cuadros dirigenciales ${ }^{49}$. El clivaje renovadores/ortodoxos que signo la organización interna del peronismo luego de las elecciones del 83, también fue estudiado por Ferrari (2016) para el caso de la Provincia de Buenos Aires, donde se pudo observar el juego de reacomodamiento de los actores internos, particularmente del sector de los Intendentes del Conurbano bonaerense, en la

\footnotetext{
48 Para la autora esta noción remite a aquellos dirigentes que se hicieron cargo del peronismo desde la muerte de Perón en 1974 hasta el golpe de estado el 24 de Marzo de 1976.

49 Es importante remarcar que la emergencia de la disputa entre renovadores y ortodoxos que se presentará a continuación tiene como base el hecho de que aun cuando fueron las dirigencias gremiales -caracterizadas como las alas de derecha del peronismo- aquellas que hegemonizaron la cúpula del PJ, ya para esas mismas elecciones existían muchas corrientes internas: "Un inconveniente mayor era el fraccionamiento interno. En la provincia de Buenos Aires se presentaron a elecciones internas 420 listas procedentes de los 125 distritos en que estaba dividida. En el orden provincial, se agruparon en torno cinco líneas." (Ferrari; 2009: 102)
} 
disputa por la articulación de una nueva propuesta nacional electoral.

Aboy Carlés interpretó la derrota del PJ en esos mismos comicios a partir de comprender como el discurso de Alfonsín constituyó una frontera externa del peronismo que lo colocaba en el espacio de las viejas prácticas antidemocráticas, asociadas a su incapacidad de adaptarse a las necesidades del nuevos sistema democrático en ciernes (2001: 271). De aquí que, hacia el interior del peronismo, la frontera interna o el clivaje sobre el cual se diferenciarían los grupos que disputaron la hegemonía fueran denominados como renovadores ${ }^{50}$-en tanto aquella corriente que pretendía refundar el peronismo en términos de partido- y los ortodoxos como aquella corriente que se articulaba con los "valores históricos" del peronismo. Una de las tantas virtudes de este texto radica en que logró mostrar como a partir de la derrota de las elecciones, los sectores ligados a la renovación política construyeron un discurso que les permitió disputar la comprensión de la propia historia del peronismo articulándola con las necesidades de una transformación en los modos de organizar al interior la fuerza, lo que les permitió recuperar el espacio de iniciativa política que habían perdido frente a la $\mathrm{UCR}^{51}$. Esta operación identitaria se asentó sobre la derrota, como también sobre ciertas figuras políticas que esgrimían recursos diferentes para posicionarse en el ámbito de los transformadores: el grupos de los renovadores incluía actores federales que había logrado ganar en sus distritos -como el caso de Menem-, al igual que figuras históricas -el caso de Antonio Cafiero ${ }^{52}$ - que contaban con un trayecto propio dentro de las huestes peronistas de larga data. El hecho de que la disputa se prolongara en el tiempo por medio de congresos, en los que aquellos sectores ortodoxos impidieran por medio de prácticas poco democráticas la incorporación y discusión de las propuestas renovadoras sólo contribuyó a reforzar las posiciones en favor de la institucionalización partidaria. El punto de inflexión fueron las elecciones de 1985 y la estrategia de los renovadores al interior de la Provincia de Buenos Aires de presentarse por fuera de las listas oficiales de candidatos -puesto que se encontraban

\footnotetext{
50 "Con la renovación, el peronismo, aun cuando no renunciaba a sus pretensión movimentista se institucionalizaba como partido político" (Aboy Carlés; 2001: 277)

${ }^{51}$ Al respecto sostiene el autor: "La derrota de 1983 aparecía así en la lectura renovadora como el producto de un alejamiento, una ruptura en la tradición de la identidad peronista cuyo responsable no era otro que la cúpula partidaria..." (Aboy Carlés; 2001: 282).

${ }^{52}$ Cafiero estuvo ligado al peronismo desde la primera etapa, llegando incluso a ser el ministro más joven de la cartera: "Pero Antonio Cafiero tenía a su favor el ser uno de los pocos dirigentes justicialistas que había participado de la histórica jornada del 17 de Octubre, había conocido a Perón y a Evita ya en sus tiempos de estudiante [...] recurrió una y otra vez a su conocimiento de Perón y Eva Perón con el objeto de obtener una legitimidad derivada para su tarea" (Aboy Carlés; 2001: 281)
} 
expulsados del partido-, y obtener más votos, lo que le permitió confirmar de cara a la sociedad la caducidad de las ideas de los denominados "mariscales de la derrota"53. Aquí encontramos dos elementos que resulta pertinente de destacar en torno al acontecimiento de 1985: por un lado el hecho de que la resolución se dio en el marco de unas elecciones generales de medio término, mostró que en términos identitarios ganó espacio el "valor" de la victoria electoral por sobre el de los límites formales de estructuración del justicialismo. De allí que, hasta la actualidad, las agrupaciones internas puedan utilizar el recurso de "ir por afuera" de las listas de candidatos oficiales y atar su suerte al resultado electoral ${ }^{54}$. El otro elemento a marcar en estas elecciones resultó en la apertura de un proceso de reposicionamiento de los actores por el cual se procesó, dentro de los márgenes del incipiente avance de la institucionalización del PJ, la recuperación del movimentismo y la rearticulación de las alianzas con los sectores derrotados, encabezados por Carlos Menem bajo la corriente "Federalismo y Liberación" 55 . Este juego de desplazamiento de roles, al estar encabezados por una figura surgida de las huestes de la renovación, tuvo margen suficiente para presentarse como novedosa al mismo tiempo que alternativa del status quo. En otras palabras, Menem pudo construirse como candidato de la renovación $\mathrm{y}$, simultáneamente, recuperar elementos del movimentismo, permitiéndole trazar una nueva frontera a partir de la cual los institucionalistas de dentro y de fuera del PJ -léase Cafiero y Alfonsín por la UCR- ocupaban el mismo espacio y por tanto compartían los mismos fracasos de cara a la sociedad que atravesaba la economía coyuntural ${ }^{56}$.

Garategaray (2013) complementa esta lectura atendiendo los pormenores de la

\footnotetext{
53 Denominación que se le atribuyó a los ortodoxos que conducían el peronismo y que fueron candidatos en las elecciones de 1983. Como sostiene Aboy Carlés, fue la elección del 85 la que resolvió la disputa entre estos grupos: "Los buenos resultados de los referentes renovadores de 1985 abrieron el camino para la normalización de la situación en el justicialismo bonaerense donde Cafiero se impuso como titular partidario de los comicios internos en noviembre de 1986. Tras ser elegido gobernador de la provincia de Buenos Aires en septiembre de 1987, alcanzó la residencia del consejo Nacional Justicialista en el siguiente año" (Aboy Carlés; 2001: 275)

${ }^{54} \mathrm{Si}$ bien, algunos analistas ya resaltan el hecho de la porosidad de los límites justicialistas -por el cual las organizaciones entran y salen de la orgánica central- para el período de la resistencia, a diferencia de otros momentos, en los 80 adquiere la particularidad de la ausencia de la figura de un árbitro. Volveremos sobre esto.

${ }^{55}$ Al respecto, Aboy Carlés muestra como ya en un acto en 1986, Menem subvertía los términos de la discusión política del momento y abría una puerta de alianzas con el sector ortodoxo derrotado: "Desde uno de sus inspiradores [Menem], aparecía un discurso que subvertía los clivajes mismos a partir de los cuales a renovación se había estructurado. El mensaje era a su vez una convocatoria y un concejo acerca de donde debían cobijarse..." (2001: 284)

${ }^{56} \mathrm{Al}$ igual que en otros países latinoamericanos, la crisis de la deuda externa de la década de los 80 impacto en la Argentina con fenómenos de hiperinflación y crisis social (Ortiz y Schorr, 2006) que concluyó con la salida anticipada del presidente Alfonsín del poder en 1989.
} 
programática renovadora: donde emergía la necesidad de reconstruir el peronismo tras un programa político -y no un líder- que permitiera acoplarse a las necesidades estructurales que la nueva democracia -de partidos políticos y no de movimientos. Lo que por medio de los votos ciudadanos se expresó como exigencia ${ }^{57}$. Lo sorprendente de este período es que la estrategia movimentista de la corriente "Federalismo y Liberación" utilizó como plataforma las exigencias de democratización interna del partido para vencer al otro sector. Al respecto sostiene el autor: "El voto directo, y el país considerado distrito único fueron las consignas que habian resultado banderas de la democratización renovadora y, que terminaron por otorgarle la victoria con el $53.4 \%$ de los votos al sector menemista." (2013:52) ${ }^{58}$. La elección del 9 de Julio de 1988 resolvió la disputa de los renovadores y catapultó a Menem a la candidatura por la presidencia para los comicios de 1989. Esta extraña superposición de movimentismo y partidismo que expresaría el PJ en los años subsiguientes multiplicaron la complejidad del ciclo que duraría una década.

\subsection{Los estudios institucionalistas}

Los análisis sobre la reorganización del peronismo de carácter institucional, se centraron en el proceso de partidización por el cual se pasó de una organización de carácter movimentista a una estructura vertical de competencia interna centrada en mecanismos informales de toma de decisión y con una práctica de movilización política de carácter clientelar. La mayoría de estos análisis se encuentran centrados principalmente en la etapa que corresponde a los años 90 con el gobierno de Menem. Sin embargo, los inicios del proceso de reconversión lo encuentran a partir del conflicto entre renovadores y ortodoxos. De esta forma, Levitsky (2004) marca que el desplazamiento del sindicalismo, la anulación del sistema de tercios y la aceptación, en el congreso del 1987, de la elección directa de representantes fueron posibles por la baja institucionalización de los lazos que históricamente el sindicalismo tuvo con el Partido Justicialista, aun cuando este se consideraba un partido de base sindical. De hecho el sector proveniente de la militancia

\footnotetext{
57 En una dura editorial luego de la derrota electoral, Unamuno afirmaba: "Juan Domingo Perón está muerto desde el $1^{\circ}$ de julio de 1974 y no regresará como el Cid Campeador porque lo que nos queda es su lucha inconclusa y no su leyenda. No precisamos - ni esa fue su herencia- de un cadáver o de un apellido sino de la identidad que él supo perfilar a partir del mandato que, generosamente, le concedimos y que ratificamos una y otra vez hasta que dejó de respirar." (Unamuno, Bárbaro, Cafiero, et all.; 1984: 31)

58 También Mustapic acuerda en la importancia que tuvo la gravitación de la elección directa de representantes por parte de los afiliados: "El momento clave de este proceso de cambio en el PJ tuvo ligar cunado, por primera vez en su historia, los afiliados fueron convocados a elegir en forma directa a su candidato presidencial"(Mustapic; 2002)
} 
estrictamente política - es decir no sindical- fueron quienes ocuparon la potestad de la designación para la ocupación de los cargos, principalmente los gobernadores y los dirigentes municipales (2004: 14-15). A este análisis habría que sumarle la variable ambiental que Gutierrez indica como resultado de los programas económicos instaurados por la dictadura y que fueron difíciles de desarmar por el gobierno alfonsinista, por los cuales la clase obrera padecía el achicamiento del salario real y los despidos $(2003 ; 63)$. Ollier (2010) por su parte, agregó que la disputa por la institucionalización imbricó necesidades estructurales de un partido de tipo personalista - contar con un líder, aun cuando este sea un primus inter pares- con los fenómenos de competencia interna, dando como resultado la utilización del voto como elemento definitorio de la legitimidad de la conducción política: “Que la legitimidad de la nueva jefatura haya sido el voto ciudadano permite que el resultado de las disputas intrapartidarias quede sujeto a esa legitimidad: la soberanía popular expresada en el sufragio." (Ollier, 2010: 133). La propuesta sostiene que esta fue la forma en que el PJ resolvió el vacío dejado tras la muerte de Perón y la instauración de una lógica de acción que marcaría el devenir de los siguientes años. Al concebirlo como rasgo estructural, Ollier expresaba una corriente de análisis que se focalizó en las elecciones internas ${ }^{59}$ como el motor por el cual el PJ logra surcar las sucesivas crisis políticas que asediaron al país mediante un sistema de rotación (íbidem: 146) de sus élites partidarias.

\section{El ciclo de gobierno menemista}

Los estudios sobre la organización del peronismo en esta etapa se dividen en tres vertientes principales: aquellos que se centran fundamentalmente en la forma organizativa que provino de la década anterior y observan la consolidación de lo que se denominó como el "aparato peronista"; aquellos análisis del discurso, derivados de los problemas identitarios, que intentan comprender como se mantuvo la unidad del peronismo a pesar del giro conservador; y los estudios de las facciones peronistas que rompieron con la organización partidaria -focalizados entre estudios sobre dirigentes, sindicalistas y hacia

\footnotetext{
59 Según la autora: "Los alineamientos locales con el vencedor de la interna partidaria, terminada la competencia, ocurren en todos lados; la diferencia en el peronismo es que son por posicionamientos personales. Ergo, terminada la confrontación, el alineamiento con el vencedor esfuma la disputa." (2010: 138). Esta aseveración es discutida, indirectamente, por otros análisis que también hacen eje en el estudio de los altos niveles de competencia. Y además choca con la experiencia ya revisada de la construcción junto a los sectores ortodoxos del Menemismo durante los 80 .
} 
el final de la década, los movimientos sociales. El punto central a tener presente es que con el gobierno de Menem entre 1989 y 1999, se inició un ciclo de poder al interior del peronismo que perduró por lo largo de diez años y que implicó profundas reformas económicas y políticas para el país. El estilo de liderazgo que este protagonizó, además, zigzagueó entre un modelo plausible de acoplarse a los requerimientos de una democracia de partidos e instituciones republicanas, y un modelo de gobierno excesivamente personalista, lo que llevó a algunos autores a considerar este período de gobierno como una democracia de estilo plebiscitario.

\subsection{Los estudios institucionales y el PJ}

La propuesta de Levitsky (2005) sobre los cambios organizativos del PJ durante este período hace foco en el proceso de adaptación a las transformaciones que en materia de política económica acontecieron en todo el mundo. La crisis del Estado benefactor, condensada en la forma de las crisis de la deuda externa de la década de los 80, y la constitución del mundo unipolar, situaron en jaque a los partidos de masa de base sindical. La supervivencia de muchos de ellos, en especial el del PJ, estuvo atada a su capacidad de adaptación en términos organizativos a las nuevas circunstancias, desplazando las mediaciones corporativistas e implementando un modelo de vinculación por medio de redes clientelares con las figuras de los militantes de base, también conocidos como "punteros". En este sentido, para el desarrollo organizativo en la base de la estructura, procedería al despliegue de redes de militantes con los que produciría una territorialización partidaria, vinculados a los ejecutivos locales -municipios- y por medio de políticas de distribución de recursos estatales ${ }^{60}$. La adaptación resulto exitosa al contar con bajos niveles de rutinización y una extendida estructura informal en la toma de decisiones (Levitsky; 2005: 85 y 102), lo que le permitió fluidez para responder a los cambios del entorno (íbidem: 120) y al mismo tiempo, capacidad de contención de las agrupaciones informales $^{61}$. Al no contar con espacios preestablecidos de la organización,

\footnotetext{
${ }^{60}$ Es de destacar que la utilización de fondos públicos para el despliegue de desarrollos territoriales no conforma para el autor los únicos recursos relevados: "La tendencia de los militantes a concentrarse en el trabajo social en las bases plantea algunos interrogantes sobre la frecuente distinción entre el activismo basado en el clientelismo y el basado en la ideología. En el caso peronista, estas dos categorías se confunden" (Levitsky; 2005: 281).

${ }^{61}$ Sobre las agrupaciones intermedias o informales: "A pesar de su naturaleza informal, las agrupaciones funcionan como la organización partidaria peronista de facto. Son ellas, y no la burocracia partidaria, las que vinculan al PJ con sus activistas de base." (Levitsky; 2005: 93).
} 
las redes horizontales que a niveles de base se desplegaron como forma de intervención en el territorio - y formas de movilización- se enlazaron con redes verticales por las que estas mismas organizaciones respondían a distintos referentes que ocupaban cargos estatales - sistema de patronazgo- y que articulaban, según su inserción en la estructura estatal, mayor cantidad de vínculos (ibídem: 96).

Es importante remarcar dos situaciones que Levitsky pone de relieve en la organización interna: por una parte la política de alianzas que el Menemismo tejió al interior del PJ, que el autor denomina como lógica centro-periferia, le otorgó a dicho referente un margen de autonomía en las decisiones ya que logró desestructurar las reacciones internas de oposición que surgieron a lo largo de los diez años de gobierno (ibídem: 235). La lectura de Levitsky es que las alianzas se tejieron transversalmente a las redes horizontales, cooptando referentes de diferentes agrupaciones, lo que es equivalente a referirse a una estrategia de dispersión de los vínculos independientes al poder central. Lo segundo es que a nivel de las bases el PJ, si bien mantuvo una estructura descentralizada del accionar de las agrupaciones, la combinación entre la pauperización económica de vastos sectores de la sociedad y la canalización de recursos de forma discrecional, fueron empujando a estos mismos espacios a trabar en forma cada vez más acentuada, lazos de dependencia económica con los referentes municipales o provinciales (ibídem: 301). Ambos aspectos, deben comprenderse como parte de un mismo proceso, por el que el Menemismo logró revalidarse electoralmente en los comicios de 1995: la lectura de Levitsky es que el caudal de votos que la fórmula Menem - Ruckauf consiguió $^{62}$, se compuso tanto sectores ideológicamente de derecha externos al peronismo que acordaban con la política económica desplegada -aunque el número no parece demasiado significativo-, sumados a un conjunto de votos correspondientes a la base electoral tradicional del PJ que se mantuvo unida por arriba, obturando disidencias significativas, y por abajo con una política clientelar de despliegue territorial (ibídem: 254-257).

Novaro, por su parte, se centra en la relación PJ y la estructura de un sistema democrático plural, para observar continuidades y rupturas con la tradición en la forma de organización peronista. Para este autor, los años del ciclo menemista, aun cuando dieron cuenta de un fuerte control de tipo vertical y centralizado (1999: 109), desplazaron la lógica populista

\footnotetext{
${ }^{62}$ Recordamos que en dichas elecciones el peronismo obtuvo el 49, $9 \%$ de los votos para presidente.
} 
en el proceso de consolidación del gobierno, manteniendo las transformaciones institucionalistas que habían sido acordadas durante la década anterior ${ }^{63}$. Si bien la posibilidad de la implementación de programas económicos en favor de la estabilidad, fueron posibles por la capacidad organizativa del PJ (ibídem: 112), tuvieron como efecto el desplazamiento del lugar retórico anti status quo que el movimentismo supo generar a lo largo de su historia.

Torre sostiene que aún en su comportamiento más intitucionalizado, el PJ no deja de presentar una tendencia hegemónica ${ }^{64}$ : El peronismo en el gobierno tiende a comportarse como un sistema político en sí mismo, vale decir, a actuar simultáneamente como oficialismo y como oposición (1999: 45). La advertencia tiene en cuenta la imposibilidad de la constitución de un bipartidismo - una de los objetivos esperados por algunos analistas en torno a la reforma constitucional de $1994^{65}$ - en tanto el peronismo exterioriza sus internas en elecciones abiertas y con listas separadas de candidatos.

\subsection{Los análisis discursivos}

Aquellas investigaciones que se han centrado en la producción discursiva del menemismo como actor hegemónico del peronismo en esta década, hacen hincapié fundamentalmente en las operaciones de desplazamiento de los símbolos propios de la tradición peronista y de la construcción de una noción de orden social emplazado en el marco de la globalización. En este sentido Barbosa (2010) sostiene que la construcción del discurso menemista presenta la cualidad de mostrarse como un seguidor de la doctrina peronista, pero trazando una diferenciación en el plano temporal -los nuevos tiempos- que implicó la necesidad de reinterpretación ${ }^{66}$. Esta operación de aggiornar los significantes

\footnotetext{
${ }^{63}$ Es interesante notar como el autor sitúa el pluralismo democrático observado en la aparición de nuevas fuerzas políticas (v.g. el FREPASO) y su acción limitante sobre las pretensiones hegemónicas del peronismo: "La conclusión que cabe extraer de esta situación es que, si bien la coalición y la política populista siguen teniendo potencialidades para articular lo diverso en el PJ, su transformación en estos años en un "partido de gobierno" ha implicado el acotamiento de esa virtud populista a los marcos de la competencia intrapartidaria" (Novaro, 1999: 129).

${ }^{64}$ Torre no lo sostiene explícitamente pero se deriva de su análisis que está pensando en la conformación del FrePaSo (Frente País Solidario) fundado por un grupo de legisladores peronistas que rompieron con el menemismo a principios de la década de los 90. Esta fuerza llegó a obtener el segundo lugar en las elecciones de 1994.

65 La reforma constitucional de 1994 generó diversos cambios en el diseño institucional del país. Entre ellos, se trasformó la duración del período presidencial de 6 a 4 años y se otorgó la posibilidad de una relección sucesiva.

66 Al respecto el autor sostiene: "La posibilidad de diferenciar entre doctrina y realidad permiten al menemismo volver eficaz la resignificación de los significantes tradicionales pero no por una causa interna
} 
tradicionales, además se ve articulada frente a la construcción de la crisis económica de la década anterior, como aquello que se encuentra en el afuera del "modelo" de estabilidad trazado por esta fuerza ${ }^{67}$. Por su parte Canelo es quizás quién mejor expresa la necesidad de revisar desde una matriz discursiva la reinvención identitaria que acompañó las transformaciones del menemismo al interior del PJ, al plantear la paradoja ${ }^{68}$ del apoyo o escasa resistencia -según la autora- que recibió de sectores que se vieron perjudicados por esas mismas transformaciones ${ }^{69}$. Una operación discursiva del menemismo fue el vaciamiento de lo político de la esfera de lo esperable en la acción del gobierno, sustentado en la urgencia de la crisis frente a la que asumía el gobierno la tarea de unificar a todos los argentinos (Canelo; 2011: 79). El efecto disciplinador de los procesos hiperinflacionarios daba margen de acción a una figura política que pretendía reunificar el país bajo la condición de eliminar los viejos antagonismos ${ }^{70}$. El vaciamiento político, además, se complementaba con la estrategia discursiva de la apropiación del enemigo: para el caso de la Unión Cívica Radical, el pacto de Olivos $^{71}$ significó la posibilidad de deslegitimarlos como alternativa política y mostrarlos como aquellos que comparten las propuestas económicas pero no logran resolver los problemas. El mismo destino le tocó a la que sería la tercera fuerza en disputa-el FrePaSo- (ibídem: 104). En este sentido, el clivaje identitario que se desprende del análisis de Canelo, ya no sería izquierda /derecha, ni gremialistas/ políticos, sino más bien retardatarios / innovadores.

sino por el propio peso de la realidad. Incluso los cambios que propone en la propia doctrina justicialista vienen exigidos por la necesidad de mantenerla viva, de que la doctrina no muera." (2010: 21).

67 "Por otro lado, encontramos en el afuera a la hiperinflación. Si la contraposición en el peronismo clásico tenía que ver con la oligarquía aquí el signo es distinto y responde a una entidad más abstracta que adquiere el valor de un mal para toda sociedad." (Barbosa; 2010: 26).

68 "El gobierno de Carlos Menem, que se autoproclamaba heredero del ideario peronista tradicional, logro compatibilizar la aplicación de vastas reformas de orientación neoliberal, con estabilidad del sistema político, reducida conflictividad social e indiscutible legitimidad democrática. Y esta experiencia inédita de transformaciones que implicaban altísimos costos sociales pudo ser instrumentada en un marco de escasa resistencia-cuando no de apoyo explícito- de los principales perjudicados." (Canelo; 2011: 71).

${ }^{69}$ Resulta muy controversial la idea de la autora de una escasa resistencia. Si bien no es tema de interés de esta revisión de fuentes, es importante marcar que es en estos años y en abierta confrontación con el gobierno de Menem, en los que surge el denominado campo piquetero en el que se encontraban un gran número de organizaciones territoriales. También sectores gremiales como la Central de Trabajadores Argentinos -CTA- y el Mov. De Trabajadores Argentinos -MTA- fueron actores importantes de la resistencia obrera a las políticas de ajuste.

${ }^{70} \mathrm{Al}$ respecto la autora sostiene la necesidad del gobierno de resolver el problema denominado como doble brecha de credibilidad (2011: 86) en relación con los grupos empresarios y los sindicatos.

${ }^{71}$ El denominado Pacto de Olivos, se trató del acuerdo entre el PJ y la UCR para lanzar la reforma constitucional de 1994. El menemismo, en medio de negociaciones tensas sobre los puntos que debían tocarse en dicha reforma, generó como acción política la "filtración de la noticia" de las negociaciones, lo que tuvo un impacto inmediato negativo sobre la ya alicaída UCR. 


\section{El ciclo de poder del Kirchnerismo y la aparición del Frente Para la $\underline{\text { Victoria }}$}

Los estudios sobre el último ciclo del peronismo, el que se configuró tras la crisis del $2001^{72}$ y la asunción como presidente de Néstor Kirchner en el año 2003 presentan diferentes abordajes según definan si esta etapa presenta una continuidad con respecto a la configuración política del PJ creada durante los 90 o en la aparición de una nueva forma de construcción política, denominada como Frente para la Victoria -desde ahora FPV. ${ }^{73}$ Las posturas que suponen la continuidad, fundamentan su perspectiva en el hecho de que son los mismos actores que ocuparon puestos en la década anterior los que conforman el kirchnerismo y por tanto se trata sólo de una transformación de élites partidarias. Quienes por el contrario suponen la emergencia de una nueva forma de construcción indagan en la incorporación de nuevos grupos y espacios políticos a la identidad del FPV y sólo reservan el lugar de un actor más a la estructura del PJ.

\subsection{Los estudios situados bajo la égida de la continuidad}

Los análisis desde esta perspectiva sostienen la centralidad de la disputa por el Estado en términos de acceso a recursos para -entre otras cosas- la construcción del poder personal. En este sentido, Calvo sostendrá que la definitiva alineación del PJ bajo el mando del Kirchnerismo se produce en las elecciones del 2005, con la victoria en la Provincia de Buenos Aires, contra la candidatura del espacio político referenciado en el ex presidente Duhalde (Calvo; 2005: 159/60). Esta perspectiva se encuadra sobre una mirada en torno al PJ que sostiene que el mismo ha conseguido estructurar, sobre la base de un porcentaje de votos fieles, un sistema de rotación de élites partidarias basadas en la fuerte disputa interna y las redes que al interior de la organización los diferentes actores son capaces de construir como forma de lealtad política (Calvo, 2013). En este sentido, el problema de los recursos, se vuelve crucial en tanto asegura la capacidad de mantener o expandir la

\footnotetext{
72 Al finalizar el gobierno del PJ en 1998, asumió la presidencia una coalición de gobierno conformada por la Unión Cívica Radical y el FREPASO. Dicha coalición comenzó rápidamente a expresar problemas internos que, sumados a un agotamiento del modelo económico, desembocó en una crisis político/económica en el año 2001 que implicó tanto la renuncia de dicha fuerza al gobierno, como también una inestabilidad presidencial inédita -en el marco de la democracia- por la que se asistió al nombramiento de 4 presidentes provisionales en el transcurso de algo más de 7 días. Existe al respecto una abultada bibliografía de estudios sobre el caso, aquí listamos sólo algunos trabajos: Mustapic (2005); Cerrutti y Grimsom (2004). ${ }^{73}$ Debe tenerse en cuenta que debido a la proximidad histórica con el objeto de estudio, la mayoría de la literatura de este período resulta más bien exploratoria o fragmentaria.
} 
red horizontal que permite ganar posiciones al interior de la estructura.

También en el marco de este grupo de análisis encontramos los estudios de tipo extracéntricos focalizados en particular en la Provincia de Buenos Aires -aunque es posible encontrar muchos trabajos en otras localidades que continúan esta tenencia- que trabajan sobre la organización del PJ en torno a las relaciones entre las élites nacionales y los intendentes. Eryszewicz (2015) presenta una tesis según la cual, gracias a las tendencias de territorialización de la agregación de preferencias -sumado a algunas transformaciones generales de la concepción de la democracia- los gobernantes municipales han obtenido un mayor protagonismo en la arena política nacional, lo que los posiciona como competidores potenciales -o efectivos- de las internas partidarias por las candidaturas. Según la mirada del autor, en este escenario conflictivo la unidad del partido se obtiene por el establecimiento de un vínculo de tipo subordinación o rebeldía, estructurado sobre la capacidad de las élites nacionales de contar con formas discrecionales del reparto de fondos. En términos estrictamente lógicos, este argumento presenta la misma estructura que el de las redes clientelares, solo que de forma intrapartidaria.

\subsubsection{Breve discusión sobre el clientelismo}

Antes de continuar y presentar al siguiente grupo de trabajos, es importante detenernos en una referencia sobre un conjunto de investigaciones con los estas investigaciones han dialogado desde los años 90 -a veces sólo utilizándola en forma de fuentes- en torno a la realidad del clientelismo. El punto nodal estriba en la situación de la discusión sobre como comprender la conformación de las redes de transmisión de recursos. En este sentido las investigaciones antropológicas realizadas en la Provincia de Buenos Aires (Auyero, 2002; Quiroz, 2008; Ferraudi Curto, 2011; Vázquez y Vommaro, 2009; entre otros) han señalado al menos dos situaciones importantes a tener en cuenta en torno a la utilización de esta noción: por una parte, que la posibilidad de distribución de recursos se produce sobre una relación preexistente que se basa en valores y en marcos simbólicos comunes. Por tanto, lo que han encontrado estas investigaciones es que la condición de posibilidad de la existencia de redes es un elemento identitario por el cual los actores, aún en una relación desigual, son capaces de reconocerse en elementos que les son comunes.

En segundo lugar, las investigaciones han marcado la existencia de fenómenos de apropiación por parte de los destinatarios, como situaciones más complejas que la simple 
aceptación mecánica y por los cuales es posible advertir la existencia de ciertos márgenes de autonomía en la autopercepción que los militantes de base tienen con respecto a las cúpulas. En este sentido, en un trabajo que funge de comunicador entre las investigaciones más preocupadas por la organización partidaria y las redes clientelares, es el de Stokes, Dunning, Nazareno y Brusco (2013) el cual, si bien resulta un estudio comparado de diversos países del mundo, destina un voluminoso apartado al caso argentino. Es de destacar una hipótesis del estudio del caso argentino, en el que los autores remarcan que las estrategias entre las élites y los brokers -o armadores- no necesariamente tienden a coincidir, en vistas a que estos últimos cuentan con incentivos propios para la acción política $^{74}$.

Estos estudios han mostrado que la noción de clientelismo, la cual muchas veces funcionaba como caja negra de la explicación, implica a un conjunto de problemas que deben ser atendidos al momento de comprender a construcción de la unidad o articulación política intrapartidaria. De aquí que exista un subconjunto de análisis que, aun manteniéndose dentro de la corriente neo institucionalista, remarque la necesidad de incorporar las variables identitarias en los estudios. Un caso de esto sería el texto de Lenarduzzi (2010) la cual, en el análisis de las elecciones del 2007 en la provincia de Buenos Aires, advierte la articulación entre identidad y procesos de renovación política que protagonizaron varios candidatos a jefes comunales. También Casullo (2015) trabaja sobre la idea de una identidad hegemónica como variable clave en la comprensión del tipo de organización del peronismo, con la particularidad de que la autora trastoca la noción de partido por la de sistema no del todo cerrado, por el cual se generarían permanentemente nuevas representaciones vinculadas a la capacidad de incorporación de demandas. Si bien estos textos no resulta más que una aproximación parcial a la organización del peronismo, logran colocar el surgimiento de actores competitivos como pregunta novedosa a la situación ya descrita de la competencia interna.

\footnotetext{
74 "Our evidence suggest that brokers are engaged in frequent day to day interactions with voters in their networks and think they know their clients preferences and behaviors well; they seek to build local power bases, often by rewarding "their" voters. Our survey experiments also reveal that brokers are disproportionately likely to reward loyal voters who would turn out to vote even absent a material inducement, even as they also target swing voters and thus build ideologically heterogenous networks, and they build large organizations by paying brokers to participate in rallies and other political events. Finally, our surveys and other evidence also reveal that brokers engage in substantial rent seeking, diverting resources for their personal benefit." (Stokes, Dunning, Nazareno y Brusco, 2013).
} 


\subsection{Los estudios críticos y la matriz movimentista}

A consecuencia de la crisis de representación del 2001/2 en la Argentina, con su fuerte impacto y cuestionamiento a las formas que la representación política había adquirido durante la época neo liberal y la posterior asunción precipitada de Néstor Kirchner a la presidencia nacional, el peronismo ensayó formas de articulación política que resultaban singulares al sistema de partido que se había consolidado a partir de 1983. Este conjunto de investigaciones se ancla en este proceso histórico para pensar el peronismo. Los supuestos sobre los que esta perspectiva se despliega son: la existencia de un vínculo político centrado en una dimensión ideológica, que excede la mera agregación de preferencias. Y la centralidad de los espacios colectivos de discusión y toma de decisiones para definir las prácticas políticas.

Así, el análisis del kirchnerismo a partir de la recuperación de la lógica movimentista (Pérez y Natalucci, 2010: 98) parte de pensar la articulación -tanto de demandas, como de grupos- como una clave para entender la conformación de la organización. Es central para el análisis de esta propuesta los modos de estructurar la identidad y la relación con el pasado, ya que es en el conjunto de estas referencias donde se construye el sentido de la construcción política. Del mismo modo la figura del liderazgo como la capacidad de articulación de grupos que contaban con su identidades propias en un espacio de coordinación superior (Natalucci y Schuttenberg, 2012) es un elemento importante para comprender la relación entre la heterogeneidad interna y la direccionalidad del movimiento (Pérez y Natalucci, 2012).

El análisis de las tensiones internas, protagonizada por las subculturas -o grupos que se suman al kirchnerismo- y las discusiones en términos ideológicos, muestran el especial énfasis de estos análisis en la relación entre organización política y orden social:

"La gramática movimentista, en cambio, da por supuesto que la acción política no sólo tiene un carácter destituyente del orden vigente, sino también uno instituyente; su predominancia depende de la coyuntura histórica." (Natalucci, 2012: 139)

Al tener en cuenta las organizaciones, esta perspectiva recupera cierto margen entre la discursividad y el conjunto de estrategias que los actores se dan en vistas de alcanzar ciertos objetivos (Natalucci, 2014) se comprende bajo el proceso histórico en el que se desarrollan y por tanto la conformación de las subculturas, esto es, cantidad de militantes, 
edad de los mismos, etc. cobra un valor significativo para el análisis al igual que las prácticas políticas entendidas a partir de sus estrategias territoriales. En este sentido, el trabajo de Schuttenberg sobre las identidades nacional populares (2014) del Movimiento de Unidad Popular -MUP-, el MTD Evita y la agrupación Libres del Sur, permite comprender desde la perspectiva de estos actores los procesos de transformación que ocurrieron en el campo identitario en su desplazamiento desde el denominado "movimiento piquetero" hasta su incorporación en el Frente para la Victoria.

\section{Conclusiones}

El repaso de las diferentes investigaciones en torno a las formas de organización del peronismo a lo largo de su historia permite observar la existencia de cierta tendencia, para todos los períodos de análisis, de desplazar el foco primario de atención hacia los actores y organizaciones subnacionales. Esta situación se debe tanto a una especialización de las investigaciones, como también, y en mayor medida, a una discusión epistemológica: los supuestos base de los análisis globales (generalmente realizados desde una perspectiva nacional) generan un caudal demasiado alto de eventos anómalos que escapan a la matriz explicativa. Esto situación se debe fundamentalmente en que los estudios globales en torno a esta problemática seleccionan la relación liderazgo / base social como la variable central con el agregado, además, de que la misma se piensa desde una lógica descendente. Así, las formas de concebir la acumulación política, las contradicciones internas o los desplazamientos identitarios se intentan explicar en y por la figura de la élite nacional. Sin embargo, a medida que las investigaciones perforan los diferentes estratos del sistema político argentino en búsqueda de actores provinciales y locales que compusieron o componen actualmente esta fuerza, se evidencia el agotamiento de dicho programa de investigación. $\mathrm{O}$ en otras palabras, si bien los líderes nacionales resultan los punto de acumulación política más alta del peronismo, su capacidad de ganar o perder elecciones no dependen exclusivamente de ellos, sino también del conjunto de actores locales y sus intervenciones en los contextos en los que estos se insertan. No todo proviene de la élite nacional, ni todo se sintetiza en ella.

Por otro lado, y ya focalizados en lo que hace al estudio de los sectores subnacionales, es posible advertir que las investigaciones recuperan fenómenos que no logran encajar de manera completa ni al abordaje institucionalista ni al identitario. Despejada la clave de 
análisis sobre el clientelismo político, como también la del carisma, cuando el foco de estudios se posiciona desde lo local hacia lo nacional, los problemas de comprensión de las tensiones y/o acuerdo entre los actores muestran que, aun contando con estrategias electorales claras, las identificaciones y la pertenencia a un espacio común resultan variables significativas para entender sus acciones. En todos los momentos históricos revisados, los actores subnacionales produjeron fenómenos que fueron explicados parcialmente por ambas matrices de estudios. De aquí que en el próximo capítulo buscaremos construir, a partir de estas revisiones, las variables de análisis que se utilizarán para el abordaje de los capítulos empíricos. 


\section{Capítulo 2: Marco Teórico y Consideraciones Metodológicas}

\section{Introducción}

En el presente capítulo se expondrá el marco teórico con el que se desarrolló esta investigación. Para esto, se expondrán los supuestos que operan como base para la selección de los conceptos principales sobre los que se estructuran los instrumentos de análisis. También se expondrán las categorías, sus variables y observables. Además, dado que el sistema electoral permite diferentes tipos de estrategias, se optó por realizar un análisis de las boletas electorales, de las reglas y por último del diseño institucional de la provincia y de la ciudad para la elección de autoridades.

\section{Marco conceptual: supuestos y conceptos centrales}

"La organización engendra organización"

(Sartori, 1994: 102)

El análisis de las diferentes investigaciones que tuvieron por objeto la organización interna del peronismo en sus diferentes momentos históricos, deja como saldo el reconocimiento de una complejidad creciente: a medida que se profundizan los estudios sobre grupos internos subnacionales, su accionar, sus interacciones con otros grupos y sus modos de construir narrativas identitarias, más dificultoso deviene la posibilidad de encontrar un elemento unificador que funcione como clave heurística a lo largo de la historia de dicha fuerza política. A este fraccionalismo cada vez más visible, se le suma la advertencia sobre la gravitación que los actores/grupos/redes internas han tenido y tienen en los fenómenos de expansión, desarrollo e intervención electoral del peronismo a nivel nacional -sobran en cada momento historias de pujas internas que terminaron en situaciones de suma cero en diferentes distritos del país-. La escasa importancia asignada a los "mecanismos disciplinares" contenidos en el estatuto partidario, como así también a la "rutinización" propia de cualquier estructura jurídica de esta índole (Levitsky, 2005: 75/76), documentada por diversos autores para casi todos los momentos, jaquean la posibilidad de establecer la noción de parido como unidad de análisis. Por el otro lado, la noción de movimiento político también resulta ambigua y poco clara para fungir como 
base de apoyo para una investigación.

Frente al conjunto de dificultades, la empresa de investigar sobre la dinámica organizativa del peronismo gana en simplicidad si se exponen los supuestos sobre los que se estructuran los instrumentos de análisis. En el presente estudio, tres supuestos son principales: la centralidad de los eventos electorales en las dinámicas políticas; la existencia de fenómenos locales específicos en la organización; y que la unidad de la fuerza política puede ser explicada a través de las interacciones de los grupos que se inscriben en la misma. A partir de la incorporación de estos, es que se han confeccionado las categorías analíticas, las variables y los indicadores con los cuales se construyeron los datos empíricos en los capítulos subsiguientes.

Ahora bien, en lo que hace al primero de ellos, es decir en la relación entre organización interna y eventos electorales, el mismo resulta de la dificultad analítica antes descripta. Tomemos la definición mínima -y multicitada- de Sartori: “Un partido es cualquier grupo político identificado por una etiqueta oficial que presenta a las elecciones, y puede sacar en elecciones (libres o no) candidatos a cargos públicos." (Sartori, 1994: 89). Esta definición presenta una serie de virtudes para los problemas con los que esta investigación se enfrenta. Por un lado, su simplicidad permite incluir diferentes formatos de participación ciudadana en los procesos políticos, quitando del medio cualquier confusión en torno a los casos atípicos como ser las coaliciones, los frentes o cualquier otra modalidad observable. Por otra parte, la centralidad que adquiere la participación electoral como fenómeno de la acción política permite incluir la disputa como elemento positivo intraorganizacional. Así, en la medida en que las disputas por el control del Estado resulta un momento crucial de este tipo de organizaciones, es posible establecer allí un corte sincrónico para comprender como la fluidez que puede llegar a darse en las interacciones entre los distintos actores que componen una fuerza política se cristalizan de forma parcial. Para todo espacio que dispute el control del Estado, los diseños institucionales que ordenan los eventos electorales, con sus fechas límites, sus reglas, sus requerimientos para la participación y, finalmente, sus resultados, resultan decisivas para poder intentar generar una sutura entre las tensiones que atraviesan tanto intra como extra organizacionales. Esto, sin embargo, no significa que las reglas electorales conforman una variable independiente, ni que la organización se explica únicamente por su vinculación con las mismas. Más bien se trata de establecer que la relación entre lo que ocurre al interior de una fuerza política compleja como la descrita anteriormente, y las 
circunstancias de participación en compulsas electivas, reside en que estas últimas dotan de cierta repetición a las dinámicas de interacción. Tomando prestada una frase fucoltiana, esto podría definirse como cierta regularidad en la dispersión (Foucault; 1979) ${ }^{75}$ y esto puede comprenderse en dos sentidos: tanto en función de que esto conforma un tropo de la acción política de los actores, en cuanto las disputas y los acuerdos tienen un momento de inscripción pública en una propuesta electoral; pero también en tanto la progresiva continuidad del sistema democrático va trazando su propia estela del pasado reciente permitiendo establecer un conjunto de saberes para los actores que les permite complejizar los cálculos y las estrategias de participación. Entendidas de este modo, las elecciones resultan en eventos temporalmente más amplios y más densos que los acotados formalmente a los cierres de listas de candidatos y la campaña hasta el día de la votación.

En segundo lugar, el supuesto resulta compartido con un conjunto de investigaciones ya revisadas en el capítulo anterior, y sostiene que la modificación del punto de análisis es sustancial para poder comprender un conjunto de fenómenos propios de la organización que suelen ser considerados como anómalos. Un caso de este tipo es la situación de la competencia interna y su impacto en los niveles de cohesión de la fuerza política. Mientras que sería plausible pensar que el crecimiento de una organización política se encuentra vinculado a la diagramación y planificación de sus élites, conjuntamente con un accionar simétrico del conjunto de militantes en todos sus niveles, leemos en Panebianco a propósito de las coaliciones dominantes y los eventos internos organizacionales, un fenómeno que se presenta en las antípodas de dicha idea:

Y dado que no es posible establecer alianzas duraderas, cada facción debe tratar de crecer para mejorar, en beneficio propio, la correlación de fuerzas en el seno de la organización. El resultado es una política expansiva que [...] no es el fruto de la estabilidad y la cohesión, sino al contrario, de una inestabilidad y desunión extremas. (Panebianco, 1990: 321)

En este caso, como apunta el autor, los factores del crecimiento político no se deben ni a

75 "De ahí la idea de describir esas mismas dispersiones; de buscar si entre esos elementos que, indudablemente, no se organizan como un edificio progresivamente deductivo, ni como un libro desmesurado que se fuera escribiendo poco a poco a lo largo del tiempo, ni como la obra de un su jeto colectivo, se puede marcar una regularidad: un orden en su aparición sucesiva, correlaciones en su simultaneidad, posiciones asignables en un espacio común, un funcionamiento recíproco, transformaciones ligadas y jerarquizadas." (Foucault; 1979: 61/62) 
la accionar de las élites, ni a cierta disciplina partidaria, sino más bien variables no controladas y al dinamismo de la disputa interna. Ahora bien, de los casos como este no es posible derivar una idea de accionar simétrico de la estructura partidaria, el cual debiera considerarse conforme a una disposición vertical descendente de las órdenes de la élite, y sin embargo esto no significa la ruptura del orden interno. Todo lo cual permite pensar que, o bien se trata de casos anómalos, o bien se trata de fenómenos que implican ser analizados desde una perspectiva que priorice el estudio de las facciones o grupos internos y sus dinámicas. De aquí que sea posible establecer que el estudio de la organización interna de un partido deba considerar lo local -sin por esto caer en la falacia del salto unitario $^{76}$ - a partir de sus especificidades y en articulación con los otros niveles de la organización. Se trata de establecer que el estudio de las interacciones locales de los diversos agentes requiere el relevamiento de los dispositivos que permiten la juntura con los demás niveles sin por esto establecer una subsunción de unos sobre los otros, ni tampoco una igualdad de posiciones que sesgaría la investigación.

El último de los supuestos adoptados deriva del cuestionamiento de la unidad del espacio político como algo dado previamente: la idea de que la participación en el marco de un partido o fuerza se sostiene a partir del conjunto de incentivos, materiales o simbólicos que esta misma dispensa, atraviesa casi toda la literatura analítica. Esta idea, además, funciona acoplada a la observación de la existencia de mecanismos que reaseguran la disciplina y proveen de cierta capacidad de anticipación, por parte de las elites, de la acción de sus cuadros intermedios y locales. Sn embargo, en casos ${ }^{77}$ de alta fluctuación organizacional y elevados índices de competitividad interna, esta idea parece perder capacidad heurística. Si la unidad es problemática, quizás una posible solución radique en desplazar la mirada sobre la noción de heterogeneidad entendida en el marco de la teoría de la identidad. Ahora bien, es sabido que las identidades no constituyen continentes estables y homogéneos, sino por el contrario enmarcados heterogéneos de negociación y disputa (Grimson, 2011). Las variaciones, además, no se producen solo a nivel general de las mismas, sino también a niveles de los agentes particulares en tanto

\footnotetext{
${ }^{76}$ Este tipo de falacia, apuntada por Sartori remite a la confusión de tratar un Estado -o en nuestro caso una Provincia- como si fuera un sistema político en sí mismo: "Se hace que un subestado, esto es, un miembro de un Estado federal, sea igual a un Estado soberano." (1980: 111).

${ }_{77}$ Quedaría indagar en qué medida un contexto institucional presidencialista impacta en la organización partidaria, en términos de menguar los mecanismos internos de coacción. Sobre las diferencias entre sistemas parlamentarios y presidencialistas y las dificultades que se presentan en el segundo sigue vigente los puntos anotados por Linz (1998) en su multicitado texto.
} 
las narrativas de los mismos implican acciones performáticas (Butler, 2007), lo cual sitúa la identidad general más como un efecto que como una causa, pero además expone el hecho de que dicho efecto se ve tensado de forma permanente por los las trasformaciones de quienes se identifican con el mismo. O en otras palabras, la unidad identitaria es más un punto de llegada -que el de origen- de unos actores, que no deja de desplazarse a causa de la misma acción de identificación de estos. Además, la singularidad que presenta la identidad política partidaria frente a otras identidades -también políticas ${ }^{78}$ - es la disputa por el control del Estado, lo cual añade a la misma un objetivo que se reactualiza permanentemente. Todo lo cual conforma un conjunto de problemas que es necesario atender para pensar la identidad en el marco de una representación política que simultáneamente lidia hacia afuera -un afuera relativo como se verá- en eventos electorales contra otras fuerzas, y lidia hacia dentro con la heterogeneidad que la constituye. Tomando la propuesta laclosiana, es posible leer que:

"La constitución de un "pueblo" requiere una complejidad interna que está dada por la pluralidad de las demandas que forman la cadena equivalencial. Ésta es la dimensión de la heterogeneidad radical, porque nada en esas demandas, consideradas individualmente, anticipa un "destino manifiesto" por el cual deberían tender a fundirse en algún tipo de unidad: nada en ellas anticipa que podrían constituir una cadena. Esto es lo que hace necesario el momento homogeneizante del significante vacio. Sin este momento no existiría una cadena equivalencial. Por lo tanto, la función homogeneizante del significante vacío constituye la cadena y, al mismo tiempo, la representa. Pero esta doble función no es otra cosa que las dos caras del proceso de representación que hemos detectado. La conclusión es clara: toda identidad popular tiene una estructura interna que es esencialmente representativa." (Laclau, 2006: 205)

A pesar de lo extenso de la cita, la misma contiene diferentes elementos que hacen a la cuestión de fondo. Como es reconocido, el análisis de las identidades en la obra

\footnotetext{
${ }^{78}$ Para la distinción entre identidades políticas partidarias y otras seguimos el análisis de Aboy Carlés: "La lógica de constitución de identidades excede siempre el sistema político tal como éste es generalmente abordado. Podrán existir estudios acerca de "identidades partidarias", de hecho es ese nuestro interés, pero debemos recordar que el mismo es siempre un recorte topológico, recorte que debe atender a la relación entre un "sistema de partidos" y otro tipo de identidades presentes en una formación política. El sistema de partidos se transformará así desde el punto de vista epistemólógico en un campo de coconstitución de actores políticos en disputa entre sí y con sus propias tradiciones." (2001: 73).
} 
laclausiana encuentra en el populismo su lógica de representación de demandas, logrando por medio de las nociones de articulación y antagonismo eludir el modelo de vinculación dialéctica. En este esquema, y como postula la cita, es el vínculo y las interacciones entre las demandas lo que, sin suprimir las diferencias entre ellas, permite establecer una identidad que opera como continente. La dinámica de este modelo, además, establecida en el hecho de que la representación, generada y operada por el significante vacío, nunca se encuentra cerrada de forma definitiva sino siempre abierta a la contingencia, habilita a pensar que también en los modos de representación puede haber diferencias. Pensar la identidad partidaria desde esta lógica, entonces, implica analizar las formas de interacción entre elementos que conforman esa misma identidad -más que en los elementos en sí mismos- y en el devenir contingente de dichas construcciones.

Es posible advertir a estas alturas que la presente investigación dialoga con dos tradiciones analíticas diferentes, lo cual posiblemente signifique no dejar satisfecha a ninguna. De todas formas, la propuesta de poder intercambiar ideas con marcos epistemológicos tan diversos resulta del problema que implica el fenómeno de la fluidez de la organización a nivel municipal, observada en la fase exploratoria de la investigación y luego reconfirmada como desafío analítico en las investigaciones recogidas en el capítulo anterior. El problema de la fluidez, esto es, que los mismos grupos que trazan alianzas luego puedan romperlas y constituirse como opositores, incluso más enérgicos que los que pertenecen a otros partidos; que convivan en un mismo territorio dos, tres o más narrativas identitarias del peronismo tan diversas; que haya pretensiones electorales que diversifiquen el supuesto único objetivo del control del Estado, todos estos fenómenos generan como efecto de superficie la idea de que prevalece la desorganización y una política nominalista extrema constituida por movimientos ad hoc de los actores. Frente a esta superficialidad y con una convicción casi hegeliana de encontrar una racionalidad en lo real, es que la presente investigación construye sus conceptos en vinculación tanto con las ideas más propias del paradigma de la elección racional como también las del paradigma de la identidad.

Atendiendo a los supuestos antes expuestos, la presente investigación se estructura en dos conceptos centrales: objetivo político e identidad. El primero de ellos remite claramente a los fines de la participación política, mientras que el segundo a los recursos simbólicos que permiten construir articulaciones comunes. Una objeción posible a esta propuesta podría radicar en el hecho de que ambos podrían subsumirse al otro en tanto que recursos 
utilizados por los actores. No obstante, la discusión sobre ambos conceptos resulta lo sufrientemente rica y compleja como para producir tal movimiento. En el caso de los objetivos políticos ya Michels había advertido la variación en los mismos con su conocida ley de hierro ${ }^{79}$ de las oligarquías partidarias (1979) lo que derivó entre otros análisis a la afirmación del ya citado estudio de Panebianco sobre el prejuicio teleológico ${ }^{80}$. Suponer que existe un solo y único tipo de objetivo político de la acción, incluso electoral, por el que se subsumiría completamente la dimensión identitaria no hace más que enfrentar la investigación a un conjunto de fenómenos que debilitarán su consistencia lógica. De modo equivalente ocurriría con el intento de transformar los fines políticos en recursos de la identidad, lo cual redundaría en un debilitamiento de la noción de disputa antes revisada ${ }^{81}$. Además, es importante remarcar el hecho de que existe una diferencia metodológica importante en la decisión de estudiar o bien agrupaciones, o bien fenómenos multi-organizacionales: si las identidades colectivas resultan un complejo entramado de relaciones y de representaciones (Gímenez: 1996: 199) que no pueden considerarse como la suma de identidades individuales, poco se gana atribuyéndole un único y mismo objetivo político como recurso a estos grupos.

Así, a los fines de una investigación como la que aquí se propone, lo mejor sigue siendo mantener los conceptos articulados entre sí, pero no subsumidos. De esta articulación se espera sea posible reconstruir las lógicas que operan al interior de la organización del peronismo platense y que toman cuerpo en las diversas trayectorias de las organizaciones locales que lo componen. Antes de avanzar, resta hacer una última mención a un fenómeno derivado de la fluidez de lo local: atendiendo los supuestos arriba mencionados, el foco de esta investigación estará puesto en experiencias multi-organizacionales del peronismo. Reservamos el concepto de frente electoral para la vinculación con organizaciones provenientes de otras tradiciones políticas. Todo esto deriva en que interesan más las interacciones que las organizaciones en particular, aunque por razones de protagonismo en la escena local, algunas organizaciones se encuentren más nombradas

\footnotetext{
79 "Sin embargo, el objetivo de la elite con base en la masa es reemplazar el poder de una minoría por el de otra: ellos mismos." (Michels, 1979: 17)

80 "El prejuicio teleológico. Se halla igualmente difundido, pero es tal vez más insidioso que el prejuicio sociológico. Consiste en la atribución a priori de "fines» a los partidos, de objetivos que según el observador representan la razón de ser del partido en cuestión, de los partidos en general o de una u otra "familia ideológica>> de partidos." (Panebianco: 1990: 30)

${ }^{81}$ Para el caso recordamos el desdoblamiento identitario en el peronismo propuesto por Altamirano entre "peronismo fáctico" y "peronismo verdadero". (2001: 108)
} 
que otras.

\section{Categorías, dimensiones y observables}

A continuación se explicaran las categorías, sus dimensiones, sus observables y las fuentes de información utilizadas para la investigación. De los dos conceptos arriba explicados, se derivan dos categorías de análisis: del concepto de objetivo político, se deriva la categoría de estrategia electoral. Por el lado del concepto de identidad se deriva la categoría de identidad política particular. La operacionalización de ambas dos será expuesta junto con algunas consideraciones de ciertas dificultades que se presentan al momento de la captura de fenómenos.

\subsection{Estrategia Electoral}

La categoría de estrategia electoral permite observar el cálculo que realizan los actores en torno a los medios disponibles en el marco de una coyuntura, a fin de alcanzar sus objetivos políticos. En este sentido, aquello que cabe dentro de esta categoría es el conjunto de variables que un conjunto de actores o agrupaciones atienden al momento de definir el modo en el que se conducirán en los procesos eleccionarios dada la información con la que disponen, las reglas que estructuran el juego democrático y la acción de los competidores y adversarios.

Ahora bien, teniendo en cuenta que aquello que es de interés a la presente investigación son las agrupaciones locales, y que debido a esta dimensión sub nacional el conjunto de posibilidades de acción se ve constreñida a la relación con las élites nacionales y provinciales -sea esto por la necesidad de contar con recursos económicos para la campaña electoral o también con recursos simbólicos- es necesario realizar algunas aclaraciones en pos de comprender como es que esta categoría puede aportar a comprender aquellas decisiones que les son propias a los actores locales, con independencia de esas restricciones.

En primer lugar, las decisiones de una agrupación local se producen en el marco de una evaluación por parte de las mismas del contexto o la coyuntura en la que estas se encuentran inmersas. Esto implica que existe una dimensión externa a las decisiones, y por tanto independiente de los actores, pero que a su vez impacta en los mismos a partir de sus diagnósticos. Debida cuenta que el concepto de coyuntura es complejo de asir, 
puesto que no presenta límites claros en torno a las variables que potencialmente puede llegar a incluir, la noción que mejor expresa esta dimensión externa creemos sería la de Estructura de las Oportunidades Políticas, tal y como la han definido Tarrow:

“Al hablar de estructuras de las oportunidades políticas, me refiero a dimensiones consistentes —aunque no necesariamente formales, permanentes o nacionalesdel entorno político, que fomentan o desincentivan la acción colectiva entre la gente. El concepto de oportunidad política pone el énfasis en los recursos exteriores al grupo - al contrario que el dinero o el poder-, que pueden ser explotados incluso por luchadores débiles o desorganizados." (Tarrow; 1997: 49)

Como el pasaje lo indica, esta noción implica esta doble dimensión: le de los eventos que ocurren en el marco del entorno y fundamentalmente la de las lecturas que los actores realizan de estos eventos, o enmarcado (McAdam; Tarrow y Tilly; 2005: 49) en tanto que moduladores de las posibles acciones. Esta noción, si se prefiere, puede ser comprendida como un concepto límite o fronterizo, es decir, al presentarse en su carácter de exterioridad a los actores pero, simultáneamente, dependiente de que estos lo constituyan como su coyuntura a partir de una evaluación general, implica el límite de lo que les es inherente a las agrupaciones.

¿Cuáles variables son controlables por las agrupaciones? En el marco de un sistema político presidencialista como el que presenta la Argentina, que además despliega las mismas características en todos sus niveles, la estrategia de los actores depende de dos recursos políticos principales: contar con un candidato al ejecutivo con proyección electoral -una figura atractiva y atrayente para el electorado- para un (el) cargo ejecutivo al que se pretenda competir y, por otro lado, tener capacidad de concretar un marco de alianzas con otros sectores para conseguir volumen de acción. Estos dos recursos parecen ser centrales al momento de comprender el conjunto de decisiones, en tanto provienen del modo en que se encuentra estructurado el sistema -en este sentido, de intentar analizar las estrategias en el marco de un sistema político de tipo parlamentarista, otras serían seguramente las variables- y con ello el conjunto de problemas que le son propios a las lógicas de los actores. A continuación analizaremos ambos recursos en tanto que conforman las dimensiones de la presente categoría.

Teniendo presente el diseño institucional de la Provincia de Buenos Aires, la posibilidad de ser candidato se encuentra restringida de forma diferente en el caso del ejecutivo provincial que en el municipal. Mientras que a nivel provincial la Constitución indica 
como delimitaciones el: Haber nacido en territorio argentino o ser hijo de ciudadano nativo, si hubiese nacido en país extranjero; tener treinta años de edad; cinco años de domicilio en la Provincia con ejercicio de ciudadanía no interrumpida, si no hubiese nacido en ella. ${ }^{82}$; las restricciones para ser candidato al ejecutivo municipal son: serán elegibles todos los ciudadanos mayores de veinticinco años, que sepan leer y escribir, vecinos del distrito, con un año de domicilio anterior a la elección y si son extranjeros, tengan además cinco años de residencia y estén inscriptos en el registro especial. ${ }^{83}$ Este conjunto de restricciones formales presenta la primera delimitación al conjunto de potenciales candidatos. Sin embargo, y aun habiendo atendido a estas, es posible realizar otra delimitación, si se prefiere de carácter informal, en torno a los candidatos al gobierno del ejecutivo municipal: debida cuenta que los procesos políticos tienden a contar con cierta extensión temporal en la que se producen diferentes eventos -o elecciones- es posible diferenciar entre aquellos candidatos que se presentan una única vez y aquellas que establecen una frecuencia ${ }^{84}$. Si bien el criterio de diferenciación parece contar con cierta relatividad -a diferencia del formal- su importancia radica en poder discernir entre una estrategia electoral a largo plazo y una situación de distracción electoral -o lo que en la jerga política se denomina operaciones políticas-. No se trata de que las candidaturas de única vez no reporten una importancia en sí mismas, sino más bien que estas pueden confundirse con aquellas que, formando parte de las decisiones de otro grupo, se llevan adelante en pos de debilitar o dispersar el voto de los contrincantes.

Realizadas las delimitaciones sobre que fenómenos conforman el contenido de esta dimensión, es necesario explicar aquellos indicadores que permiten la observación. En primer lugar-vinculado a la frecuencia- un indicador lo conforma la diferencia de votos obtenida en al menos dos elecciones ejecutivas diferentes. Así si un candidato obtiene una diferencia negativa, se podrá sostener que su proyección electoral es descendente; si es igual, se dirá que su proyección electoral es estacionaria; y si es positiva se podrá sostener que es creciente.

Existe otro elemento que participa de la constitución de la candidatura y de su performance, en forma indirecta: la trayectoria pública del candidato/a por la cual se

\footnotetext{
82 Artículo no 121 de la Constitución de la Provincia de Buenos Aires.

${ }^{83}$ Artículo no 191 de la Constitución de la Provincia de buenos Aires, inciso 3. Cabe destacar que en el inciso 6 se agrega otra restricción en torno al Concejo Deliberante: Los concejales extranjeros no podrán exceder de la tercera parte del número total de los miembros del Concejo Deliberante.

84 Obviamos claramente los eventos ambientales que puedan afectar a las candidaturas -v.g.

fallecimiento-
} 
comprende el capital simbólico con el que él mismo cuenta, y que refiere a la centralidad que su figura adquiere en tanto "capacidad de ejercer el gobierno". Claramente este observable resulta difícil de asir si no es a través de la recurrencia del nombramiento de su figura en la escena política local. Para lograr captar esto, es necesario recurrir a entrevistas con miembros de las agrupaciones participantes como también a apariciones en noticias de medios de comunicación local. La intención es poder establecer el grado de reconocimiento de los pares como figura emergente de una estrategia colectiva.

La segunda dimensión de la categoría es la del marco de alianzas con otros grupos existentes en la región. Esta también refiere a una variable sobre las que un grupo determinado puede tomar decisiones ya sea en términos de amplitud, como también en términos de selección. A diferencia de las candidaturas a los ejecutivos, el marco de alianzas intenta capturar aquellos fenómenos de acuerdos entre sectores que no necesariamente se adecúan a los límites partidarios, sino que los atraviesan, y que le imprimen a la organización en cuestión mayor capacidad de captación de votantes para afrontar un evento electoral. En este sentido, en la medida de la amplitud o restricción del marco de alianzas, es posible suponer una caracterización de la competitividad electoral; sin embargo el hecho de que las alianzas implican sectores con intereses propios $-\mathrm{y}$ dinámicos- muchas veces esta relación no es directa o causal, ya que las exigencias para el acuerdo por parte de otros grupos pueden empujar a equilibrios inestables. Debido a esto, la dimensión del marco de alianzas debe poder contar con un indicador concreto por el cual se observe sin lugar a dudas como se vinculan las agrupaciones y cuales presentan mayor importancia en la consideración de los dirigentes. El mejor índice para esta observación resulta la nómina de candidatos al Concejo Deliberante del municipio. Esto por dos razones: en primer lugar porque en la nómina se expresa ese marco de alianzas traducido en candidaturas. En segundo lugar, porque la composición de la nómina permite observar la importancia que para los que la componen tienen los grupos que en ella participan -así si un grupo logra obtener un candidato en los primeros lugares, puede considerarse más relevante su participación en el marco de alianzas que si obtiene una candidatura en los últimos lugares. Más adelante se detallan las formas de comprensión de la estructuración de la nómina de candidatos.

Otro indicador del marco de alianzas es la participación en declaraciones públicas realizadas por los referentes de dichos grupos. En este caso la observación de las denominadas "solicitadas" que se realizan en medios gráficos resultan las más significativas ya que estas funcionan tanto en términos de dejar asentada la vinculación, 
como de funcionar en términos de propaganda electoral.

\subsection{Identidad política particular}

La categoría de identidad política particular permite observar e identificar los modos de vinculación de las articulaciones multiorganizacionales locales respecto del espacio identitario común del campo más amplio -o terminológicamente más claro: universal- y las formas de diferenciación que establecen entre ellas. De esta forma, los fenómenos que esta categoría ilumina son aquellos que corresponden a los posicionamientos, en el transcurso de un proceso político, de las coaliciones de las agrupaciones locales respecto del campo nacional identitario, luego y en un estrato con menor universalidad, de la élite nacional -que transitivamente intenta saturar el campo general-, luego en relación con la estructura del PJ y, por último, en relación a la captura de votantes. En otras palabras, la identidad política particular que construyen las agrupaciones en conjunto permite observar lo modelización de un discurso que simultáneamente lo posiciones en un campo identitario más amplio y, además, le permita interpelar a los vecinos del distrito.

Ahora bien, teniendo en cuenta que los modos en que estas construcciones identitarias particulares se plasman son múltiples, nuestra intención es centrarnos en las intervenciones públicas realizadas en el marco o a propósito de las campañas electorales. Tomando tanto los discursos de los candidatos, como la propaganda electoral, el objetivo es ver como estos conjuntos de organizaciones logran estructurar una intervención que opera fundamentalmente en tres estratos semióticos diferentes: uno, de tipo más general, a la estructura del PJ, o en otros términos, a la tradición peronista. Existen diferentes formas de recuperación del pasado en términos de símbolos, personas reconocidas, eventos significativos, entre otros, por parte de los actores y muchas veces estas formas de actualización pública del pasado implican tanto una búsqueda del voto fiel, como también una disputa sobre los límites de las acciones presentes como acciones con sentido tradicional.

El segundo estrato semiótico vinculado a la figura de la élite nacional o, también de la élite provincial. En este estrato lo que nos interesa observar si es que se entablan identificaciones con dichas figuras, si hay ausencias de identificación o si, por el contrario, se construyen intervenciones que expresan desacuerdos.

El tercer y último estrato corresponde al modo de interpelación respecto del electorado 
en general. También en este caso existen diferentes modulaciones discursivas, pero teniendo presente el escenario sobre el que las agrupaciones se movilizan y la relación de este en términos de lo local-nacional, nos interesa observar como aparecen delimitados dos grandes grupos de interpelaciones electorales: los de tipo municipal y los de tipo extra-municipal. En el primer caso se trata de aquellos discursos que se desacoplan de los problemas nacionales dando primacía a los temas locales. En el segundo caso, por extensión, resultan de aquellos discursos que articulan lo local y la relación con la provincia o la nación. Lo que se espera ilumine el análisis de este estrato es el modo de construcción de la ciudad por parte de los actores.

La intervención de los espacios multiorganizacionales sobre estos tres estratos puede analizarse por separado o en conjunto según la plataforma del discurso público que se tome como observable. En vistas a una simplicidad analítica y al conjunto de supuestos arriba explicitados, en la presente investigación optamos por delimitar estos discursos a dos elementos: por un lado los discursos de campaña expresados por los candidatos. Estos desarrollan sentidos y posicionamientos de cara a la captura de votos y la articulación con otros sectores internos de la fuerza política.

El segundo elemento que conforma los observables de esta categoría es la propaganda gráfica electoral. Una campaña gráfica se compone de distintas intervenciones pero manteniendo un registro común. Para la selección de muestras de estas producciones se privilegiara las campañas aparecidas en el diario El Día, puesto que este matutino resulta el de mayor tirada del distrito. Sin embargo, esta selección requiere algunas precisiones. Una cuestión con este tipo de observable es que se encuentra reglado por disposiciones jurídicas sobre los derechos de uso de las imágenes. No obstante, la habilitación del uso no asegura su uso, por lo que el presupuesto de la variación de los indicadores se mantiene. Por otra parte, un fenómeno que está ocurriendo con la creciente importancia de las redes sociales, es la migración de las campañas publicitarias gráficas a estos nuevos formatos -como Facebook, Twitter e Instagram- lo que obliga a complementar los observables del diario con lo utilizado en tales plataformas. Para los casos que así lo requiera, y atendiendo a la unidad de sentido que asigna "la campaña" como conjunto, se seleccionarán muestras provenientes de redes sociales. 


\section{Consideraciones metodológicas y recorte temporal}

La estrategia metodológica de esta tesis responde a lo denominado como un estudio de caso (Kröll, 2000), donde pretendemos comprender el proceso político en el cual un conjunto de agrupaciones disputan, en el marco de una identidad común, la representación local de la orientación nacional de la fuerza. En este sentido, lo que se intenta observar no es a cada agrupación por sí misma, sino los efectos de conjunto en el marco de una disputa. Por este motivo nuestra selección del caso es intencionada y se rige bajo el criterio no de la representatividad, sino de la capacidad de particularizar el fenómeno, de su cualidad descriptiva y de su valor heurístico, lo que equivaldría a la denominación de un estudio de caso intrínseco (Archenti; 2007).

Las fuentes primarias de información consultadas fueron:

a) Entrevistas a referentes de agrupaciones: se realizaron un total de 16 entrevistas a diferentes referentes locales de las agrupaciones que compusieron el peronismo platense durante este período. Las mismas se realizaron durante el período de investigación de campo entre agosto del 2015 y Septiembre de 2017, luego de las elecciones PASO de dicho año.

b) Discursos en el ámbito del Concejo Deliberante platense: se utilizó el Diario de Sesiones del Concejo Deliberante local, focalizando principalmente en las alocuciones realizadas por quien fuera el Intendente al principio de cada período ordinario del 2003 al 2015 inclusive, como también en las intervenciones de los Concejales en torno a efemérides importantes en la historia del peronismo, como también de eventos nacionales de fuerte impacto, como la denominada crisis del campo, o la muerte de Néstor Kirchner, entre otros.

c) Propaganda de campañas: se compilo y analizó las propagandas que los diferentes conjuntos de agrupaciones realizaron en medios gráficos de la ciudad. Debido a la desproporción en el peso específico que ciertos periódicos tienen por sobre el resto, en particular el del denominado diario El Día, se confirió mayor importancia a las publicidades realizadas en este matutino. Para el caso del polo de agregación de agrupaciones que se conformó a partir del 2013, referenciado en la figura de Florencia Saintout, que por decisión explícita definió no publicar en dicho periódico, se utilizó su perfil de Facebook, el cual operó en sus campañas 
como plataforma de propaganda.

d) Solicitadas en medios gráficos: esta forma de intervención pública es bastante usual en la Argentina, aunque por sus costos su frecuencia varía. Se trata de la compra de un espacio en un medio gráfico para expresar públicamente un mensaje -generalmente se trata de apoyos a candidaturas- el cual se combina con la firma de un conjunto de actores o agrupaciones.

e) Resultados electorales: Se recopiló los datos electorales correspondientes a los niveles nacionales, provinciales y locales en el período estudiado, expuestos por la Junta Electoral Nacional, dependiente del Ministerio del Interior de la Nación, como también de la Junta Electoral Provincial de Buenos Aires.

f) Boletas Electorales: se estudiaron las diferentes boletas electorales que participaron de los comicios en la ciudad de La Plata en el mismo período de tiempo. Las mismas también fueron extraídas de la Junta Electoral Provincial de Buenos Aires.

g) Noticias de los medios locales y nacionales: se realizó una compilación y análisis cruzado de las noticias de los medios gráficos locales como también de los nacionales a fin de aportar a la comprensión del contexto.

h) Discursos públicos en actos de campaña

La presente investigación se focaliza en los procesos electorales que transcurrieron entre 2011 y 2017. En dicho período ocurrieron 4 elecciones generales: dos con carácter ejecutivas y dos de carácter legislativas. Además, luego del 2015, el peronismo abandonó el control del ejecutivo tanto a nivel nacional, provincial y municipal luego de 12 años ininterrumpidos de gobierno -en el caso municipal, si se suman los años de la anterior gestión, el peronismo gobernó el municipio desde 1991- lo que implicó un gran impacto al interior de la organización. En lo que hace a los eventos ambientales es necesario mencionar la inundación de abril de 2013, que también afectó la performance de los actores políticos.

El criterio utilizado para la selección de eventos electorales consistió en poder tomar el cierre de un ciclo político al interior del peronismo y una muestra de su reorganización a partir de encontrarse fuera del control del Estado. Teniendo en cuenta que la historiografía del peronismo establece los ciclos organizativos internos a partir de la hegemonía que logra construir una élite nacional, y además, que tras la muerte del ex presidente Néstor Kirchner en 2010, la élite nacional vio acotada su posibilidad de 
mantenerse como tal a nivel nacional, consideramos que las elecciones del 2011 conforman el punto de partida de un proceso de reorganización interna que encontraron su punto de mayor dispersión las elecciones del 2017.

\subsection{Algunas consideraciones sobre las reglas electorales}

Debido al recorte temporal propuesto, es importante realizar algunas consideraciones sobre las reglas electorales que rigieron en los comicios analizados ya que en el año 2009 -luego de las elecciones- las mismas fueron reformadas y se pasó a un nuevo esquema que implicó una revisión en las estrategias electorales de las agrupaciones.

Desde el retorno de la democracia en 1983 a la Argentina, el sistema electoral tuvo dos grandes conjunto de cambios: unos de importante trascendencia a nivel nacional, con la reforma constitucional de 1994 y luego la sanción de la ley n 26571 denominada como Ley de Democratización de la Representación Política, la Equidad y la Transparencia Electoral que impusieron las elecciones internas abiertas y obligatorias -conocidas como PASO-. Y un conjunto de cambios menores que fueron comprendidos por la literatura como resultado de las decisiones de los partidos o coaliciones gobernantes en función de resolver situaciones internas o mejorar su competitividad electoral.

Cabe señalar en torno al conjunto de grandes cambios que, luego de la reforma constitucional de 1994 en el que se modificó la extensión del mandato presidencial -de 6 a 4 años-, se introdujo la posibilidad de contar con un período de relección para el ejecutivo nacional y se eliminó el Colegio Nacional Electoral, las leyes que rigieron los comicios hasta el 2009 fueron: el Código Electoral Nacional (ley nº19945 y modificatorias), la Ley Orgánica de los Partidos Políticos n 23298; La Ley de Cupo Femenino, no 24012 y la Ley de Financiamiento de los Partidos Políticos, $n^{\circ} 26215$ (Tagina; 2013). Con la sanción de la ley no 26571 del 2009, a la que la Provincia de Buenos Aires adhirió por la ley provincial $n^{0} 14086$, se produjeron tres cambios de fundamental importancia: en primer lugar, todos los partidos o coaliciones que pretendieran disputar electoralmente deberían realizar internas abiertas simultáneas y obligatorias el mismo día. En segundo lugar, el piso electoral para poder competir en las elecciones se estableció en la cifra del 1,5\% de los votos válidamente emitidos (artículo 45). En tercer lugar, los candidatos solo podrían ir por una sola boleta electoral y por una 
sola categoría a elegir (artículo 22), complementándose esto con que las reparticiones de los casos de mayoría y minoría quedaron sujetas a la carta orgánica de cada agrupación $(\operatorname{art} .21)^{85}$.

El grupo de modificaciones menores que se realizaron hasta el año 2009, implicaban las posibilidades de acuerdos entre agrupaciones de un mismo partido para construir diferentes propuestas plasmadas en las boletas electorales. A continuación se realizarán consideraciones sobre estas mismas.

\subsubsection{Consideraciones sobre las boletas electorales}

La primera consideración es que la dinámica electoral de la provincia se encuentra fuertemente vinculada a las decisiones nacionales. No nos referimos a ello en términos únicamente de decisiones partidarias, sino también en términos de organización de los eventos electorales. Salvo las elecciones del 2003, todos los acontecimientos electorales fueron simultáneos con los nacionales, lo que se debe al denominado peso en el padrón electoral nacional de la provincia. Ahora bien, hasta la aprobación y puesta en vigencia

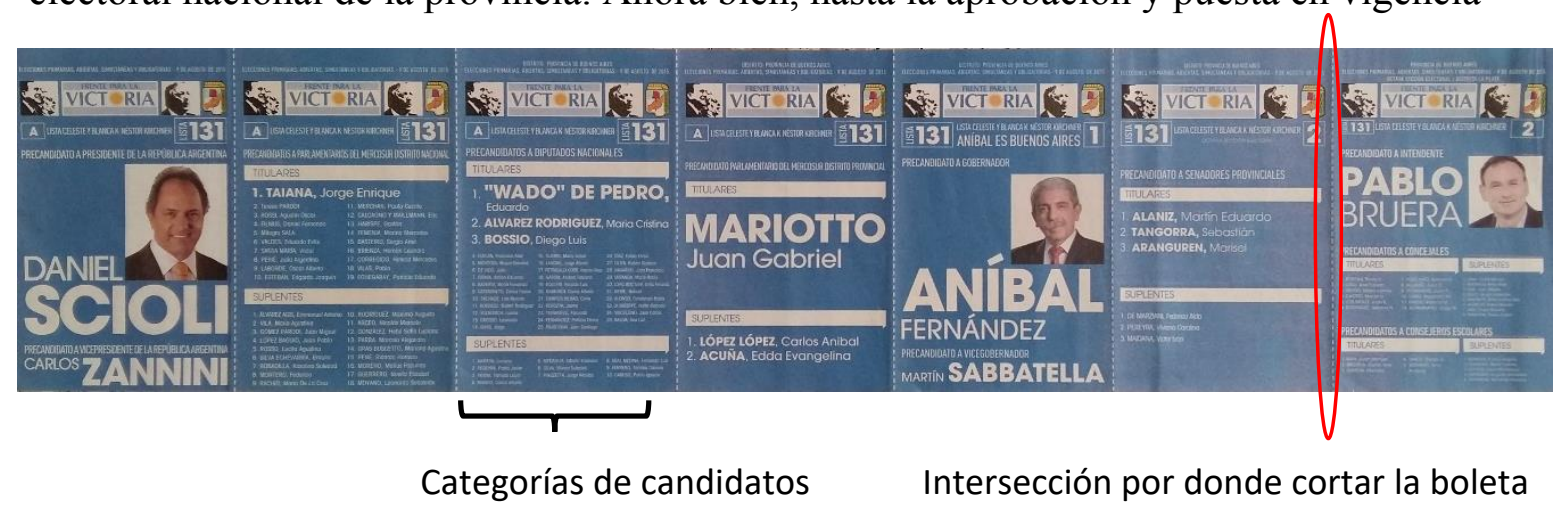

Imagen 1 Ejemplo de boleta electoral completa

de la ley de 14086 se permitían ciertas estrategias electorales en la construcción de boletas que es necesario presentar. Una boleta, o papeleta electoral se estructura en cuerpos o categorías de candidatos -ver imagen 1. Como cada categoría es independiente de las otras, ocurría que era necesario realizar acuerdos al interior de cada fuerza política para construir la boleta completa. Esto producía que: podían presentarse candidatos para alguna categoría -aunque mayoritariamente fueron situaciones municipales- sin contar

\footnotetext{
${ }^{85}$ Fuente: LEY DE DEMOCRATIZACION DE LA REPRESENTACION POLITICA, LA TRANSPARENCIA Y LA EQUIDAD ELECTORAL, № 26571, disponible en: http://www.mininterior.gov.ar/asuntospoliticos/pdf/Ley 26571 .pdf
} 
con la boleta completa, a esto se lo denominaba boleta corta -ver imagen $2^{86}$.

Imagen 2 Ejemplo de Boleta Corta

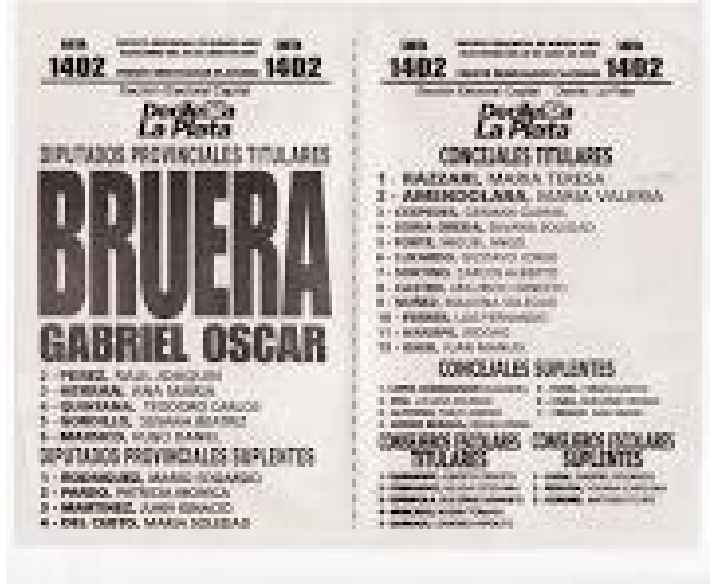

También se permitía a una fuerza que presentara alianzas a niveles municipales con varios candidatos además de los internos de la estructura partidaria, a estos se los denominaba listas colectoras. Otra estrategia era presentar los mismos candidatos para diferentes boletas, a esto se lo denominaba listas espejo. La diferencia entre una lista colectora y una boleta corta

es que la primera va adjuntada a la boleta general del resto de los candidatos.

Cabe realizar una última aclaración en vistas a la mejor comprensión de la presente tesis. Atendiendo a la construcción de la categoría para los candidatos al Concejo Deliberante del municipio, es importante resaltar, que de los 12 cargos -titulares y el mismo número de suplentes- la "tradición" que presenta la práctica de los ingenieros electorales de cada fuerza, consiste en dividir la lista en tres grupos: a) Aquellos cargos que por la imagen positiva de la lista son considerados como "seguros" a ingresar al Concejo. Estos se suelen denominar en la jerga política, también como "blanco". b) Aquellos que componen el espacio expectante, puesto que dependen de la diferencia en el cociente de $\mathrm{Hare}^{87}$-que es el utilizado por el diseño institucional municipal-. Estos también se consideran en la jerga como "gris". c) Y por último, el conjunto de candidatos que es seguro que no ingresen pero que, de todas formas, su nombre en la lista implica simbólicamente un reconocimiento a su trayectoria o importancia dentro de las alianzas de las nóminas. Estos espacios se denominan como "negro" 88 . Mientras más "claro" es el lugar en la lista, más firme o importante es la alianza con ese sector.

\footnotetext{
${ }^{86}$ Fuente: fotografía propia.

${ }^{87}$ Artículo 109 de la ley no 5109: Ley Electoral de la Provincia de Buenos Aires. Es interesante marcar que a nivel nacional, el cociente utilizado para la elección de cargos legislativos el de D’hont.

88 Un dato no menor es que por la exigencia del "cupo femenino" - una mujer cada tres candidatosmuchas veces sectores que se encuentran en la casilla "b" pueden pasar a la "a" y viceversa.
} 


\subsection{Consideraciones sobre el diseño institucional provincial y local}

La Provincia de Buenos Aires se divide en 135 partidos distritales, o municipios. Si bien para los cargos ejecutivos la Provincia se considera como distrito electoral único, para las elecciones legislativas, la distribución se realiza sobre la constitución de 8 secciones electorales, de la cual la de La Plata, por ser la ciudad capital, es sección única (la octava $)^{89}$. Esta división electoral se realiza sobre el criterio mínimo de la elección de 3 senadores provinciales por distrito y al menos 6 diputados provinciales. La organización bicameral del poder legislativo de la provincia se compone de 92 diputados y 46 senadores $^{90}$. Si bien el criterio para la asignación de bancas de diputados es poblacional, el criterio de senadores es territorial, pero como las secciones agrupan un número disímil de municipios, algunas llegan a elegir hasta 9 senadores -sección tercera- mientras que otras, como la sección 8va elige sólo 3.

Al igual que en la organización nacional, las elecciones legislativas -tanto de diputados como de senadores- son mixtas y alternan eventos concurrentes con las elecciones para Gobernador y elecciones de medio término, cada 2 años $^{91}$. Para la asignación de bancas se utiliza el cociente de "Hare" 92 , el cual también aplica para la asignación de bancas de los Concejos Deliberantes Municipales.

La creación de municipios es facultad del poder Legislativo Provincial y la organización política de los mismos está asentada en el decreto ley 6769/58 o Ley orgánica de las municipalidades. Según la misma, todos los municipios cuentan con dos poderes elegidos por voto directo: un poder ejecutivo, conformado por la figura del intendente y un poder legislativo denominado como Concejo Deliberante Municipal, en el que se eligen cargos de concejales. La cantidad de bancas de este último está definido por la misma ley y su criterio es estrictamente poblacional, ajustándose a los datos que arrojan los censos poblacionales realizados por la nación cada 10 años. Debido a que el distrito de La Plata cuenta con más de 200 mil habitantes, la cantidad de concejales que componen su órgano

\footnotetext{
${ }^{89}$ Artículo 61 de la Constitución de la Provincia de Buenos Aires.

${ }^{90}$ La ley 5109 o Ley electoral, fija la distribución de los cargos a elegir según los distritos en su artículo 13.

${ }^{91}$ Vale la aclaración que a nivel nacional la elección de Senadores se realiza con una periodicidad diferente a la de diputados, pues su mandato dura 6 años. En este sentido la renovación de la cámara se realiza por tercios, cada dos años.

92 Artículo 109 de la ley 5109, Ley electoral, de la Provincia de Buenos Aires. Es interesante marcar que a nivel nacional, el cociente utilizado para la elección de cargos legislativos el de D’hont.
} 
legislativo municipal es de 24 -que es el mayor número posible.

Como se desprende del artículo 123 de la Constitución nacional, reformada en 1994, los municipios cuentan con un régimen de gobierno autonómico. Sin embargo en la Provincia de Buenos Aires, el mismo sólo es constituido parcialmente (Di Paola y Oliver; 2002) ya que es atribución de la Legislatura Provincial el determinar los alcances de dicha autonomía ${ }^{93}$ para cada municipio. De todas formas, entre las atribuciones de gobierno con las que cuentan los municipios de la Provincia está la definición presupuestaria, la posibilidad de fijar impuestos municipales y la postulación de candidatos para ocupar cargos judiciales con atribuciones locales -jueces de faltas $-{ }^{94}$.

\subsubsection{Diseño Institucional del Municipio de La Plata}

Si bien la estructura del diseño institucional municipal emula en su división de poderes al sistema presidencialista nacional -y provincial- con la única salvedad de que cuenta con un sistema de relección indefinida, es notorio ciertos aspectos que hace a la organización del Consejo Deliberante local: por un lado, este órgano elige autoridades cada cuatro años, teniendo las figuras de un presidente, 2 vicepresidentes $-1^{\circ}$ y 2 do- y un secretario ${ }^{95}$. La elección se realiza por votación de los miembros del cuerpo y de haber paridad en los votos, el presidente se define por aquella fuerza -o alianza- que resultó ganadora en la elección ejecutiva municipal. De no ser esto posible, el criterio utilizado es el de la mayoría de edad. La importancia del criterio en favor de la fuerza que ganó las elecciones ejecutivas municipales se debe a que el Presidente del Concejo Deliberante es la figura que ocupa la cadena de mando, de producirse una eventual remoción del Intendente.

Además de los elementos ya destacados la estructura de gobierno del ejecutivo municipal de La Plata, se compone de un conjunto de 16 secretarías, 2 consejos municipales y un conjunto de entidades autónomas, entre ellas se encuentran las delegaciones municipales,

\footnotetext{
93 El artículo de la Constitución Provincial que define esta situación es el 191.

${ }^{94}$ En este punto es interesante remarcar dos elementos: por un lado el artículo 192 de la constitución establece que cada municipio tiene la atribución de definir su presupuesto y de darse la situación de que el mismo no sea aprobado, el intendente se regirá por el presupuesto del año anterior (5ta disposición). Por otro lado, en lo que respecta a la posibilidad de establecer impuestos municipales, el criterio para su aprobación también se encuentra definido constitucionalmente en el artículo 193 según el cual se establece la necesidad de contar con una mayoría absoluta o un número igual o mayor de contribuyentes municipales.

95 Ley 6769, de título: Ley Orgánica de las Municipalidades. Artículo 19.
} 
las cuales corresponden a la estructura de descentralización territorial municipal. La Plata cuenta con 18 centros comunales, en los que se atienden reclamos, se habilita el pago de tasas municipales y actualmente funciona la policía comunal ${ }^{96}$. Si bien en el año 2000 se promulgó una ordenanza -la 9200- que habilitaba la elección por medio del voto de los delegados comunales, luego esta fue derogada y actualmente la figura es designada por el Intendente.

${ }^{96}$ De reciente creación -2014- se rige por la ley 13482. 


\section{Capítulo 3: El peronismo platense y las elecciones del 2011: división, anticipación y acumulación diferenciada}

\section{Introducción}

En el presente capítulo se analizarán las interacciones entre las diferentes agrupaciones que conforman el universo del peronismo platense de cara a la construcción de propuestas electorales para las elecciones del 2011. El esquema de presentación del mismo se encuentra estructurado atendiendo a los grandes movimientos que se produjeron en los campos de las identidades peronistas y kirchneristas durante estos años. Como se podrá ver en el articulado del capítulo, en este período, el peronismo platense se fracturó y reagrupó en dos grandes polos o marcos de alianzas, cada uno de los cuales trazó sus estrategias electorales y sus formas de interpelación pública en un equilibrio entre los recursos con los que contaba -principalmente la capacidad de tener un candidato al ejecutivo y los márgenes de autonomía relativa respecto a la élite nacional y provincial del PJ-FPV- y los objetivos políticos que se propusieron en términos de un juego de anticipación al devenir de los escenarios coyunturales de la política nacional y provincial.

Dos advertencias son necesarias para ayudar en una mejor comprensión de lo que se expone a continuación: en primer lugar, existieron algunos conflictos que fueron anteriores al inicio del ciclo temporal aquí analizado. Una forma que se encontró para dar cuenta de los mismos, sin desvirtuar la reconstrucción de la línea de sucesos, fue insertar en algunos pasajes referencias a dichos eventos a sabiendas de que se sacrificaba cierta profundidad de la descripción en función de no perder el hilo conductor. La segunda advertencia tiene que ver con las siglas elegidas para denominar ambos polos de agrupaciones: en ambos casos se optó por siglas que permitieran señalar algún dato de sus trayectorias. Como se señaló en el capítulo anterior, a nivel municipal la dimensión de las agrupaciones políticas - por lo menos en el caso del distrito de La Plata- constituyen un desafío explicativo ya que se diferencian tanto a nivel de la territorialidad ${ }^{97}$ en la que operan-gremiales, barriales, políticas, culturales, universitarias, eclesiásticas, partidarias, entre otras- y captan militantes, como también se diferencian en el tempo de duración en la arena pública que cada una de las mismas presentan. Esta complejidad, además, hace

\footnotetext{
${ }^{97}$ Es necesario distinguir la noción de territorio como espacio de acumulación política establecido por cada organización a la idea de organización barrial en tanto esta refiere a los desarrollos militantes en sectores humildes o desfavorecidos económicamente. La distinción es central ya que en la jerga cotidiana se utiliza territorio y barrios como sinónimos.
} 
difícil construir una claridad descriptiva ya que son muy similares las denominaciones que cada agrupación utiliza para referenciarse públicamente. Por ello, tanto en este capítulo como en los siguientes, se utilizar ciertas siglas de manera constante para ganar en simplicidad aun cuando queden desincronizadas de la temporalidad electoral aquí analizada. Así al Frente Renovador Platense se presenta como FRP-FPV para dar cuenta de su inscripción dentro del espacio legal del Frente Para la Victoria, aun teniendo en cuenta que esta agrupación dejó de utilizar esa sigla después del 2009. En el caso de Unidos y Organizados -UyO- que nunca llegó a ser una inscripción jurídica, la utilización de sus siglas remite al establecimiento de una mesa de articulación entre diversas organizaciones posterior al 2011, pero que no fue significativamente diferente de la mesa constituida a nivel local en el polo de agrupamientos que se presentó en 2011 a elecciones.

Por último, la elección de la presentación de las resultados electorales en el marco del articulado de los diversos apartados, el cual se podrá observar que se encuentra por fuera del análisis de las variables elegidas para la investigación, intenta dejar en claro que los mismos no explican las decisiones tomadas por los actores, como tampoco conforman una consecuencia lineal de las mismas. Los resultados electorales son comprendidos en el marco de esta investigación como variables ambientales, puesto que los mismos se conforman con un conjunto de elementos internos que exceden el de las acciones de los grupos que participan de los comicios. Además, es importante remarcar que en vistas a la simplificación de los datos, se decidió solo exponer los resultados electorales .tanto de las PASO como de las generales- en la categoría de Concejales ${ }^{98}$.

\section{Los múltiples escenarios ante la elección 2011}

El 21 de junio del 2011 Cristina Kirchner anunciaba el lanzamiento de su candidatura a la relección presidencial. Dicho evento, para la organización interna del peronismo, significo la aparición de un escenario político en el cual concurrían dos fenómenos distintos: por un lado, el anuncio significaba, en vistas a la buena imagen con la que contaba en ese momento la candidata (La Nación, 22/06/2011), la posibilidad de retener el ejecutivo nacional durante un nuevo mandato. Pero, por otro lado, el anuncio también significaba que los siguientes 4 años serían los últimos del ciclo de hegemonía

\footnotetext{
98 Teniendo en cuenta que el corte de boleta es poco significativo -menos de 1 punto- para estas elecciones, consideramos que alcanza con estos datos para poder orientar la lectura contextual.
} 
kirchnerista sobre el peronismo nacional ${ }^{99}$. Se abría desde ese día un proceso de reconfiguración de las relaciones internas de la organización que supondría un escenario cargado de movimientos anticipatorios. De hecho, muchos de los desplazamientos que protagonizaron los diferentes grupos internos de esta fuerza y que se cristalizaron en las grandes diferencias observadas entre las elecciones del 2011 y las del 2013, encuentran una clave explicativa en tanto procesos de renovación interna de las élites de la organización.

En la Provincia de Buenos Aires, en particular, el lanzamiento de la candidatura a presidente ordenó de forma simétrica las presentaciones a diferentes cargos ejecutivos. Días después se presentó la candidatura a la reelección del gobernador y luego, con el correr de los días, la de los intendentes en los distintos municipios. Resulta interesante observar que existieron discusiones entre el equipo del entonces gobernador con un conjunto de intendentes "críticos" que, encabezados por Sergio Massa -jefe comunal de Tigre- pujaban por ir a internas ese mismo año (El Día, 03/06/2011), en vistas de poder generar una lista de unidad. Teniendo en cuenta que ese año sería la primera vez que se pondrían en funcionamiento las PASO, las restricciones informales que existieron años anteriores para bloquear la disputa interna no corrían. Sin embargo en poco tiempo se obtuvieron los acuerdos para ir con una lista de unidad (E1 Día 04/06/2011) y las tensiones se trasladaron a las listas legislativas.

Si el movimiento de los candidatos a diferentes cargos ejecutivos fueron simétricos (todos buscaron la relección), diferente fue el caso de las listas de cargos legislativos, fundamentalmente provinciales y nacionales (de la provincia), donde lo que se observó fue un conjunto de conflictos entre la élite nacional y los armados locales. La tradición de que las listas de legisladores (sobre todo la provincial) le correspondía a las mesas de consenso existentes entre los Intendentes de diferentes distritos, sufrió un duro revés a horas del cierre de listas (E1 Día, 26/06/2011). Las acusaciones de los armados locales era que la cúpula nacional del FPV había manipulado las listas para darle más lugar a los militantes de la agrupación La Cámpora (La Nación, 27-06-2011) en desmedro de otros sectores que también pugnaban. La hipótesis que mejor explica ambos fenómenos

\footnotetext{
${ }^{99}$ La muerte del ex presidente Néstor Kirchner en 2010, quién hubiese intentado ser el candidato nacional del FPV al año siguiente -como sostuvo CFK en una entrevista en 2013 (Desde Otro Lugar, 29/09/2013 min. 19:53, disponible en https://www.youtube.com/watch?v=GuPIOi2LKN8) dejó trunco un proyecto de alternancia interna con el que contaba esta elite nacional.
} 
(acuerdo y unidad en las listas ejecutivas y disputa en las legislativas) parece ser la de la anticipación: así como todos los posibles candidatos a disputar cargos ejecutivos pospusieron sus intenciones en pos de acumular políticamente, previendo una mejor posición frente a las elecciones siguientes, la cúpula nacional (y en menor medida, pero en sintonía, la cúpula provincial de Bs. As.) dispuso la exigencia de contar con espacios legislativos para sectores que expresaban el mayor grado de verticalismo posible. Esto le permitiría, a dicha cúpula, en una probable pérdida de poder a medida que se acercara la fecha de finalización del mandato, mantener cierto nivel de control sobre los bloques legislativos.

En La Plata, los acuerdos no prosperaron y el peronismo fue a elecciones en dos polos agrupacionales. Por un lado se encontraba el FRP-FPV, el cual conducía el ejecutivo municipal desde el 2007, el PJ local desde el 2008 y presentaba una forma de intervención pública de fuertes características vecinalistas que le permitía incorporar en su marco de alianzas a sectores no peronistas con cierta visibilidad en la arena local. A su vez, contaba con dos figuras centrales: Pablo Bruera, quien fuera el jefe comunal y su principal candidato con proyección electoral y uno de sus hermanos, Gabriel Bruera, quién fue candidato legislativo del espacio en distintas ocasiones -en diferentes categorías- y fungiera como articulador del espacio ${ }^{100}$.

El otro espacio, $\mathrm{UyO}^{101}$, correspondía a un entramado de organizaciones fuertemente identificado con la élite nacional del FPV y surgió post elecciones del 2009. Se trataba de un conjunto que agrupaba sectores provenientes del PJ local que habían sido desplazados del ejecutivo municipal en 2007, grupos que habían formalmente roto su alianza con el FRP-FPV debido a desacuerdos con las estrategia electoral del 2009 y sectores que no pertenecían a la tradición del peronismo platense pero postulaban una pertenencia a un espacio identitario denominado como kirchnerismo. Si bien este polo no contó con un claro candidato al ejecutivo que presentara una trayectoria electoral extensa, al principio suplió esta deficiencia tanto con el intento de captar el voto platense fiel a la élite nacional, como también con la construcción del dispositivo de una mesa de acuerdos locales que le

\footnotetext{
${ }^{100}$ El hecho de que compartieran apellido les permitía construir un juego de instalación en la arena pública de alternancia interna manteniendo siempre el apellido en los lugares más visibles de las listas.

${ }^{101}$ Si bien la mesa de coordinación política denominada Unidos y Organizados fue lanzada posteriormente a las elecciones del 2011, se utiliza aquí esta denominación en vistas a que muchas de las organizaciones nacionales o provinciales que participaron de la misma, tuvieron como correlato la construcción del polo organizacional en La Plata.
} 
permitía contener experiencias militantes con recorridos disímiles.

Ahora bien, la confrontación sólo ocurrió a nivel del ejecutivo municipal y de la lista de concejales. La lista de Senadores provinciales por la 8va sección terminó siendo de unidad a pesar de los diferentes tirones de los sectores (El Día, 29/06/2011). Este proceso de unidad en la lista legislativa no fue por acuerdo sino por una imposición vertical descendente. Al respecto, Gabriel Bruera sostuvo:

"Pablo en eso siempre fue muy intransigente en el buen sentido de la palabra. Muy defensor del armado local. Tuvimos imposiciones como la de los senadores del 2011, que Pablo me puso a mi de senador, después tuvimos que bajar la lista, hubo problemas y terminamos metiendo tercer senador, que obviamente entró porque metimos todo. Pero sí, nos pusieron gente, increíble." (Entrevista a Gabriel Bruera, junio de 2017) ${ }^{102}$

La respuesta hace referencia a los acontecimientos que se produjeron antes del cierre de listas el 28 de Junio de dicho año. El FRP-FPV había propuesto una lista de Senadores Provinciales ${ }^{103}$ que terminó siendo bloqueada por la élite nacional bajo el dispositivo de coerción que representa el control de las boletas nacionales y provinciales de la fuerza: “Ese es el elemento de presión. Porque si no, vos, toda la discusión nacional te la perdés. Nosotros eso lo hemos retado muchas veces. Y hay veces que la correlación de fuerzas te da y otras no." (Entrevista a Gabriel Bruera, junio de 2017). Al igual que en el escenario provincial, localmente el FPV nacional se impuso en la lista legislativa.

\subsection{Resultados electorales}

Los resultados electorales tanto de las elecciones de agosto -PASO- como los de Octubre fueron en esta ocasión contundentes para la fórmula del FPV. Al igual que a nivel nacional, en el distrito el FRP-FPV cosechó una cifra por encima del $45 \%$ de los votos válidos que, si se suman a los votos obtenidos por el polo de UyO - ver Tabla 1- superan en conjunto el $53 \%$ de los votos válidos.

\footnotetext{
102 Diferente fue el caso de las elecciones 2009. En la misma entrevista Bruera sostiene: “En el 2009 Néstor nos dio todo a nosotros. Y no quedó contento porque esa vez ellos no ganaron. Esa es la verdad. Él nos dio todo." (Entrevista a Gabriel Bruera, junio de 2017).

103 El 17 de Junio en un plenario del FRP-FPV platense se había proclamado la consigna de que "Pablo [Bruera] debe tener las manos libres para armar las listas" (El Día, 17/06/2011) no solo como una clara alusión a los grupos internos de ese polo, sino también como mensaje para las élites nacionales y provinciales de que dicho espacio pretendía definir sus candidatos locales.
} 
Tabla 1 resultados electorales La Plata

\begin{tabular}{|l|r|r|r|r|r|}
\hline \multicolumn{1}{|c|}{ Fuerza } & \multicolumn{2}{c|}{ Paso } & & \multicolumn{2}{c|}{ Generales } \\
\hline FRENTE PARA LA VICTORIA & Votos totales & Porcentaje & & Votos totales & Porcentaje \\
\hline FTE.SOCIAL DE LA PCIA DE BS. AS. & 142322 & 41,81 & & 162.265 & 45,32 \\
\hline FRENTE AMPLIO PROGRESISTA & 26710 & 7,85 & & 30.844 & 8,61 \\
\hline UNION PARA EL DES. SOCIAL & 28671 & 8,42 & 46.063 & 12,87 \\
\hline FRENTE POPULAR & 51982 & 15,27 & & 38.225 & 10,68 \\
\hline COMPROMISO FEDERAL & 38980 & 11,45 & 24.683 & 6,89 \\
\hline COALICION CIVICA- A.R.I. & 7472 & 2,2 & & 16.900 & 4,72 \\
\hline FTE. IZQUIERDA Y DE LOS TRABAJ. & 17350 & 5,1 & & 13.440 & 3,75 \\
\hline NUEVO ENCUENTRO & 72650 & 3,72 & & 12.399 & 3,46 \\
\hline PROYECTO SUR & 7800 & 2,29 & & 8.837 & 2,47 \\
\hline Total de Votos / porcentaje sobre & 6448 & 1,89 & & 4.386 & 1,22 \\
el padrón total & 386938 & 78,58 & & 391.472 & 79,5 \\
\hline \hline
\end{tabular}

Tabla de elaboración propia con fuentes de: Junta Electoral de la Provincia de Buenos Aires. Disponible en http://www.juntaelectoral.gba.gov.ar/ revisado 20/05/2019

De los fenómenos más significativos de estas dos elecciones se encuentra el hecho de que ambas listas del FPV platense obtuvieron un crecimiento entre agosto y septiembre, aunque el caso del FRP-FPV fue mucho más pronunciado. Así también, aun cuando la lista de UyO solo alcanzó el 8,61\%, era suficiente para traspasar el piso de votos requeridos para poder meter los dos primeros candidatos a Concejal de sus listas. Esto es importante en tanto esta cifra opera como frontera que divide experiencias electorales en la lógica interna del peronismo local- entre aquellas que pueden construir una frecuencia ${ }^{104}$ y cuáles no. Por último, es llamativa la gran afluencia de votantes en ambos comicios.

\section{Actuación del FRP-FPV en las elecciones}

El FRP-FPV fue el resultado de un conjunto de agrupaciones locales en su mayoría de extracción peronista, que aparecieron en la arena pública en 2003 tras romper formalmente con el marco de alianzas del entonces PJ local, conducido por Julio Alak ${ }^{105}$ -quien fuera Intendente desde 1991. Su recorrido en la arena pública, comenzó a hacerse

\footnotetext{
${ }^{104}$ Ver apartado 3.1 del cap. 2 de la presente tesis.

105 Julio Alak era el entonces jefe comunal de la Ciudad de La Plata como también de la estructura del PJ. Asociado públicamente con la época del Menemismo -durante la década de los 90- como uno de los actores políticos provinciales que habían surgido bajo ese liderazgo nacional.
} 
visible desde el 2000 cuando aparecieron las primeras muestras ${ }^{106}$ de la intención de este sector de pelear por la conducción de la jefatura municipal. Tras la crisis de representación del $2001^{107}$, la caída electoral de la performance del peronismo local y la progresiva territorialización de las preferencias lectorales (Calvo y Escolar; 2005), que permitió el surgimiento de un centenar de partidos vecinalistas; este espacio político advirtió la existencia de una ventana de oportunidad desde donde generar un fenómeno de externalización (Torre, 1999) exitoso. Su perfil público, desde sus inicios hasta después de las elecciones del 2009, consistió en una modulación particular del discurso vecinalista $^{108}$ por el cual accedió a un margen de desplazamiento con el que impugnar al igual que muchas de las experiencias de este tipo en otros municipios- las prácticas de las dirigencias políticas que habían protagonizado el ciclo de poder de las dos últimas presidencias ${ }^{109} \mathrm{y}$, simultáneamente, sostener un diálogo con la tradición peronista local.

En términos de itinerario electoral su performance fue despareja aunque con dos alicientes: en primer lugar, en términos de objetivos políticos, logró alcanzar las metas que le permitían mostrar una cristalización como espacio opositor. Un caso paradigmático de esto fue la experiencia de las elecciones del 2005 donde, en el marco de una fuerte polarización provincial estructurada por las candidaturas a Senadores nacionales ${ }^{110}$, el FRP-FPV pudo, sin contar con acuerdos extra municipales, alcanzar los 46,461 votos $(15,74 \%$ de los votos positivos) que le permitió ingresar dos Diputados provinciales y dos

\footnotetext{
${ }^{106}$ EL FRP-FPV comenzó una campaña de pintadas callejeras con la consigna "Bruera es Agosto" que tuvo un reconocido impacto en la ciudad, así como también con recorridas y conversaciones con los vecinos (EL Día, 01/08/2000).

${ }^{107}$ En las elecciones del 2001 la particularidad de los resultados llevaron a la prensa a realizar una nueva denominación como "voto bronca" (o voto de protesta) a aquellos sufragios que expresaban malestar con la dirigencia política (incluía el voto nulo más el voto en blanco). En La Plata este tipo de voto alcanzó en 2001 el $26 \%$ de los sufragios (diario El Día, 15-10-2001) sólo superado por la lista de candidatos del PJ. A nivel nacional la cifra de ese "voto bronca" alcanzó el $22 \%$.

${ }^{108}$ Si bien no existe una definición formal del vecinalismo como forma de intervención política, aquí es utilizado como aquel discurso que construye demandas territorializadas en el distrito y que se prescinde de realizar declaraciones Provinciales o nacionales. Para tomar dimensión de la cantidad de partidos vecinales o municipales en la Provincia de Buenos Aires, en las elecciones del 2007 fueron 184 agrupaciones de este tipo las que compitieron (El Día, 08/10/2007) y en 2009 se presentaron 318 partidos para 135 partidos o municipios. Además, para las elecciones del 2011, habían caducado 212 agrupaciones de este tipo. (Carrizo y Galván; 2012).

109 Una de las demandas más importantes con las que contó este armado político durante estos años fue la impugnación a la reelección del jefe comunal (El Día, 09/08/2007).

${ }^{110}$ Nos referimos a la polarización que se produjo entre la candidata a Senadora Cristina Fernández de Kirchner e Hilda Duhalde. A tal punto esta confrontación se expresó en términos identitarios, que existió una flagrante disputa judicial para impedir que alguno de los sectores utilice los símbolos tradicionales peronistas. Una anécdota paradigmática fue la discusión sobre la "marcha peronista" en la que el entonces ministro del Interior sostuvo frente a los duhaldistas "que la marcha se la metan en el culo" (Página 12; 30/08/2005).
} 
Concejales. En segundo lugar, y quizás más importante aún, su principal oponente se encontraba en un ciclo descendiente desde 1999 en términos de captura de nuevo electorado. Como se puede observar en el cuadro 1, tras la curva descendente de participación entre 1999 y 2001, el PJ local nunca se recuperó, mientras que el FRP-FPV logró estructurar un ciclo de crecimiento que acompañó la curva de participación del electorado. Esto, en parte, muestra cierta capacidad de adaptación al cambio de época y a la investidura progresista con la que contaba este polo agrupacional:

"Hay que entender cómo llegó Bruera a la Municipalidad. Ellos iniciaron una pelea interna en el peronismo local, con una visión desde local hacia lo provincial y hacia lo nacional. No como parte de un proyecto más global. Ellos anclaron en la ciudad y elección tras elección fueron buscando aliados distintos que les permitieran avanzar en sus posiciones. Entonces la concepción organizativa de ellos se ha trasladado a la concepción política." (Entrevista a Federico Martelli, agosto 2015)

La referencia a la construcción desde abajo, como se suele denominar en la jerga política, permite observar un aspecto de la organización del peronismo a escala municipal, a saber, que existen en su interior, márgenes de crecimiento para organizaciones autónomas. Siempre y cuando se entienda el autonomismo únicamente como contrapuesto a una modalidad delegativa. El FRP-FPV supo y pudo construir al interior del peronismo local su propia estrategia de crecimiento que presentó diferentes etapas, entre ellas la de ganar centralidad en el marco de alianzas del PJ, lo que implicó un alto grado de organicidad con la figura del ex intendente Alak hasta el 2001.

Ciertamente dentro de la estructura del PJ, hasta ese momento, muchos de los cuadros gobernantes de la misma provenían de la década de los 90 y arrastraban, por ende, el signo de "liberales", que era lo que el FPV pretendía transformar en el espacio del peronismo"11 a nivel nacional. La Plata, era quizás un caso ejemplar de esta situación ya que quién fuera el Intendente hasta el 2007, no sólo había iniciado su gobierno en pleno auge del menemismo, sino que además resultaban públicas sus afinidades con dicho ex Presidente, lo que imposibilitaba su capacidad de reconfiguración. De aquí que le fuera más fácil al FRP-FPV colocar a este último como adversario y también ir perforando ese marco de

\footnotetext{
${ }^{111}$ Un análisis de la tendencia política de "renovación" de los Intendentes del conurbano bonaerense y como la decisión de habilitar la estrategia de listas colectoras se encuentra en Lenarduzzi (2012a y 2012b). También hay una interesante revisión histórica de esta estrategia -que se utilizó desde 1999-en diario El Día (23/09/2007).
} 
alianzas de forma progresiva.

La configuración de un discurso progresista anclado en el doble juego de pertenencia entre la tradición peronista y un novedoso vecinalismo, fue acompañado por un marco de alianzas que, aun con sus fluctuaciones, trató de expresar una alta heterogeneidad de sus figuras públicas. Así, además del conjunto de agrupaciones peronistas que protagonizaron la primera ruptura en 2003 con el PJ local ${ }^{112}$, el FRP-FPV logró convocar a grupos que provenían de otras tradiciones como a sectores del socialismo ${ }^{113}$, del radicalismo ${ }^{114}$, del FrePaSo $^{115}$ y grupos que provenían de la experiencia del partido Acción por la República ${ }^{116}$ dándoles lugares importantes en las listas para el Concejo Deliberante. Esto

\section{Cuadro 1}

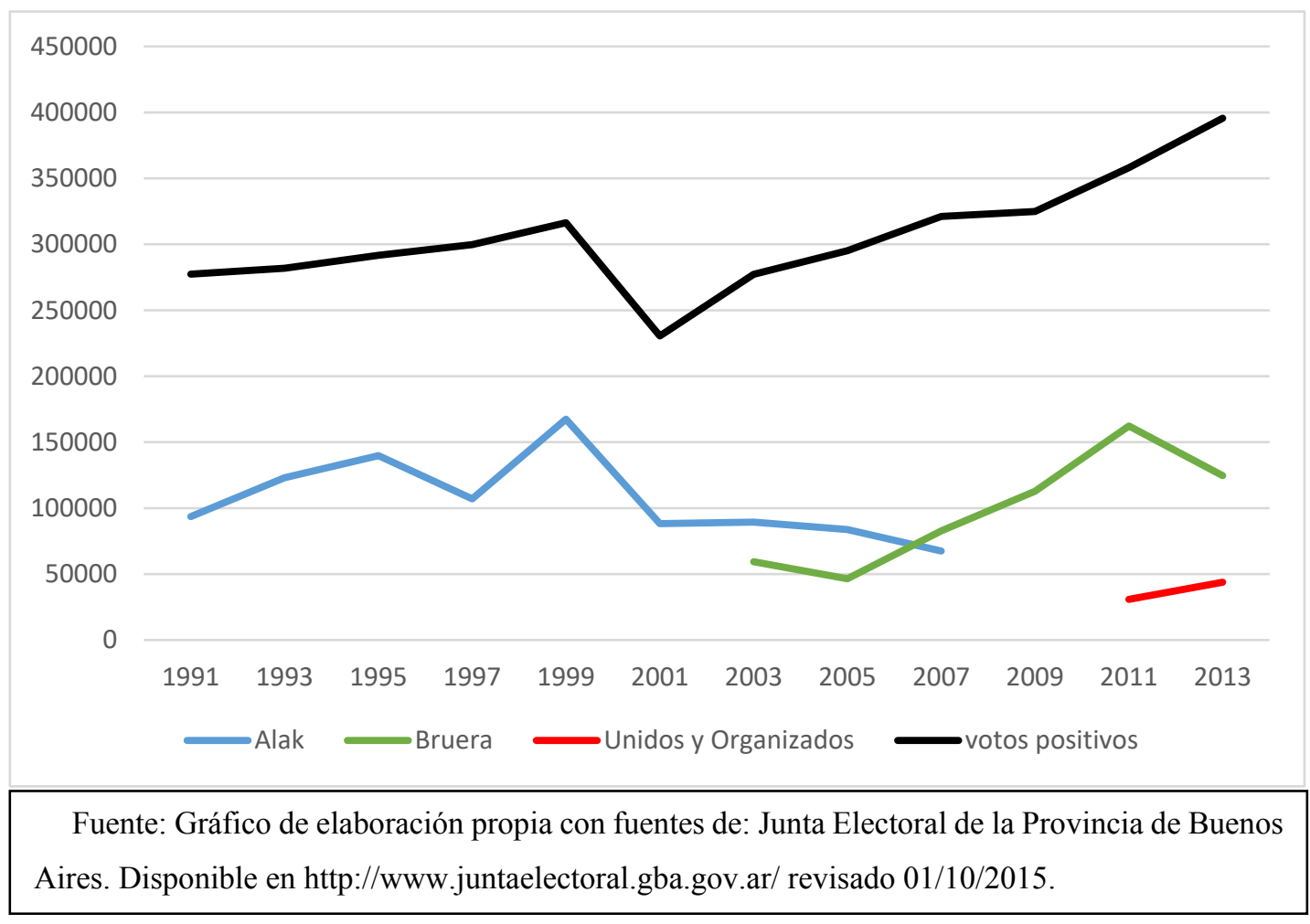

112 Casos como los de Teresa Razzari, concejal desde el 2001 por el PJ que en 2005 y 2009 fue candidata por el FRP. O la agrupación "Liberación Nacional" -armada en 1982-y que fueron opositores desde dentro del peronismo local a las políticas alakistas: "Nosotros también construimos nuestra propia opción política, siempre enfrentados al menemismo y al alakismo pero siempre obteníamos la minoría." (Entrevista a Luis Lugones)

${ }^{113}$ El séptimo candidato a Concejal en 2009 por este espacio fue Carlos Sortino (El Día, 17/05/2009).

${ }^{114}$ El caso del Concejal Campanaro que fuera parte del bloque de la Alianza (EI Día, 19/12/2000) y luego fue candidato por el FRP en 2003.

115 "Yo participé en la primera etapa del bruerismo, era el kirchnerista dentro de ese frente local, digamos." (Entrevista a Iván Maidana). Tanto el caso de Campanaro como este de Ivan Maidana, deben comprenderse como alianzas por separado ya que estas agrupaciones se desvincularon entre sí ya para las elecciones del 2003.

116 La trayectoria de María Alejandra Sturzenegger resulta interesante ya que ingresó al Concejo Deliberante en 1999 con un acuerdo que selló Alak con el partido Acción por la República -que llevaba de 
le permitió nutrirse rápidamente de cuadros con experiencia legislativa y a su vez abrir espacios de intervención en sectores del electorado que no necesariamente se encontraban vinculados entre sí en términos de preferencias electorales provinciales o nacionales. Así el FRP-FPV comenzaba a ofrecerse como depositario local de la "nueva política". La potencia electoral terminó de consolidarse cuando logró capturar agrupaciones peronistas con mayor volumen político, recursos y penetración barrial. Tras la buena performance electoral del 2003 -y en contraste los descendentes resultados del PJ-, el FRP logró sumar organizaciones sindicales como $\mathrm{UPCN}^{117}$ y referentes barriales de mayor peso, como Susana Gordillo ${ }^{118}$. Si bien se especuló mucho durante estos años si esta fuerza política sería depositaria del voto nacionalizado de la élite del FPV, puesto que el PJ local contaba tanto con el acuerdo oficial, para el 2007 este espacio logró sellar acuerdos con organizaciones fuertemente identificadas con dicha élite nacional ${ }^{119}$. El caso más significativo - por el volumen de la organización- fue el del Movimiento Evita ${ }^{120}$ ya que desde el 2005 formaba parte del marco de alianza del PJ local con una Concejala ${ }^{121}$ y luego, con el acuerdo con el FRP lograron las candidaturas de Santiago Martorelli como segundo candidato para la categoría de Senadores Provinciales ${ }^{122}$ y a Lorena Riesgo como 5ta Concejala -lugar expectante al que finamente terminó accediendo-. En el acto de

candidato a Presidente a Domingo Cavallo- para lograr ser la opción local de dicho espacio y con ello el PJ platense se aseguraba aparecer en dos boletas nacionales (El Día, 05/09/1999). En 2003 fue candidata por el FRP.

${ }^{117}$ En 2005 Mario Quintana -Sec. General de UPCN- fue segundo candidato a Diputado Provincial por el FRP. De todas formas Pablo Bruera había participado durante el final de la década de los 80 y principio de los 90 en la estructura gremial de UPCN, llegando a ocupar una secretaría gremial.

118 Gordillo en 1999 era delegada de Los Hornos con su agrupación "Crecer", un barrio importante de la ciudad (diario El Día; 04/02/1999) para luego llegar a ser Concejala por la lista del PJ. El 02 de Septiembre del 2007 realizó en conferencia de prensa el anuncio de su pase al FRP con "duras críticas al entonces Intendente" (diario El Día; 02/09/2007). Otro caso interesante es el del Fernando "Grillo" Ferrer quien fuera reconocido representante barrial del PJ alakista hasta dos años antes y para 2009 ocupó el lugar undécimo en la lista de este espacio.

${ }^{119}$ El caso de la agrupación Los "Apóstoles de Perón” que se cristalizó con la candidatura de Sabrina Rodriguez en 3er lugar en la lista de Concejales. También la organización "La Vuelta de Obligado" que llevó a Juan Malpeli en el 5to lugar. Para el 2008, a esta lista se le sumará el Movimiento de Unidad Popular http://mupbsas.blogspot.com.ar/2008/01/encuentro-entre-el-intendente-platense.html

${ }^{120}$ El 17 de noviembre del 2005 -posteriormente a las elecciones de dicho año- se realizó en la ciudad de La Plata la presentación pública en la Provincia de Buenos Aires del Movimiento Evita. El acto, al que asistieron: el Gobernador de la Provincia de Bs. As. y el Intendente de La Plata, entre otros (diario El Día, 18/11/2005), tuvo una amplia cobertura mediática en la ciudad y en los medios nacionales donde se presentaba a dicho espacio político como una nueva corriente kirchnerista: "Se trata de tener una actitud diferente cuando llegamos al Estado, que es estar con la gente, y buscar soluciones, y terminar con la política punteril" (Emilio Pérsico, declaraciones al diario La Nación, 18/11/2005).

${ }^{121}$ Silvana Soledad Soria fue electa concejala en 5to lugar en la nómina del alakismo para el período 20052009.

122 Recordamos que al ser distrito único electoral, La Plata -denominada como 8va sección- elige cada 4 años tres Senadores Provinciales propios. 
incorporación del Movimeinto Evita a este espacio, Emilio Pérsico, su dirigente nacional más importante, destacó: "El kirchnerismo significa la renovación política, y si en La Plata hay un espacio de renovación política es éste que encabeza Pablo Bruera, de manera que nosotros, como kirchnerista, lo vamos a apoyar" (El Día, 29/05/2007).

\subsection{Estrategia electoral}

La estrategia electoral que presentó este polo de agrupaciones para el 2011 fue claramente de acumulación. Tras dos victorias electorales consecutivas, un buen resultado en las elecciones de dicho año significaría para este espacio la posibilidad de constituirse en un polo de agrupamiento a nivel provincial y posicionarse como depositarios del necesario recambio para el 2015. En pos de este objetivo buscaron la relección de Pablo Bruera al frente del gobierno municipal aun cuando una de sus propuestas para ganar la elección de 2007 consistió en impugnar las prácticas de este tipo. Sin embargo, esta candidatura había mostrado contar con una proyección electoral importante. Ya desde el 2001, cuando había encabezado la lista de Concejales por el PJ y en los sucesivos comicios posteriores, su figura iba en ascenso respecto de la cooptación de nuevos sectores del electorado ${ }^{123}$. Además, dos eventos señalaban esta orientación: el primero de ellos fue la asunción de la presidencia del PJ local en diciembre del 2008, con un acuerdo, más que interesante, con un conjunto de líneas que formaban parte del marco de alianzas peronistas opuestas a este frente $^{124}$. Esto le permitía bloquear cualquier iniciativa de disputa interna en esa estructura y, simultáneamente, entrar en la dimensión de discusión del peronismo provincial.

El segundo evento consistió en la realización de un acto en CABA, con prensa nacional, donde Pablo Bruera fue el orador principal y donde afirmó:

"Venimos a pedirle a nuestra conducción [...] que seamos claros sobre lo que va a pasar el año que viene. La única oportunidad que tiene el peronismo es la unidad de todos los peronistas: de los que están adentro, de los que están afuera y de los que están en algún lado. Pero el peronismo tiene que volver a unirse para ser el gran movimiento nacional y popular y no un partidito que se anda peleando por los medios de comunicación."

\footnotetext{
123 Incluso en las elecciones del 2009, que fueron adversas para el FPV en la PBA, en La Plata el FRP salió airoso de la misma llevando como candidato a Gabriel Bruera como 1er Diputado Provincial.

${ }^{124}$ El 22/12/2008 Bruera asumió la presidencia del PJ local, acordando con actores del peronismo que habían sido referentes en los tiempos alakistas como Carlos Bonicatto -asumió como Congresal Provincial- y Guido Carlotto -Sec. de prensa-, entre otros (EI Día, 23/12/2008).
} 
(Crónica TV, 25/08/2010)

En este pasaje del discurso, donde claramente queda expuestas las intenciones de quién exigía la construcción de mecanismos para la forma que adoptaría la renovación política del FPV nacional, la referencia al movimiento de retracción organizativa -“un partidito"hacía referencia a la salida de la crisis política que se había generado tras los conflictos de la resolución nacional núm. 125/08 y la subsiguiente derrota electoral del 2009. El FRP-FPV, que para ese acto había cambiado la referencia a Frente Renovador Peronistapulsaba por precipitar un recambio dirigencial a nivel provincial, en principio desde dentro del espacio. De hecho, su primer entramado de alianzas a nivel provincial fue el denominado "grupo de los 8" que consistió en un conjunto de intendentes de la provincia que se mostraban disconformes con la conducción política de la élite nacional (Ámbito Financiero, 22/09/2010 ${ }^{125}$ y que buscaban construir una candidatura común para las elecciones del 2011.

Tras el fallecimiento del ex presidente Néstor Kirchner y la posterior decisión de su candidatura a la reelección por parte de Cristina Kirchner, estas tensiones internas entraron en suspenso. La relación entre lo nacional y lo local nunca se recompuso completamente, constituyendo un punto de inflexión que acompañaría la relación naciónciudad hasta el 2015. El impacto de la misma tuvo varias manifestaciones políticas: en términos de alianzas, significó la ruptura de un conjunto de agrupaciones que hasta ese entonces acompañaron las boletas del FRP. También se manifestaría en el recinto del Concejo Deliberante local. Al respecto hay dos eventos que ejemplifican mejor el distanciamiento que, durante la campaña -y luego de ella-, se produjo entre el FPV nacional y el FRP-FPV: la primera situación se refiere al discurso de apertura de Sesiones que realiza el Intendente cada año. En el 2010, fue el único, de los 8 discursos que pronunció Bruera, en el que no se menciona ni el nombre de la presidenta, ni del gobernador, ni existen referencias a una buena relación entre la Intendencia y algunos de los ejecutivos antes mencionados. La notoriedad de la ausencia de referencias ejemplifica la situación de una tensión política y una apuesta, en términos de proyección, a la capacidad propia por parte del FRP para poder desenvolverse sin necesidad del vínculo

\footnotetext{
${ }^{125}$ EL grupo de los 8 Intendentes díscolos lo componían: Pablo Bruera, por La Plata; Sergio Massa, por Tigre; Jesús Cariglino, por Malvinas Argentinas; Sandro Guzmán, por Escobar; Joaquín De La Torre, por San Miguel; Jose Eseverri, por Olavarría; Luis Acuña, por Hurlingham; Gilberto Alegre, por General Villegas.
} 
con la dirigencia nacional.

La segunda situación la protagoniza el Concejal Forte, en el acto de homenaje al fallecido Néstor Kirchner: “...yo llegué a este Concejo de la mano de Néstor Kirchner en la lista y con el compañero Bruera y no entiendo cómo se desvió de ese camino siendo que sus bases manifiestan lo que manifiestan del compañero Kirchner..." (Diario de Sesiones del Concejo Deliberante de la Ciudad de La Plata, 28 Sesión Ordinaria, 3-11-2010). La referencia del Concejal a las bases del FRP -nótese la operación discursiva de diferenciación por medio del uso del adjetivo sus- resulta luego de escuchar los discursos de los Concejales que ensalzaban la imagen del fallecido ex Presidente. La tensión era en ese momento inocultable, pero este proceso de autonomización local con una figura de candidato "fuerte", la notoria presencia provincial y los acuerdos críticos, le bastaron a este espacio para bloquear parcialmente las iniciativas de la élite nacional del FPV de exigir lugares en las listas legislativas distritales.

\subsection{Marco de alianzas}

Tras la crisis desatada post elecciones $2009^{126}$, el marco de alianzas de este espacio se reconfiguró sobre sus vínculos más firmes para la construcción de una lista de candidatos al Concejo Deliberante y así también a Senadores Provinciales. No obstante, en esta última categoría, el desenvolvimiento de la negociación asimétrica con la élite nacional no fue exitosa. Lo que ocurrió fue que el FRP-FPV presentó una lista de Senadores (El Día 26/06/2011) en forma paralela a la lista de candidatos para los mismos cargos que presentara la élite nacional por medio del marco de alianzas de UyO -ver listado 1-, lo que generó una negociación entre las partes. El FRP-FPV contaba como mayor recurso un caudal de votos bastante amplio, mientras que la élite nacional contaba con la capacidad jurídica de definición de la estructura en la boleta partidaria y una cierta sospecha de tener votos propios en la región. Finalmente la resolución de este conflicto terminó con un híbrido de fórmulas por el que el FRP-FPV obtuvo el 3er candidato

\footnotetext{
${ }^{126}$ Ver apartado 4 del presente capítulo.
} 


\section{Listado de candidatos 1}

\begin{tabular}{|c|c|}
\hline \multicolumn{2}{|c|}{ Senadores del FRP-FPV La Plata } \\
\hline Nombre & Organización \\
\hline Gabriel Bruera & Frente Renovador Platense \\
\hline Marcela Pastore & ONG "Fundación de Defensa Social"127 \\
\hline Carlos Quintana & UPCN \\
\hline \multicolumn{2}{|c|}{ Senadores de UyO La Plata } \\
\hline Gustavo Oliva & Calle $13^{128}$ \\
\hline Nora de Lucía & $\begin{array}{l}\text { Vinculada a la figura del entonces } \\
\text { gobernador Scioli }\end{array}$ \\
\hline Roberto Prandini & $\begin{array}{l}\text { Vinculado a la figura del ex intendente } \\
\qquad \text { Alak }^{129}\end{array}$ \\
\hline \multicolumn{2}{|c|}{ Senadores de unidad FPV La Plata } \\
\hline Gustavo Oliva & Calle $13^{130}$ \\
\hline Nora de Lucía & $\begin{array}{l}\text { Vinculada a la figura del entonces } \\
\text { gobernador Scioli }\end{array}$ \\
\hline Emilio Muntaner & $\mathrm{FRP}^{131}$ \\
\hline
\end{tabular}

127 Esta ONG se dedicaba a temas de género, como así también a trabajos con sectores socialmente vulnerables -como el personal auxiliar de casas particulares- y de militancia peronista. Además, Pastore fue titular del Concejo Municipal de la Mujer ese mismo año.

128 Proveniente de un conjunto de militantes del ARI (Argentina por una República de Iguales) que rompieron en 2004 y se volcaron al Kirchnerismo, Oliva conformó esta agrupación que no tuvo gran desarrollo local. Su postulación obedecía a su vinculación directa y de fidelidad con la élite nacional.

${ }^{129}$ La agrupación que conduce el ex Intendente Julio Alak se denomina Frente Amplio Peronista (FAP) y se presentó públicamente en 2013. Por eso no consignamos aquí el nombre de dicho espacio.

130 Proveniente de la Dirección del Colegio Nacional "Rafael Hernández" de la UNLP -lugar más visible que ocupó dicho referente-, la agrupación de Oliva, no tuvo gran desarrollo local. Su postulación obedecía a su vinculación directa y de fidelidad con la élite nacional.

${ }^{131}$ Quién fuera anteriormente militante del Movimiento Evita y luego del 2009 quedará vinculado al FRP hasta el 2013, año en el que pasa a formar parte del entramado de UyO: "Muchos de esos compañeros que estábamos cortando rutas, y que haciendo piquetes fuimos incorporados, quién te habla es uno de ellos, a través del Movimiento Evita, con Emilio Pérsico incorporamos muchos compañeros al Estado." (Entrevista a Emilio Muntaner, agosto 2015). 
En este caso, el criterio utilizado estuvo más vinculado a un reparto entre las élites de los diferentes estratos de la arena política: el primero respondiendo a la élite nacional, el segundo a la élite provincial y el tercero -quizás el caso más negociado- respondiendo a la élite local, pero con el condicionamiento que sea aceptable por la élite nacional. La clarificación de este criterio permite comprender el desfasaje observable entre la dimensión de un cargo tan disputado como el de Senador Provincial y la ocupación por parte de una agrupación minúscula de la primera candidatura -es decir que todo su capital político estaba situado en la fidelización a la élite nacional.

En la lista de Concejales, donde el FRP-FPV presentó su propia nómina, se ponderó para las candidaturas más importantes a aquellas figuras que ya contaban con un recorrido en el Concejo Deliberante.

\section{Listado de candidatos 2}

\begin{tabular}{|c|c|}
\hline \multicolumn{2}{|c|}{ Concejales por el FRP-FPV } \\
\hline Nombre & Organización \\
\hline Javier Pacharotti & FRP \\
\hline Fabián Lugli & Crecer $^{132}$ \\
\hline Lorena Riesgo & Agrupación Evita $^{133}$ \\
\hline Pedro Borghini & $\begin{array}{c}\text { Asociación de Trabajadores de la } \\
\text { Sanidad de la Argentina -ATSA- }\end{array}$ \\
\hline Juan Lotúmulo & $\begin{array}{c}\text { FATERYH -trabajadores de edificios- } \\
\text { 134 }\end{array}$ \\
\hline Sabrina Rodriguez & Apóstoles de Perón ${ }^{135}$ \\
\hline Mauricio Castro & FRP ${ }^{136}$ \\
\hline
\end{tabular}

132 Ver nota al pie 118 del presente capítulo.

${ }^{133}$ Escisión del Movimiento Evita tras la ruptura entre esta última agrupación y el FRP-FPV post elecciones del 2009. Ver apartado 4 del presente capítulo.

${ }^{134}$ Secretario General de dicho sindicato, Lotúmulo había sido candidato suplente a Concejal por la lista de Alak en 2007 y que tras un movimiento de los titulares, en su asunción anunció su pase al FRP (El Día, 17/10/2008).

${ }^{135}$ Ver nota al pie 119 del presente capítulo.

136 Posteriormente asumió como Subsecretario de Entidades y colectividades de la Municipalidad. 
La lógica de construcción de los candidatos más importantes representa diferentes sectores -ver listado 2-: la línea dura del candidato a Intendente, la línea barrial del PJ local, la línea de las organizaciones sociales, la de los sectores de trabajadores vinculados a los gremios y la de los sectores políticos jóvenes. Este criterio de construcción, muy alejado ya de la clásica composición del PJ por ramas o tercios ${ }^{137}$, permite ver que la lista de Concejales, para el FRP-FPV se estructuraba con una cantidad de grupos que permitían un control político del Concejo y otros grupos a los que se los participaba en su diferencia de territorialidad, es decir, a partir de las penetraciones en diferentes ámbitos de la sociedad platense.

\subsection{Construcción identitaria particular}

La estrategia comunicacional de la campaña estuvo concentrada en la figura del candidato a Intendente, haciendo eje en el nombre "Pablo" en un claro caso de propuesta plebiscitaria (ver propaganda 1), y en la consigan del cambio, construyendo un contraste con la gestión desbancada en 2007. Además, atendiendo el clima político y la alza en la imagen positiva del FPV nacional, el FRP-FPV articuló un discurso en el que estuvo presente, en mayor medida que las campañas anteriores, los símbolos y las referencias que daban cuenta de su participación en el kirchnerismo (ver propaganda 2). Es interesante notar la ausencia de las siglas del Frente Renovador Platense -e incluso de "peronista", como se había denominado la corriente provincial antes comentada- en la propaganda gráfica de la campaña. Los tres anuncios comparten la centralidad de la imagen del candidato a Intendente. No hay referencias a los candidatos a concejales, ni tampoco a las siglas del Frente Renovador Platense, sin embargo, se mantiene el uso del color verde como modo de diferenciación en la integración del color azul de la boleta del

\footnotetext{
${ }^{137}$ El establecimiento de los criterios de distribución de las bancas legislativas en el peronismo resulta más que interesante por como expresa los espacios de crecimiento que se fueron dando a lo largo del tiempo y la capacidad adaptativa (Levitsky, 2005) de la organización a los cambios ambientales. Ya para las elecciones de 1973 en La Plata el peronismo utilizó un criterios de cuartos, incorporando a los jóvenes de la tendencia a la conocida distribución de tercios (Dell'Unti 2017). En la década de los '80 con la reorganización partidaria el peronismo platense siguió la lógica nacional e incorporó a los sectores de desarrollo barrial, aunque sin un criterio de distribución por cupos. Esta situación duró hasta la reconfiguración en torno del FPV post 2003.
} 
FPV. Además, el discurso está construido en términos de plebiscito de la gestión, retomando como evento central la victoria del 2007 y la noción de "Cambio" y "Camino". Esto podría permitir comprender que la modulación del discurso público se construyó como un tipo de municipalismo kirchnerista, es decir, aún encuadrado dentro del espacio general identitario del kirchnerismo, se mantenían por encima las propuestas locales, la figura del candidato y los colores propios.

Nótese como la imagen de la propaganda 3, en el que se presenta la boleta completa del FPV, busca atraer votos que se encuentren identificados con las candidaturas en las categorías nacionales y provinciales. Si se compara con la elección del 2003 y 2005, en la que preponderó la propuesta del corte de boleta" y la apuesta a la disociación del voto local, del provincial, se puede comprender como, para esta elección se preveía el impacto de la buena imagen nacional sobre la local. 


\section{Propaganda 2}

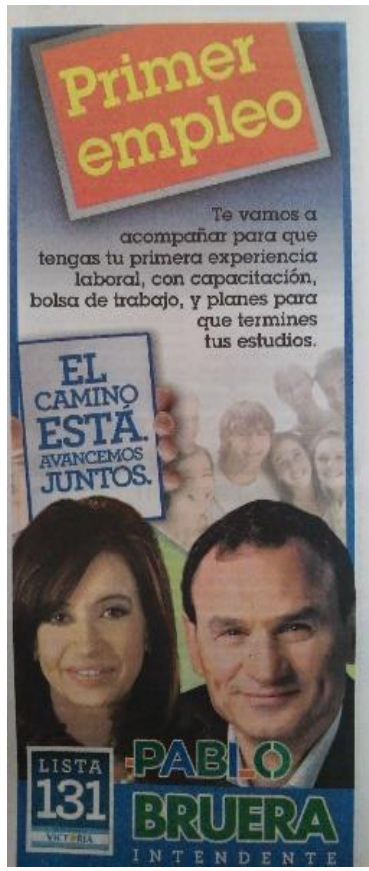

Fuente: diario El Día. 18/10/2011; Pág. 7.

\section{Propaganda 1}

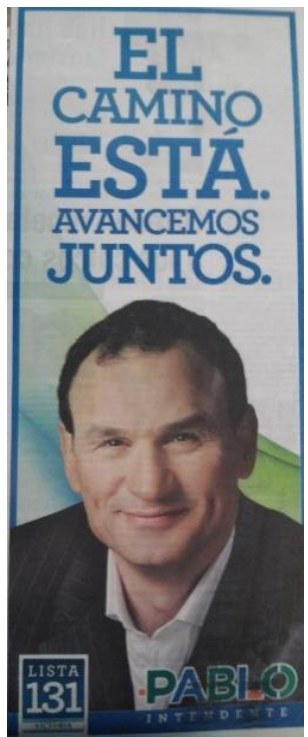

Fuente: diario

El Día.

02/10/2011;

pág. 13.

\section{Propaganda 3}

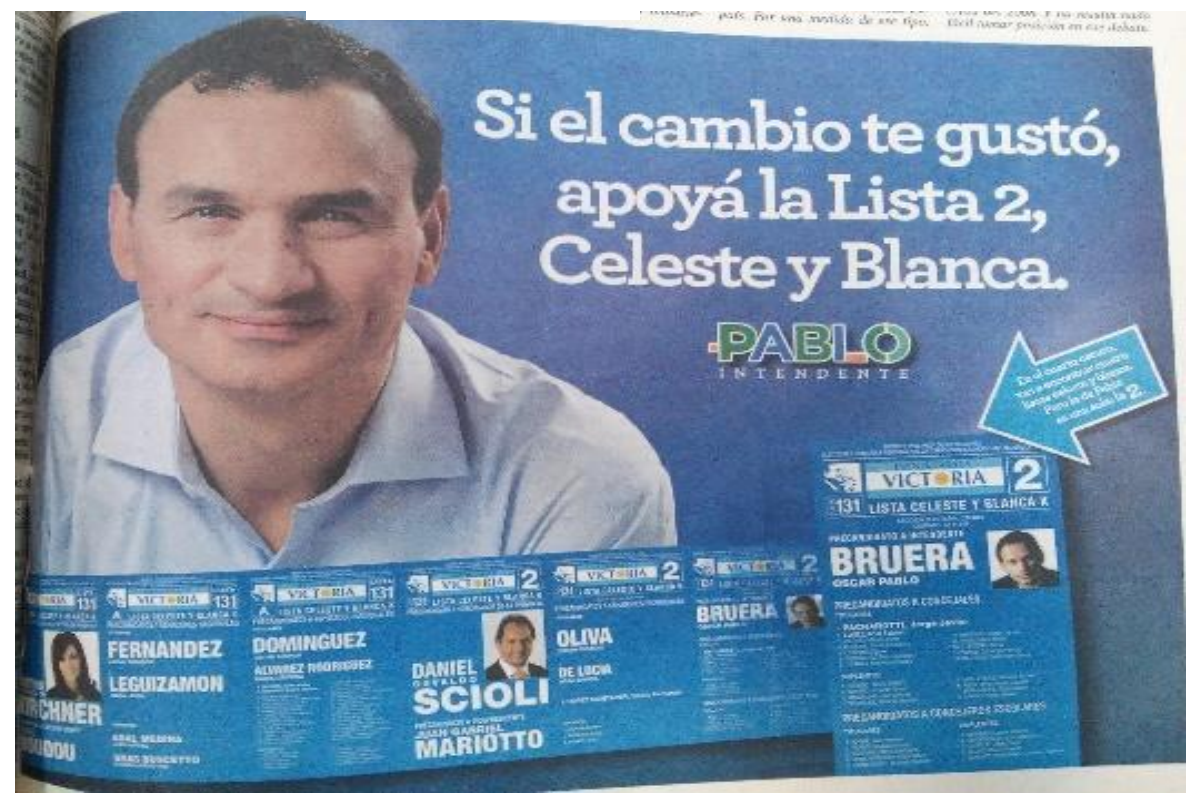

Fuente: diario El Día. 09/08/2011; pág. 7. 


\section{Actuación de UyO-FPV en las elecciones}

El polo organizacional denominado como UyO nació en La Plata tras las elecciones del 2009 y la acusación de traición del FRP-FPV a la élite nacional, por parte de un sector de la militancia platense peronista vinculada verticalmente a las cúpulas nacionales de la fuerza. Dicha imputación provenía tanto de los resultados de evento electoral como de la campaña: concretamente se acusaba al FRP de haber "escondido" la boleta $-\mathrm{y}$ principalmente las figuras- de los candidatos a diputados nacionales ${ }^{138}$ por la baja performance electoral “esperada” (El Día, 07/06/2009) optando por realizar una campaña vecinalista. Ciertamente en términos de propaganda gráfica, las únicas publicaciones que se realizaron para dicha elección con las figuras del ex presidente y del Gobernador (ver solicitadas 1 y 2) fueron hechas por agrupaciones que luego formarían parte de este nuevo polo de agrupaciones, pero también es importante mencionar el hecho de que existieron eventos en conjunto entre el entonces Intendente y el Ex Presidente, como una caminata en conjunto (El Día, 25/06/2009) ${ }^{139}$. Sin embargo, las acusaciones cruzadas daban cuenta de que se produjo un desplazamiento en el centro de representación de la élite nacional del FPV en el distrito. Este margen fue interpretado como las condiciones de posibilidad para construir una reconfiguración de la organización del FPV platense. Sobre este quiebre, un referente local de La Cámpora lo caracterizó de la siguiente forma:

"Ese es el punto donde el chabón [el Intendente] se corre y ahí empieza -inclusive en esta [unidad] básica fue el primer plenario-, a surgir una idea y un concepto del kirchnerismo platense. De algo que tenía plena afiliación con la conducción de Néstor y que entendía que en la ciudad el eje se estaba corriendo para otro lado. Y de hecho quién te habla

\footnotetext{
138 Recordamos que en dicha elección los dos primeros lugares de candidatos a Diputados por el FPV los ocupaba el entonces ex Presidente Néstor Kirchner y el entonces Gobernador de la Provincia Daniel Scioli. La lista se completaba con un conjunto de candidaturas de Intendentes -principalmente del conurbano bonaerense- con la intención de reforzar la competitividad apostando a los votos que se podían captar por las representaciones locales. Como de ser electos se presumía que ninguno iba a asumir, la prensa las denominó “testimoniales" (El Día 09/05/2009).

139 Posteriormente a los comicios hubo una reunión entre Néstor Kirchner y el bloque de Diputados del FPV de la Provincia de Bs. As. donde se discutió sobre lo ocurrido en las elecciones. Hubo muchas interpretaciones sobre el tema del caso La Plata, al respecto un entrevistado sostuvo: "Néstor se enojó mucho, hizo muchas maniobras en contra de todo el grupo, pero finalmente hubo una reunión para mí histórica, porque fue una reunión que hizo Néstor con los diputados de la provincia de Buenos Aires sin Scioli. Fue muy famosa, salió en Clarín, en todos lados. Donde tengo un intercambio con Néstor porque yo le presenté el documento del Frente Renovador adelante de todos los diputados y le digo "para los que creemos que la unión es posible en el Frente para la Victoria, tenemos que ir para este lado". Todo pergeñado por Néstor. El tipo lo que quería finalmente era armar como el peronismo disidente, el kirchnerismo crítico." (Entrevista a Gabriel Bruera, Junio 2017).
} 
tuvo una discusión directa y concreta con el que encabezó la lista del grupo local, que era Gabriel Bruera, en ésta misma unidad básica sobre ese tema y donde el tipo hablaba de post kirchnerismo ya en el 2009. Le dije "No. Nosotros vamos a dejar todo lo que tengamos que dejar para que Néstor vuelva a recuperar la empatía popular, porque la va a recuperar, porque va por el camino correcto". Y la política también tiene esa fe" (Entrevista a Guillermo Cara, agosto 2015.)

Solicitada 1

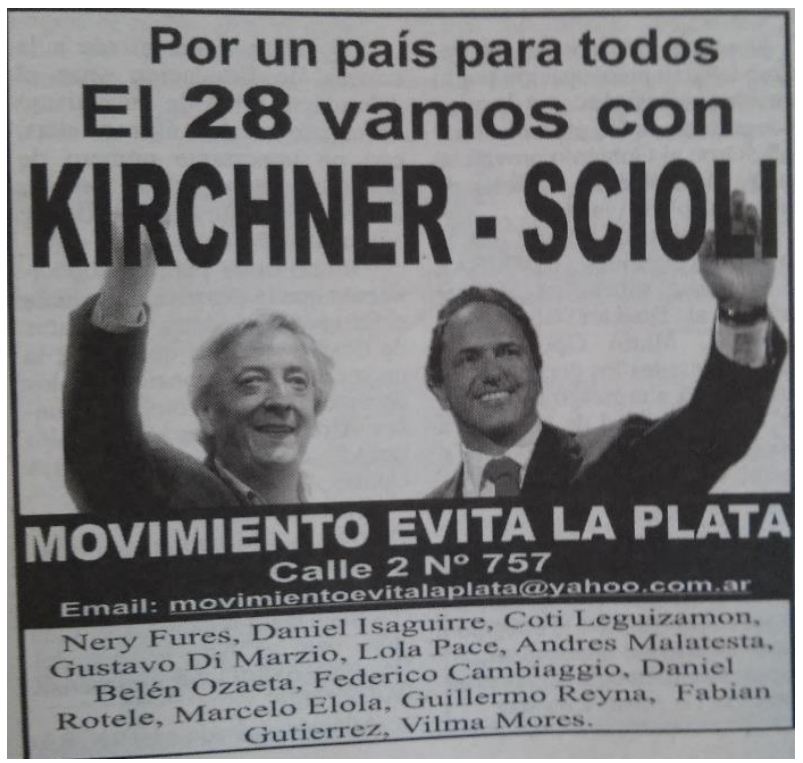

Fuente: diario El Día, 26/06/2009: pág. 19
Este señalamiento sobre las perspectivas de construcción tras la derrota electoral permiten indicar algunos puntos: en primer lugar, el hecho de que el FRP-FPV se hubiera lanzado a la construcción de una corriente provincial exigiendo una renovación de cuadros dirigenciales, implicaba a nivel local una réplica de aquellos actores que leían en este movimiento la conformación de una oposición interna más que una propuesta de continuidad con las

políticas de la élite nacional pero por medio de otros protagonistas. La caracterización del FRP por parte de los integrantes de las agrupaciones locales críticas fue cambiando en estos años de traidor a opositor interno ${ }^{140}$. Este deslizamiento devenía en la "necesaria" conclusión de que las acciones realizadas por el entonces Intendente eran expresión de un problema político que excedía los términos organizativos.

En segundo lugar, el distanciamiento también dejaba en un lugar complejo a aquellas agrupaciones que construían políticamente sobre el recurso de la lealtad a la figura nacional de la élite del FPV. En aquellos grupos que llevaban adelante una convocatoria a la militancia focalizada en el acompañamiento al conjunto de políticas públicas

\footnotetext{
140 Las declaraciones públicas de Pablo Bruera, además, alentaban estas lecturas suspicaces. El 25 de Marzo en una entrevista afirmó que el gobierno nacional no le giraba fondos como represalia (Pablo Bruera, Radio Mitre, 25/03/2010. Disponible en https://www.youtube.com/watch?v=LNdWbiLwqyl ). Además exigía que se conforme "...una comisión de peronistas históricos que garantice un contrato de confianza y credibilidad para que el peronismo no sea una fábrica de expulsión de militantes y dirigentes" (Pablo Bruera, San Martín Noticias, 08/06/2010, disponible en https://www.youtube.com/watch?v=xAOzUsN7fJw )
} 
desplegado desde el 2003 por el gobierno nacional; sostener una posición en un marco de alianzas que viraba -o parecía hacerlo- hacia la confrontación, podía significar el costo de perder capacidad de movilización. Además, el hecho de que el principal referente del FRP-FPV sostuviera públicamente como eje de su desarrollo una interpelación al conjunto de los demás Intendentes peronistas de la Provincia, le exigía a estas agrupaciones definir su propio posicionamiento respecto a lo que se denominaba como "la estructura del PJ" -y no ya el FPV- la cual era, para ese entonces, un campo de batalla. $\mathrm{Y}$ es que muchos de los cuadros militantes de estas organizaciones contaban con una trayectoria alejada y en confrontación con el peronismo en la década de los '90, que había cambiado tras la convocatoria de Néstor Kirchner en $2003^{141}$. Al respecto un referente platense del Movimiento Evita sostenía:

“...algunos compañeros nos vamos, al poquito tiempo que asume Menem y plantea lo que va a hacer, nos vamos del peronismo, no renegando de nuestra identidad, si no renegando de que lo se estaba haciendo en nombre del peronismo."

Y luego en relación al kirchnerismo:

"Así que desde ese lugar, el kirchnerismo es el nombre del peronismo actualizado, no se puede hablar del kirchnerismo sin primero decir "soy peronista" y hoy la expresión de esa etapa es el kirchnerismo. No están separados esos dos términos. El kirchnerismo es peronismo, en esta, si querés como lo había planteado Perón, actualización doctrinaria de esta etapa." (Entrevista a Gustavo Di Marzio, agosto de 2015).

La caracterización que dicha cita realiza del peronismo durante los 90 se vincula claramente con la diferencia entre lo que los militantes de esta organización comprenden que implicaba el núcleo duro ideológico del peronismo y las políticas públicas que llevó adelante el presidente Menem -y aquellos jefes distritales del PJ que acompañaron dichas políticas- durante sus mandatos. Esta distinción recuerda la interpretación que realizó Altamirano del desdoblamiento del peronismo en fáctico, que se correspondería con las formas históricas concretas que el peronismo adoptó siendo gobierno u oposición; y el peronismo verdadero vinculado a las expectativas e interpretaciones que muchos militantes, excluidos del fáctico, mantenían al sentirse parte del movimiento: “...el

\footnotetext{
${ }^{141}$ El rol del liderazgo nacional, en términos organizativos, como garantía de una política de trasformación con la cual se podía rearticular fuerzas dentro de la estructura del PJ sin perder el núcleo de concepciones políticas de cada organización, fue analizado por Perez y Natalucci (2010).
} 
peronismo verdadero ha sido y es una expectativa real, así como una forma de ser y de estar en el peronismo desde hace casi cuatro décadas" (2001: 108). Siguiendo esta clave interpretativa, el kirchnerismo -o en términos formales, el FPV- significó la posibilidad de trasvasar dicho desdoblamiento y retornar al peronismo fáctico, a disputar en su interior con los actores que formaron parte de la exclusión en la década pasada. Una aventura como la que proponía el FRP podía significar una tensión del marco de alianzas que alguna de estas organizaciones tenían a nivel nacional.

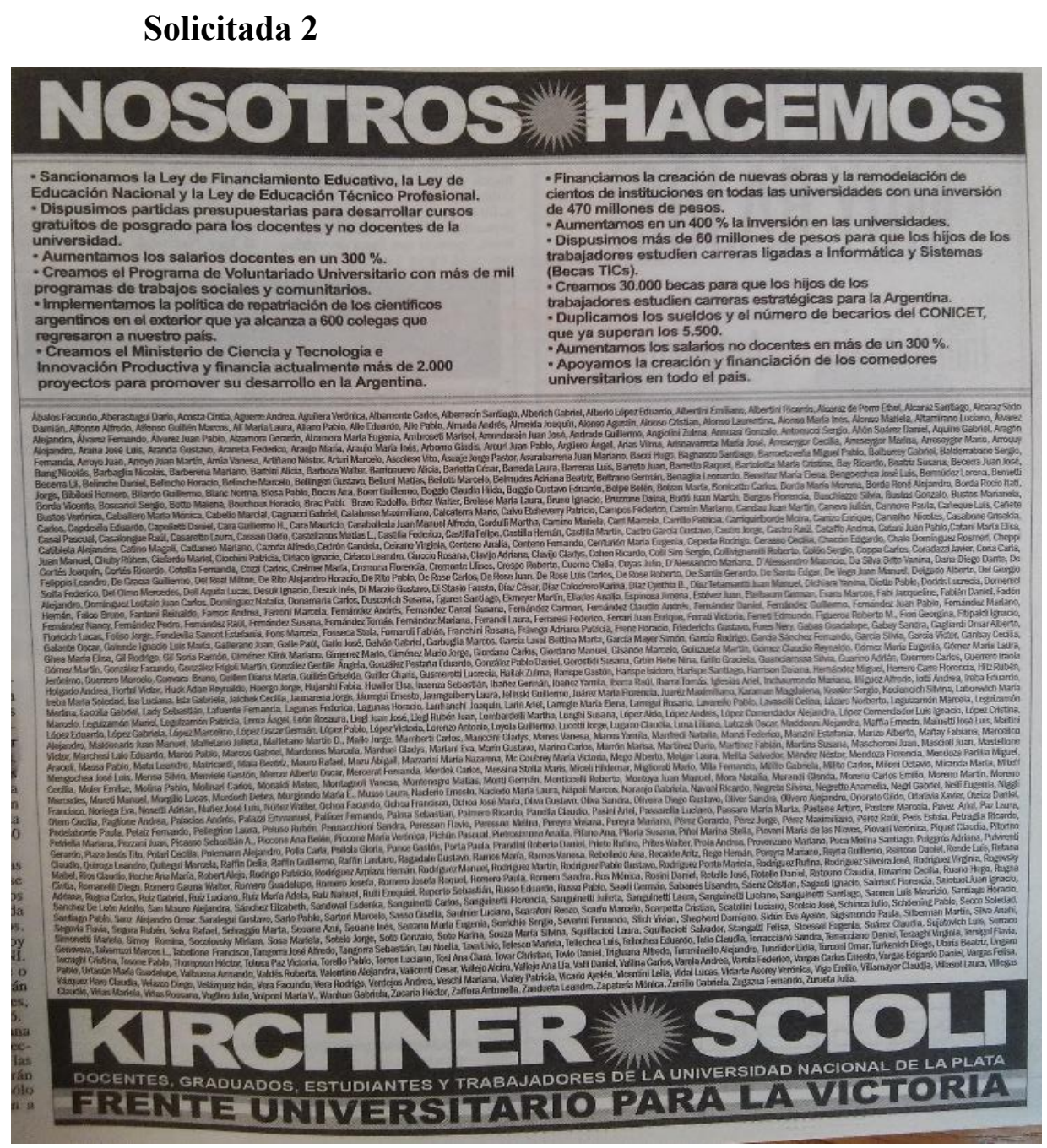

Fuente: diario El Día; 26/06/2009: pág.15.

De todas formas, esta desvinculación no se produciría sin "costos" para las organizaciones. Teniendo en cuenta que al fin y al cabo el FRP-FPV contaba aún con la inercia de la novedad al interior del peronismo, como también con el hecho de que la 
disociación no se terminaba de producir, los posicionamientos fueron dispares ${ }^{142} \mathrm{y}$ en algunos casos, como los del Movimiento Evita, llegaron incluso a un proceso de ruptura interna $^{143}$. La rearticulación de este espacio se produjo, entonces, en la marginalidad del entramado político que ocupaba la estructura del PJ local y el gobierno municipal. Su objetivo, en primera instancia, parece haber sido la captura del "voto duro" hacia la élite nacional del FPV en el distrito. Cabe destacar que la escasa gravitación de la élite provincial como figura de acumulación política para estos grupos, se podría explicar por cierta representación de la figura del Gobernador casi como "delegado" de la conducción nacional.

\subsection{Estrategia electoral}

La mesa de articulación de este entramado de organizaciones se nutrió principalmente de grupos locales que contaban con el recurso de la "lealtad" a la élite nacional como principal método de movilización, militantes peronistas desplazados de la conducción del PJ local tras la derrota electoral en 2007 frente al FRP-FPV y, finalmente, aunque de modo escaso, algunas organizaciones con trabajo barrial en la periferia platense. El contraste en la lógica de construcción política de este espacio con la experiencia del FRPFPV se observa centralmente en que la mesa de articulación se construyó primero y el "candidato al gobierno ejecutivo municipal" se seleccionó posteriormente. Este evento resulta decisivo en tanto se comprende que tuvo en esta propuesta mucha más importancia el marco de alianzas que la figura de tracción de votos. Además, la construcción de la candidatura presentó elementos más que interesantes para el análisis. Un referente de la organización Ateneo Jauretche relataba sobre el hecho:

"Así que juntos lo fuimos a buscar a Carlotto un día. "Necesitamos un candidato, vamos a buscar a Carlotto", dijimos. Le tocamos la puerta y le dijimos "Kibo [Carlotto],

\footnotetext{
142 "Nosotros nos quedamos en el partido porque cuando se produce éste quiebre al principio, en el 2009, entre Néstor Y Pablo, a nosotros nos piden que llevemos la renuncia a la municipalidad. Todos los compañeros tienen cargos en la muni. Entonces todos los compañeros llevamos la renuncia a Parrilli. [...] Parrilli dijo "esto Néstor se los va a agradecer, la lealtad" yo le dije - cuando salieron todos los compañeros"mira Oscar, todos éstos compañeros viven de su sueldo, no te digo que los hagas funcionarios del gobierno nacional, pero tenemos que organizar su situación económica". Me dijo "sí, quedate tranquilo". A los tres meses empezó a explotar todo ese armado nuestro y nunca nadie se hizo cargo, obviamente." (Entrevista a Federico Martelli, agosto 2015).

${ }^{143}$ Emilio Pérsico sostuvo en 2011 -previo a la fecha de cierre de listas para esa elección-: "Al alejarse el bruerismo del Proyecto Nacional, quienes perdieron fueron el jefe de Gabinete, Santiago Martorelli, y las concejales Lorena Riesgo y Silvana Soria" (diario Diagonales, 18/01/2011).
} 
nosotros queremos hacer kirchnerismo en esta ciudad por afuera pero no tenemos nombre, ni apellido. Vos tenés un apellido, estás muy vinculado al kirchnerismo, estás enfrentado con Bruera, construyamos juntos". Y lo primero que hicimos fue traer una muestra del museo Evita, fuimos a hablar con Cristina Alvarez Rodríguez y conseguimos el Teatro Argentino e hicimos una muestra de Evita que la abrió Kibo" (Entrevista a Isidoro Harispe, agosto 2015)

La elección del candidato presentaba dos ventajas: por un lado, Carlotto contaba con una trayectoria en el peronismo local que le permitía trazar ciertos puentes de dialogo con los votantes duros de dicha identidad. De hecho, para el 2011 cumplía su mandato como Senador Provincial, cargo al que había accedido en 2007 en la lista del PJ-FPV (enfrentado al FRP-FPV), lo que lo dotaba de cierto reconocimiento público. En segundo lugar, su vinculación con los organismos de DDHH le permitía disputar en la ciudad un sector del electorado de centroizquierda que no necesariamente provenía de la tradición peronista pero comulgaba con las políticas del gobierno nacional en estos temas.

De esta manera, la figura de Carlotto constituyó un caso muy particular de candidato al gobierno municipal. Ungido como figura central para el evento, no parecía mostrar pretensiones de ser un protagonista con continuidad en la arena local. Esto podía llevar a que el conjunto de las decisiones, las de campaña como también las de los criterios intraorganizativos estuvieran depositados en otras figuras que funcionaron como armadores. Si bien resultaba afín a la lógica de construcción del FPV nacional, el hecho de que hubiera sido convocado desde el espacio local refiere, de manera distinta, al fenómeno ya observado de la reafirmación de ciertos márgenes de crecimiento autonómicos de los grupos locales.

Todo este proceso de selección de la candidatura para Intendente por este espacio permite realizar algunas reflexiones importantes de manera más formal: en primer lugar, desde una perspectiva global, se podría considerar el hecho de que la postulación fue producto de un entramado local, expresa un rasgo de democracia interna dentro de la organización del peronismo kirchnerista, aceptando la propuesta de Freidenberg y Sanchez López para el análisis de la selección de candidaturas, donde una mayor participación de sectores subnacionales en la definición de postulantes para las elecciones implica un mayor nivel de democratización en la organización (Freidenberg y Sanchez Lopez, 2001: 12). En segundo lugar, y quizás más importante aún, es que el desplazamiento del centro de 
gravedad del armado, desde el candidato hacia el marco de alianzas, observable también en la construcción de la lista de Concejales -ver apartado siguiente- recuerda otra hipótesis propia de los estudios de partidos:

"En el caso de que la definición de la candidatura esté en manos del partido, el aspirante querrá estar en gracia con los líderes de éste, lo que contribuye a la disciplina interna. Mientras que si su nominación depende sólo de los votantes, le importará menos su relación con el aparato partidista, a pesar de que éste continúa controlando la estructura de oportunidades." (Freidenberg, 2003:15)

Lo que permitiría comprender mejor los contrastes entre el candidato del FRP/FPV y el de UyO. El primero, contando con votos propios, logró estabilizarse como punto de acumulación de su propio armado y por ende, no tenía sobre sí mayores niveles de dependencia con la élite nacional o provincial, mientras que el segundo, Carlotto, por el contrario, debía mantener mayor atención a los requerimientos y exigencias del conjunto de grupos que le había permitido postularse.

\subsection{Marco de alianzas}

La lista de candidatos a Concejales de UyO muestra la diversidad de agrupaciones que cohabitaron dicho marco de alianzas:

\section{Listado de candidatos 3}

\begin{tabular}{|c|c|}
\hline \multicolumn{2}{|c|}{ Concejales de UyO } \\
\hline Nombre & Organización \\
\hline Martín Alaniz & La Cámpora \\
\hline Sebastián Tangorra & FAP ${ }^{144}$ \\
\hline Ludmila Kostiuk & Movimiento Evita \\
\hline Ariel Archango & Compromiso y Militancia \\
\hline Victoria Tolosa Paz & John William Cooke \\
\hline Isidoro Harispe & Ateneo Jauretche \\
\hline
\end{tabular}

\footnotetext{
${ }^{144}$ Ver nota al pie número 129 del presente capítulo.
} 


\begin{tabular}{|l|l|}
\hline José Luis Agarraberes & Frente Grande \\
\hline
\end{tabular}

Sobre la distribución de las candidaturas cabe mencionar el hecho de que el criterio elegido expresa la visibilidad de un frente de organizaciones, donde lo que se trataba era de darle lugar a aquellas agrupaciones que habían decidido romper con el FRP-FPV. Como se mencionó en el apartado anterior, si el centro de decisiones se encontraba en el marco de alianzas, finalmente lo que la lista de candidatos al Concejo Deliberante refleja son los acuerdos internos, frutos de las evaluaciones de los actores que participaban con anterioridad a la candidatura. De aquí que más que buscar experiencia legislativa o constituir una plataforma de crecimiento posterior a donde poder convocar a otros grupos, la lista está cerrada sobre sí misma, o en otras palabras, la (siempre) difícil situación de establecer formas de equivalencia de los distintos capitales políticos acumulados por cada grupo fue saldada sin referencias a una continuidad del espacio -lo que implicaría la virtual idea de una inclusión futura de otros grupos- en sucesivas elecciones. Quizás por esto no ocupó el primer lugar de la lista el representante de la agrupación Ateneo Jauretche que, en definitiva, eran quienes habían logrado convencer a Carlotto de ser el candidato $^{145}$.

\subsection{Construcción identitaria particular}

La estrategia comunicacional de la campaña no tuvo grises en términos de agenda ya que se construyó en torno a los temas nacionales. Si bien no contaron con mucha publicidad gráfica, los avisos tenían la impronta de desplegar en el espacio local una agenda nacional (ver propaganda 4) Además de la permanente referencia a la imagen de Cristina Kirchner y la notoria ausencia de referencias a Scioli, la lógica fue la de la asociación entre ambas candidaturas. Si bien se presentaron bajo la estructura de un partido provincial de poca extensión territorial ${ }^{146}$ como era el Frente Social de la Provincia de Buenos Aires, la posibilidad de ir en la misma boleta con las categorías nacionales y provinciales del FPV ayudaban a la vinculación (Propaganda 5). La construcción del mensaje de la propaganda 6 es interesante puesto que en ella aparecen, aún sin nombres y sin referencias partidarias, la figura de la Presidenta y la de Estela de Carlotto, como referentes políticas y "madres".

\footnotetext{
${ }^{145}$ Recordamos que el primer lugar de la lista de concejales, por tradición política, lo ocupa aquel que representa directamente la figura del candidato a Intendente. Ver Cap. 2 de la presente tesis.

${ }^{146}$ En la jerga estos partidos se denominan "sellos". Se trata de estructuras formalmente válidas, pero sin una realidad de cuadros militantes concreto. Se suelen alquilar para participar de las elecciones.
} 
Se podría lanzar una hipótesis -de tipo semiótica- en torno a la posibilidad de que la figura de Cristina Kirchner aparezca en esta imagen como "madre" de la candidatura de Carlotto.

Como se puede observar, al igual que el FRP-FPV, la estrategia comunicacional de esta experiencia política, estaba centrada en la figura pública del candidato más que en un nombre o símbolos propios del espacio colectivo de articulación de las agrupaciones. Sin embargo la diferencia esencial con la propaganda del otro polo de agrupaciones, es que esta estrategia comunicacional buscaba de forma explícita sostener la vinculación entre la figura nacional y la local. En este caso, la modulación discursiva podría definirse como kirchnerismo duro o vertical descendente, donde se establece la no intermediación con la élite nacional, como también la pura identificación -casi delegativa- del candidato local. 


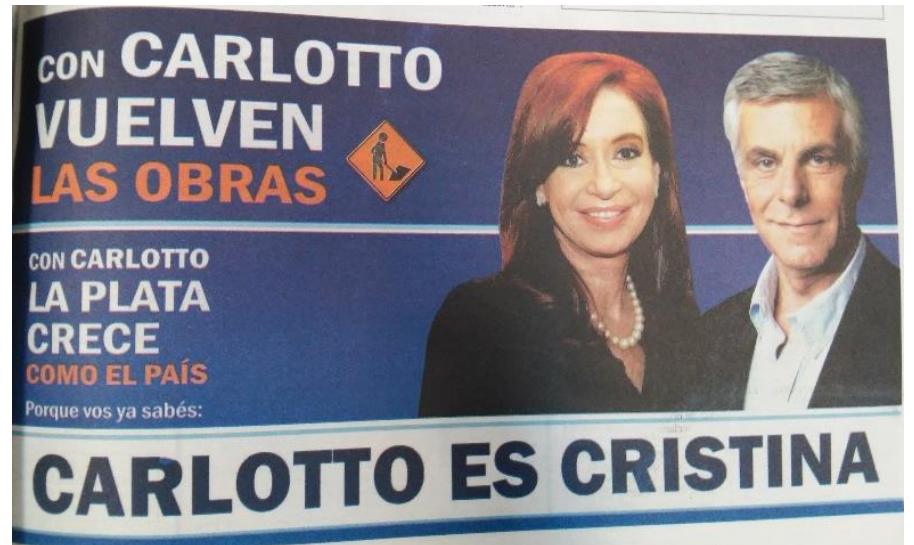

\section{Propaganda 4}

Fuente: El Día, 04/09/2011: pág. 19.

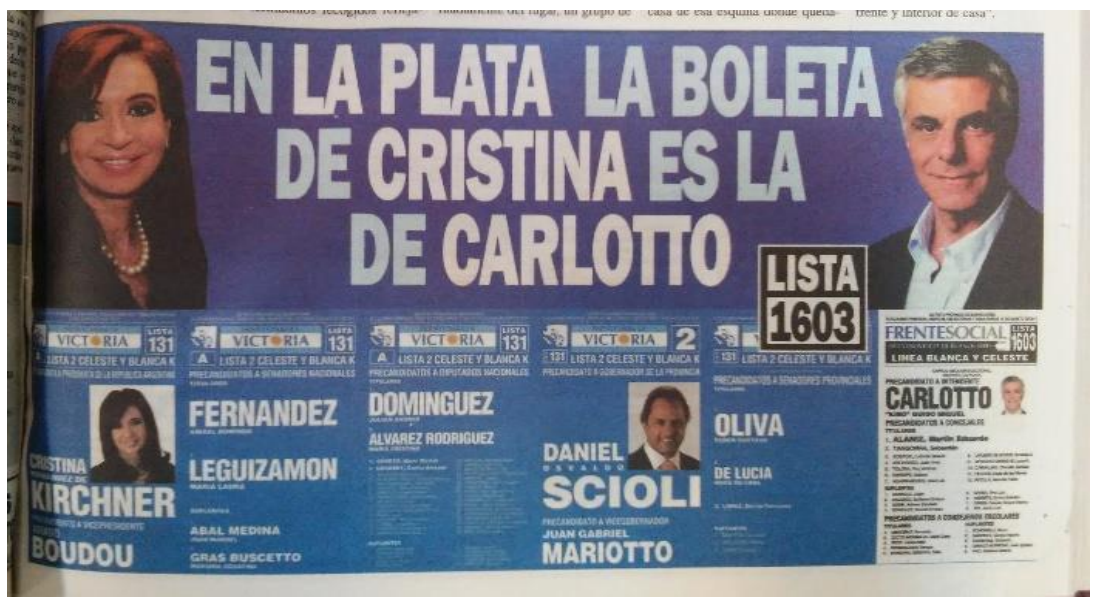

Propaganda 5

Fuente: Diario El Día, 17/08/2011: pág. 19.

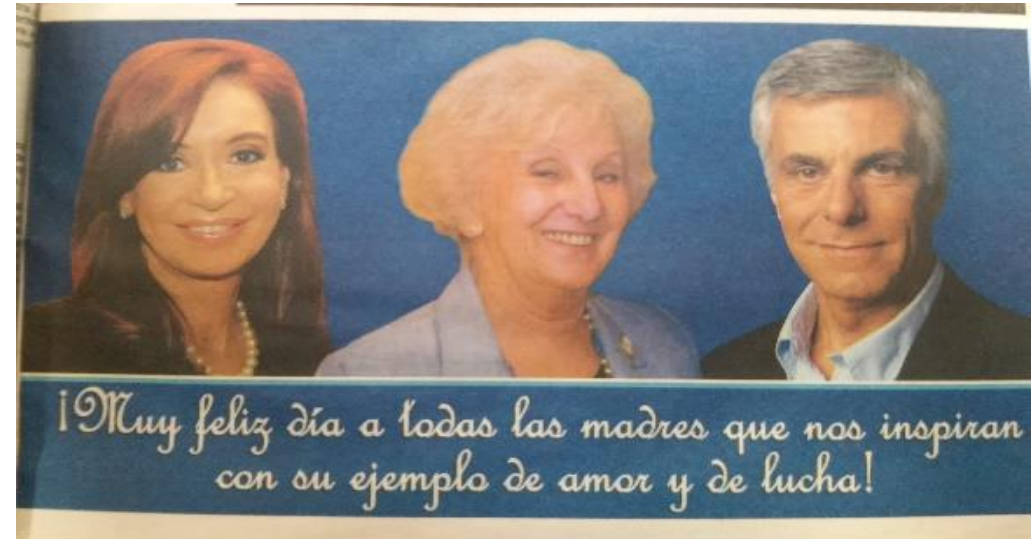

Propaganda 6

Fuente: Diario El Día, 16/10/2011: pág. 13. 


\section{Conclusiones}

El evento electoral del 2011 dejó varios elementos para el análisis. En principio, que las agrupaciones municipales inscriptas dentro del espacio del FPV platense, desarrollaron diferentes estrategias de acumulación y organización de cara a los comicios. Este primer dato permite desacoplar la idea de una organización predominantemente vertical para la composición de las compulsas electorales. La agencia que los actores obtienen en el territorio supone que la construcción de la unidad implica un conjunto de negociaciones entre diferentes estratos y, aun cuando estas mismas negociaciones sean asimétricas, el resultado no constituye un hecho consumado previamente a los cierre de listas. Esta situación permite pensar que el mismo movimiento por el que se da el crecimiento y expansión en las bases del peronismo, al menos en su ciclo político como FPV, es el mismo movimiento que termina tensionando la estructura de forma vertical y construye escenarios de disputa con sus élites nacionales y provinciales. Si bien no pareciera ser un fenómeno de autonomización total, los diferentes estratos de la organización construyen procesos de acumulación de forma descentralizada.

En segundo lugar, las diferentes trayectorias que se dieron en los dos polos de agrupaciones establecieron fuertes contrastes: mientras el polo del FRP-FPV contaba con un candidato fuerte al ejecutivo local, el cual venía de realizar una gestión al frente del municipio y contaba en sus espaldas haber protagonizado al menos 4 elecciones anteriores; UyO presentó un candidato con cierto nivel de conocimiento pero débil en términos de proyección. Aun cuando ambas figuras contaban con una trayectoria en la arena pública platense y también dentro del peronismo local, el candidato de UyO no fungió como un punto de acumulación de dicho espacio, que pareciera haberse preocupado más por fortalecer su marco de alianzas. Específicamente en lo que hace al marco de alianzas el dato más importante fue el criterio arquitectónico de los armados: mientras que el FRP-FPV presentó una lista de Concejales que expresaba -aun incorporando diversos grupos- más que nada líneas de trabajo y desarrollo en diferentes ámbitos como los gremiales o los barriales; el marco de alianzas de UyO presentó una lista que expresaba más los acuerdos de los diferentes grupos por la ocupación de las bancas, aun cuando estos mismos grupos se solaparan territorialmente. En este último caso y como ya se mencionó, primo más los tipos de capital político con el que las organizaciones contaban -su fidelidad a la élite nacional- más que sus diferencias. 
También en la construcción de las estrategias comunicativas y la construcción de identificaciones hubo fuertes contrastes. La modulación discursiva sobre como "estar" en la identidad del FPV fue diferentes en ambas propuestas. Mientras que el FRP-FPV no perdió su tono vecinalista, aunque si lo disminuyó bastante, participó de la campaña dándole más peso al candidato local, en contraste con la propuesta de UyO que le dio más peso a la figura de la élite nacional.

Por último, dos cuestiones que llaman la atención de estos comicios: por una parte la escasa gravitación de la figura de la élite provincial y candidato a Gobernador en las campañas de ambos polos. Incluso teniendo en cuenta que Daniel Scioli iba por una relección y por tanto se podría pensar que quedaba lejos ya la idea de ser sólo un delegado de la élite nacional, sin embargo, no hubieron propagandas gráficas con el candidato por parte de ninguna de las dos expresiones locales. En segundo lugar, algo que queda para el análisis de los próximos capítulos, el hecho de que el enfrentamiento entre estos dos polos no configura exactamente una externalidad, en tanto ambos acumulaban votos para la élite nacional y provincial. La ruptura de ambos espacios, como se verá a continuación, no fue meramente circunstancial, sino profunda y decisoria, sobre todo observable en el contexto de una baja de captación de electorado. 


\section{Capítulo 4: Las elecciones del 2013: disputa, inundación y asignación diferencial de} responsabilidad

\section{Los diferentes escenarios}

Tras los buenos resultados del 2011, el FPV ocupó el centro de la arena política argentina. Al interior de este, el peronismo gobernaba la mayoría de las provincias - 16 en total y con aliados el número llegaba a 18- como también la mayoría de las intendencias. Sin embargo, el clima político cambió fuertemente durante el 2012: por un lado se reabrió un ciclo de protestas de tipo gremial y, además, se activó un ciclo de protestas denominados como "cacerolazos" - la distinción entre ambos es importante- (Gamallo, 2012) ${ }^{147}$. Este nuevo ciclo operó como una ventana de oportunidad para la disputa interna dentro del FPV/peronismo, fundamentalmente al momento de conocerse la baja en la imagen positiva de la primera mandataria. Se produjo entones un efecto de externalización (Torre, 1999) dentro del peronismo por el que un sector terminó presentándose por fuera de la lista del FPV. Independientemente de que este fenómeno no ocurrió en todas las provincias, estas listas peronistas opositoras estaban articuladas entre sí y la mayoría de estos actores aprovecharon la ocasión de las elecciones de medio término para mostrarse como alternativa viable de recambio en 2015.

Por su parte, la élite nacional del FPV, en el juego de anticipaciones, generó un espacio de articulación a nivel nacional entre organizaciones que militaban con el capital político de la lealtad a la figura de Cristina Kirchner. Se trató de Unidos y Organizados, una experiencia que intentaba funcionar como un espacio de agregación de grupos paralelamente a la estructura organizativa del PJ pero con el objetivo de convertirse en un espacio de presión dentro de esta misma estructura. Su presentación pública fue el 27 de abril del 2012, en un acto en el que la oradora principal fue Cristina Kirchner. Debido a la cantidad de militantes con la que contaban y la expansión barrial que tenían las dos organizaciones más importantes de dicho espacio fueron La Cámpora y el Mov. Evita, aunque también participaba el partido Nuevo Encuentro, el partido Kolina, La Corriente de la Militancia, El Movimiento Octubre y oras agrupaciones de clara identificación

\footnotetext{
${ }^{147}$ Además, como señala el autor, sumado a la masividad que alcanzaron ambas formas de conflictividad social, se pudo observar un cambio de estrategia por parte de la élite nacional del FPV pasando de una forma de integración por partes -que fue la estrategia hasta el 2008- a una abierta confrontación (Gallo, 2012).
} 
kirchnerista (Página 12, 18/04/2012). Esta experiencia fue recibida de forma polémica por gran parte del arco político, pero fundamentalmente por parte del peronismo que acusaba a la misma de ser un movimiento centrípeto de la organización. Ciertamente Unidos y Organizados ocupó un espacio central en la estructura del FPV, como describe el referente del Movimiento Octubres:

"Así que fuimos de Unidos y organizados. Pero Unidos y Organizados en ese momento tuvo la posibilidad de hacer un camino que no hizo. Como una bifurcación y había dos opciones: o ser un partido, una herramienta política de construcción del proceso para la gobernabilidad; o ser lo que acelerara y le diera una nueva dinámica al proceso histórico. O sea, una revolución dentro de la revolución, o el camino de la burocratización, el aparato político del proceso. Y bueno, fue un poco las dos cosas, pero ocupó el centro de la fuerza política del kirchnerismo y algunas tendencias burocráticas terminaron limitando el proceso político. También había una cuestión a tener en cuenta, y para ser justos, que es que el asedio del enemigo, la violencia política o discursiva, el accionar, la muerte de Nisman, desde mucho antes la guerra de cuarta generación puesta en marcha; generó que hubiera una tendencia defensiva dentro del proceso político y el objetivo de que llegara a buen puerto al cambio de gobierno, pero terminar el mandato. Y ese fue un objetivo." (Entrevista a Gastón Harispe, octubre de 2017)

En el marco de una pelea por mantener la capacidad de desarrollo de políticas públicas, esta experiencia dotaba a la élite nacional del FPV con una cadena de mando casi sin márgenes de interpretación o de resistencia. Los militantes que participaban de Unidos y Organizados y además ocupaban cargos en las diferentes áreas estatales, intentaban asegurar la implementación de las acciones de gobierno en cualquier espacio territorial que se encontraran, lo que trajo cierta rispidez con los armados provinciales o locales. En este sentido es que la respuesta citada remite a la práctica burocrática y política.

En la provincia de Buenos Aires ambas situaciones se replicaban. El entonces gobernador Scioli, anticipándose al proceso electoral de ese año, avisaba sus intenciones de competir por la presidencia en 2015 (La Nación, 13/05/2013), aclarando además que lo haría siempre y cuando existiera acompañamiento de la actual élite del FPV nacional. Pero, por otro lado, el que fuera el conjunto de los 8 Intendentes críticos, se había expandido y se 
presentaba como el Frente Renovador ${ }^{148}$ en la Provincia, bajo una campaña que pretendía impedir la mayoría para el FPV y bloquear con ello una posible reforma constitucional que habilitara una siguiente reelección ${ }^{149}$. Esta ruptura encuentra una explicación en tanto efecto del gran volumen político que acumuló la élite del FPV nacional, teniendo en cuenta que, tras los impactantes resultados de la elección anterior, la posibilidad de forzar un recambio de cuadros desde dentro se encontraba más desdibujada. Siguiendo la propuesta de Hirschman en Salida, voz y lealtad (1977), la externalización fue más un resultado de la propia obturación de los canales de recambio debido a una cierta lectura (auto) confirmatoria -y el acto de Vélez pareció ser un punto de visibilización de esto- de la propia estrategia de la élite nacional. Ahora bien, este mismo movimiento produjo a la inversa -al interior del PJ-FPV de la provincia- entre aquellos actores y grupos que se quedaron un interesante efecto de presión interna que dominaría el tablero político por los siguientes dos años: se trató del hecho de que aquellos intendentes leales -o que preferían quedarse a jugar al interior del FPV- vieron crecer su capacidad de negociación con la élite nacional contando como elemento de presión la posibilidad de jugar por fuera (El Día, 20/06/2013). De hecho la lista de diputados nacionales la terminó encabezando Martín Insaurralde, Intendente de Lomas de Zamora y los integrantes de UyO sólo obtuvieron los lugares 15 y 16 (El Día, 23/06/2013) ${ }^{150}$ quedando los demás lugares repartidos con un criterio de renovación de un conjunto de militantes del FPV desde sus inicios -que debían renovar- y que tenían sus propios vínculos con el resto del PJ de la Provincia. Además, si bien Cristina Kirchner tuvo apariciones a lo largo de la campaña electoral, fue Daniel Scioli quién se encontró en el centro de la escena acompañado la lista (El Día, 03/07/2013).

\footnotetext{
148 Los Intendentes que construyeron este espacio fueron: Sergio Massa, del municipio de Tigre; Darío Giustossi, de Almirante Brown, Joaquín de la Torre, de San Miguel; Luis Andreotti, de San Fernando; Luis Acuña, de Hurlingham; Jose Eseverri, de Olavarría; Marcela Passo, de Gral. Lavalle; Gilberto Alegre, de Gral. Villegas; Gabriel Katopodis, de San Martín; Sandro Guzman, de Escobar, Jesús Cariglino, de Malvinas Argentinas; Humberto Zúccaro, de Pilar; Mario Meoni, de Junín; Jorge Macri, de Vicente Lopez; Gustavo Posse, de San Isidro; Raúl Feito, de Trenque Lauquen; Luis Ghiione, de San Andrés de Giles; Martín Caso, de Rojas; Patricio Hogan, de Gral Alvarado y Carlos Selva, de Mercedes.

${ }^{149} \mathrm{Si}$ bien el tema de una posible reforma constitucional giro en los medios nacionales antes de las elecciones, esta situación resultaba una posibilidad dificultosa y remota por diversos motivos, entre ellos, la habilitación para rediscutir un conjunto de acuerdos como el sistema de coparticipación, establecidos en 1994 -además claro de la falta de una oposición fuerte que sirviera de contraparte en el acuerdo para dicha política. La temática, sin embargo, fue utilizada más por los opositores como emblema de campaña que por el oficialismo. De hecho, el primer candidato a diputado nacional por el FPV de la provincia, lo desmintió como primera declaración pública (El Día, 01/07/2013).

150 Donde sí obtuvieron lugares fue en las listas de diputados provinciales y de algunos Concejos Deliberantes de varias intendencias.
} 
En el distrito de La Plata la coyuntura sumó a estos ciclos de protestas la tragedia de la inundación del 2 y 3 de abril de $2013^{151}$, la cual redefinió el contexto político local trastocando cualquier pretensión u objetivo de los actores. Este evento tuvo un impacto diferencial en la asignación de compromisos de la sociedad sobre los grupos, generando situaciones de debilidades políticas y transferencia de responsabilidades los cuales operaron entre los dos marcos de alianzas diferentes que se esbozaron en las propuestas electorales del 2011. Ahora bien, el impacto de las inundaciones tuvo un correlato directo con un desplazamiento en la representación de las demandas por parte del polo de UyO, el cual buscó representar a los damnificados a través de un discurso en el que se articulaba la catástrofe a la mala administración del municipio. Si, como sostiene Casullo el peronismo canaliza demandas de abajo hacia arriba (2015: 23), el análisis de este desplazamiento en la búsqueda de expansión de la representación, resulta un dato más que relevante en torno a las consecuencias que dicha situación tuvo posteriormente en las elecciones del 2015.

\subsection{Resultados electorales}

Los resultados electorales de este año implicaron una derrota electoral importante para el FPV en general en la Provincia, con la fuga de votos hacia el sector del frente renovador de Sergio Massa, fenómeno que -como su puede observar en la tabla 2- también ocurrió en el distrito; pero también en particular en la ciudad tras los eventos de la inundación. La asignación de responsabilidades por parte de la sociedad hacia el manejo de los eventos tras la inundación, construyen junto con el contexto general parte significativa de las causas de la curva decreciente de la performance electoral del FRP-FPV.

De los fenómenos más significativos se encuentra tanto la caída del FRP-FPV de un poco más de 93 mil votos -algo así como un $20 \%$ del padrón- dejando a esta fuerza cercana a su mejor elección cuando aún eran oposición en $2005^{152}$. Por otra parte, el espacio de UyO -en la lista del Frente Social- creció en casi 13 mil votos mostrando la consolidación

\footnotetext{
151 La inundación del 2013 se trató de una de las catástrofes climáticas y sociales de la ciudad más importante de los últimos 100 años. La misma resultó en más de 80 muertos (aunque la cifra se encuentra discutida porque se considera que fueron más) y miles de damnificados. Si bien la población de los barrios periféricos fue la más perjudicada por su situación de vulnerabilidad, prácticamente todo el casco urbano terminó padeciendo dicha inundación (Cipponeri et all, 2014)

152 En dicha ocasión alcanzaron los 46 mil votos. Fuente http://www.juntaelectoral.gba.gov.ar/ Revisado el 20/05/2019.
} 
de su curva de crecimiento.

Tabla 2 resultados electorales La Plata

\begin{tabular}{|l|r|r|r|r|r|}
\hline \multicolumn{1}{|c|}{ Fuerza } & \multicolumn{2}{|c|}{ Paso } & & \multicolumn{2}{c|}{ Generales } \\
\hline FRENTE RENOVADOR & Votos totales & \multicolumn{1}{c|}{ Porcentaje } & & Votos totales & Porcentaje \\
\hline FRENTE PARA LA VICTORIA & 90347 & 24,22 & & 124.615 & 31,5 \\
\hline FTE. SOCIAL DE LA PROV. DE BS.AS & 62931 & 16,87 & & 68.783 & 17,39 \\
\hline FTE. PROGRESISTA CIVICO Y SOCIAL & 64746 & 10,12 & & 43.830 & 11,08 \\
\hline UNIDOS P/ LA LIBERTAD Y EL TRAB. & 54389 & 17,33 & & 64.282 & 16,25 \\
\hline FTE DE IZQ.Y DE LOS TRABAJADORES & 21267 & 14,58 & & 29.412 & 7,44 \\
\hline ALIANZA FRENTE CIUDAD NUEVA & 16784 & 5,7 & & 27.315 & 6,91 \\
\hline ESPACIO UNION PRO & 7733 & 2,07 & & 20.350 & 5,14 \\
\hline FTE. POPULAR DEMOCRATICO Y SOC & 7599 & 2,04 & & 5.175 & 2,83 \\
\hline COMPROMISO FEDERAL & 4157 & 1,11 & & - & - \\
\hline UNION CON FE & 3644 & 0,98 & & - & - \\
\hline PARTIDO LEALTAD Y DIGNIDAD BS.A & 1743 & 0,47 & & - & - \\
\hline Total de Votos / porcentaje sobre & & & & & \\
el padrón total & 399370 & 76,51 & & 415.033 & 79,5 \\
\hline
\end{tabular}

Tabla de elaboración propia con fuentes de: Junta Electoral de la Provincia de Buenos Aires.

Disponible en http://www.juntaelectoral.gba.gov.ar/ revisado 20/05/2019

Nuevamente vuelve a ser interesante de remarcar la alta participación ciudadana en los comicios, más teniendo en cuenta que los mismos -sobre todo la elección de agostoocurrieron a pocos meses de la tragedia.

\section{Actuación del FRP-FPV}

El fenómeno de la inundación, sumado a los problemas de legitimidad política causados por el ciclo de protestas iniciado que afectaba al FPV en su conjunto, transformó la buena performance electoral que en 2011 había obtenido el FRP-FPV, en una situación del pasado. La debilidad política en la que consecuentemente se encontró esta agrupación provino de diferentes vertientes: a la adjudicación social de la responsabilidad por la ausencia o falta de protagonismo del Estado municipal durante la catástrofe ${ }^{153}$, se le debe

\footnotetext{
${ }^{153}$ Existió un evento comunicacional que fue importante al haber trascendido hasta los medios de noticias nacionales. En medio de la inundación el equipo de comunicación del entonces Intendente comunicó -el mensaje estaba escrito en términos personales- que dicho mandatario se encontraba ayudando a los evacuados, mientras que el mismo estaba de viaje en Brasil (Todo Noticias, 04/04/2013. Revisado el
} 
sumar el hecho de que el gobierno municipal no supo o no pudo -en términos de resultados es equivalente- manejar las relaciones con los afectados (El Día, 11/04/2013) quienes se organizaron en asambleas barriales para exigir, entre otras demandas, justicia por los fallecidos (López, 2013). La discusión en torno a la cantidad de víctimas por el temporal y la falta de respuestas claras, colocaron a la dirigencia política con responsabilidades institucionales en el espacio de la sospecha -se le atribuía el intento de encubrir la cantidad total de decesos- al punto de que la misma Presidenta de la Nación, un mes después, y por cadena nacional, emitió un mensaje en el que sostuvo: "espero que se arbitren todas las medidas para que se sepan quiénes fueron los fallecidos" (La Nación, 09/05/2013) ${ }^{154}$. Además, como se verá a continuación, la articulación institucional entre el Estado nacional y el municipio fue casi nula ${ }^{155}$, ya que la intervención de la estructura nacional se situó en la Facultad de Periodismo y Comunicación Social de la UNLP, cuya decana se perfilaba como una figura con proyección política afín a la conducción nacional del FPV.

Todos estos elementos expresaron el clima de debilidad política en el que quedó sumido el gobierno municipal, al punto de que el mismo Intendente tuvo que salir a aclarar en su discurso de apertura de sesiones frente al plenario del Concejo Deliberante que no pretendía renunciar a su cargo: "Estoy absolutamente convencido que si mi nombre pudiera servir para paliar un milímetro del dolor de alguien estaría en mi disposición pero estoy convencido de que poner en crisis institucional a la ciudad sería ponerla en un lugar que nos alejaría del rescate, del dolor, del sacrificio, de la solidaridad y de ponernos de pie" (Bruera, Pablo, Diario de Sesiones del Concejo Deliberante de La Plata, Sesión Ordinaria $N^{\circ} 1$, Apertura, Abril 10 de 2013). Teniendo en cuenta que entre el fenómeno de la inundación y las elecciones legislativas del 2013 solo existieron tres meses de diferencia, para este sector, la participación electoral definiría su suerte en el entramado político local.

Debida cuenta de que la distancia entre la élite nacional del FPV y el FRP-FPV se había profundizado, fue la figura del entonces Gobernador la que intercedió a favor de este

23/02/2016. Disponible en: http://tn.com.ar/sociedad/el-intendente-de-la-plata-y-un-polemicotweet 380877 ).

${ }^{154} \mathrm{El}$ discurso completo se encuentra disponible en https://www.youtube.com/watch?v=EoimcLLtw2c (revisado el 28/02/2016). Es menester resaltar que en todo el discurso no se nombra ni agradece a la figura del Intendente pero, además, de forma implícita se le asignó responsabilidades.

${ }^{155}$ La gran mayoría de las acciones conjuntas se cernieron a trasferencias de recursos económicos por medio de programas paliativos y focalizados. 
grupo en el proceso electoral. Este accionar se pudo observar con claridad durante la campaña electoral donde, en un acto en el distrito, el mismo realizó un discurso en el que sostuvo:

"Como dice el paisano: no hay que cambiar de caballo en el medio del río. Hay que fortalecer la gobernabilidad, fortalecer las posibilidades, desde las Legislaturas, desde el Congreso Nacional, para unir esfuerzos y poder concretar estos dos años. [...] Pablo [Bruera] lo ha dicho con mucha claridad, es más que nunca imprescindible, particularmente para esta ciudad de La Plata, que no hubiésemos logrado acceder precisamente a estos instrumentos, a estas posibilidades de cambio, si no hubiésemos trabajado juntos en momentos difíciles la nación, la provincia y el municipio..." (Daniel Scioli, discurso de campaña en la ciudad de La Plata, 15/07/2013 ${ }^{156}$ )

La intervención permite realizar la observación de que durante estas elecciones la estrategia electoral del Scioli -en pos de su proyecto 2 años después- implicó reunir a aquellos sectores del peronismo que estuvieran disconformes o distanciados con la élite nacional del FPV. Teniendo en cuenta que si el mismo lograba ser el candidato del FPV dos años más tarde, contaría con el voto duro identificado con la entonces Presidenta, este apoyo a sectores del peronismo que bordeaban la ruptura le permitiría aumentar su performance. De ahí que, si se observa, en el pasaje del discurso no existe confrontación con el otro polo de organizaciones y además hay un intento por mostrarse como articulador entre los tres estratos del Estado "en momento difíciles". Por el lado del FRPFPV, contar con redes de articulación a nivel provincial que excedan el municipio les servía tanto para intentar mejorar lo que se esperaba fuera una caída estrepitosa en los resultados, pero más importante aún, la posibilidad de contar con márgenes de gobernabilidad para los años subsiguientes.

\subsection{La estrategia electoral}

La propuesta del FRP-FPV fue proponer como primer candidato a Concejal a Gabriel Bruera, en ese momento diputado provincial, el cual ya contaba con varias elecciones encima. Además de encabezar la lista, el mismo fue la figura pública sobre la que giro la

\footnotetext{
${ }^{156}$ Disponible en: http://www.infobae.com/2013/07/15/720204-scioli-como-dice-el-paisano-no-hayque-cambiar-caballo-medio-del-rio revisado el 04/03/2016.
} 
campaña electoral. Apostar al apellido Bruera en medio del conflicto social y político del distrito señalaba una clara búsqueda de cierto voto identificado con la figura local. Aun contando con otros nombres posibles ${ }^{157}$, ciertamente el problema era de conocimiento público puesto que ninguna otra figura de este entramado de organizaciones contaba con ello y eso implicaría una nueva dificultad. La campaña se centró en recomponer los lazos con la comunidad tras la inundación y contó con un repertorio de acción que combinó intervenciones urbanas como caminatas, conversaciones con los vecinos casa por casa ${ }^{158}$, reunión con sectores de vecinos inundados (El Día, 09/08/2013) y actos masivos. Al respecto el referente del FRP-FPV sostuvo:

"En el medio de la inundación, a mí me tocó encabezar la lista de concejales. Yo era diputado y fui candidato a concejal. Me caminé toda la ciudad de La Plata en el medio de la crisis. El peronismo sacó 28 puntos $^{159}$ a nivel provincial, nosotros sacamos 17 y ellos 11. Para mí fue una elección histórica esa porque ahí fuimos contra el gobierno nacional y contra el gobierno provincial, solos. Haber sacado 17 puntos en esa oportunidad para nosotros fue muy importante. Me ayudó mucho Martín Isaurralde, primer candidato a diputado nacional y fue un tipo que desde el minuto 1 se pegó mucho a nosotros independientemente de lo que le decía el gobierno. Se solidarizó con lo que nos estaba pasando. Entre todos los intendentes había solidaridades dispares, por ahi eran por abajo. Martín vino toda la campaña conmigo, nunca se mostró con los candidatos de La Cámpora, en eso tuve un buen apoyo." (Entrevista a Gabriel Bruera, junio de 2017).

Claramente la campaña estuvo cruzada por el conflicto político interno del FPV que, aun siendo anterior a la catástrofe, se agudizó con la misma. Las dificultades que expone el entrevistado -el no acompañamiento- pueden comprenderse en este contexto donde las actividades con candidatos extra municipales no alcanzaron a cubrir las necesidades que

\footnotetext{
157 De hecho esta agrupación contaba con diferentes cuadros que podrían haber sido protagonista de la lista de Concejales. Un caso de estos es el de Pacharotti, quien era integrante del FRP desde sus orígenes y que pretendía competir por la sucesión de Pablo Bruera en el municipio. En agosto de dicho año terminó rompiendo con dicho espacio de forma pública y un mes después emitió un duro comunicado con formato de solicitada, en el que sostenía el agotamiento del modelo de gestión del FRP-FPV en la ciudad (El Día, 01/09/2013: pág. 11).

158 Muchos de estos eventos llegaron a los diarios: El Día, 23/07/2013; 28/07/2013, 24/10/2013.

159 Se refiere a los resultados de las PASO donde el FPV en la Provincia alcanzó el $29,60 \%$ de los votos válidos.
} 
requería un proceso electoral adverso como el que se había encaminado ${ }^{160}$. Cabe resaltar que en la cita aparece cierta sospecha de veto que hubiera ejercido la élite nacional sobre los candidatos locales. Más allá de la certidumbre de esta afirmación, fue claro que la campaña en general del FPV a nivel provincial estuvo signada por un conjunto de tensiones internas que también se expresaron en el distrito.

\subsection{Marco de alianzas}

Similar a lo ocurrido en 2011, pero desde una coyuntura completamente diferente, la lista de candidatos a diputados Provinciales terminó siendo de acuerdo entre ambos polos de agrupamientos.

\section{Listado de candidatos 4}

\begin{tabular}{|c|c|}
\hline \multicolumn{2}{|c|}{ Diputados del FPV La Plata } \\
\hline Nombre & Organización \\
\hline Valeria Amendolara & FRP \\
\hline Gustavo Gabriel Di Marzio & Lovimiento Evita \\
\hline Federico De Marziani & Kolina \\
\hline Lucía Ramos Costa & FAP \\
\hline Antonio Imperiali & Nuevo Encuentro \\
\hline Guillermo Guerin & \\
\hline
\end{tabular}

Como es posible observar, la lista expresaba dos particularidades: por un lado, ser el punto de acuerdo entre el FRP-FPV y el resto del kirchnerismo, es decir, fungir como espacio de polarización con el resto del campo político -otros partidos. Teniendo en cuenta que no era amplio el conocimiento del candidato a Diputado Nacional por esta fuerza (La Nación 07/07/2013), en el FPV nacional y provincial comenzaba a quebrarse la hipótesis

\footnotetext{
${ }^{160}$ De las actividades con actores extra municipales del FPV se cuentan 5 acciones: 3 en las que estuvo presente Scioli y 4 Insaurralde. Posterior a las PASO, Insaurralde, además, estuvo una vez él solo de recorrida por los barrios con los candidatos del FRP-FPV.
} 
de una posible "transferencia de votos". Esta situación implicaba para las élites nacionales, por lo menos en términos de armado de boletas electorales, la necesidad de forzar acuerdos locales en ciertas categorías.

Pero esta lista muestra también que el criterio de selección utilizado, el de un candidato por organización, se encontraba muy alejado de lo que supo ser el criterio clásico del peronismo dividido por ramas. Además, en la selección de las organizaciones -vinculada, como se verá con el criterio de selección a Concejales por la lista de UyO- parece haber primado a la par del equilibrio entre los polos de agrupamientos, la relación de acompañamiento vertical a la élite nacional del FPV. A diferencia de la arquitectónica de la lista unificada de Senadores Provinciales del 2011, en este caso se trató de un intento de contener la mayor cantidad de grupos posibles, lo cual permite pensar que la fractura entre ambos polos del FPV local era para esta altura cada vez más profunda.

A nivel de las candidaturas al Concejo es donde mejor se apreció la polarización con la lista de UyO. Frente a la debilidad política que enfrentaba el FRP-FPV tras los sucesos de las inundaciones, esta agrupación se recostó fuertemente en aquellos sectores que le aseguraban un grado de fidelidad.

\section{Listado de candidatos 5}

\begin{tabular}{|c|c|}
\hline \multicolumn{2}{|c|}{ Concejales del FRP-FPV } \\
\hline Nombre & Organización \\
\hline Gabriel Bruera & FRP \\
\hline Gabriel Céspedes & Agrupación Evita \\
\hline Silvana Soria & Hombre de Oscar Parrilli $^{161}$ \\
\hline Germán Marcelo Beltrano & Ex combatiente y delegado municipal de \\
GRP en Villa Elisa
\end{tabular}

${ }^{161}$ Quien era un actor político vinculado a Oscar Parrilli, hombre fuerte de la élite nacional del FPV Si bien la lista no consiguió los votos suficientes como para que Beltrano ocupara una banca, en diciembre de dicho año, se produjo un reacomodamiento en la nómina de Secretarías del municipio y uno de los tres Concejales electos tomo licencia, por lo que Beltrano terminó jurando como Concejal. Es interesante notar que las crónicas sostienen que el mismo "juró por Néstor y por Cristina" (El Día, 20/12/2013). Sin embargo, el mismo nunca participó del bloque de Concejales formado a partir del nuevo polo del FPV local. 


\begin{tabular}{|c|c|}
\hline Julia Larcamon & Ex Coalición Cívica \\
\hline Julio Lamarque & PJ local \\
\hline
\end{tabular}

Es de destacar que aún con el acontecimiento de las inundaciones y la debilidad en la que se encontraba el FRP-FPV, no obstante mantenían un marco de alianzas amplio -aunque quizás menos diverso que en otros años- cosa que quedó plasmado en la solicitada que en dicho año publicaran (ver solicitada 3). Además es necesario remarcar que, con la consolidación del polo UyO en la ciudad, se expuso de forma más evidente la discusión horizontal entre grupos y con ello, el FRP tuvo frente a si la urgencia de no potenciar sectores de dudosa fidelidad con la conducción municipal. En este sentido, el FRP-FPV no podía permitir que el otro polo terminara por perforar su marco de alianzas, más si, como era factible tras su actuación en los eventos de las inundaciones, los mismos llegaban a realizar una elección con un mayor caudal electoral que en 2011. 
Solicitada 3

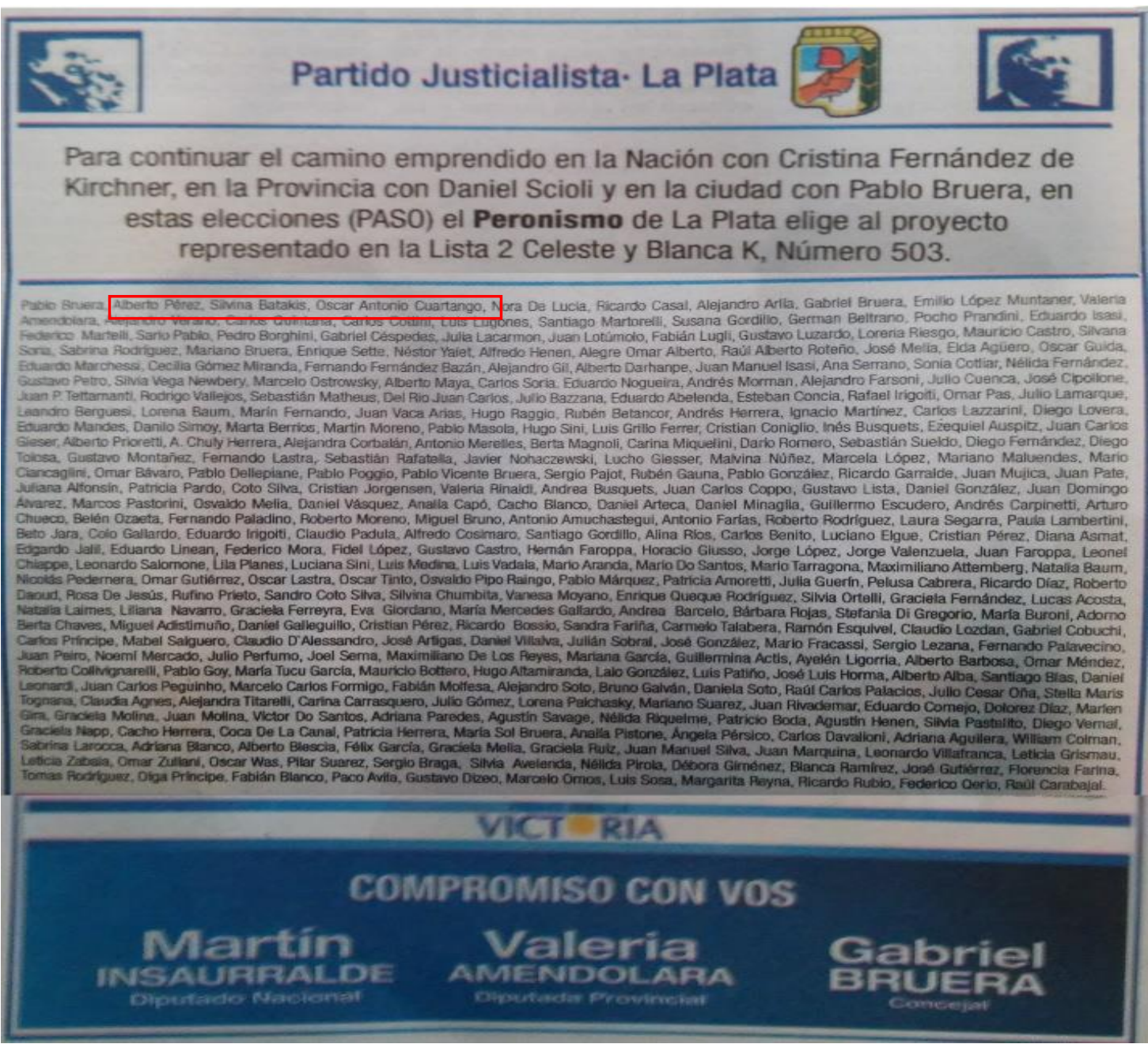

Fuente: El Día, 09/08/2013: pág. 7.

La solicitada, con más de 300 nombres, buscaba resaltar una situación de unidad aún frente a la adversidad de la catástrofe. Nótese como, junto con el logo de Perón y Evita a la izquierda, se encuentra la imagen de Néstor Kirchner a la derecha, alineando ambos símbolos. Otro elemento a destacar, es que entre los primeros nombres figuran ministros del gabinete provincial, conducido en dicho año por el FPV -ver recuadro rojo.

\subsection{Construcción identitaria particular}

Las campañas electorales de ambas listas aquí estudiadas, tuvieron como denominador común la apelación al espacio del FPV nacional y provincial. Sin embargo el modo de apelación, los medios utilizados para la interpelación pública y las referencias discursivas 
fueron claramente diferentes.

La estrategia comunicacional de FRP-FPV, en esta ocasión, se situó en el intento de recuperar el espacio de representación del FPV en la ciudad, pero de un modo particular: esto es, se moduló un discurso sin la imagen de la élite nacional del FPV y con escasas y casi nulas- referencias a la élite provincial. La denominación posible para esto sería la de una postkirchnerismo extralocal, donde se pone de manifiesto el hecho de un intento de heredar el proceso político iniciado en 2003 y con fecha de finalización en 2015. Para esto, se construyó una forma de interpelación basada en la asociación clara de los candidatos provinciales y locales (ver propaganda 7), que además buscaba recuperar el apoyo obtenido previamente al fenómeno de las inundaciones vinculándolo con la noción de futuro. Al observar la propaganda 8 , donde se encuentran los candidatos referentes de los tres cuerpos de la boleta, se puede observar, en el costado izquierdo una franja naranja. Este detalle corresponde al color con el que se identificaba la élite provincial del FPV como elemento distintivo -o como marca de cierto grado de autonomización- y que en este caso, al estar dispuesta al costado de los candidatos, daría a comprender una vinculación entre unos y otros.

Otro intento de recuperar el espacio de representación fue el de (re) vincular a la identidad peronista tradicional -para la cual, en todos estos años se le asignó un mensaje propiocon el espacio del FPV (ver propaganda 9). Teniendo en cuenta que Bruera continuaba al frente de la estructura del PJ local, este desplazamiento en la propaganda resulta notable, ya que se trata de un intento de articulación entre ambos espacios para los que desde el 2003 mantenían un mensaje discriminado.

Además en esta ocasión también estuvo presente la búsqueda de un voto "confianza", proponiéndose como la única fuerza capaz de realizar las obras de reconstrucción del distrito (El Día, 08/08/2013, pág. 8) bajo el título “compromiso con las obras”. 


\section{Propaganda 7}

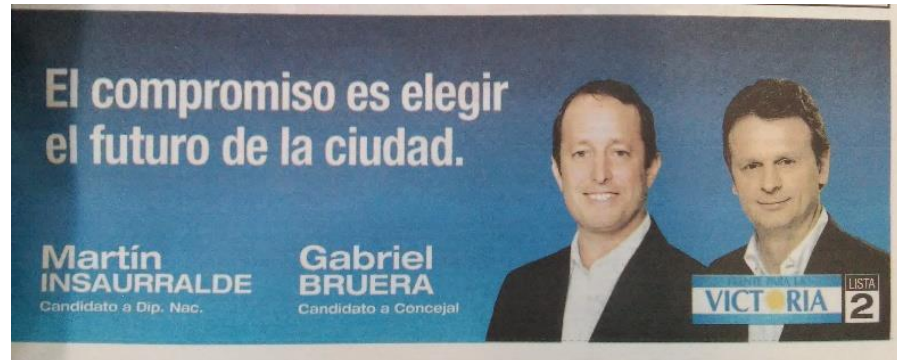

Fuente: diario El Día, 04/08/2013: pág. 25.

\section{Propaganda 8}

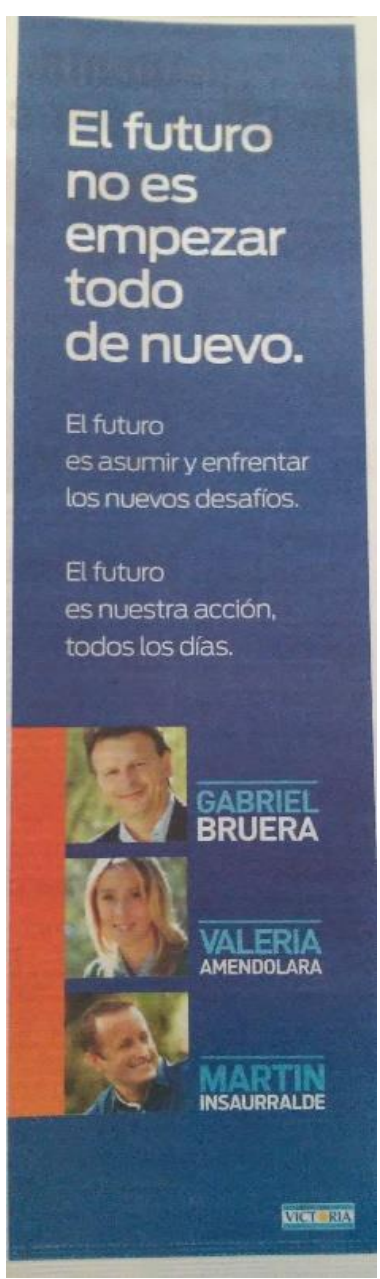

Fuente: El Día, 06/10/2013: pág. 7.

Fuente: El Día, 22/08/2013: pág. 07. 


\section{Actuación de UyO en las elecciones del 2013}

Tras las elecciones del 2011 y la aceptable performance, el espacio de UyO tuvo por delante el desafío de crecer sin quebrar el conjunto de acuerdos internos logrados. Aún cunado, el acto del 27 de 2012-con Cristina Kirchner como oradora- les dio un posicionamiento público notorio que les proveyó de la capacidad de captar nuevos militantes, como también de trazar nuevos acuerdos con otras organizaciones locales, la falta de un candidato fuerte con proyección electoral para competir por el gobierno municipal podía derivar en un estancamiento y una parálisis del espacio. Además, la necesidad de construir una agenda local alternativa al FRP-FPV y que sea coincidente con las políticas públicas accionadas desde la Presidencia de la Nación era un desafío cada vez más central. Finalmente el polo de agrupamiento local que gobernaba el municipio no se había ido del espacio del FPV -aunque mantuviera tensiones- y esto conducía a la compleja situación de tener que articular una oposición a estos últimos que debía diferenciarse también de otras ofertas partidarias del distrito. La consolidación del espacio requería entonces contar con propuestas propias con las que construir un perfil propio y a la vez que les permitiera procesar las tensiones internas electorales en una política de contención mayor. La tragedia de las inundaciones, sin embargo, precipitó la resolución -parcial- de muchos de estos problemas.

El evento del 2 de abril y el mal manejo del FRP-FPV, desembocó en que -como ya se mencionó- el gobierno nacional decidiera trasladar la asistencia a los damnificados a la Universidad de La Plata ${ }^{162}$ y en particular al edificio de la Facultad de Periodismo. Las organizaciones que participaban del entramado de $\mathrm{UyO}$ fueron convocadas a construir una intervención social en el distrito por fuera de la estructura municipal ${ }^{163}$. Las acciones de intervención barrial de los militantes, fortalecida por una campaña nacional de ayuda

\footnotetext{
162 Resta mencionar que frente a la magnitud del acontecimiento existieron muchos centros de acopio y distribución de ayuda para los damnificados, incluso en la misma Universidad. Las menciones aquí realizadas, recortadas en torno al impacto político, expresan la intención de captar la vinculación de este acontecimiento al interior del FPV.

${ }^{163}$ Al respecto, un militante del espacio político de UyO realizaba la siguiente lectura: "No se confía en el gobierno municipal para eso, el gobierno municipal arranca generando ésta mentira con lo cual tampoco generaba mucha confianza en la comunidad porque, si vos arrancas diciendo que estás ayudando y estás en otro lugar, digamos que no era muy creíble, y es ahí donde se decide políticamente, el gobierno nacional decide que se concentre el conjunto de la ayuda de todos los ministerios y de toda la política nacional en la Facultad de Periodismo. Eso funciona como un punto articulador, se usa este edificio de una universidad pública, de una facultad, se habla con otras facultades para los que quieran hacer lo mismo, por distintas razones otras facultades no lo aceptan, no aceptan que el gobierno nacional lo despliegue ahí..." (Entrevista a Carlos Leavi, agosto 2015)
} 
que motorizaron muchas de las organizaciones de este espacio, se articularon con la presencia de efectivos militares, cruz roja y funcionarios de gobierno nacional, creando un dispositivo de ayuda que se denominó "La Patria es el Otro" (Telam, 14/04/2013). En términos estrictamente organizativos, el saldo de la experiencia de intervención sobre la catástrofe fue, para este espacio, positivo por varios motivos: en primer lugar, porque les permitió amalgamar mejor las diferentes corrientes que participaban del espacio, a la vez que sumar otros grupos vinculados a sectores universitarios y gremiales fundamentalmente de la juventud. En segundo lugar en términos de posicionamiento público el problema de la inundación abrió para este polo un flanco de construcción política vinculado al análisis de las “causas" ${ }^{164}$, como también a la construcción de un imaginario sobre una ciudad inclusiva. Por último en términos de referencia pública, ya que el emplazamiento en el edificio de la Facultad le dio visibilidad a la figura de la Decana, Florencia Saintout, quien sería finalmente candidata por el espacio.

La decisión de volver a presentarse electoralmente con una lista "colectora" en vez de ir a internas tuvo para estos comicios, teniendo en cuenta la performance del 2011, un sentido de la oportunidad más marcado: si se acepta la hipótesis de que en la elección anterior el objetivo era la búsqueda -en el marco de una acumulación política- del voto duro vinculado a la figura de la élite nacional, y que en dicho proceso habían logrado 2 concejales; en esta ocasión, de abierta disputa en todo el territorio nacional por la renovación de cuadros, ir a internas con una alta posibilidad de perder resultaba poco negocio. Según la carta orgánica del PJ -finalmente la estructura partidaria electoral- en una interna quienes pierden solo alcanza a obtener el candidato por la minoría, por lo que yendo por fuera podrían alcanzar a tener 2 concejales en vez de uno-que además sería poco probable que ingrese.

\footnotetext{
${ }^{164}$ En el año 2010 el Intendente Pablo Bruera presentó el proyecto de ordenanza municipal con la cual modificó el "Código de Ordenamiento Urbano" que impedía, entre otras cosas, la construcción de edificios de más de tres pisos en la zona céntrica de la ciudad. Si bien la ordenanza 10703 sólo requería de mayoría simple para su aprobación, dicho proyecto despertó fuertes controversias en diferentes actores de la ciudad entre los que se encontraron el Colegio Provincial de Arquitectos, la Universidad Nacional de La Plata, un conjunto de ONG vecinales -por ejemplo "Nuevo Ambiente"- y la Central de Trabajadores de la Argentina -CTA- distrito La Plata, que denunciaban un proceso de gentrificación urbana impulsada por los acuerdos que el intendente construyó con los sectores económicos inmobiliarios. La polémica terminó dirimiéndose en La Corte Suprema Judicial de la Provincia (Página 12 21/06/2014). Con las inundaciones del 2013, luego de este proceso de debate, no fue difícil vincular los problemas de desagote de agua con la construcción de edificios.
} 


\subsection{Estrategia electoral}

La apuesta por la candidatura de Florencia Saintout presentaba varios elementos que la posicionaban de forma interesante. Además de contar con una trayectoria en el peronismo local ${ }^{165}$, era Decana de la Facultad desde el 2010 lo que le proveía un capital simbólico de autoridad y una capacidad de intervención pública por medio de políticas universitarias. Algunos de los eventos más destacados que produjeron desde dicho espacio universitario fue la premiación a Hugo Chávez (La Nación, 26/03/2011), evento que llegó a ser noticia nacional. Sus vínculos con agrupaciones estudiantiles como La Walsh ${ }^{166}$-la cual terminará vinculada al marco de alianzas de UyO- dotaban de volumen militante a su figura y le permitía presentarse en el marco de agrupaciones como una par y no- como en el caso de Carlotto- como una candidatura sin base de sustentación propia. Además había participado activamente de la discusión sobre la reforma de la Ley de Medios, política que la misma hizo jugar activamente durante la campaña.

Con la candidatura resulta, la estrategia electoral de UyO se encaminó a ampliar su base electoral intentando representar a los sectores damnificados por las inundaciones, a la vez que intentaban replicar políticas nacionales en los barrios. Un caso paradigmático de esto último fue la construcción de la denuncia al Diario El Día como empresa hegemónica de comunicaciones $^{167}$. Al igual que en último tramo del ciclo político de la gobernación municipal de Julio Alak, el enfrentamiento con este medio de comunicación implicaba una apuesta fuerte en términos de capacidad de incidir en la opinión pública local. Por contraposición, frente a la ausencia de participación en dicho matutino ${ }^{168}$, se apeló a las estrategias de intervención callejeras -timbreados, caminatas, etc.- y sobre todo a las redes sociales.

\footnotetext{
${ }^{165}$ En rigor estos vínculos eran muy lábiles. En el marco de la discusión en 2005 de sectores que pretendían impulsar una renovación en el peronismo platense, Saintout apoyó una de las líneas críticas del entonces intendente Alak (El Día, 01/07/2005). Lo que si nos interesa marcar es que el amplio campo del peronismo platense no le era ajeno.

${ }^{166}$ Agrupación universitaria de filiación peronista que condujo -con ciertos intervalos- el Centro de Estudiantes de la Facultad de Periodismo de la UNLP en los últimos 20 años. Terminó participando activamente de La Cámpora de La Plata.

167 La acusación también implicaba el que los capitales de esta empresa se vinculaban con empresas constructoras que habrían realizado "negocios inmobiliarios" en la ciudad. Ver apartado 3.3 del presente capítulo.

168 La cual fue tanto del polo de agrupamiento al no generar publicidad en dicho diario, como también del mismo diario, que casi no cubrió la campaña. De hecho solo aparecieron 3 notas en el mismo y una de ellas era una corrección de un error de una nota anterior (El Día, 27/07/2013).
} 


\section{Imagen 1: Boletas electorales}

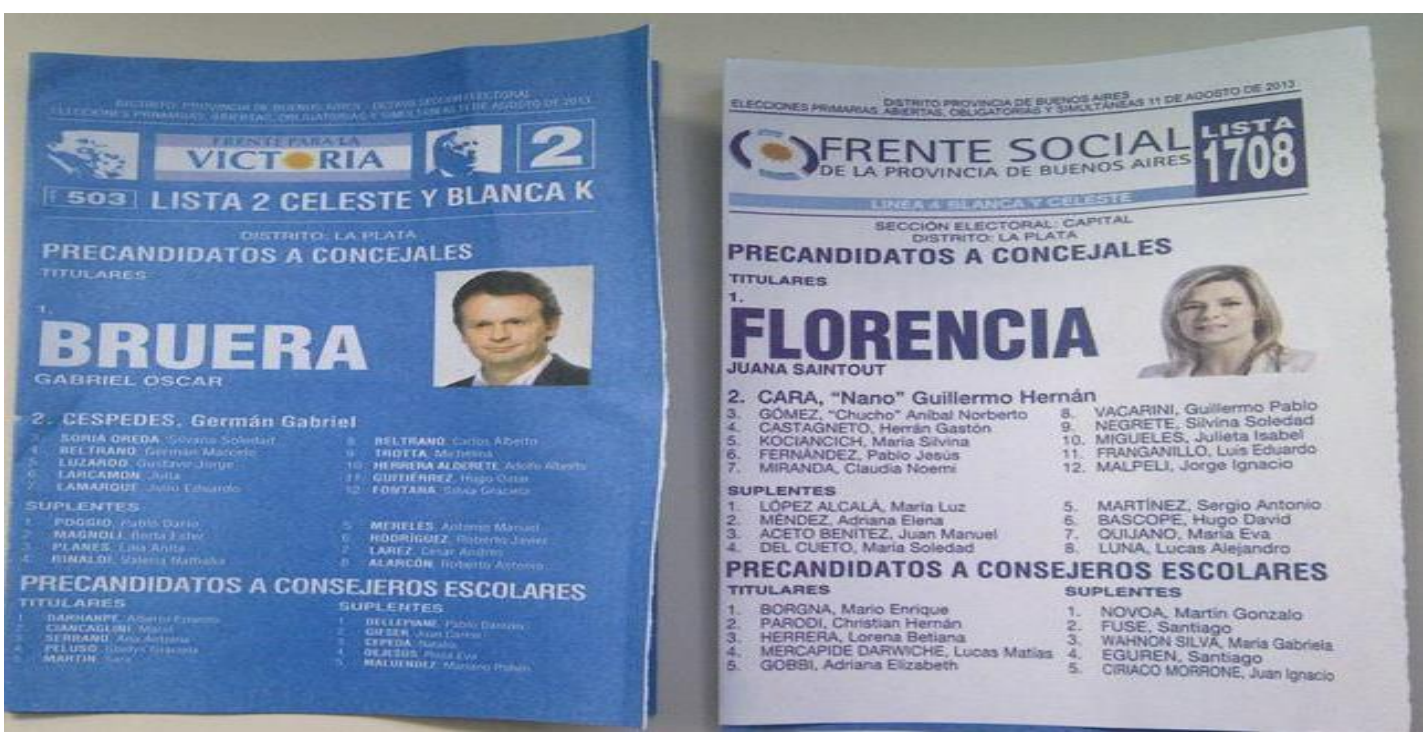

Fuente: imagen propia. Las boletas corresponden a las presentadas para las elecciones internas. De todas formas, debido a que ambas boletas pasaron sin problemas el umbral requerido, no sufrieron alteraciones en las elecciones generales.

Otro fenómeno de la campaña electoral de este espacio es que no contaron con la vinculación de Insaurralde -que, como ya se marcó, apoyó la candidatura del FRP-FPVpero si con otras figuras del gobierno nacional, como el Vicepresidente quién estuvo de caminata con los candidatos ${ }^{169}$. Esta situación, señalaba que aun en la debilidad en la que se encontraba el FRP-FPV mantenía la capacidad de establecer vínculos con sectores del PJ-FPV ${ }^{170}$ provincial que le permitían contar con la boleta oficial.

Más allá de los resultados electorales finales, para este polo de agrupaciones contar con una candidatura que busque acceder al gobierno municipal les significó un salto cualitativo. Al respecto un referente de La Cámpora sostenía:

"La gran diferencia con el 2011, es que dijimos -en el 2011- "che, pará, nosotros no somos lo mismo", te diría que también fue un resguardo de un patrimonio político cultural ir a elecciones. Pero la disputa por el poder y por la transformación de la idea de cómo interviene el municipio sobre la realidad de los vecinos y cuáles son las

\footnotetext{
${ }^{169}$ Resulta más que llamativo el que esta actividad, realizada el 30/07/2013 no llegó a los medios ni tuvo amplia difusión. Solo fue registrada por algunos portales y por la página de prensa del Movimiento Evita (https://movimiento-evita.org.ar/2013/07/30/amado-boudou-gustavo-tio-di-marzio-y-florenciasaintout-recorrieron-la-victoria-en-la-plata/ )

${ }^{170}$ Desde el punto de vista de los armadores provinciales del PJ-FPV, el apoyo se podría haber justificado en términos de cálculo electoral, pues aún en declive, el FRP-FPV era la única fuerza en la ciudad que había garantizado cierta cantidad de votos en elecciones anteriores.
} 
prioridades que tiene que tener un municipio peronista, nacional, popular, en el contexto actual; esa idea, arranca en el 2013." (Entrevista a Guillermo Cara, agosto 2015)

La relación entre contar con una figura que pretendía una proyección electoral y la "disputa por el poder" como se sostiene en la cita de la entrevista resulta interesante de observar, puesto que refiere a una voluntad de fortalecer el espacio local. Recordando la tensión entre el robustecimiento de la figura local y la dependencia del marco de alianzas (Freidenberg, 2003), en esta ocasión parecería haber primado un desplazamiento de un punto a otro, operado por la figura de la candidata. Ciertamente la Cámpora ocupó, nuevamente un lugar privilegiado en la lista de Concejales, solo que esta vez, a diferencia de la elección anterior, quién participó de este lugar provenía de una relación más cercana con la candidata ${ }^{171}$.

\subsection{Marco de alianzas}

La lista de candidatos a Concejales de este espacio se compuso de la siguiente forma:

\section{Listado de candidatos 6}

\begin{tabular}{|c|c|}
\hline \multicolumn{2}{|c|}{ Concejales de UyO La Plata } \\
\hline Nombre & Organización \\
\hline Florencia Saintout & La Walsh $^{172}$ \\
\hline Guillermo Cara & La Cámpora \\
\hline Aníbal Norberto Gómez & FAP \\
\hline Hernán Gastón Castagneto & Kolina \\
\hline María Silvina Konciancich & Movimiento Octubres \\
\hline Pablo Jesús Fernández & La Walsh \\
\hline
\end{tabular}

${ }^{171}$ Las internas de la agrupación la Cámpora en La Plata, exceden los marcos del presente trabajo. Sin embargo, resulta importante señalar que Nano Cara, provenía de un sector de la Cámpora que nació en el marco de la militancia universitaria.

172 En rigor, Saintout no presentaba una agrupación propia clara. La Walsh era la agrupación que ella comandaba al interior de la facultad de Periodismo de la UNLP. Se le asigna la misma en esta ocasión para diferenciar candidata del resto del marco de alianzas. Además, finalmente la Walsh terminó formando parte de la Cámpora de La Plata -aunque sin perder su autonomía. 
Como datos interesantes fueron las candidaturas de Silvina Soledad Negrete, en 9no. $\operatorname{lugar}^{173}$ y de Jorge Ignacio Malpeli en el puesto $12 \mathrm{avo}^{174}$.

El criterio utilizado, fue muy similar al del 2011, donde se intentó dar visibilidad a los diferentes grupos que pertenecían al marco de alianzas. Vuelve a resultar interesante el notar el fuerte posicionamiento del candidato de La Cámpora, que expresa, junto con la visible candidatura a diputado provincial que obtuviera el Movimiento Evita, la centralidad de la presencia de estas agrupaciones en este frente. Tanto la lista de Concejales como la de Diputados Provinciales se encuentran vinculadas en la distribución de los espacios para las organizaciones: de allí que en esta última los tres primeros lugares, los cuales eran los más expectantes de ingresar, estuvieran ocupados por quien se proponía como candidata para futuros comicios por parte de este polo organizacional $\mathrm{y}$, luego, dos de las tres agrupaciones más grandes o con mayor peso específico dentro del polo.

\subsection{Construcción identitaria particular}

La estrategia comunicacional de UyO presentó varias diferencias respecto de la observada tanto por el FRP-FPV como también por la que este mismo espacio desplegó 2 años antes. Estas diferencias provinieron tanto del amplio conocimiento de las estrategias comunicacionales -recordamos que la candidata provenía de la Facultad de Periodismocomo también de las necesidades de lograr construir una agenda propia.

Debe tenerse en cuenta que Florencia Saintout contaba como capital político cierto nivel de reconocimiento en el espacio de los votantes del FPV a nivel nacional, puesto que había sido parte del conjunto de actores que públicamente defendieron la denominada Ley Servicios de Comunicación Audiovisual, n²6.522, promulgada el 10 de Octubre de 2009. La sanción de esta norma implicó severos enfrentamientos con diferentes Holdings de comunicaciones ${ }^{175}$, que se extendió en el tiempo, hasta el final del mandato de Cristina

\footnotetext{
173 De la Juventud Sindical de la CGT platense.

${ }^{174}$ De la agrupación Vuelta de Obligado y pariente de Juan Malpeli que en 2007 fuera Concejal por el FRPFPV.

175 Para un análisis de la estructura de concentración de Medios de Información en la Argentina desde el retorno de la democracia y las acciones que desarrollo el gobierno Kirchnerista ver Becerra; 2015.
} 
Kirchner en 2015. Si bien desde la asunción en 2003, el kirchnerismo tuvo como rasgo distintivo la disputa por la mediación con los mass media (Vincent; 2011), la sanción de la ley implicó un debate nacional que incluyó a diferentes actores sociales. Entre ellos, la Decana de la Facultad de Periodismo de la UNLP, quien actuó como especialista en el tema.

Este recurso con el que contaba la ahora dirigente política, se tradujo en lo local en una discusión -y luego enfrentamiento- con el diario El Día, que fuera el medio de comunicación más importante de la región y también contara con cierta estructura monopólica -solo que a menor escala que los holdings nacionales-. Esta situación derivó en una estrategia comunicacional realizada por medio de redes sociales ${ }^{176}$ y despliegue barrial que sorpresivamente, presentó un nivel de éxito relativo ${ }^{177}$.

La interpelación también utilizó la noción de compromiso, sin embargo, en este caso se resaltó la idea de un compromiso social, la cual buscaba expresar una propuesta de gobierno centrada en atender a los sectores más carenciados que, además, estaba vinculada a la noción de conocimiento. Esta articulación que se basaba en su cargo de decana, buscaba dotar la figura de un know how de gobernabilidad institucional.

Un elemento de comparación en la forma de identificación con el FPV nacional que esta propuesta política tuvo a diferencia de la perteneciente al FRP-FPV, fue que tuvo mucha más presencia la figura de Cristina Kirchner (propaganda 10 y 11). Salvo en el caso de la propaganda 12, la cual claramente busca mejorar el conocimiento de la candidata, todas las demás imágenes de campaña funcionan con ese vínculo entre lo nacional y lo local. La denominación posible para este enmarcado discursivo sería el de un kirchnerismo local.

Incluso en términos discursivos - comunicado oficial por la página de Facebook- donde la candidata, en el lanzamiento de la campaña de dicho año, afirmó:

\section{"Los vecinalismos son expresiones de proyectos neoliberales disfrazados, que pretenden}

\footnotetext{
176 La decisión fue sostenida incluso hasta el 2016. En el aniversario número 125 de dicho diario, no se encuentran presentes en la lista de asistentes ninguno de los integrantes de este polo político -cuando si asistieron la gran mayoría del arco político platense- (fuente El Día, 01/03/2016).

177 Debe tenerse en cuenta que las campañas políticas en la ciudad, al menos desde el retorno de la democracia, encontraban en el diario El Día (el cual tiene más de 125 años de tirada) una plataforma de publicidad fundamental. Solo los partidos políticos con escasos recursos no publicitaban en dicho medio -e incluso a veces lograban colocar al menos una pauta-, lo que transforma la estrategia comunicacional de este agrupamiento en un caso para el estudio.
} 
pensar la política desde las fracciones, los localismos y las voluntades aisladas del pueblo. No hay Ciudad sin Patria, sino a costa de los que más sufren. Cuando los problemas habitacionales se transforman en oportunidades de negocios inmobiliarios no solamente perdemos el sol y el "buen vivir", sino que quedan las marcas profundas del dolor y la tragedia." 178

En este breve pasaje se puede observar cómo se comenzó a construir la agenda local: por un lado la denuncia del vecinalismo como expresión del neoliberalismo, parece expresar un diagnóstico de la realidad política nacional realizado por este sector, que se basa en la consideración de la existencia de una clausura de los fenómenos de territorialización de las preferencias electorales y con ello la propuesta de construcción de una agenda local vinculada a la dimensión nacional de forma más clara y directa.

En segundo lugar, la denuncia de los “negocios inmobiliarios" recupera la relación entre una mala gestión municipal y el fenómeno de la inundación (además de derivar los problemas de gestión en términos de efectos de un diagrama ideológico neoliberal ${ }^{179}$ ) adjudicando la responsabilidad al FRP-FPV. Por último es llamativo la no interpelación del espacio peronista no kirchnerista en la estrategia comunicacional de UyO. Sobre todo porque algunas de las agrupaciones -el caso del 3er candidato a Concejal- sostenían una importante vinculación en su historia con el mismo.

\footnotetext{
178 Fuente: Facebook/fsaintout. Disponible en: https://www.facebook.com/media/set/?set=a.142104535993641.1073741833.139492882921473\&type $=3$

${ }^{179}$ Más allá de lo que objetivamente se comprenda bajo el rótulo de neoliberalismo, como así también por la ideología nacional-popular del kirchnerismo, debe tenerse en cuenta que este último se construyó (aunque más no sea) discursivamente de manera confrontativa con el primero.
} 


\section{Propaganda 10}

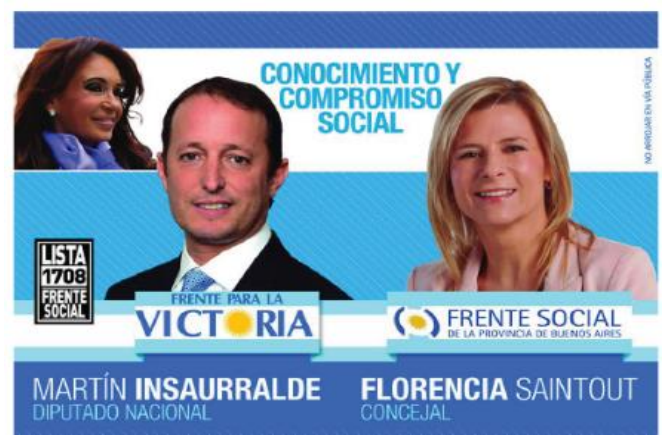

\section{Propaganda 11}

Fuente: facebook.com/fsaintout.

Disponible en:

https://www.facebook.com/media/s

et/?set=a.145186345685460.107374

$1835.139492882921473 \&$ type $=3$

Revisado el 1/02/2016.

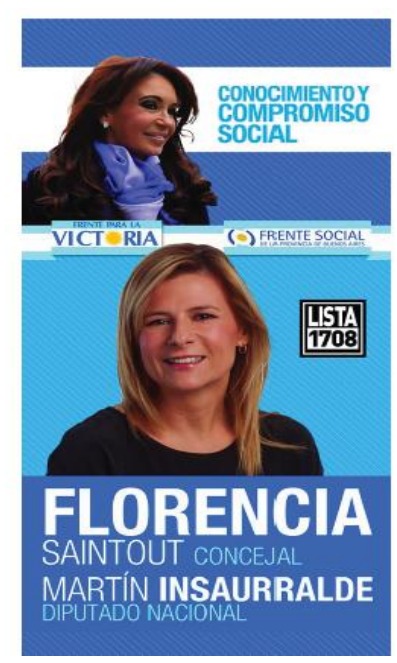

Fuente:

facebook.com/fsainto

ut.

Disponible en:

https://www.facebook.c om/fsaintout/photos/a. 145186345685460.1073 741835.1394928829214 73/145186782352083/? type=3\&theater

Revisado el

$13 / 02 / 2018$

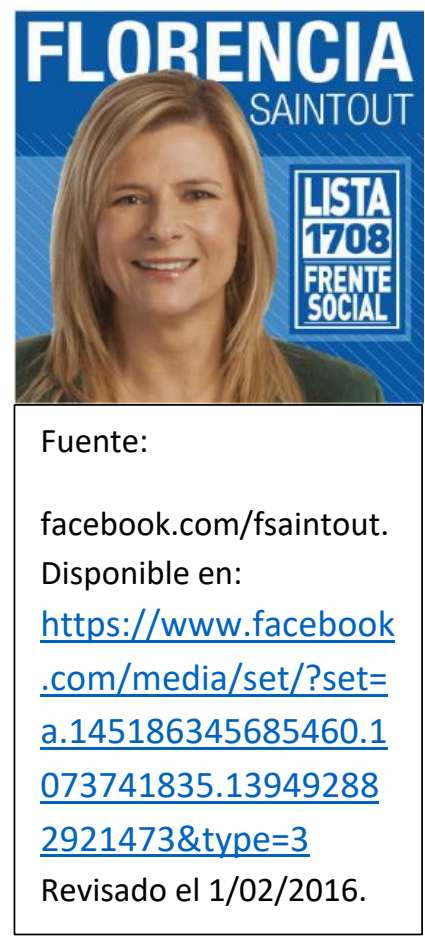




\section{Conclusiones}

La división del FPV platense en estos comicios, lejos de saldarse, tendió a fortalecerse. Si ya existían argumentos antes de la catástrofe de la inundación para que estos polos organizacionales tendieran a confrontar entre sí, las acciones y reacciones posteriores al hecho solo agudizaron esta separación. La imposibilidad del FRP-FPV de representar a los damnificados y al mismo tiempo la búsqueda de $\mathrm{UyO}$ de expresar sus demandas, terminó cristalizando una contradicción que excedía las discusiones internas organizativas del FPV. Además, desde una mirada global, y aun cuando el polo de UyO mantuvo un crecimiento de su performance electoral, el FPV platense paso de representar más de la mitad del electorado a solo un tercio. Cuanto de responsabilidad y que debió resolver cada polo de agrupamiento, quedará para un análisis posterior. La potencia del acontecimiento fue tal que marcó los procesos políticos locales subsiguientes, incluso cuando su mención dejó de ocupar un lugar significativo en los discursos públicos.

En segundo lugar, llama la atención que ninguno de los dos polos logró perforar de forma significativa el marco de alianzas del otro. Si bien el FRP-FPV se encontraba en una situación de mayor desventaja, pudo abrir el municipio para una negociación posible, y lo mismo corre en cuenta para el otro espacio. Sin embargo la consolidación de las relaciones internas parece indicar que ante un escenario de retracción los grupos tendieron a cerrarse sobre si mismos. Las dos boletas de candidatos a Concejales expresan esta situación de forma casi radiográfica.

Del mismo modo, las construcciones identitarias particulares que cada polo de agrupamientos construyó, fueron dicotómicas entre sí. Si bien se pudo observar cierto nivel de diálogo encubierto entre las estrategias comunicacionales de los dos espacios, el FRP-FPV siempre apostó a una forma de interpelación basada en elementos centralmente locales, con discursos que tenían diversos tipos de modulaciones desplazándose de lo que había construido en 2011 como un localismo nacionalizado, con visos de una intención plebiscitaria de la gestión, a una propuesta post-kirchnerista en 2013. Por su parte el polo de UyO trazo formas de interpelación bastante homogéneas de la elección anterior a esta, buscando el voto duro de la élite nacional en el distrito. Sus tipos de modulación del discurso fueron siempre verticales descendentes. En este marco vale resaltar el hecho de que hayan optado por formas de comunicación alternativas a los canales informales propios de la comunicación política local. 


\section{Capítulo 5: Las elecciones del 2015: Cierre del ciclo político y reconfiguraciones}

\section{Los múltiples escenarios ante las elecciones del 2015}

La derrota electoral del 2013 a nivel provincial, para el FPV, significó una dura advertencia al conjunto de actores que componían esta organización: aún con la elección de un candidato que era un Intendente de la zona conurbada de Buenos Aires ${ }^{180}$ y el involucramiento de las figuras del Gobernador y -en menor medida- de la entonces Presidenta en la campaña, la hipótesis de la transferencia de votos no prosperó. Con este antecedente, el panorama parecía indicar que el factor que primaría en la elección siguiente sería el de la dispersión del electorado. Teniendo en cuenta que eran dos los grandes espacios en el peronismo que habían quedado configurados a nivel nacional, el FPV se encaminaba a la renovación de su élite nacional en una situación de performance electoral decreciente que, además, estaba jaqueada por la posibilidad permanente de que los propios actores subnacionales no satisfechos, utilizaran el espacio ya consolidado del Frente Renovador como posibilidad de presión. Este juego multilateral podía significar, para la élite nacional en retirada, la disminución de su capacidad de definir los nombres de las listas legislativas aun cuando su imagen positiva (La Nación, 26/06/2015) estuviera fuerte en la opinión pública.

Con un escenario abierto varios grupos propusieron precandidatos para competir por el ejecutivo nacional ${ }^{181}$. Sin embargo tras poco tiempo de dichos anuncios ${ }^{182}$, terminaron quedando solo dos de forma más firme: por un lado Daniel Scioli, Gobernador de la Provincia de Buenos Aires y quién -como ya se señaló en el capítulo anterior- había expresado su intención de competir, dos años antes. Por otro lado Florencio Randazzo, Ministro de Interior y Transporte del gabinete nacional. Es interesante señalar el hecho de que ninguna de estas dos figuras contaba con una agrupación fuerte que sostuviera sus postulaciones. Mientras que el primero basaba su estrategia electoral en su buena imagen

\footnotetext{
${ }^{180}$ Esta situación no es un dato menor si se comprende que durante los años anteriores existió cierto nivel de reclamo público de los gobernantes municipales hacia la élite nacional del FPV, por impedirles que comanden el proceso electoral provincial.

${ }^{181}$ Entre ellos se encontraba Jorge Taiana en vinculación con el Movimiento Evita (Voces del Sur, la revista del Movimiento Evita; $n$ o 7, año 2015). Este dato resulta interesante puesto que en 2017 se produjo un reacomodamiento que implicó una ruptura de este vínculo.

182 Fue público el pedido de Cristina Kirchner para que hubiera un "baño de humildad" entre los precandidatos y que se bajaran de las postulaciones la mayoría de ellos (Página 12, 08/05/2015).
} 
positiva y un marco de alianzas con un sector del peronismo vinculado a un conjunto de Gobernadores e Intendentes de distritos populosos; Randazzo buscó posicionarse como el candidato progresista que trazaba alianzas con sectores del FPV renuentes aún a incorporarse a la estructura del PJ. Finalmente la disputa no llego a convertirse en internas, ya que adelantándose a los tiempos electorales, Daniel Scioli acordó una fórmula presidencial $^{183}$ y una lista de diputados nacionales con amplios lugares para sectores de organizaciones partícipes de Unidos y Organizados.

En la Provincia de Buenos Aires, el escenario no se despejó de forma tan sencilla. Si bien aquí también se "bajaron" varios pre-candidatos a gobernador ${ }^{184}$, finalmente el FPV presentó dos fórmulas: por un lado Aníbal Fernández y Martín Sabbatella -la cual fue la nómina victoriosa de las internas- que presentaba como estrategia electoral la búsqueda del voto progresista exhibiendo la alianza con sectores del FPV no PJ. Por el otro lado, la fórmula Julián Domínguez y Fernando Espinoza, apelaron a una estrategia de buscar el voto peronista tradicional de la provincia junto con un intento por capturar el voto de sectores rurales.

En el distrito de La Plata, tras dos elecciones de abiertas confrontación, los polos de agrupamientos en el que se dividía el campo del FPV local fueron a competir en las PASO. Si bien -como se verá más adelante- la idea de compartir una elección y una posterior unificación provenía más de la presión de sectores extra-distritales que de los incentivos locales, ambos espacios configuraron su participación pensando en el cierre de un ciclo político nacional. Así, mientras que el FRP-FPV tenía como objetivo propio retener el gobierno municipal considerando que el recambio de élites nacionales les permitiría una nueva reinserción en el peronismo provincial; el espacio de UyO pretendía dar el salto definitivo que le permitiera ganar la referencia distrital del espacio peronista y con ello acercarse a ganar la intendencia, intentando asegurar la supervivencia en los años subsiguientes de una agenda política vinculada a la figura de la élite nacional saliente.

\footnotetext{
183 Propuso llevar de Vicepresidente al Secretario de Legal y Técnica de Nación, Carlos Zanini, quien fuera del riñón de la élite nacional desde sus orígenes en el grupo Calafate.

${ }^{184}$ Hubo en la Provincia al menos 4 referentes del peronismo que pretendían ir como candidatos (TELAM, 21/03/2015).
} 


\subsection{Resultados electorales}

A diferencia de los dos comicios anteriormente revisados, los resultados electorales del 2015 tuvieron un interés especial en el hecho de que ambos polos de agregación fueron a una elección interna. Teniendo en cuenta que a nivel nacional y provincial el FPV en este año tuvo una baja performance, los resultados globales deben leerse en dicho contexto. De todas formas y aún sin una candidatura extra distrital que lograra traccionar votos, el global de ambas listas mostró que parecía haberse alcanzado un techo en la captura de votos por parte del FPV en la ciudad.

Tabla 3 resultados electorales La

\begin{tabular}{|c|c|c|c|c|c|}
\hline \multirow[b]{2}{*}{ Fuerza } & \multicolumn{2}{|c|}{ Paso } & & \multicolumn{2}{|c|}{ Generales } \\
\hline & Votos totales & Porcentaje & & Votos totales & Porcentaje \\
\hline CAMBIEMOS BUENOS AIRES & 128223 & 33,43 & & 170.369 & 41,64 \\
\hline \multicolumn{3}{|l|}{ FRENTE PARA LA VICTORIA } & \multirow{3}{*}{33,22} & \multirow{3}{*}{115.333} & \multirow{3}{*}{28,19} \\
\hline FRP-FPV & 70187 & 55,08 & & & \\
\hline UyO & 57237 & 44,92 & & & \\
\hline UNIDOS POR UNA NUEVA & & & & & \\
\hline ALTERNATIVA (UNA) & 68155 & 17,77 & & 65.379 & 15,98 \\
\hline FIT & 16742 & 4,37 & & 23.158 & 5,66 \\
\hline PROGRESISTAS & 21282 & 5,55 & & 19.577 & 4,78 \\
\hline \begin{tabular}{|l|} 
PATRIA GRANDE \\
\end{tabular} & 7999 & 2,09 & & 15.376 & 3,76 \\
\hline FRENTE POPULAR & 2990 & 0,78 & & - & - \\
\hline COMPROMISO FEDERAL & 2531 & 0,66 & & - & - \\
\hline UNION DEL PUEBLO LA PLATA (U.D.P) & 2323 & 0,61 & & - & - \\
\hline MOVIMIENTO AL SOCIALISMO & 2173 & 0,57 & & - & - \\
\hline MST & 2028 & 0,53 & & - & - \\
\hline TODOS POR BUENOS AIRES & 954 & 0,25 & & - & - \\
\hline PARTIDO POPULAR & 696 & 0,18 & & - & - \\
\hline $\begin{array}{l}\text { Total de Votos / porcentaje sobre } \\
\text { el padrón total }\end{array}$ & 414600 & 75,03 & & 441.813 & 79,99 \\
\hline
\end{tabular}

Por el lado del FRP-FPV -ver tabla 3- se habían estabilizado en los 70 mil votos, creciendo apenas en 7 mil votos respecto de los dos años anteriores -algo que podría traducirse como una meseta. Muy diferente es el caso de UyO que creció en casi 19 mil votos. Aun cuando esta cifra no le alcanzó para superar a su adversario, mostró que la tendencia -quizás algo desacelerada- seguí siendo positiva. Un dato importante es que, como se puede observar, tras las PASO la fuga de votos fue poco significativa-casi 12 mil votos- respecto a la modulación de la oposición que ambos espacios venían sosteniendo. Por último, también es muy significativo a cifra que alcanzó la fórmula 
CAMBIEMOS en el distrito -algo que pocas veces se había observado- capturando entre otros, los votos que dos años antes había optado por la fórmula de Massa.

\section{Actuación del FRP-FPV ante las primarias del 2015}

La situación de debilidad en la que se encontraba el FRP-FPV, observada en torno a las elecciones del 2013, lejos de subsanarse tras dos años de la catástrofe, se mantuvo. Sumado a esto, un conjunto de acusaciones de corrupción que salieron a la luz en 2014 parecían jaquear la posibilidad de volver a reconstruir una vinculación con sectores del electorado en términos de una propuesta política progresista ${ }^{185}$. En este punto, ya sin las aspiraciones -al menos transitoriamente- de protagonizar un armado provincial, los objetivos a los que podía aspirar este conglomerado de agrupaciones locales, consistían en ganar las internas y mantenerse en el gobierno municipal a la espera de que se produjera el necesario evento de recambio de cuadros del FPV a nivel nacional.

Ciertamente el panorama a largo plazo, de conseguir mantener la hegemonía de la arena municipal, no era desalentador. Las relaciones que el FRP-FPV mantenía con la figura de Daniel Scioli y con un conjunto de Intendentes peronistas del conurbano bonaerense, les permitía suponer que, de ganar las elecciones -en todos los niveles- los años venideros serían la apertura de un nuevo ciclo en el que contaran con mejores vínculos para el desarrollo de políticas para el distrito. De esta manera el FRP-FPV se recostó activamente en una modulación de la identidad peronista de la provincia de Buenos Aires que buscaba exhibirse como la garantía de gobernabilidad: "Este es el peronismo [bonaerense] que da estabilidad a toda la República Argentina" "186. En consonancia con este desplazamiento identitario, durante la campaña de las PASO -pero también de cara a las elecciones de Octubre- se buscó saturar el espacio delegativo ${ }^{187}$ local del candidato a Presidente del FPV. Ciertamente la estrategia electoral de Scioli incluía recostarse en La Plata sobre la

\footnotetext{
${ }^{185}$ La acusación de un "pedido de coimas para la habilitación de un loteo de tierras" que involucraba a Mariano Bruera, el tercero de los hermanos, llegó a los medios nacionales (Perfil, 16/07/2014) y tuvo repercusiones hasta el 2017 inclusive. El punto esencial, para el argumento que aquí se sostiene, es que se trató de una situación que involucraba a sectores de clase media platense que participaban del programa nacional ProCreAR, el cual buscaba -desde nación- ser un punto de recuperación del diálogo entre el FPV y las clases medias argentinas.

${ }^{186}$ Discurso de Pablo Bruera en la apertura del VII Encuentro de Reflexión y Debate del PJ de la Provincia de Bs. As. 30-11-2014 (disponible en https://www.youtube.com/watch?v= t7uceTdass ).

187 Utilizamos esta noción para dar cuenta de la existencia del recurso político de intentar capturar el voto fiel que una élite nacional o provincial tiene en un distrito local.
} 
figura de Bruera, quién, aún en su ciclo electoral descendente, mantenía el mayor caudal de votos en la ciudad. De esta forma, ambos candidatos compartieron varios actos y una campaña gráfica -ver propaganda 13- que se sumaba a la acción comunicacional local del FRP-FPV. Las escasas menciones a la figura del Cristina Kirchner en todo este proceso, teniendo en cuenta la centralidad que esta figura tenía en el discurso del otro polo de agrupaciones, bien podría suponerse que se basó en una especulación "ganadora": por la cual, si ganaban las PASO, los votos de dicho espacio irían necesariamente a aumentar su propia performance. Un poco de esta lectura puede apreciarse en el contrapunto que ambos polos organizacionales protagonizaron en torno a la noción de "proyecto" en sus estrategias comunicacionales.

\section{Propaganda 13}

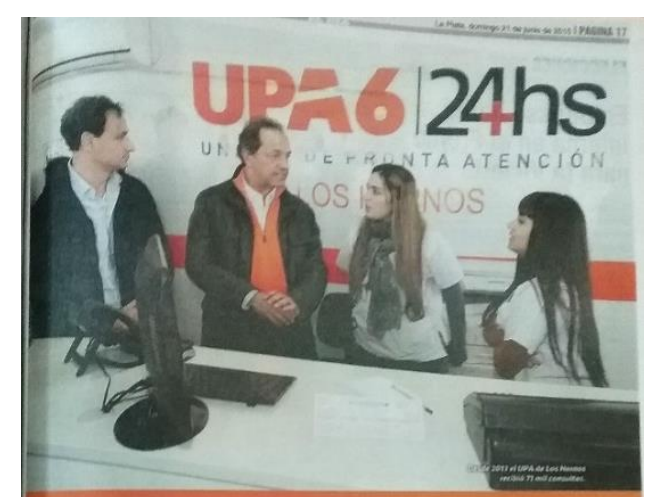

NUEVOS HOSPITALES

INTERMEDIOS

UPA/24hs

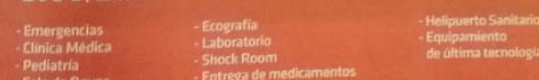

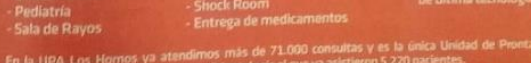

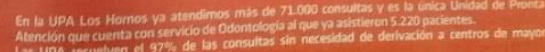

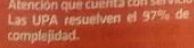

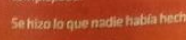

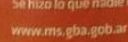

Q8 lateriade aproincia

Fuente: El Día, 21/06/2015, pág.

17.
Cabe resaltar la escasa gravitación que tuvieron las internas provinciales del FPV durante la campaña de las PASO. Teniendo en cuenta como las dos fórmulas provinciales habían modulado sus configuraciones identitarias particulares, donde una presentaba una apelación al peronismo clásico y otra a un progresismo más kirchnerista ${ }^{188}$, este armado local podría haber apostado a uno de los dos sectores sin que ello le resultara en un conflicto identitario. Sin embargo, la ausencia de referencias explícitas más que una inacción puede comprenderse como una decisión deliberada: el FRP-FPV buscó capturar votos de ambas fórmulas construyendo una prescindencia de la disputa provincial.

\footnotetext{
188 Entendiendo por esto la inclusión de sectores políticos no provenientes de la tradición peronista.
} 


\subsection{Estrategia electoral}

La estrategia electoral que desplegó el FRP-FPV estuvo centrada en fortalecer la figura del entonces Intendente y candidato Pablo Bruera. Pasados los comicios del 2013 y la rotunda baja en la captura de votos, la renovada apuesta a su figura pareció responder más a una debilidad del entramado local que a una situación de avanzada. Entre las ventajas que presentaba esta postulación estaban sin dudas las de ser el punto de acumulación más conocido del FRP-FPV y la garantía para un conjunto de grupos, de que se mantuvieran las posiciones estratégicas que habían obtenido en años anteriores. Ya sin el halo de ser una figura novedosa para el electorado, la estructuración del perfil público del candidato buscó trazarse sobre un vínculo de confianza en la gestión. Sin embargo, este desplazamiento no resultaba tan sencillo debida cuenta que el impulso de ser la renovación de la política local, que había marcado su perfil en sus inicios, encontraba en esta búsqueda de un tercer mandato un cierto agotamiento a diferentes niveles. Algo similar ocurrió con muchos otros referentes distritales que habían logrado estructurar formas de intervención política durante el ciclo de gobierno post 2003. Siguiendo el análisis de Lenarduzzi, la cuestión del ethos de la renovación en este período estuvo dada por una serie articulaciones discursivas que le permitían a los candidatos establecer un perfil de cercanía con sus votantes: "La crisis - como parte de la enunciación del discurso de los líderes- es el terreno sobre el que se postula el discurso de la "renovación”, que plantea la restauración del vínculo representativo fracturado por responsabilidad de la “clase politica” desvinculada de su base de sustento." (2012a: 53). Este tipo de discurso, además de permitirles repensar la legitimidad del sistema democrático en base a una noción de proximidad, se complementaba con un giro discursivo por el cual se podía enunciar la renovación desde el poder (2012b: 158) definiendo como antagonista a aquellos referentes que fueron parte de la "vieja política"189. El perfil que traía Pablo Bruera como candidato ${ }^{190}$ hasta estos comicios se basaba en esa cercanía como también

\footnotetext{
${ }^{189}$ Asociada a los referentes políticos que encarnaron el "modelo neoliberal" que terminó en la crisis del 2001. De ahí que la tensión entre vieja y nueva política estuviera dada por el problema de la gobernabilidad: "En un contexto de cuasi ingobernabilidad, lo nuevo era la única alternativa para gobernar, por lo que la tensión se reconvirtió y se pasó a asociar lo "nuevo" a la capacidad de gobierno, porque todo otro poder se encontraba deslegitimado. " (Lenarduzzi, 2012b: 164)

${ }^{190}$ Ver Cap. 3 apartado 3 de la presente tesis.
} 
en la disputa con la figura del anterior Intendente -también peronista- como parte de aquello que debía ser superado:

Pablo había logrado una relación con el vecino casi, si no era familiar, casi te diría de una persona conocida del barrio, querida, de mucha cercanía. Y casi de empatía, de ponerse en el lugar del otro. Tanto de Pablo con el vecino, como del vecino con Pablo. (Entrevista a Gabriel Bruera, junio de 2017)

El punto central de este "cierto agotamiento" del lugar de enunciación de la renovación se expresaba tanto en la mal administrada "nueva crisis" que constituyó la inundación del 2013, y con ello cierto distanciamiento entre la figura de la representación y las bases; como también, y quizás con mayor importancia, la imposibilidad de encontrar un antagonista político que ocupara el lugar de la vieja política. Esto tanto porque los partidos no peronistas no contaban con candidatos que hubieran ocupado cargos ejecutivos anteriormente, así como porque su oposición interna, la que resultaba de la lista de $\mathrm{UyO}$, lo caracterizaba a él en dicho lugar. Cercado entonces desde dentro y desde fuera, el nuevo perfil que le quedaba para adoptar al candidato, vinculado a un peronismo más de tipo clásico, le resultaba un poco forzado. De aquí que la tarea que se dio en esta campaña fue la de buscar puntos de síntesis y contención de aquellos sectores peronistas que durante sus gestiones anteriores habían quedado raleados del centro del poder local. La figura de Bruera estructuro una intervención de campaña sumando apoyos de sectores gremiales y de algunos actores locales que habían sido parte de la "mesa de Randazzo" en La Plata191 (El Día, 10/07/2015), mientras que se mantenía distante de la tensión que levantaba la interna para gobernador entre las dos fórmulas del FPV. Finalmente para el cierre de campaña, lograron contar con la presencia de los tres candidatos -Scioli, Fernández y Domínguez- (El Día 03/08/2015) un gesto de intentar consolidar el armado local.

\subsection{Marco de alianzas}

Al igual que en las elecciones del 2011, el FRP-FPV presentó una nómina propia de candidatos a Senadores Provinciales buscando apropiarse de la capacidad de decisión sobre dicha categoría de la boleta (El Día, 22/06/2015). Como se observó en relación a

\footnotetext{
${ }^{191}$ Si bien la misma no contaba con grupos de gran despliegue territorial -lo cual cambiará hacia el 2017durante este año, la importancia estaba dada por la posibilidad de obtener apoyos locales de sectores críticos. Esta estrategia se focalizaba así en intentar recuperar cierto espíritu de pluralidad política.
} 
todos los procesos electorales anteriores, esta acción también servía para intentar bloquear las candidaturas del otro polo de organizaciones frente a la decisión de la élite nacional. Sin embargo en esta ocasión el resultado fue que la misma no solo no prosperó, sino que tampoco sirvió para poder negociar alguno de los tres lugares en juego. El argumento público “en "pos de la unidad” (El Día 25/07/2015) apareció días más tarde intentando contener sectores internos que habían quedado fuera de competencia.

\section{Listado de candidatos 7}

\begin{tabular}{|c|c|}
\hline \multicolumn{2}{|c|}{ Senadores de FRP-FPV La Plata } \\
\hline Nombre & Organización \\
\hline Gabriel Bruera & Frente Renovador Platense \\
\hline Omar Alegre & SITRAMEN (Sindicato de trabajadores \\
& Agrupación Evita \\
\hline Silvana Soria & \\
\hline
\end{tabular}

La lista de Concejales en esta ocasión buscó asegurar la reelección de un conjunto referentes que ya componían el bloque del FRP-FPV. Si se observa de manera articulada los dos listados -listado 7 y 8 - se observa que este espacio apostó sus cuadros con mayor trayectoria y peso político a la -fallida- lista de Senadores mientras que apostó a consolidar el espacio legislativo local sobre la experiencia de cuadros que ya contaban con algún mandato a cuestas. En términos generales, esta estrategia no resultaba tan extraña si se atiende al hecho de que en primer lugar, tanto Gabriel Bruera, como Silvana Soria ya ocupaban una banca en el Concejo por la elección del 2013, lo cual le daba margen para probar suerte en una candidatura de mayor trascendencia. 
Listado de candidatos 8

\begin{tabular}{|c|c|}
\hline \multicolumn{2}{|c|}{ Concejales del FRP-FPV La Plata } \\
\hline Nombre & Organización \\
\hline Pedro Borgini & ATSA - Asociación de Trabajadores de \\
& Sanidad $^{192}$ Crecer \\
\hline Fabian Lugli & Agrupación Evita $^{193}$ \\
\hline Lorena Riesgo & FRP \\
\hline Mauricio Castro & FATERYH -trabajadores de edificios- \\
\hline Juan Lotúmulo & Apóstoles de Perón ${ }^{194}$ \\
\hline Sabrina Rodríguez & \\
\hline
\end{tabular}

Además de los acuerdos reflejados en los candidatos a Concejal, el FRP-FPV logró explicitar acuerdos con otros grupos peronistas de la región. Un caso interesante de esto fue el del Frente de Unidad Peronista -ver solicitada 4- puesto que en el mismo aparecen grupos como el Ateneo Eva Perón, con su referente Prandini- que fue parte del marco de alianzas del PJ anterior a la victoria del FRP en 2007. También en este espacio, apareció el grupo J.W. Cooke, que en 2011 había participado del marco de alianzas de UyO llevando una candidata a Concejal. El hecho de que dicha solicitada recuperase el nombre de la élite nacional saliente del FPV, abona a la idea de una estrategia de construcción de síntesis entre los grupos dispersos y anteriormente enfrentados. En este sentido, nuevamente la no aparición de la interna provincial entre las dos listas del FPV, parece remitir a no construir dicotomías internas.

\footnotetext{
192 Borgini llevaba ya 4 años como Concejal del FRP y, además, ese mismo año había asumido como Presidente del Concejo Deliberante.

193 Recordamos que esta agrupación correspondía a un armado territorial de un barrio platense -ver cap. 3- aunque para esta ocasión Lugli ya llevaba un mandato encima de Concejal.

${ }^{194}$ Es interesante el caso de esta candidata, puesto que en 2012 había anunciado su ruptura con el FRPFPV (El Día, 24/04/2012) y su incorporación al Movimiento Evita (Diagonales, 05/06/2012) que era parte del otro polo de agrupaciones de La Plata. Finalmente parece que estos desplazamientos no prosperaron y la misma volvió a ser candidata por este marco de alianzas.
} 


\section{Solicitada 4}

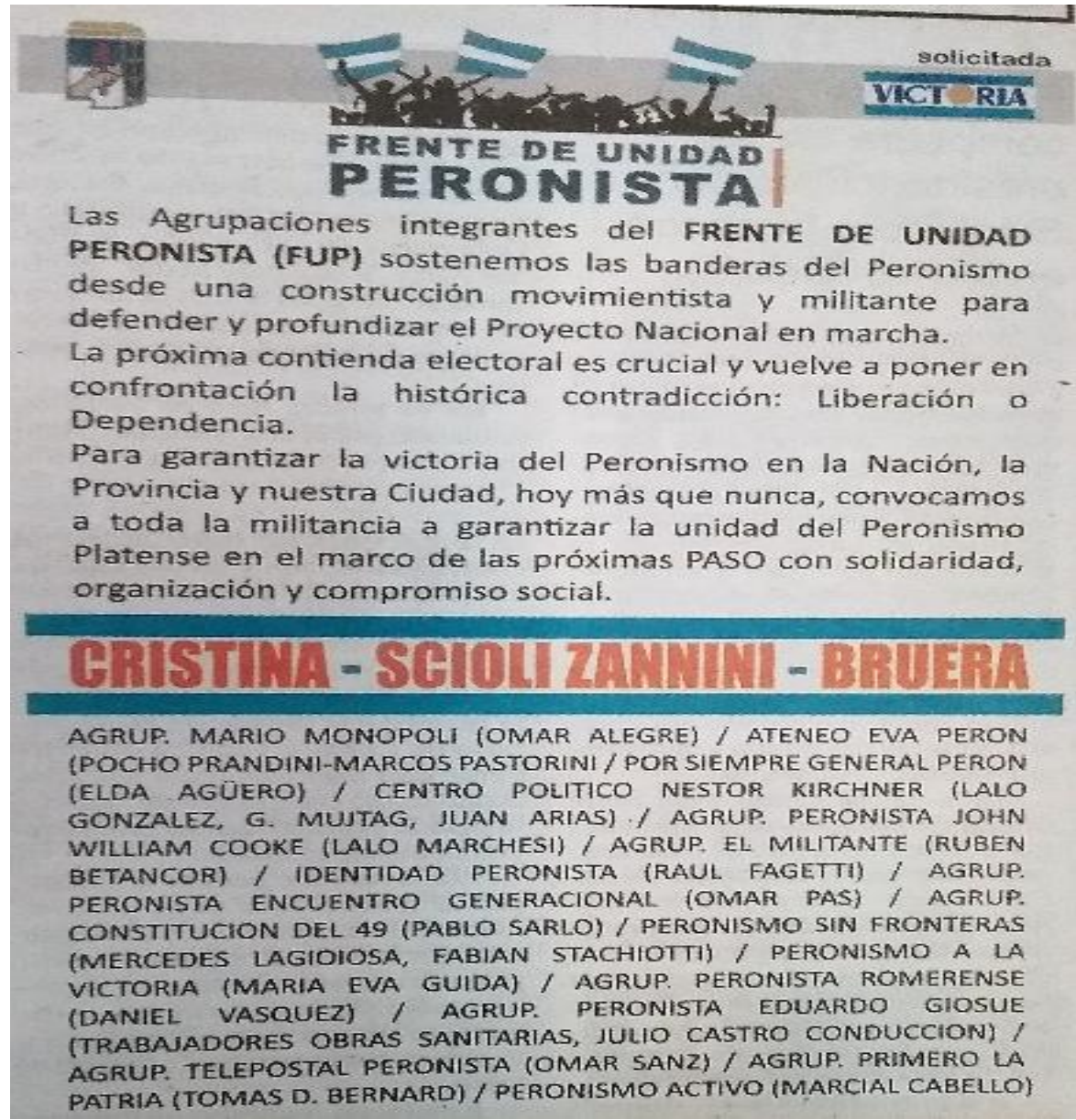

Fuente: El Día, 19/06/2015, pág. 5.

2.3 Construcción identitaria particular

Para estas elecciones la estrategia comunicacional del FRP/FPV buscaba reconstruir una agenda vecinal en el marco de un proyecto nacional. En este sentido, la posibilidad de imponerse electoralmente estaba circunscripta a una eventual superación del recuerdo de la inundación y para eso, se apostó a un tipo de interpelación que le era familiar a esta agrupación: intentar construir un perfil público de "cercanía" con los vecinos del municipio (ver propaganda 14) acentuando la idea de un conocimiento cabal de las demandas sociales existentes en el territorio.

Además, el hecho de que finalmente haya sido Scioli el candidato nacional le permitía a 
esta estrategia comunicacional desplazar el conflicto existente con la élite nacional del FPV y recostarse sobre esa figura (ver propaganda 15) esperando saldar sus propios déficit de competitividad. En este sentido se podría hablar de un enmarcado discursivo de tipo postkirchnerista como unidad de sentido de la campaña.

Un elemento importante de esta campaña fue la noción de "proyecto" como eje articulador del discurso. Si bien, como se verá, nuevamente hubo un diálogo con la lista de UyO en torno al contenido semántico de dicha palabra, en el caso del FRP/FPV esta noción se vinculaba con el ejercicio municipal de gestión y su permeabilidad sobre el tejido social: el proyecto en este caso, refería a la ampliación de beneficios obtenidos por la comunidad (ver propaganda 16) gracias a la participación del estado municipal en sus actividades cotidianas. Además, la noción de que sea "compartido" dejaba entrever -en la hipótesis del contrapunto- una posible acusación al polo opositor de UyO de cierta decisión para no articular. 

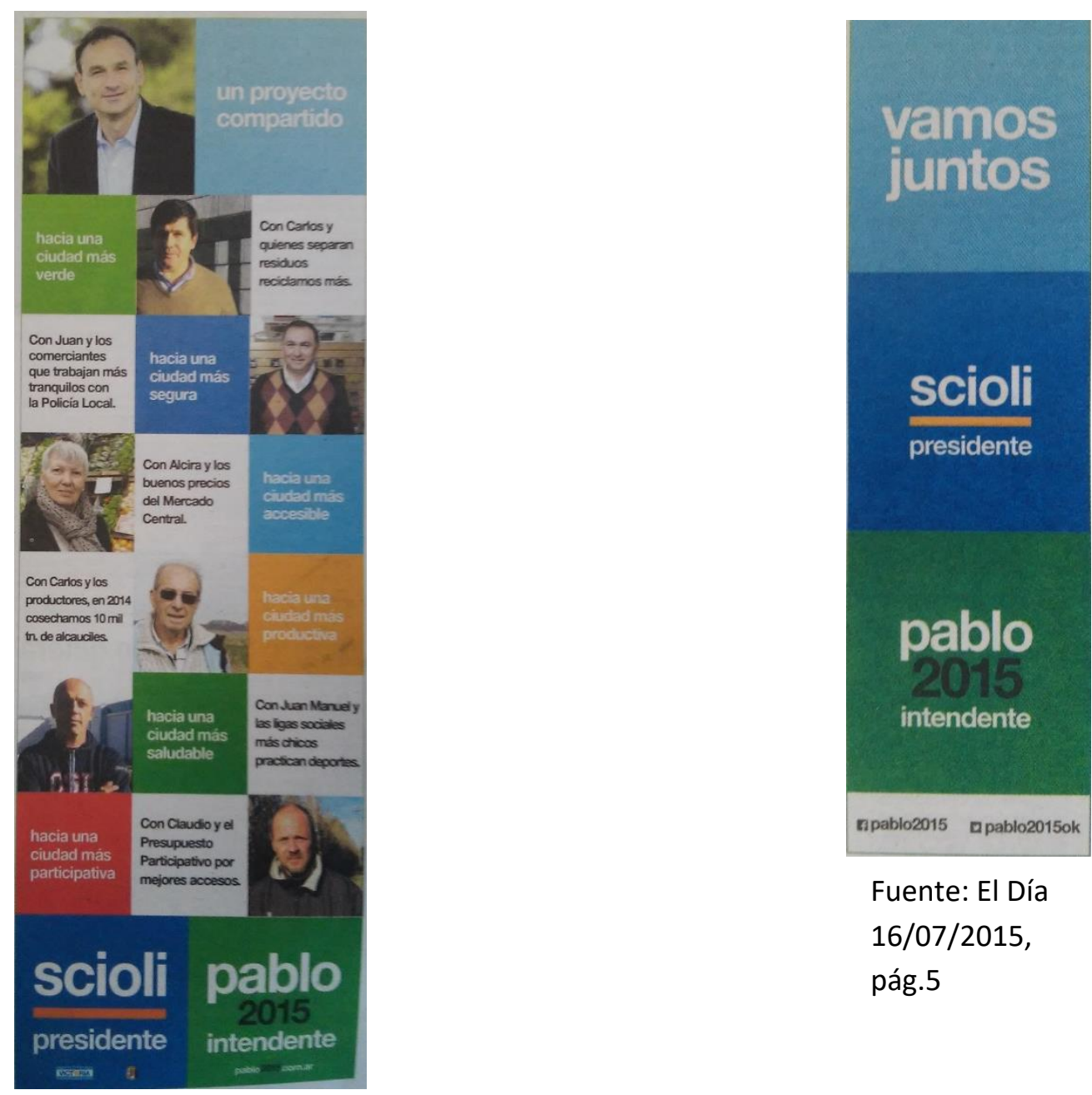

Fuente: El Día 16/07/2015, pág.5

Fuente: El Día

07/08/2015 pág.3.

\section{Propaganda 16}

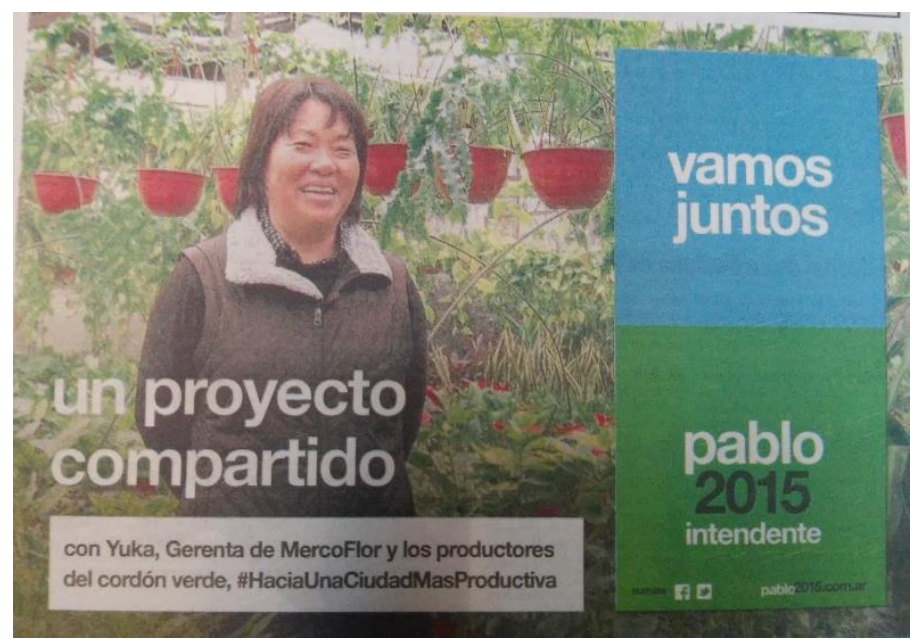

Fuente: El Día 13/07/2015 pág. 5. 


\section{Actuación de UyO ante las primarias del 2015}

La lista de UyO presentaba para las elecciones una situación diferente: debido a la buena performance la elección del 2013, gracias a la cual habían ingresado los dos primeros concejales de la nómina, se encontraban en una mejor posición comparativamente al $2011^{195}$, para afrontar la primera elección ejecutiva municipal de su candidata. Como contracara de esta situación de fortaleza, el escaso crecimiento de agrupaciones que presentó este espacio en relación a las elecciones anteriores expresaba cierto aletargamiento en la proyección electoral.

Dejar de lado la estrategia de externalización y apostar a jugar una interna resultaba por lo menos riesgoso en términos de costos-beneficios. Teniendo en cuenta que, tras dos período electorales, habían dado muestras de que eran capaces de traspasar el mínimo requerido para ingresar al Concejo Deliberante, como también el hecho de que según la carta orgánica del $\mathrm{PJ}^{196}$, si perdieran las elecciones -alcanzando la minoría como era esperable- les correspondería solo un Concejal en vez de dos posibles, ir por adentro parecía un mal negocio. Sin embargo, a diferencia de las elecciones anteriores, en esta ocasión lo que estaba en juego era el recambio de la élite nacional y provincial en el marco de una escasa confianza sobre la hipótesis de la trasferencia de votos y la situación de un escenario complejo, lo que podría devenir, si fuera el caso de una derrota electoral -que terminó ocurriendo de todos modos- en una acusación de haber sido los causantes de la misma. De esta manera, el costo político de ir por fuera podría haber sido muy superior al de perder en las PASO.

Respecto a los vínculos extra/municipales cabe decir que resultaban un tanto paradójicos: mientras que no había una relación consolidada con el candidato nacional -como si lo tenía el FRP-FPV- en términos del conjunto del polo organizativo, las agrupaciones que

\footnotetext{
195 Nos referimos a la candidatura de Carlotto. Si bien ambas elecciones son difícilmente comparables entre ellas porque no se trató del mismo proceso de construcción de una referencia pública- los militantes de las agrupaciones que habían protagonizado una y otra elección realizaban esta lectura.

196 “Art. 73 : En las elecciones internas para cargos partidarios corresponderá el 75 \% de los cargos a la lista más votada y el $25 \%$ restante a la que sigue en número de votos siempre y cuando supere el $25 \%$ de los votos válidos emitidos. La integración de la minoría se producirá en los últimos lugares de la categoría de candidatos de que se trate. Para los candidatos a los cargos electivos la minoría se incorporará en iguales condiciones que para los cargos partidarios, se integrarán intercalándose en los lugares 4우, 8우, 12은 y subsiguientes en igual relación, produciéndose el corrimiento al puesto inmediato inferior de los candidatos de la lista más votada." Disponible en: http://www.pjbonaerense.org.ar/carta-organica/
} 
componían el espacio, principalmente las de mayor volumen como La Cámpora y el Movimiento Evita, si presentaban vinculaciones y apoyos explícitos (E1 Día, 03/07/2015) a nivel nacional. Es posible que esta ausencia de vínculo haya estado dada por algún bloqueo que el FRP-FPV exigiera o por la actuación de Scioli en el marco de las inundaciones en 2013. Sea como fuere, el no-enlace fue notable. En relación con los precandidatos a gobernador, tampoco hubo una presencia marcada de los mismos en el marco de la campaña de este polo. Si bien se especuló con la posibilidad de que este polo estuviera apoyando en mayor medida la candidatura de Fernández ${ }^{197}$, no existen pruebas empíricas para sustentar dicha afirmación. Así, salvo las relaciones con sectores muy puntuales del FPV nacional y provincial ${ }^{198}$, este polo transitaba en paralelo los vínculos con el resto del peronismo.

\subsection{Estrategia electoral}

La estrategia electoral que se dio este espacio de cara a las PASO fue de continuidad con lo realizado en 2013. La apuesta central siguió siendo consolidar el voto duro a la élite nacional de ese momento, mantener la oposición interna dura con el Intendente ${ }^{199}$, apuntalar la acción militante callejera y en redes sociales -puesto que mantuvieron el enfrentamiento con el diario El Día- y sostener el perfil progresista en el discurso político $^{200}$.

Siendo esta la segunda vez que Saintout encabezaba el proceso electoral de este espacio, el conjunto de las acciones de campaña estuvieron puestas en consolidar la imagen de la candidata tanto para ese momento como para los años subsiguientes. La posibilidad de

\footnotetext{
${ }^{197}$ Hubo un acto en conjunto con la fórmula Fernández Sabbatella (https://www.facebook.com/pg/fsaintout/photos/?tab=album\&album id=418274471709978 ) y no así con la de Domínguez Espinoza.

198 En una cena que se realizó el 21-05 de dicho año y en la que se lanzó la candidatura de Saintout estuvieron presentes los Diputados Nacionales: Horacio Pietragalla, Carlos Raimundi y Gastón Hasrípe; el Titular de la Unidad de Información Financiera -nacional- José Sbatella; el Secretario Nacional de Vivienda Rubén Pascolini, los Senadores Provinciales Emilio Mountaner y Gustavo Oliva, y mandaron adhesiones el Secretario de Justicia Julio Alak y el Diputado Nacional Mario Oporto. http://www.diariocontexto.com.ar/2015/05/21/el-kirchnerismo-platense-unido-y-con-candidata/

${ }^{199}$ En un cierre de actividad en Tolosa sostuvo "Mientras otros hacen campaña sin poner el apellido, pero no es solo eso, sin poder poner la foto de Cristina" en referencia a la propaganda de Bruera que acentuaba el nombre Pablo. Disponible en: https://www.youtube.com/watch? $\mathrm{v}=\mathrm{dUj} 6 \mathrm{cpmAhXQ}$

200 Una de las actividades de campaña fue una caminata con el candidato a Vice Gobernador, Martín Sabbatella. Disponible en: https://www.youtube.com/watch?v=auAAk63wH8A
} 
que su figura representara una tendencia electoral creciente, estaba puesta en la necesidad de superar los propios resultados del 2013. De alcanzar esas metas -aun perdiendo la elección de agosto- al espacio se le abriría una opción firme de disputar la referencia local del peronismo. Al respecto un referente del espacio sostenía:

"Por eso decía, esta última interna es muy positiva porque habilita, es una realidad contundente. Primero, es una elección que, por lo menos en término electorales creo que el bruerismo decidió no perder y a nosotros nos faltó un poco para ganar ¿no? Ahora, eso ¿a qué habilita? a que lo nuevo en la política y lo nuevo en el peronismo somos nosotros. La segunda fuerza política más votada de la ciudad es Florencia y para el peronismo somos ese otro 50\%, digamos. [...] Fue, el aparato municipal, expresado en el bruerismo, porque ellos pretenden ser bruerismo como identidad política y ahi es donde está su debilidad política, y el kirchnerismo." (Entrevista a Iván Maidana, agosto 2015)

Siguiendo el trazo de esta lectura política, por tanto, la construcción de un escenario victorioso para este espacio estaba puesto más en su propia trayectoria que únicamente en la victoria sobre el espacio del FRP-FPV. Es de comprender que esta interpretación de la estrategia electoral resulte un tanto compleja en cuanto que el supuesto clásico de interpretación de las acciones electorales es siempre el de "buscar ganar". Sin embargo a nivel local, y teniendo en cuenta la declaración arriba citada, es posible sostener que los actores construyen estrategias múltiples donde ganar no constituye el único objetivo. Si se observa que las interpretaciones de los eventos electorales se enmarcan, para los actores, en procesos más extensos, entonces es posible establecer que en ocasiones la posibilidad de participar de una elección bajo el objetivo de quedar "mejor posicionados" para otra ocasión se consolida como supuesto explicativo de la acción.

\subsection{Marco de alianzas}

En el cierre de presentación de candidatos, el espacio de UyO presentó una nómina para el Senado Provincial que, finalmente y con la decisión del FRP-FPV de bajar la que ellos habían presentado, terminó primando como categoría de unidad. 


\section{Listado de candidatos 9}

\begin{tabular}{|c|c|}
\hline \multicolumn{2}{|c|}{ Seandores de UyO La Plata } \\
\hline Nombre & Organización \\
\hline Martín Alaniz & La Cámpora ${ }^{201}$ \\
\hline Sebastián Tangorra & FAP \\
\hline Marisol Aranguren & Movimiento de Unidad Popular \\
\hline
\end{tabular}

El caso más extraño en esta lista fue el de la tercera candidata, ya que le Movimiento de Unidad Popular formaba parte del entramado del FRP-FPV hasta ese entonces. Es posible que la misma haya ido como candidata de consenso entre ambos polos agrupacionales aunque debe marcarse el hecho de que esta agrupación, aun cuando ya contaba con trayectoria en el otro polo, no tenía el mismo peso político que las agrupaciones de la fallida lista de Senadores (ver listado 9)-. En todo caso, de haber sido un punto de consenso, lo fue a elección del polo de UyO, lo cual vuelve a demostrar cierta debilidad política del FRP-FPV.

\section{Listado de candidatos 10}

\begin{tabular}{|c|c|}
\hline \multicolumn{2}{|c|}{ Concejales de UyO La Plata } \\
\hline Nombre & Agrupación \\
\hline Hernán Gastón Castagneto & Kolina \\
\hline Alejandro Rusconi & Movimiento Evita \\
\hline Silvina Negrete & Juventud Sindical CGT platense ${ }^{202}$ \\
\hline Lucas Luna & Proyecto Nacional \\
\hline Nahuel Vicchi & Nuevo Encuentro \\
\hline
\end{tabular}

${ }^{201}$ Que en ese año había renunciado a la banca del Concejo Deliberante por asumir funciones en la AFI. En su lugar había asumido Ludmila Kostiuk del Movimiento Evita (El Día, 28/01/2015).

202 Quién había ido en 2013 como 9vena candidata a Concejala. 


\begin{tabular}{|l|l|}
\hline Julia Di Jorgi & Peronismo Militante \\
\hline
\end{tabular}

Es de destacar que el mecanismo de selección de candidatos, en el marco de alianzas de este polo, expresa acuerdos horizontales que contrastan con la estructura de la lista del otro polo y que continúan desde la elección del 2013. Por ejemplo: La Cámpora, no llevó entre los tres primeros candidatos a concejal, un militante de su fuerza, puesto que ya había colocado uno en la categoría de Senadores Provinciales. El Mov. Evita, por su parte, hizo el camino inverso ya que en 2013 había logrado posicionar un cuadro militante en la boleta unificada de Diputados Provinciales. La agrupación Kolina, que en la elección anterior había ido cuarta, en esta ocasión obtuvo el más claro de los candidatos -teniendo en cuenta la disposición de la interna. El criterio del armado respondió, una vez más, al equilibrio de organizaciones del propio polo.

Al igual que el FRP-FPV, el marco de alianzas no se restringía únicamente a los grupos que participaban con nombres para al Concejo y, como búsqueda de fortalecimiento de la nómina, se publicó una solicitada (ver Solicitada 5) que contaba con más de 300 nombres en apoyo al espacio. La misma, que contuvo firmas de sectores de los organismos de DDHH, de la justicia, del bloque de Diputados Nacionales y de sectores universitarios entre otros- buscaba interpelar al electorado progresista construyendo una articulación que se podría definir de tipo movimentista - a diferencia de una de tipo partidaria- puesto que excede las interpelaciones a identidades tradicionales. 


\section{Solicitada 5}

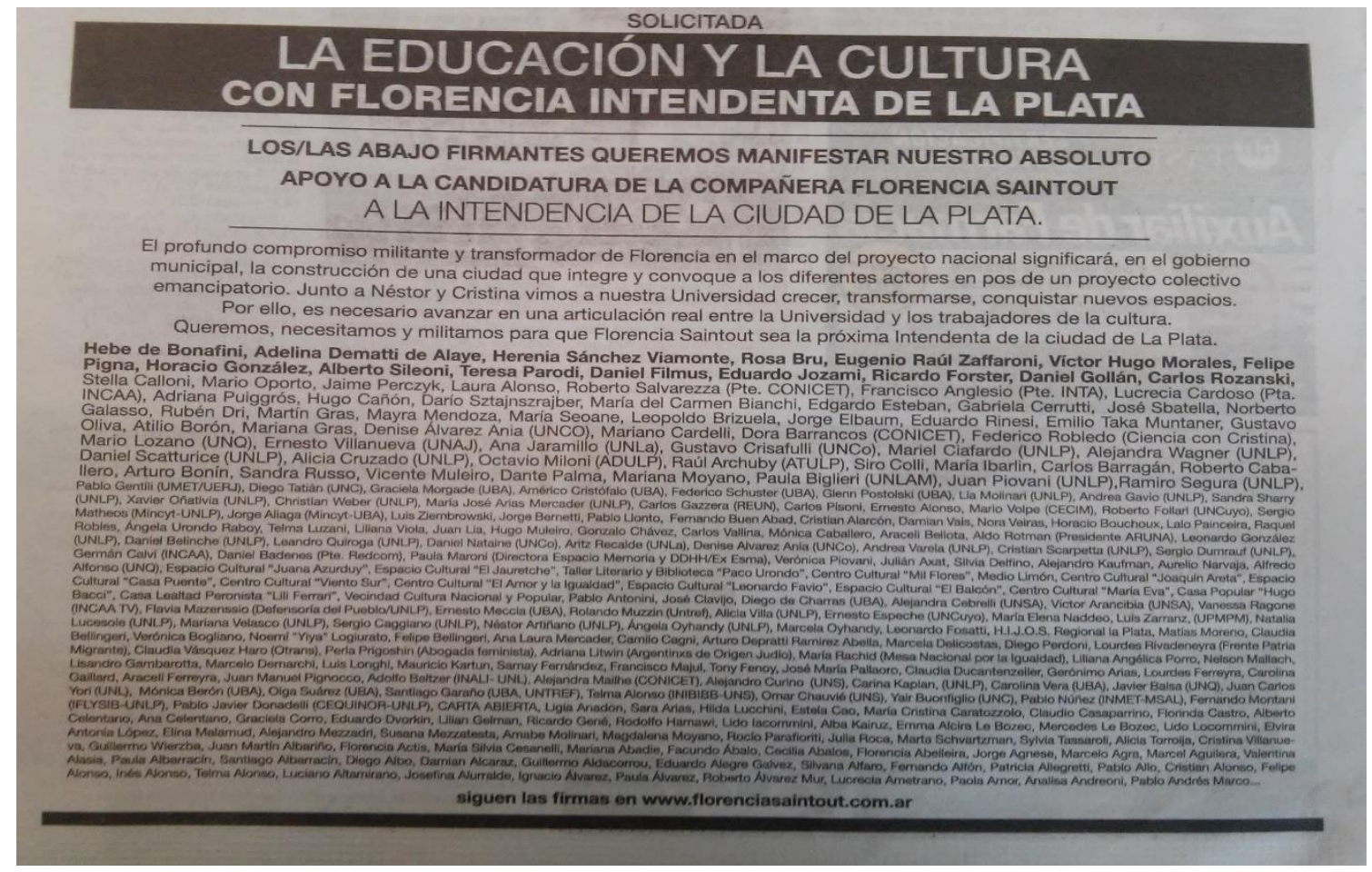

Fuente: El Día, 02/08/2015, pág. 15.

\subsection{Construcción identitaria particular}

La lista de UyO apostó nuevamente a hegemonizar el espacio delegativo local de la élite nacional. La identificación vertical entre la candidata y Cristina Kirchner (ver propaganda 17) buscaba sostener el argumento de que, aun dejando la presidencia, Cristina iba a conducir la política del FPV. LA estrategia comunicacional en esta ocasión fue la de sostener que "El candidato es el proyecto", en alusión a las políticas nacionales desarrolladas por el kirchnerismo en los 12 años de gestión. Como ya se marcó, esto trajo aparejado el contrapunto con el FRP-FPV -que, vale sostener, fue una respuesta a la propuesta de este espacio- que implicó una disputa semántica. Para esta postura, se trató de un proyecto "colectivo" en alusión a una modulación discursiva que implicaba una cierta des-subjetivización individual de la candidatura en pro de una política que podían encarnar diferentes nombres.

Una situación interesante para marcar de esta propuesta fue la incorporación de demandas sociales que por esos años iban cobrando impulso público -y que, salvo algunos partidos de izquierda, no eran tomadas en cuenta por la mayoría del sistema político- como las 
expresiones del frente feminista (ver propaganda 18). En este punto, UyO logró entablar un diálogo con las mismas que se extendió en el tiempo -más allá del evento electoral concreto. En este punto de remarcar que, como se verá, la vinculación de la candidata con la temática de género estuvo muy presente a lo largo de su trayectoria ${ }^{203}$.

A contra mano de toda la estrategia comunicacional, existió esta vez una propaganda publicada en el diario El Día, la cual fue generada por el candidato a primer Concejal de esta lista (ver propaganda 19). Esta publicidad, no sólo no salió de la estrategia comunicacional estructurada en torno a esta candidata, sino que además, cuenta con el hecho de funcionar como doble propaganda: por Florencia y Scioli por un lado, y por Castagneto por el otro. Ahora bien, este caso no es extraño si se recuerda el estatuto del PJ antes citado: a la lista que fuera minoría, es decir, aquella que perdiera, le tocaría colocar en la lista unificada el cuarto, el octavo y el doceavo candidato a concejal. En vistas de que sólo el cuarto sería aquel que quedaría en un lugar gris claro -con altas expectativas a ingresar de Concejal- es comprensible que dicho candidato intentara construir un esquema comunicacional propio.

En el acto de cierre de la campaña, este polo resaltó su vinculación con los referentes nacionales a los que adscribía por medio del discurso de la candidata:

“...podría citarles a Sartre, pero les voy a citar a Néstor para decir esto: hemos corrido el campo de lo posible, porque nadie imaginaba que íbamos a llegar a esta elección como estamos llegando. [...] Nuestro único candidato y candidata es el proyecto nacional."

Y en relación a la lista del FRP/FPV:

"Ellos tienen una idea de lealtad como una categoría de libero que pueden utilizar a gusto. Ellos no han sido leales con los que sufren, no han sido leales con los que necesitan del Estado, no han sido leales con los desamparados y tampoco han sido leales con nuestros conductores."

Por último, la candidata construyó un vínculo con el pasado peronista de la ciudad:

Tenemos la responsabilidad, compañeros, de ganar. Tenemos que volver a integrar a

\footnotetext{
${ }^{203}$ Hay varios registros de la participación de Saintout -y de militantes de UyO- en las movilizaciones de "Ni Una Menos"

https://www.facebook.com/pg/fsaintout/photos/?tab=album\&album id=405087459695346
} 
esta ciudad Eva Perón ${ }^{204}$ a la patria. Esta ciudad para Cristina, compañeros.

(Saintout, Florencia. Discurso de cierre de campaña; 05/08/2015. Disponible en https://www.youtube.com/watch?v=BNj2u-gMsNw . Revisado el 01/03/2016).

Estas tres ideas expresadas en el discurso de cierre de campaña, señalan la construcción identitaria de este polo político. Por un lado, la noción del "proyecto" en este caso -y a diferencia del esgrimido por la lista del FRP/FPV- concierne a una dimensión nacional, que incluye lo local, pero que lo subsume. En este sentido, el destino de la ciudad -noción que aparece en diferentes discursos de este espacio- está vinculado en esta concepción al destino de la patria. De aquí la importancia de la segunda idea, que constituiría la frontera que separa esta lista de la que encabezaba el entonces Intendente, que corresponde al problema del par lealtad/traición: al constituirse el vínculo entre lo local y lo nacional de forma inseparable, la traición sobre los conductores del proyecto político que buscaba la emancipación de la nación, correspondía a la traición a aquellos que habitaban dicha nación.

Por último, la apelación al nombre de Ciudad Eva Perón, buscaba mostrar que este polo político, no sólo disputaba las elecciones locales, sino que además disputaba la comprensión de un "peronismo histórico" y su subsistencia en la figura de Cristina Kirchner. Es de notar que en ningún pasaje del discurso de cierre de campaña, se mencionó la figura de Scioli.

\footnotetext{
${ }^{204}$ La ciudad de La Plata pasó a llamarse ciudad Eva Perón -no así el distrito- luego de la muerte de Evita, entre los años 1952 y 1955.
} 


\section{Propaganda 17}

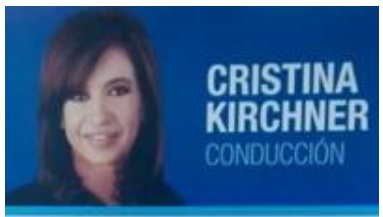

FLORENCIA

SAINTOUTLAPLATA 2015

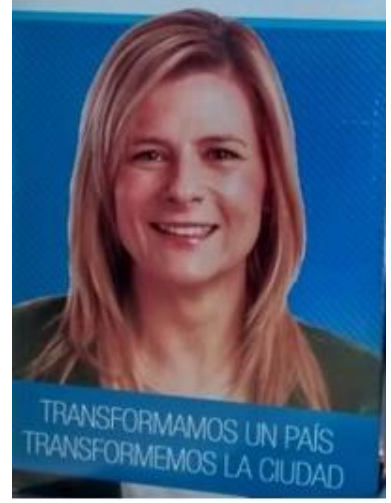

Fuente:

facebook.com/fsaintout. Disponible en:

https://www.facebook.co $\mathrm{m} / \mathrm{media} / \mathrm{set} /$ ?set $=\mathrm{a} .3688$ 62883317804.1073741972 $.139492882921473 \&$ type $=$ $\underline{3}$

Revisado el 1/02/2016.

\section{Propaganda 18}

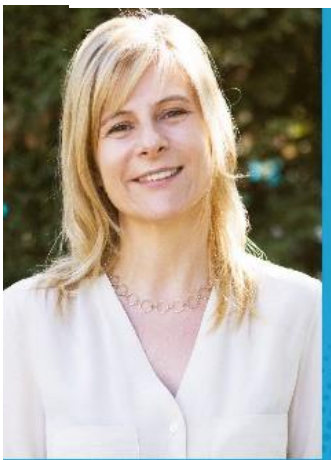

Las Moneres

con

Florencia

VIERNES 3 DE JULIO - 15hs

MATEADA EN

VILLA ELVIRA

propuestas de gÉnero para una GiUdan IncLusiva

UB "LEONARDO FAVIO" 85 e/9 Y 10

Intendenta 2015 (s)

Fuente: https://www.facebook.com/UnidadB\%C3\%A1sica-Leonardo-Favio-Villa-Elvira687866191249601/. Disponible en: https://www.facebook.com/68786619124960 1/photos/a.692213907481496/878580072178 211/?type=3\&theater

Revisado el 01/02/2016

\section{Propaganda 19}

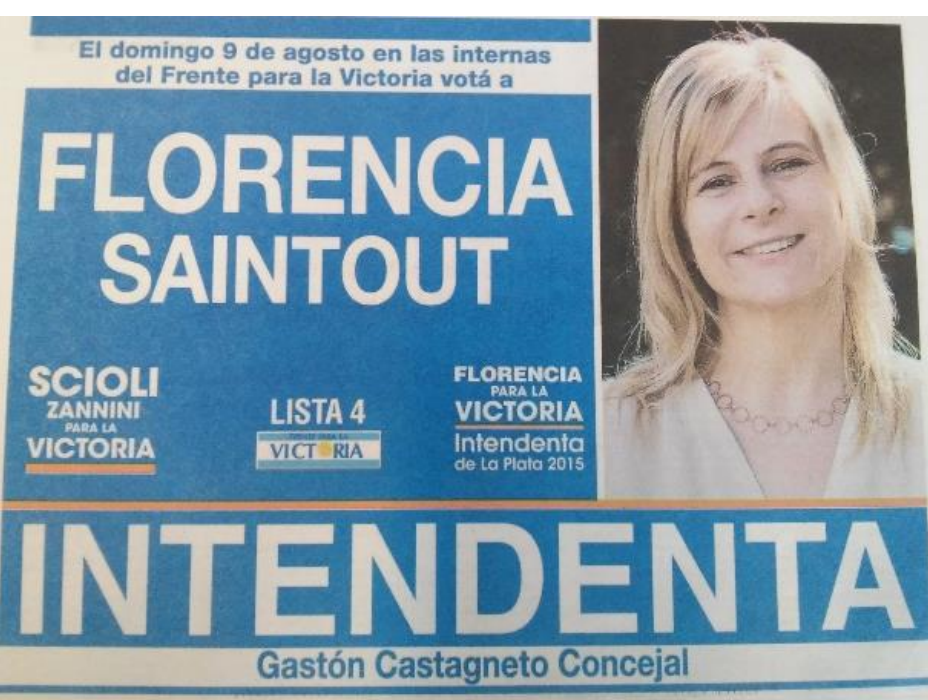

Fuente: diario El Día; 05/08/2015: pág. 3. 


\section{Las elecciones del 2015}

Tras las elecciones del 22 de agosto, y con la lista unificada, comenzó el último tramo de la campaña, donde ya sin listas paralelas, el peronismo buscaba dar vuelta un escenario difícil. La estrategia que se dieron para estos meses tuvo dos marcados perfiles: por una parte, se apostó a la consolidación del peronismo como grupo unificado, lo que le permitió organizar mejor la línea de oposición con la alianza CAMBIEMOS. Por el otro lado, se buscó perforar los marcos de alianzas de las otras propuestas electorales, haciendo eje, principalmente, en la propuesta del Frente Renovador -aunque no sólo en ella.

La primera de estas líneas de trabajo consistió en realizar una serie de encuentros y proclamas de apoyo a la lista oficial con diferentes grupos: primero que todos y de forma autónoma, hubo un encuentro con dirigentes del Movimiento Evita (El Día, 30/08/2015), quienes el día anterior habían realizado junto con agrupaciones de ambos polos un plenario en el local de apoyo a la candidatura a Gobernador de Aníbal Fernández. Luego, con un conjunto de agrupaciones sueltas, en la Sede del PJ local con la que conformaron la "mesa de campaña del FPV" (El Día, 06/09/2015) 205; seguidamente hubo un "plenario" ya con el conjunto de agrupaciones de $\mathrm{UyO}$, aunque sin la presencia de Florencia Saintout (El Día, 09/09/2015). También tuvo caminatas con Martín Sabbatella (El Día, 27/09/2015) como para captar el electorado progresista kirchnerista no peronista ${ }^{206}$. También hubo un encuentro con Carlos Bonicatto, ex Defensor del Pueblo de la P.B.A. (El Día, 15/10/2015) y perteneciente al esquema del peronismo que supo estar vinculado al alakismo.

\footnotetext{
${ }^{205}$ Las agrupaciones que se sumaron fueron: "Vamos que venimos", "Volveremos", "Agrupación Néstor Kirchner", "La Cafiero" y "Soñar Argentina".

${ }^{206}$ Jornada en la que participó Florencia Saintout.
} 
En este marco, hubo una discusión en torno al necesario pronunciamiento de la candidata Florencia Saintout llamando a votar por Pablo Bruera. Ciertamente si bien el mismo no llegó a ser noticia del diario más importante de La Plata, existió un comunicado por parte de la ex candidata convocando a votar la boleta completa del FPV (INFOCIELO, 14/08/2015) $)^{207}$. Además se realizaron -ver imagen 2- al menos cuatro actividades públicas en conjunto. Esto permite suponer que la falta de pronunciamiento en el matutino local más importante se puede haber debido al enfrentamiento que la ex candidata tenía con el mismo ${ }^{208}$.

\section{Imagen 2}

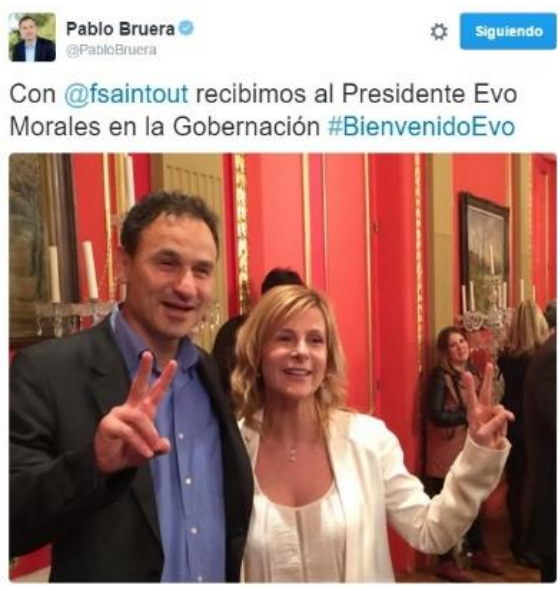

Fuente: https://twitter.com/PabloBruera

Fecha: $17 / 09 / 2015$

Disponible en:

https://twitter.com/PabloBruera/status/64462215

$\underline{1249719297}$

Revisado el 18/02/2018

La segunda línea de trabajo, que fue en paralelo a la anterior, estuvo en consonancia con la estrategia nacional que desplegara Daniel Scioli, la cual ya había comenzado desde Junio con una declaración en la que afirmaba que "Los massistas que vuelven son peronistas que quieren ganar" (El Día, 09/06/2015), pero que se potenció hasta alcanzar su pico más alto con la declaración de Francisco De Narvaez, llamando a votar por la fórmula del FPV (El Día, 21/10/2015). En esa línea, en el peronismo local no se hicieron esperar las acciones para tratar de perforar los espacios opositores minoritarios. Aprovechando que tras las PASO hubo una crisis en el Frente Renovador local (El Día, 03/09/2015) en torno a cómo se recompondrían las listas de Concejales, las negociaciones lograron acercar a Javier Pacharotti -ver capítulo anterior- (El Día, 08/09/2015), que si bien se pronunció por la candidatura de Scioli, se dijo prescindente de la disputa local. Lo

\footnotetext{
${ }^{207}$ Disponible en:

https://infocielo.com/nota/63906/con un texto ambiguo y sin nombrarlo saintout comunico que apoyara a bruera en octubre/

${ }^{208}$ Aunque también es válida una hipótesis más arriesgada según la cual la misma podría haber preferido preservarse en pos de elecciones subsiguientes.
} 
mismo con otro pre candidato a Intendente de ese espacio, Marcelo Leguizamón (El Día, 07/10/2015). Finalmente, dos días después, sumaron a Carlos Melzi (El Día, 09/10/2015) también en las mismas condiciones, salvo que este ex candidato si se pronunció en apoyo a la figura de Bruera. Si se tiene en cuenta que los pre-candidatos a Intendente por esa fuerza fueron 5 en total, estos pases claramente significaron un sacudón para la misma.

\subsection{Reconfiguración identitaria particular}

La estrategia comunicacional del FRP-FPV siguió manteniendo el doble juego de recostarse sobre las intervenciones realizadas desde la candidatura nacional del FPV y mantener un canal propio de intervenciones gráficas. Para este último caso, se hizo mucho hincapié en la noción de "La Plata, Gran Capital” -ver propaganda 20 y 21- con la cual se modulaba un discurso de gestión local vinculada a un programa nacional. Resulta llamativo el que, en vistas de la búsqueda de votos de todos los sectores no existiera en este tramo de la campaña una interpelación a los votantes duros de la élite nacional del FPV en retirada, aunque si se utilizara la sigla. Tampoco hubo una convocatoria particularizada a los votantes de la tradición peronista local. 


\section{Propaganda 20}

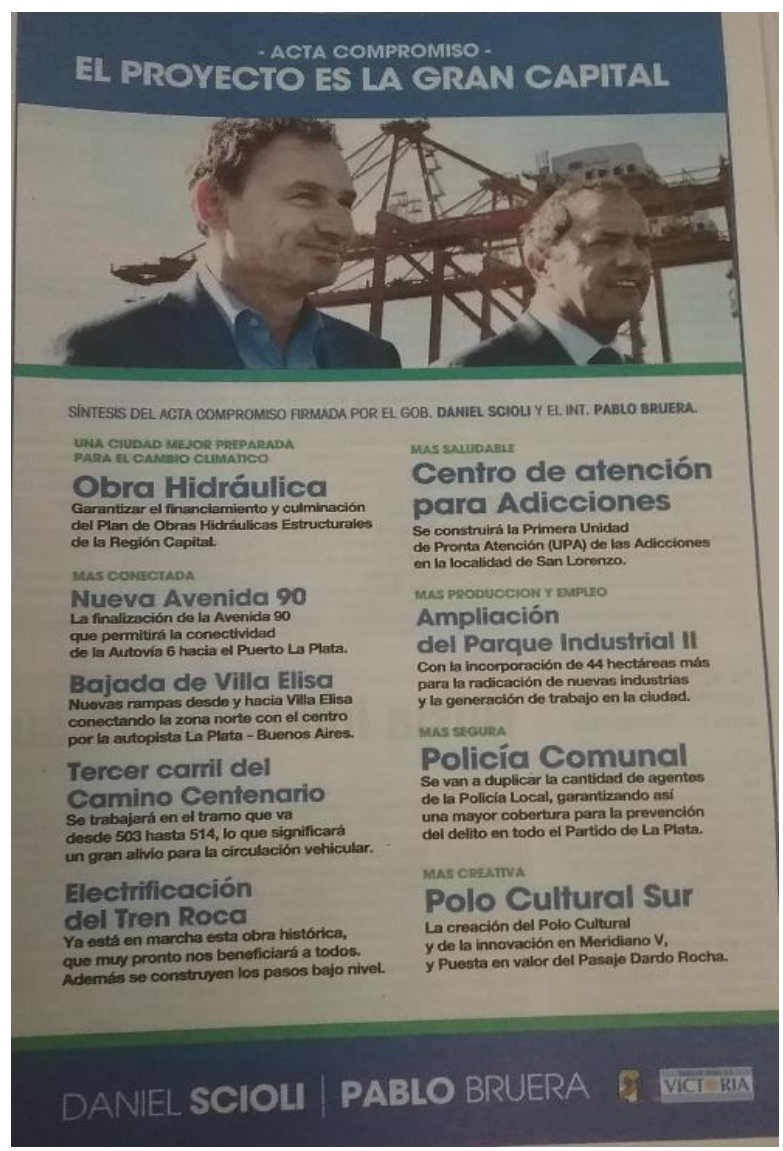

\section{Propaganda 21}

Fuente: El Día, 04/10/2015, pág. 5.

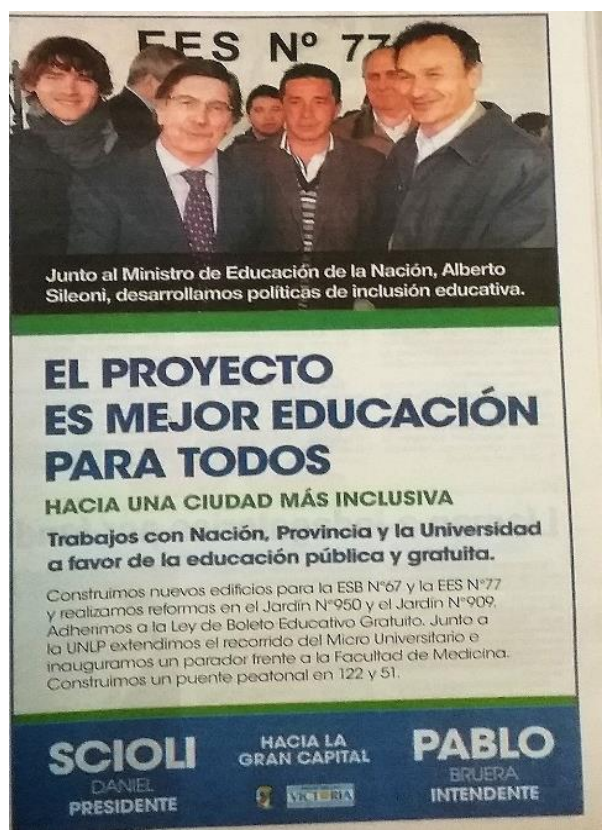

Fuente: El Día, 16/10/2015, pág. 3. 


\section{Conclusiones}

Tras los resultados electorales del 2015 se produjeron un sinfín de artículos en torno a las causas que llevaron al peronismo a perder las elecciones tras 14 años en el poder contando la Presidencia de Eduardo Duhalde. Más allá de dichas evaluaciones a nivel local fue posible observar algunos comportamientos de ambos polos organizacionales que tornaron compleja la tarea de poder sintetizar en una expresión electoral única las contradicciones y disputas internas de los diferentes espacios. Si el signo de esta elección fue el de una síntesis fallida, mucho tuvo que ver las dinámicas que se arrastraron de años anteriores, como también las escasas formas de construir recambios de élite con bajos costos organizativos. Claramente ninguna de estas situaciones explica por si misma los resultados electorales, sin embargo, es de destacar el aporte de las mismas a una respuesta global.

En lo que hace a la construcción de candidaturas, si bien ambos polos presentaron figuras con trayectorias, lo interesante se advirtió en el juego de desplazamiento que las mismas presentaron en torno a sus perfiles. Pablo Bruera debió abandonar el espacio de renovación de la política y ocupar el lugar de una gestión con trayectoria. En la tensión entre renovación y permanencia, claramente Saintout terminó ocupando el espacio vacío que dejó su competidor. Las estrategias desplegadas también fueron diferentes entre ambos candidatos, incluso cuando ambos intentaron potenciar su penetración en el electorado incorporando apoyos de sectores reconocidos, Bruera tuvo que fortalecer su imagen, apostando a la contención de grupos, mientras que Saintout desarrolló una campaña más opositora basada en la idea de subsistir tras una eventual derrota en las urnas.

Los marcos de alianzas volvieron a expresar criterios diferentes en sus arquitectónicas. El FRP-FPV apostó a la reelección de quienes, con un alto nivel de fidelidad al espacio, ya contaban con mandatos legislativos locales. Por el lado de UyO se observó la continuidad de los acuerdos entre agrupaciones que se distribuyeron los espacios teniendo en cuenta los lugares ocupados la elección anterior. Una importante situación se observó en la lista de candidatos a Senadores, donde la debilidad en la que se encontraba el FRPFPV para la negociación con la élite nacional quedó plasmada en su imposibilidad de establecer candidatos propios para dichas bancas.

En las construcciones identitarias de cada polo es donde se pudo apreciar con mayor 
claridad la profundización de la ruptura que distanció a ambos armados. La forma de construcción de oposiciones internas en el peronismo tiene una extensa tradición de altos niveles de confrontación. Afortunadamente tras la década de los 80 , los casos en que dicha disputa llega a transformarse en violencia física parecen ser solo casos aislados. Sin embargo, la estructura de disputa no por haberse colocado principalmente en la dimensión retórica deja de ser intensa, llegando a veces a posiciones casi irreconciliables. En esta ocasión se pudo observar en los tres niveles -aunque el presente capítulo solo indagó en la dimensión local- de candidaturas del FPV. Excede las pretensiones del presente trabajo poder analizar la relación entre construcción de interpelación pública y voluntad popular de los votantes identificados, para lograr saber si es que las internas expresan malestares de la base o las candidaturas construyen lecturas que luego los votantes admiten como propias. Lo que sí se pudo observar en esta ocasión es que las estrategias comunicacionales de ambos polos, aun teniendo un diálogo subrepticio en torno a la noción de proyecto político, se diferenciaban casi tanto como con otros partidos. La modulación identitaria del FRP-FPV presentó un discurso que intentó ocupar el centro ideológico pensando más en un ciclo novedosos de política que se hubiera abierto con el acceso al Estado Nacional de mano de la figura de Scioli, mientras que la de UyO volvió a apostar a saturar el espacio delegativo de la figura de Cristina Kirchner. 


\section{Capítulo 6: El día después: nuevas agrupaciones y cambio del escenario local}

"La derrota de noviembre de 2015, fue una derrota del peronismo, del Frente para la Victoria en su conjunto y sus aliados, y, evidentemente, produjo un proceso de dispersión. Ese proceso no ha terminado hoy de resolverse. [...] Así son las derrotas".

Jorge Taiana ${ }^{209}$

Tras la derrota electoral en el ballotage lo que sucedió fue un proceso de dispersión política para el FPV. El conjunto de los actores tendió a dividirse en, por lo menos, dos grandes campos: aquellos que tenían responsabilidades institucionales por estar al mando de algún estamento ejecutivo -y con ellos los legisladores que formaban parte de sus espacios-, y aquellos sectores que agrupaban militantes por fuera de la estructura estatal o contando con representaciones legislativas deslindadas de los ejecutivos. Tanto unos como otros no conformaban, necesariamente, polos de agrupamientos fuertemente organizados con una élite común que representara una estrategia clara, sino más bien sectores vinculados por la necesidad de establecer algún tipo de relación frente al gobierno de CAMBIEMOS. Así, mientras aquellos actores del peronismo que debían gobernar algún rincón del Estado trataron de construir una vinculación en el marco de una reconfiguración del sistema político, los actores del otro campo tendieron a entablar un vínculo de oposición dura y confrontación directa.

A nivel distrital, la dispersión terminó generando una ventana de oportunidad para que un conjunto de nuevas agrupaciones asuma cierto protagonismo público. De hecho, en el período entre la primera y la segunda vuelta presidencial, emergió en La Plata -aunque también en varios puntos del país- un conjunto de nuevos grupos que realizaron lo que se denominó como "plazas del pueblo" a favor de la candidatura de Scioli (El Día, 01/11/2015 y 15/11/2015) que buscaron convocar desde cierta auto-organización a sectores sociales desvinculados de los espacios de representación. Un caso de esto fue el de Mujeres Platenses Unidas -desde ahora MPU. Una de las referentes de dicho espacio sostuvo:

"Mujeres Platenses Unidas. El grupo de mujeres nació en un contexto de balotaje,

\footnotetext{
209 Entrevista en el programa “Minuto 1" el 24/07/2017. Disponible en: https://www.youtube.com/watch?v=rfl434epvyg\&t=1722s
} 
después de la elección de octubre. Somos en realidad el grupo que lo inicia, fundador, entre comillas, somos el grupo de cinco amigas que todas tuvimos una trayectoria militante previamente y que por distintitas razones hacía bastante tiempo que no teníamos una participación orgánica en ningún espacio. [...] Empezamos a invitar a unas amigas y queríamos armar un documento donde pudiéramos decir como mujeres comunes de la ciudad de La Plata, por qué queríamos votar a Scioli y sacarnos una foto en la plaza Moreno como significativo de la ciudad, La Catedral, etc. Armamos una página de Facebook, porque cada una fue invitando gente y al rato ya éramos una banda. No sé, 100, 200, 300. A la semana ese grupo llegó a las diez mil personas. O sea que evidentemente hacía falta algo diferente." (Entrevista a Florencia Espinosa, septiembre 2017)

La llamativa masificación de esta agrupación pareciera encontrar una clave de lectura en la frase "hacía falta algo distinto". Ciertamente en la historia del peronismo la participación del colectivo de mujeres tuvo diversos formatos: desde la experiencia del Partido Peronista Femenino (Barry, 2009; Zaremberg, 2009) en la década de los '40 210 , hasta las secretarías del partido justicialista desde el establecimiento del último ciclo democrático a principios de los '80. Aun cuando algunas mujeres llegaron a ser candidatas y ejercer cargos públicos, con el abandono del criterio tripartito para la construcción de listas, también perdió peso -incluso hasta desaparecer en algunos casoslos espacios de organización del colectivo de mujeres que funcionaban con un criterio de convocatoria específico.

Ahora bien, la representación de este colectivo social se asentó sobre un fenómeno de politización de los colectivos feministas que es posible rastrear hasta los inicios del ciclo democrático actual, donde con más de 30 años de realización continuada del Encuentro Nacional de Mujeres ${ }^{211}$, como también con la irrupción de las movilizaciones masivas encuadradas en la demanda de "Ni una Menos", fue posible observar que las mujeres en tanto que actoras políticas transitaban el camino de construirse como un sector social muy activo y con un elevado potencial de intervención pública. De esta manera la virtud de la

\footnotetext{
${ }^{210}$ La trayectoria del PPF puede rastrearse hasta la elección de 1973 incluso, la cual constituyó la última experiencia de elección de candidatos de la organización peronista bajo el sistema de tercios -aunque para ser precisos, en dicha ocasión con la incorporación del sector juvenil, el mismo fue de cuartos- que luego sería reemplazado por otros mecanismos (Levitsky, 2005). Sin embargo, ya en el período de resistencia y con el cambio en las lógicas de acumulación, el PPF perdió toda gravitación específica -al menos en la Provincia de Buenos Aires.

${ }^{211}$ Una buena historización de esta experiencia se puede consultar en: Alma y Lorenzo (2009).
} 
convocatoria pareciera estar en la capacidad de lectura de la ausencia de representación, bajo la reposición del criterio específico, al interior del peronismo de dicho proceso de politización y allí radica la diferencia de esta organización con otras.

En lo que hace a sus demandas políticas, resulta importante también recuperar la discusión en la que este colectivo se propuso intervenir en torno a la agenda de temas. Al respecto la entrevistada sostuvo:

"Porque hay como una estrategia que a nuestro entender era muy, no sé qué palabra usar, si de encasillar y también de cercenar nuestra posibilidad de participación política como de mujeres, no de mujeres platenses, sino de cercenar la posibilidad de participación y debate que tenemos las mujeres en la política. Delimitarnos. Entonces de la política de verdad, de la política económica hablan los hombres y nosotras hablamos de aborto. Yo quiero sentarme a hablar no sé, de la política de transporte con un compañero." (Espinosa, septiembre de 2017)

Esta configuración de las demandas permite realizar algunos señalamientos importantes ya que la decisión de establecer una discontinuidad entre el criterio de captación de militancia y los márgenes de acción política, se asienta sobre un proceso de discusión de la figura del actor/a político/a. A saber, la negación a reducir el margen de acción a una agenda de temas "específicos" de las mujeres, expone que la politización de este colectivo social implica la no aceptación de la "mujer" como una actora ya dada a la cual la interpelarían solo el conjunto de problemáticas cercanas. Por el contrario, la opinión pareciera indicar que se trata de un colectivo social que se encuentra construyendo un tipo de militancia, en este caso ser mujer, disruptiva a diferentes niveles: en lo organizativo, porque no aceptan los espacios establecidos o dados para su participación; en lo representativo, puesto que el corte de género les permite atravesar al mismo tiempo clases sociales y espacios de acumulación diversos -ver propaganda 23-; en lo temático, puesto que, simultáneamente, impulsan demandas a la agenda general -ver propaganda 22- y también imprimen una mirada propia a los temas ya establecidos. 


\section{Propaganda 23}

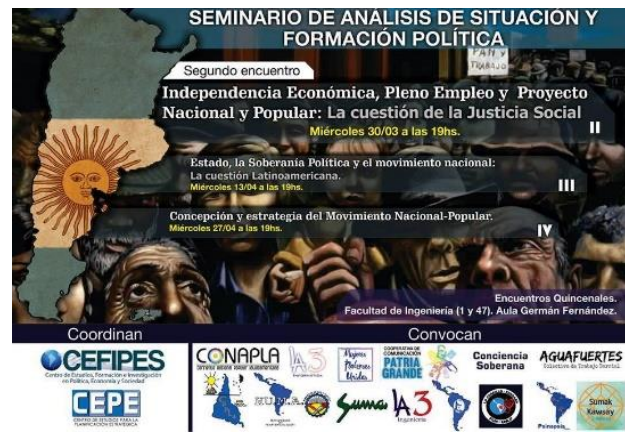

Fuente:

https://www.facebook.com/mujere

splatensesunidas/

Disponible en

https://www.facebook.com/mujere splatensesunidas/photos/a.108500

$\underline{5614867364.1073741828 .1084987}$

724869153/1174867759214482/?t

ype $=3 \&$ theater
Propaganda 22

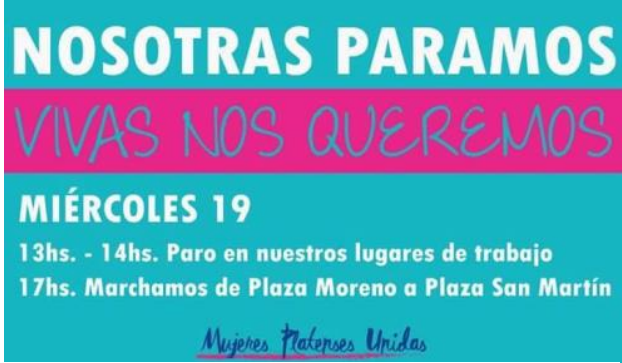

Fuente:

https://www.facebook.com/mujere

splatensesunidas/

Disponible en:

https://www.facebook.com/mujere splatensesunidas/photos/a.108500

$\underline{5614867364.1073741828 .10849877}$

24869153/1331495613551695/?typ

e=3\&theater

Revisado el: 27/02/2018

Revisado el 27/02/2018

Otra de las agrupaciones que encontró espacio para crecer en el marco de la dispersión fue La Cafiero. Esta agrupación presentaba un perfil más cercano al de una corriente interna del peronismo, tratando de interpelar sectores que, aún vinculados a la conducción de la élite nacional, no formaban parte de los espacios centrales de la toma de decisión en los diferentes lugares. Un referente de la misma contaba:

"Yo dije, "va a haber mucho rechazo. Nosotros tenemos que apuntar a la renovación del peronismo. Vamos a empezar a dar una discusión que nadie da". Ahora, en el contexto de La Cámpora no podíamos discutir ¿qué íbamos a discutir? si Cristina es la jefa, nosotros nos ordenamos acá...no. Nosotros queríamos ir a dar la discusión al peronismo de base. Vamos por las unidades de básicas, compañeros que nos quieran escuchar, nos vienen a escuchar. Entonces armamos una agrupación ¿qué nombre le ponemos? y, si estamos hablando de la renovación del peronismo vamos a ejemplificar con el nombre: Antonio Cafiero. Que tampoco nunca fue santo de mi devoción, pero tenía gestos hacia la política que pocas veces se han visto después de Perón. Ese gesto democrático, solidario. Ese gesto de entender un proyecto político de alternancia, la continuidad. Porque el tipo dijo "bueno, está bien le cavan la tumba a Alfonsín, pero me la cavan a mi". Entonces entender eso para mí fue valioso." (Entrevista a Ramón Galache, septiembre 2017) 
Vinculados en principio a la posible pre candidatura de Florencio Randazzo, este grupo estructuró -el nombre daba cuenta de ello- un discurso en el que incorporaba la demanda de una reestructuración el peronismo y la recuperación de ciertos elementos republicanos desde una perspectiva progresistas. Similar al discurso de los renovadores de la década de los 80, aunque sin proponerse un camino de externalización -ver propaganda 24- esta agrupación encontraba en la estructura del peronismo su territorialidad, por lo que, aun cuando la mayoría de sus militantes correspondían al municipio de La Plata, su despliegue no se acotaba a los límites distritales teniendo participación en un municipio aledaño como es Berisso. Lo que resulta más interesante de esta experiencia es el hecho de la rearticulación de militantes tras un capital político de "apego a las reglas del sistema democrático". No se trata de que fueran los únicos que sostenían esto, sino que este grupo hacía del juego democrático y su necesaria internalización en los partidos, su elemento central.

Una tercera experiencia organizativa que presentó una trayectoria significativa fue la de Casa Para la Victoria Peronista -CPVP-. A diferencia de las otras dos revisadas, este grupo se compuso con militantes que estaban insertos en la estructura estatal -muchos de ellos en sectores burocráticos de despliegue de programas- y que no contaban con un espacio de contención el peronismo local. Sus redes con actores del peronismo provincial les proveyeron de canales de inserción en los debates locales sin estar mediados por ninguno de los grupos con más ascendencia en el distrito. Ahora bien, estas redes provinciales no eran necesariamente

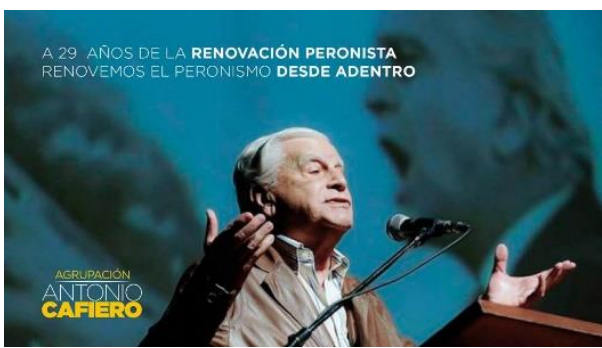

Fuente:

https://www.facebook.com/lacafi erolp/

Disponible en:

https://www.facebook.com/lacafi erolp/photos/a.156773734018064 3.1073741828 .1567694133518297 L1747558195531889/?type=3\&the ater

Revisado el 27/02/2018 vinculantes con la élite nacional ni con la élite provincial, por lo que no podían contar con la pretensión de ocupar el centro delegativo de dichas élites en el territorio como punto de partida, sino que debían disputarlo con el resto de los actores. Al respecto la referente del espacio contaba:

"Bueno, la realidad es que nosotros empezamos a caminar como Casa para la Victoria en el escenario electoral del 2015. Éramos un grupo de militantes peronistas que no 
teníamos una participación política en lo local, o sea no comulgábamos con la idea de la municipalidad que había llevado adelante el peronismo de Bruera, por decirlo de alguna manera; así que nos volcamos en plena campaña del 2015 muy fuertemente con una idea de provincia de Buenos Aires con Julián Domínguez [...] Y cuando perdimos la interna con Julián Domínguez, continuamos toda la etapa del ballotage apostando a lo que era el Frente para la Victoria, y cuando perdimos todo; perdimos la ciudad, perdimos la provincia, perdimos la nación, después del 22 de noviembre nos miramos con los 50 compañeros con los que habíamos armado la casa con mucha vocación política y dijimos "bueno, tenemos todo cuarenta y pico de años, militamos desde los veintipico, hemos tenido cargos de responsabilidad, de gestión y que realmente es nuestro momento de poder volcar esa experiencia en lo que para nosotros era una alternativa de gobierno para la ciudad de La Plata en el 2019". (Entrevista a Victoria Tolosa Paz, septiembre de 2017)

Casa Para la Victoria Peronista se trató de militantes con trayectoria que emparejan la acción política al trabajo desde el Estado y que por diversas situaciones no forman parte de uno de los grupos preexistentes. Es entonces una reagrupación política con el objetivo claro de protagonizar la disputa electoral. Esto es observable también en la situación de que la misma contó desde sus inicios con una figura pública que buscaba convertirse en candidata con proyección electoral. De hecho, el nombre de la agrupación establece un juego con el nombre de la referente y a la vez con una noción central en la historia del peronismo: la palabra Victoria. En términos estrictamente de lógica organizativa interna, contar con un/a candidato/a estructura la acción política de la organización de forma muy puntual y focalizada: para toda acción de vinculación con otros grupos, para toda forma de interpelación pública, para toda ocasión de acción colectiva, la figura central debe estar presente -ver propaganda 25- para lograr constituirse como punto de acumulación política del grupo. Similar al caso -y a varios otros en distintos distritos de la Provinciaque ocurrió con la aparición pública del Frente Renovador Platense -FRP-FPV- en 2003 y que estructuraba los acuerdos de modo que potenciaran la figura de Pablo Bruera.

En términos de demandas, la claridad con a que contaban para construir una candidatura, también se expresaba en la comprensión del lugar que ocupaban en el entramado del peronismo provincial:

"Yo creo que nosotros desde acá vamos a hacer un aporte muy grande a tratar de 
empezar a discutir qué ciudad queremos y que esa ciudad que queremos también encuentre un vínculo y un nexo con la provincia que queremos y con la recuperación del estado nacional." (Victoria Tolosa Paz, septiembre de 2017)

Más que tratarse de un vecinalismo -por lo demás fácilmente confundible- la apuesta de la organización era forzar una renovación interna del conjunto de dirigentes locales. Una

Propaganda 25

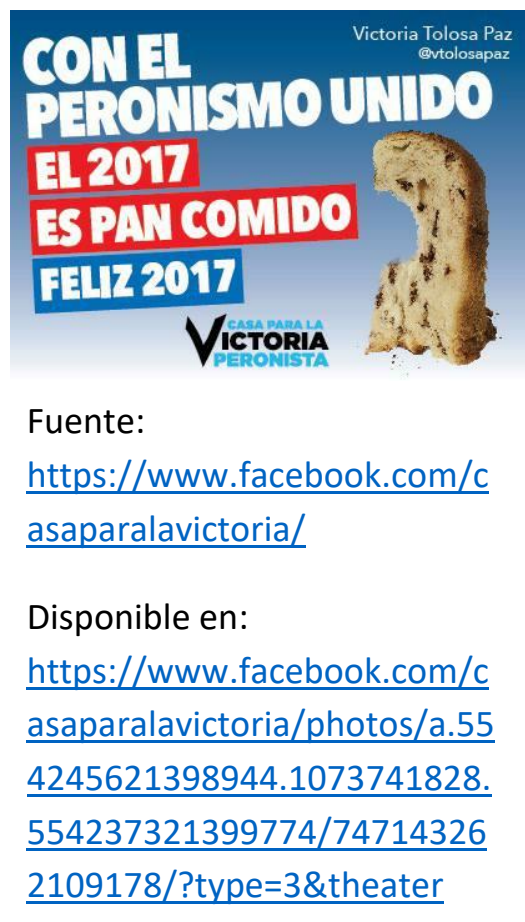

Revisado el 27/02/2018 apuesta osada proviniendo de una experiencia con tan poca trayectoria. Sin embargo, la derrota electoral de 2015 y la situación de la exterioridad del peronismo respecto del Estado Municipal, señalaban la posibilidad de jugar dicha estrategia. Nótese que la propaganda política que esta organización construyó en el transcurso de 2016, tenía como destinatarios al conjunto del peronismo local.

Por último, la experiencia de la agrupación Vecinxs Contra el Neoliberalismo -desde ahora VCN- que también fue un emergente de las "plazas del pueblo". Con una acentuada decisión política de ocupar el espacio público, y una novedosa comprensión de la territorialidad, esta agrupación articuló a diferentes personas provenientes de barrios de la zona norte de la ciudad, donde hay mayor concentración de familias con buenos ingresos y donde, en 2015 hubo un alto porcentaje de votos hacia la fórmula de CAMBIEMOS.

"Mirá, fue en el marco del ballotage del 2015. En realidad, el inicio fue un compañero, un grupito de compañeros de los cuales yo no era parte, empezaron a mandar a sus allegados mensajitos para, a la semana siguiente de las elecciones generales del 2015 , reunirse en una plaza de City Bell y bueno, me llegó porque uno de los compañeros le había mandado a mi hermana, así que ahí fuimos y bueno; como varios de los grupos que surgieron ahí al calor del ballotage, digamos. [...] nuestro planteo fue salir a hacer una campaña en la calle, digamos. Mano a mano, con los vecinos, haciendo mesa, yendo a los comercios; obviamente bastante inorgánica en relación a las estructuras que había ya de los partidos. Porque fue bastante en ese sentido, no sé si "desorganizada" es la 
palabra, pero bueno, no iba en consonancia con los tiempos, si es que hay planificados tiempos." (Entrevista a Violeta Sbatella, septiembre de 2017)

Aun cuando la agrupación contaba con algunos integrantes que tenían trayectoria militante previa, la articulación buscó contener a personas que se encontraban queriendo realizar su primera experiencia de participación políticas, movidas fundamentalmente por su rechazo a las propuestas electorales de CAMBIEMOS. Tomando como punto de encuentro privilegiado la plaza central del barrio de City Bell, esta organización trasformó el espacio público en su plataforma de intervención política: desde reuniones de la organización, hasta actividades dirigidas a diferentes sectores, la plaza se trasformó en su "unidad básica". Con esto pudieron realizar un doble movimiento: por un lado, convertir sus encuentros en acciones de intervención y, por otro lado, solapar cierta dimensión política del orden de lo privado - la toma de decisiones y las evaluaciones- con un área de lo visible y por ende accesible a cualquiera: "También el objetivo de estar ahí es que es mucho más fácil para la gente acercarse. [...] Es mucho más fácil acercarse a una ronda en una plaza que entrar a una casa o entrar a un local" (Sbatella, septiembre de 2017). Este doble movimiento se completa con una noción de territorialidad por cercanía en la que los militantes tienen muy presentes su pertenencia al espacio urbano donde desarrollan sus acciones. Se trata de personas que buscan discutir de política con otros ciudadanos desde el soporte que les provee ser cohabitantes con el interpelado de un barrio, de ahí la importancia de la noción de vecindad. Incluso la posibilidad de crecimiento de este formato está dada por la inclusión de vecinos de barrios linderos. El nombre de la agrupación no es entonces una referencia abstracta, sino una clave heurística para comprender la noción de territorio que sus militantes adoptan.

En términos de la construcción de sus demandas, este grupo trabaja desde una lógica que se podría definir como vecinalismo invertido ${ }^{212}$, en tanto se entienda por esto la articulación de problemáticas nacionales en su impacto territorial o en el barrio:

"Lo más local fue el tren, la cuestión más local de que no pasaba el tren por ahí, pero bueno, fue bastante bien laburado. Pero después el resto son todas cuestiones más nacionales. El tema de las tarifas, lo bajamos al territorio, bueno cuántos negocios

\footnotetext{
${ }^{212}$ Si bien existen diversos trabajos sobre las expresiones partidarias vecinalistas, en este caso seguimos las derivadas de los procesos de progresiva territorialización de las preferencias electorales (Calvo y Escolar; 2005).
} 
cerraron en este barrio, por la baja del consumo, por el aumento del alquiler [...] cuando hicimos el 24 en la plaza de City Bell, pusimos los desaparecidos de nuestros barrios." (Sbatella, septiembre de 2017).

Si el vecinalismo fue clásicamente en nuestro país un discurso articulador de demandas estrictamente locales que exigían una valoración por sobre las problemáticas nacionales,

Propaganda 26

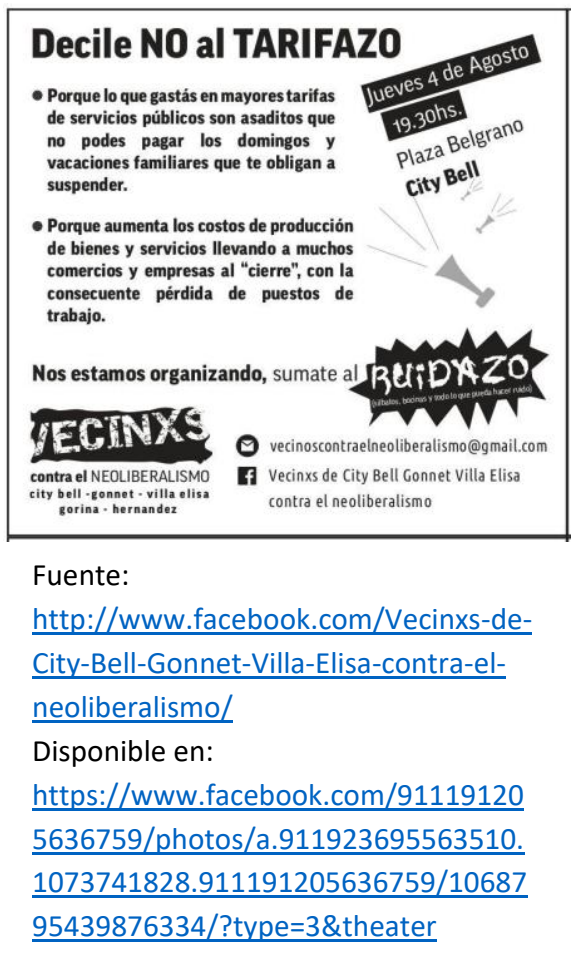

en este caso, estaríamos frente a una modulación que sin perder la lógica de articulación local, la construye desde una traducción de la dimensión nacional. Ese fenómeno de traducción los impulsó a generar sus propias construcciones de materiales -ver propaganda 26- los cuales se solventaron con los recursos propios.

Ahora bien, en el marco de la dispersión, las diferentes agrupaciones que componían el amplio espectro del peronismo local, realizaron varias campañas de forma articulada -ver propaganda 27 ocupando el espacio vacante de una dirección política. El peronismo local, incluso en el marco más amplio de alianzas como era el FPV local, transitó

durante fines del 2015 hasta principios del 2017 una situación de ausencia de liderazgos fuertes. Por una parte, el FRP-FPV, tras la derrota electoral, se encontraba fuertemente cuestionado por un conjunto de agrupaciones internas; por otro lado, el bloque de UyO se encontraba atravesando una crisis interna que, además, no correspondía únicamente a situaciones distritales, sino que contenía elementos de discusiones a niveles nacionales. El hecho de que las autoridades partidarias, que en el caso local seguían correspondiendo al entonces cuestionado FRP-FPV, también bloqueaban como posibilidad el que el Partido Justicialista opere como elemento de organización. Esta sumatoria de factores explica el porqué de muchas acción públicas fueron diseñadas y ejecutadas desde lugares periféricos de la política municipal, o lo que es equivalente, por fuera de las 
representaciones electas.

En términos de demandas, estos eventos multiorganizacionales sostuvieron agendas mixturadas entre problemas locales y nacionales. Problemáticas como la falta de servicio del tren (El Día, 26/06/2016) -principalmente en la demora en la electrificación del servicio-, como el aumento en las cifras de pobreza de la región, el problema del municipio con las cooperativas de trabajo, entre otros, ocuparon un lugar importante en las acciones de estos grupos. Debido a la marginalidad política desde donde se organizaban estas acciones colectivas la ocupación callejera y la cantidad de grupos articulados conformaban los indicadores de crecimiento disponibles para analizar la

Propaganda 27

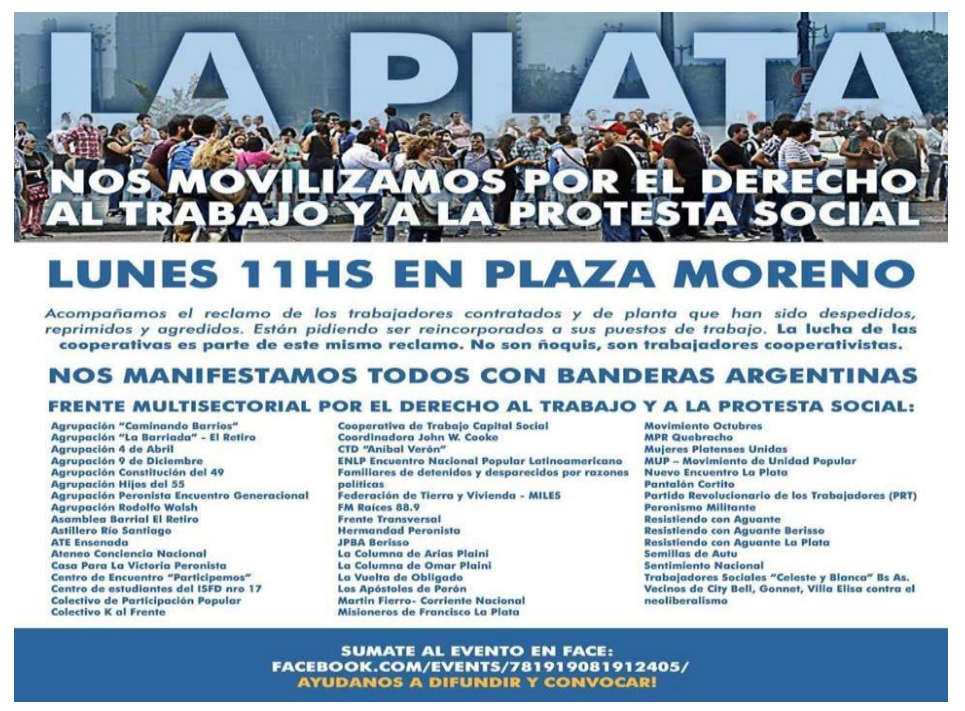

Fuente: https://www.facebook.com/Vecinxs-de-CityBell-Gonnet-Villa-Elisa-contra-el-neoliberalismo911191205636759/ Disponible en: https://www.facebook.com/911191205636759/photos/ a.911923695563510.1073741828.911191205636759/94 1049482650931/?type=3\&theater eficacia de dichas iniciativas. De ahí que fuera tan importante la aparición de los nombres de las agrupaciones, como así también el dato de la no inclusión de la firma del PJ local ni de la Cámpora. Este caso ejemplifica bien la relación entre la disputa por la reconfiguración de los capitales políticos de cada grupo.

1. Las elecciones del 2017

Tras un año y medio de idas y vueltas, el peronismo comenzó a encaminar las conversaciones internas para su participación electoral. Debido a que las mismas no eran elecciones nacionales, la presión sobre la ausencia de conducción nacional quedó relativizada tras la discusión, en cada provincia, de las formas en las que se estructurarían las listas. En la provincia surgieron a partir de la iniciativa de los Intendentes - 
principalmente del conurbano bonaerense- un conjunto de mesas de discusión que agrupaban diferentes actores. La caracterización de estas mesas resultó novedosa, pues las mismas no eran ni corrientes internas del partido, ni estructuras estables de organización, sino, simplemente, cristalizaciones ad hoc de referentes municipales que buscaban construir consensos en torno a las listas de candidatos. Los grupos constituidos fueron: Esmeralda ${ }^{213}$, Fénix ${ }^{214}$, Patria ${ }^{215}$ y el grupo Establo ${ }^{216}$. Estas mesas de negociación indicaban una forma de acumulación transitoria en vistas a la disputa por la construcción electoral. Sin embargo, a medida que se fue acercando la fecha del cierre de listas, la necesidad de contar con un candidato con proyección electoral que les permitiera contener los votos que les faltaban en los diferentes distritos, terminó decantando en la candidatura a Senador Provincial ${ }^{217}$ de Cristina Fernández de Kirchner, la cual contaba con un alto nivel de imagen positiva - principalmente en la zona del conurbano bonaerense. El proceso de organización del peronismo desde los sectores intermedios o municipales resulta interesante si se lo contrasta con las organizaciones centralizadas de partidos políticos similares de otras regiones. En este punto, los modos de acumulación transitoria bloqueaban las pretensiones de otros actores -por ejemplo, del presidente del partido en funciones- de ser los armadores de la propuesta electoral. Por otro lado, se conformó un sector que pretendía disputar en las internas llevando como candidato a Senador por la Provincia a Florencio Randazzo (Clarín, 09/06/2017). Este espacio comenzó a articularse en 2017 y sumó a sectores disconformes o con la candidatura de Cristina Kirchner o con los lugares ofrecidos para participar de las listas. Entre los grupos más importantes que sumaron estuvieron algunos intendentes del Conurbano -principalmente Gabriel Kataopodis, Juan Zabaletta y Eduardo Bucca- y a movimientos sociales como el Movimiento Evita. La irrupción de este marco de alianzas y su intención de llegar a las

\footnotetext{
${ }^{213}$ Lo integraban los intendentes: Martín Insaurralde (Lomas de Zamora), Gabriel Katopodis (San Martín), Mariano Cascallares (Almirante Brown), Fernando Gray (Esteban Echeverría), Eduardo Bucca (Bolivar) y Juan Zabaleta (Hurlingham).

${ }^{214}$ Lo integraban los Intendentes: Gustavo Menéndez (Merlo) Leonardo NArdini (Malvinas Argentinas) Verónica Magario (La Matanza), Ariel Sujarchuk (Escobar) Santiago Maggiotti (Navarro), Marisa Fassi (Cañuelas), Juan Ignacio Ustarroz (Mercedes), Walter Festa (Moreno), Francisco Echarren (Castelli) y Ricardo Curutchet (Marcos Paz).

215 Lo integraban los Intendentes: Jorge Ferraresi (Avellaneda), Mario Secco (Ensenada),

${ }^{216}$ Fassi - Capitán Sarmiento Oscar Ostoich - Roque Pérez Juan Carlos Gasparini - Monte Hermoso Marcos Fernández - (Punta Indio) Hernán Yzurieta - (Guaminí) Néstor Alvarez - Gral. Paz Juan Carlos Veramendi - Yrigoyen Jorge Cortéz - Tres Lomas Roberto Alvarez - Saavedra Hugo Corvatta - Benito Juárez Julio Marini - Colon Ricardo Casi - Tapalqué Gustavo Coconi - Daireaux Alejandro Acerbo - Gonzáles Chaves Marcelo Santillán - Marcos Paz Ricardo Curuchet - Alberti Germán Lago - (José C. Paz) Mario Ishii.

${ }^{217}$ La categoría electoral más visible de dicha elección.
} 
PASO produjo un conjunto de tensiones en el ya fragmentado campo de acuerdos del peronismo provincial.

Más allá de si se buscó realmente un acuerdo entre ambas listas o no, el marco de alianzas que impulsaba a CFK realizó dos movimiento en respuesta a la aparición de esta opción interna: por un lado, estableció una táctica de desvinculación de la estructura del PJ de la Provincia, utilizando como plataforma jurídica para la participación un conjunto de acuerdo de partidos más pequeños a la que denominaron como Unidad Ciudadana-desde ahora U.C- (El Día, 09/06/2017). Aunque se especuló bastante con la posibilidad de la restirada de las estructuras del PJ, a nivel municipal los actores mantuvieron el control. Este desplazamiento que generó un conjunto de discusiones en torno al peso real de la simbología peronista en el electorado, sin embargo, fue más un efecto de superficie a nivel provincial, puesto que todo el marco de alianzas construido previamente migró hacia este nuevo sello. El segundo movimiento implicó la elección del segundo candidato a Senador, el cual fue Jorge Taiana, quién en 2015 participaba activamente como referente del Movimiento Evita. En este caso, la intención claramente era la de traccionar los votos de los sectores sociales que acompañaban al ex ministro de transporte.

En el distrito de La Plata los movimientos fueron casi simétricos con los de la Provincia. Al no contar con una conducción local robusta, los diferentes grupos pugnaron por acumular los meses previos en pos de un posicionamiento ventajoso para la obtención de candidaturas. Tras un año de acciones fragmentadas e intentos de acuerdos, los grupos comenzaron a trazar estrategias de masividad pública, como también de acuerdos que buscaran bloquear a otros sectores.

Florencia Saintout realizó de una cena de mujeres que contó con la presencia de casi 2000 asistentes, (INFOCIELO, 04/03/2017). Con el lema “Cristina Conducción”, la actividad lograba dos objetivos simultáneos: mantener la hegemonía dentro del centro delegativo local de la figura de Cristina Kirchner y, a la vez, disputar la representación de las demandas de igualdad de género al interior del peronismo. El FRP-FPV, por su parte, realizó una movilización "Contra el Ajuste” en la que estuvieron presentes, además de Pablo y Gabriel Bruera, Gonzalo Atanasof ${ }^{218}$ y Gastón Harispe, del Movimiento Octubres

\footnotetext{
${ }^{218}$ Quién tuvo una trayectoria oscilante dentro del peronismo: en 2005 ingreso como Concejal por el marco de alianzas que lleva como candidata a Senadora Provincial a Hilda Duhalde. En 2009 fue diputado Provincial por el frente Unión Pro. Y por último fue funcionario del gobierno provincial de Daniel Scioli.
} 
(Hoy, 10/06/2017), apostando por una estrategia que implicaba una organización más peronista local clásica y movimientos de ocupación del espacio público. El Frente Amplio Peronista, que tenía como referente al ex intendente Julio Alak, realizó un acto en conjunto con la Intendenta de La Matanza en la ciudad (InfoCielo 11/06/2017) mostrando su capacidad de conexión con sectores peronistas de peso territorial de la provincia ${ }^{219}$. Por su parte, Victoria Tolosa Paz, realizó una fuerte campaña callejera de instalación con afiches propios y un alto perfil de participación en diferentes medios de comunicación local y nacional. Todas estas acciones, además, incluían la generación de propaganda gráfica-ver propagandas $28,29,30,31,32$ y 33 - que se publicaba en el diario Hoy -de distribución gratuita en la ciudad- y con el cual, pareciera que el peronismo local había llegado a una suerte de acuerdo -que incluyó participación en la lista de diputados provinciales $^{220}$.

En lo que respecta al marco de alianzas de los actores que jugaron con Randazzo, la mayoría había construido una mesa promotora en la ciudad que ya tenía un cierto recorrido. Esto hizo que se supiera desde muy temprano (E1 Día, 05/06/2017) la existencia de una lista -finalmente para las PASO hubo dos- de Diputados Provinciales y Concejales de este espacio en la ciudad. Una de las organizaciones más importantes de este entramado fue el Movimiento Evita, pero también lo compusieron agrupaciones que estuvieron durante mucho tiempo con el FRP-FPV como el MUP o la Agrupación Evita $^{221}$, como también sectores que fueron aliados del FAP, como el Ateneo Eva Perón ${ }^{222}$. En este sentido, el "Frente Justicialista Cumplir" se nutrió de diversos sectores que en otros momentos estuvieron enfrentados en estrategias cruzadas.

\footnotetext{
219 Otro de los sectores que participó de estas estrategias de acumulación, fue el de los sindicatos nucleados en la CGT local, quienes realizaron un acto en señal de unidad y expresaron su intención de "volver a recuperar representación sindical en el PJ" (Hoy, 31/05/2017). Frente a la cercanía del cierre de listas Ilevaron la compulsa al punto de avisar que "estaban dispuestos a armar una lista" (El Día 6/06/207). ${ }^{220}$ Ver apartado 2.2 del presente capítulo.

${ }^{221}$ Es la agrupación que se formó tras la ruptura local del Movimiento Evita -ver apartado 4 del cap. 3 de la presente tesis- y que quedaron vinculados al FRP-FPV hasta el 2015 con altos cargos en la gestión municipal.

${ }^{222}$ Ver apartado 3.2 del presente capítulo.
} 
Propaganda 28

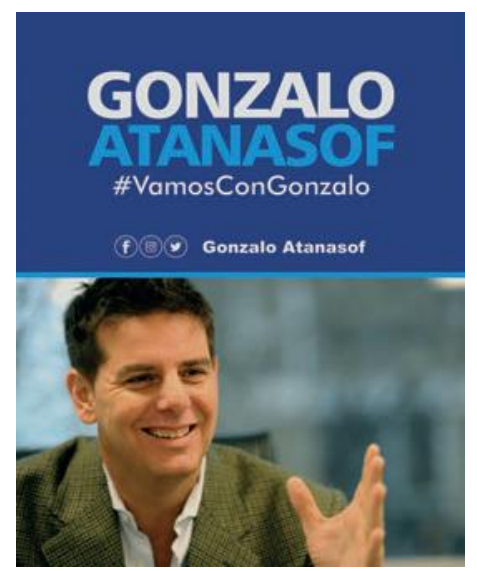

Fuente: Hoy

24/05/2017 p.6

\section{Propaganda 31}

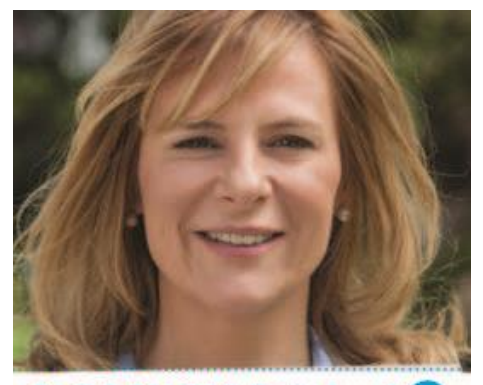

FLORENCIA Saintout $\mathrm{APR}$

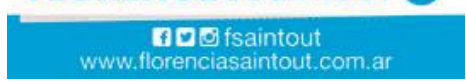

Fuente: Hoy

27/05/2017 p. 10.

\section{Propaganda 33}

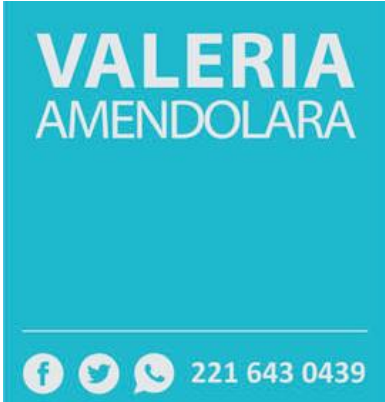

Fuente: Hoy 26/05/2017 p. 6.
Propaganda 29

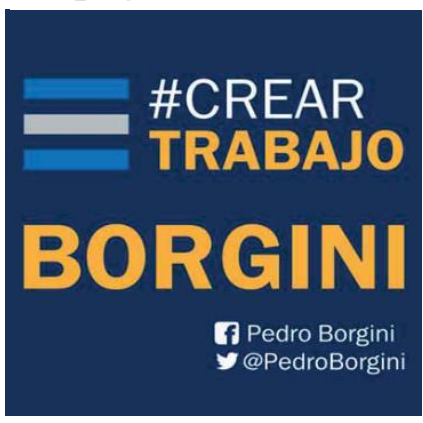

Fuente: Hoy

25/05/2017 p. 11.

\section{Propaganda 30}

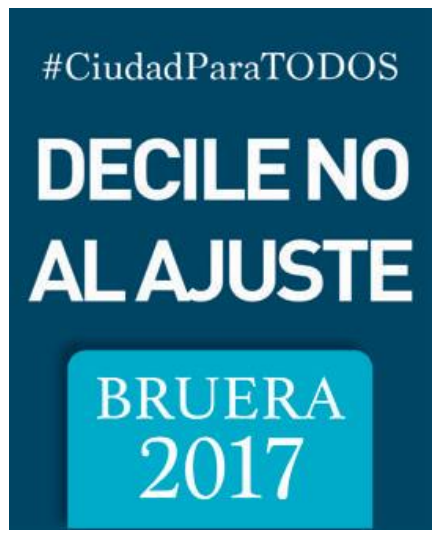

Fuente: Hoy $27 / 05 / 2017$ p. 5.

\section{Propaganda 32}

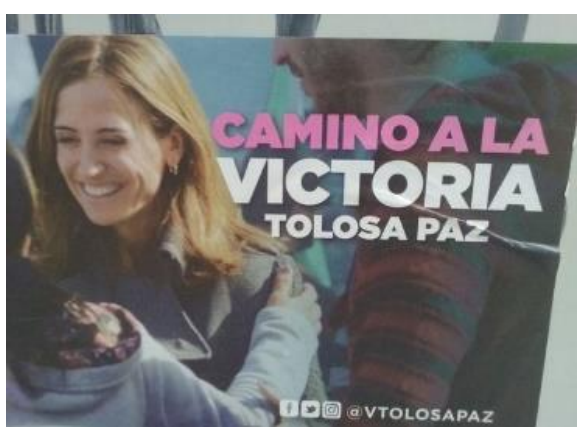

Fuente: NOVA 27/04/2017 Disponible en: http://www.agencianova.com/nota.asp? $\underline{\mathrm{n}=2017 \quad 4 \quad 27 \& \mathrm{id}=55626 \& \mathrm{id} \text { tiponota }=10}$ 
Un elemento central de las propagandas previas a los cierres de listas, es la ausencia de símbolos partidarios que todas comparten. Esta situación particular responde tanto al hecho de que hasta el cierre de listas no se sabía la denominación de los frentes electorales que finalmente se tejerían a nivel provincial, pero también se debía al proceso de acumulación. Con la dispersión como clave explicativa, ocurría que aún hasta semanas antes del cierre de listas, los grupos ensayaban diálogos cruzados en vistas a posibles candidaturas. El caso de Valeria Amendolara o el de Pedro Borgini ${ }^{223}$ que provenían del marco de alianzas del FRP-FPV y que buscaron ser candidatos en el Marco de alianzas de "Cumplir" (El Día, 15/06/2017). Durante todo el mes de Junio se armó un juego de doble presión de parte de muchos grupos, fundamentalmente de los que contaban con menor cantidad de militantes, en torno a la posibilidad de ocupar un lugar en un lado o en otro (El Día, 19/06/2017).

\subsection{Resultados Electorales}

Los resultados electorales en 2017 fueron interesantes a la luz de los procesos que se venían dando en eventos anteriores. Por un lado, la fórmula Cambiemos logro estabilizar sus votos en una cifra superior al $45 \%$ de los votos. Un dato más que significativo en la historia del distrito. En el caso del peronismo platense -ver tabla 4- dos situaciones fueron interesantes de observar: por un lado, el que el polo de agregación denominado Unidad Ciudadana alcanzó casi exactamente la misma cifra que 2 años antes -una diferencia de poco más de 400 votos. Por el lado de las propuestas del Frente Justicialista, aun cuando atravesaron holgadamente el piso de 1,5\% necesario para competir, su performance fue muy deficitaria al punto de no llegar a la cifra del 8,33\% necesaria para aspirar a ingresar un Concejal. Es importante notar el descenso de votantes en esta elección respecto a eventos anteriores, donde casi 3\% del padrón, respecto a los años anteriores no concurrieron a votar.

\footnotetext{
${ }^{223}$ Ninguno de los dos terminó siendo candidato. Otro caso similar fue el de Teresa Razzari quién fue parte de la Mesa promotora del Frente Cumplir y que no aceptó ser candidata finalmente (Infoplatense, 28/06/2017).
} 
Tabla 4 Resultados electorales La Plata

\begin{tabular}{|c|c|c|c|c|}
\hline \multirow[b]{2}{*}{ Fuerza } & \multicolumn{2}{|c|}{ Paso } & \multicolumn{2}{|c|}{ Generales } \\
\hline & Votos totales & Porcentaje & Votos totales & Porcentaje \\
\hline CAMBIEMOS BUENOS AIRES & 164529 & 40,85 & 203.970 & 48,13 \\
\hline UNIDAD CIUDADANA & 99992 & 24,82 & 115.801 & 27,33 \\
\hline FRENTE JUSTICIALISTA & 30436 & 7,56 & 25.168 & 5,94 \\
\hline ALIANZA 1 PAIS & 49954 & 12,4 & 38.021 & 8,97 \\
\hline FIT & 19900 & 4,94 & 26.638 & 6,29 \\
\hline VAMOS CREANDO CIUDAD NUEVA & 9086 & 2,26 & 10.399 & 2,45 \\
\hline $\begin{array}{l}\text { IZQUIERDA AL FRENTE POR EL } \\
\text { SOCIALISMO }\end{array}$ & 6662 & 1,65 & 3.767 & 0,89 \\
\hline $\begin{array}{l}\text { CORRIENTE DE PENSAMIENTO } \\
\text { BONAERENSE (CO.PE.BO) }\end{array}$ & 5861 & 1,46 & - & - \\
\hline PARTIDO FEDERAL & 4566 & 1,13 & - & - \\
\hline PARTIDO FEDERAL & 4566 & 1,13 & - & - \\
\hline PARTIDO SOCIALISTA & 4445 & 1,1 & - & - \\
\hline ALIANZA FRENTE UNION FEDERAL & 2179 & 0,54 & - & - \\
\hline PARTIDO RENOVADOR FEDERAL & 1810 & 0,45 & - & - \\
\hline UNION VECINALISTA PLATENSE & 1225 & 0,3 & - & - \\
\hline PARTIDO TODOS POR BUENOS AIRES & 1180 & 0,29 & - & - \\
\hline $\begin{array}{l}\text { ENCUENTRO POPULAR POR } \\
\text { TIERRA, TECHO Y TRABAJO }\end{array}$ & 985 & 0,24 & & - \\
\hline $\begin{array}{l}\text { Total de Votos / porcentaje sobre } \\
\text { el padrón total }\end{array}$ & 424293 & 74,18 & 437.934 & 76,56 \\
\hline
\end{tabular}

2. Actuación de Unidad Ciudadana ante las elecciones del $2017^{224}$

La decisión de conformar el Frente Unidad Ciudadana a nivel provincial trazó una clave organizativa que rápidamente derramó sobre los distritos: la propuesta electoral sería excluyente de la estructura del PJ, pero incluyente de los grupos que quisieran desplazarse hacia ese mismo frente. A su vez, en los lugares donde existiera un punto de acumulación en la figura de un intendente, las listas de UC estarían diseñadas por el mismo. En el caso de La Plata, la configuración fue más difícil. Sin figuras de peso indiscutido -aunque con varias representaciones- se conformó una mesa de discusión en la que participaron varios grupos. La dificultad para estructurar un criterio de distribución de candidaturas radicaba en dos puntos centrales: por un lado el problema de la imposible equivalencia de los capitales políticos, puesto que mientras unos grupos contaban con la construcción de

\footnotetext{
${ }^{224}$ Debido a que esta fuerza no tuvo contrincantes en las PASO se analiza su actuación como un continuo entre ambas elecciones.
} 
varios años en torno a la sobre-representación de la figura de Cristina Kirchner en La Plata, otros mantenían una fuerte penetración territorial en los barrios periféricos ${ }^{225}$; otros contaban con cuadros históricos del peronismo con espacios institucionales, y, por último, otros grupos contaban con redes propias con Intendentes de distritos populosos de la Provincia -lo que les aseguraba a estos niveles importantes de participación en la discusión provincial de las listas- que les servía de plataforma para ingresar en la discusión.

El otro problema central para el armado de listas era la cuestión del horizonte político: quienes ocuparan los lugares más visibles de las categorías locales posiblemente se quedarían con la referencia política para posteriores elecciones. Además, como no era segura la victoria, los primeros cargos serían los que ingresarían a los espacios legislativos en disputa. El problema del equilibrio de fuerzas entre los grupos, sin una figura que oficiara de decisora, implicaba también al futuro cercano.

Tras el acuerdo y la distribución de cargos, la campaña se desarrolló de forma bastante lineal a diferencia de la realizada a nivel provincial ${ }^{226}$. La misma osciló entre intervenciones urbanas, coordinadas por "subcomandos de campaña" -el número total fueron 22 y ocuparon todos los circuitos electorales de la ciudad-, una importante cantidad de intervenciones en redes sociales que completaba la estrategia comunicacional centrada en el diario $\mathrm{Hoy}^{227}$, y un conjunto de actos masivos, entre los cuales se destaca el realizado por Cristina Kirchner, tras las PASO en el club Atenas (El Día 30/08/2017) ${ }^{228}$. Si se tiene en cuenta que la candidata a Senadora Nacional no realizaba un acto de campaña en La

\footnotetext{
225 Al respecto vale la pena remarcar que en las elecciones PASO del 2015, Saintout consiguió mayor caudal de votos en los circuitos del centro de la ciudad -mayoritariamente habitados por sectores de clase media-, mientras que Pablo Bruera obtuvo mayor cantidad de votos en barrios periféricos -de mayor tradición peronista (Diario CONTEXTO, 24/08/2015. Disponible en: http://www.diariocontexto.com.ar/2015/08/24/el-triunfo-de-saintout-en-el-casco-urbano-clave-parafrenar-a-cambiemos/).

${ }^{226}$ La campaña de UC a nivel provincial presentó dos grandes perfiles: hasta las PASO las formas de intervención estuvieron centradas en las intervenciones de los vecinos de diferentes localidades -donde las y los candidatos se presentaban como facilitadores de la masificación el mensaje de dichas personas-; la segunda etapa de la campaña estuvo centrada en la búsqueda de votos identificados con el peronismo tradicional, así como también en la figura de Taiana -segundo candidato a Senador Nacional.

227 Durante la campaña y, en este diario, salieron a relucir tensiones internas del frente en forma de editoriales periodísticas que tenían como destinataria a la figura de Vitoria Tolosa Paz (Hoy, 02/08/2017). La acusación radicaba en que esta candidata sostenía una estrategia comunicacional propia. ${ }^{228}$ También hubo una recorrida por las calles y luego un acto con Jorge Taiana (INFOCIELO 09/08/2017).
} 
Plata desde el $2009^{229}$, el mismo tuvo un peso simbólico significativo.

Otra de las actividades masivas realizadas fue por el Aniversario de la Muerte de Eva Perón -ver propaganda 34- en la que se realizó una movilización (Hoy, 27/07/2017), la cual presenta cierta importancia dado que fue una de las pocas acciones donde se recuperó la vinculación "informal" - dada la estrategia de campaña del frente de UC- entre la lista de UC y el peronismo. Como se puede observar en la imagen de invitación, la frase "el peronismo con Cristina" instala una vinculación de hecho entre ambos espacios intentado

\section{Propaganda 34}

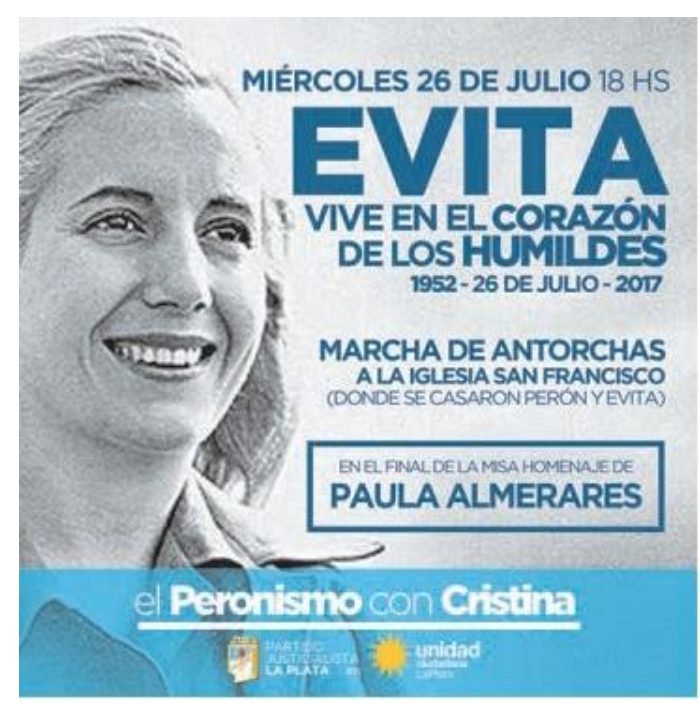

Fuente: Hoy, 26/07/2017, pág. 7 cerrar cualquier iniciativa de discusión sobre si UC expresaba una nueva forma de articulación política por fuera de la identidad peronista.

En términos de estructuración discursiva, la campaña de UC en La Plata sólo reparó en su polarización con el frente CAMBIEMOS, sin dar lugar a la discusión con el Frente Cumplir ni con otras agrupaciones. Salvo lo ocurrido con la figura de Sergio Mannarino, quien fuera precandidato por el Frente Cumplir y que decidiera tras las paso apoyar la lista de UC (La Política Online, 19/08/2017), la estrategia de perforar el marco de alianzas del Frente Cumplir no tuvo una relevancia significativa. Otro elemento que cruzó toda la campaña electoral fue el caso del pedido por la libertad de Mariano Bruera ${ }^{230}$ (Hoy, 15/09/2017) la cual, si bien no constituyó parte del discurso central de los y las candidatas de UC, si fue parte de los movimientos de los integrantes del FRP-FPV y fueron públicas.

\subsection{Estrategia electoral}

\footnotetext{
${ }^{229}$ En rigor hubo un acto, fuera de las campañas electorales, en el 2016 organizado por el frente de agrupaciones que conducían dicho año la Federación Universitaria de La Plata (FULP) y en el que CFK expuso su intención de "contribuir al armado de una frente electoral amplio y heterogéneo" (El Día, 21/09/2016).

${ }^{230} \mathrm{El}$ tercer de los hermanos quien fuera encarcelado con prisión preventiva en una causa por coimas. Ver nota 184, cap. 5 de la presente tesis.
} 
La construcción de candidaturas finalmente quedó saldada con cierta simetría a las categorías nacionales: las primeras candidatas fueron mujeres y, respetando la ley de paridad de género ${ }^{231}$, el resto de las candidaturas fueron alternando hombres y mujeres. En la categoría para la diputación provincial, Florencia Saintout ocupó el primer lugar. Este espacio de referencia claramente estuvo vinculado al ciclo de crecimiento en la performance electoral que dicha candidata obtuvo desde su primera elección en 2013, conjuntamente con el conjunto de variables coyunturales que coadyuvaron a esta salida parcial del esquema de dispersión. Si se reconstruye la trayectoria de esta candidata, se puede observar que la misma muestra cierta similitud con la realizada por Pablo Bruera entre el 2003 y 2007, en tanto fueron atravesando procesos electorales en una estrategia de acumulación de votos y consolidación de la imagen en el espacio público local.

En la categoría para concejales, sin embargo, hubo una sorpresa. La primera candidata fue Victoria Tolosa Paz, quién salvo marcadas ocasiones, no había tenido protagonismo en el peronismo local y respondía a una agrupación de las que surgieron solo dos años antes. La diferencia que volcó la posibilidad a su favor fue sin dudas su capacidad de instalación pública -realizó una fuerte campaña callejera y de medios nacionales- como también su modulación de un discurso municipalista-peronista, que se diferenciaba tanto del vecinalismo que supo construir el FRP-FPV y el municipalismo-vertical de la coalición de UyO que operó hasta 2015. Al respecto, la candidata sostuvo:

"Había una voz que se unificaba que era la imagen de Cristina en el centro de la escena política, no porque se nos ocurriera a nosotros los que teníamos pretensiones electorales, sino que eso surge de caminar los barrios. La gente la reconoce a ella que mejoró su calidad de vida en los últimos 12 años, que, si bien faltaba muchísimo, había un cambio en esto que era que se garantizaba el plato de comida en cada casa, los pibes podían ir al colegio, había una mirada. Y en eso nuestra ciudad tuvo dificultades enormes [...] Yo creo que la provincia se va a recuperar con esta cantidad de intendentes. No sé cuál va a ser nuestra figura de cara al 2019, pero sin lugar a dudas me parece que el nacimiento de una manera de mirar la provincia y de tratar de encontrar nuevamente tener un gobernador o una gobernadora afin, va a pasar por los intendentes." (Entrevista a Victoria Tolosa Paz, septiembre de 2017)

Resulta significativa esta intervención puesto que se advierte una modulación novedosa

${ }^{231}$ Ley 14848 de la Provincia de Bs. As. 
respecto de las formas discursivas del peronismo local en la última década. En este caso se trata de una acentuación de las figuras de los intendentes peronistas los cuales, tras los procesos de recambios generacionales que se produjeron en los años del gobierno del FPV, ya no se figuraban en el formato de los barones del conurbano sino más bien en actores con capacidad de gestión. Sea cual fuere la variable que determinó la posibilidad de esta candidatura, a la vista de los actores extra municipales del peronismo, este discurso resultaba convocante en torno a una figura que podía abrevar en marcos de alianzas provinciales.

\subsection{Marco de alianzas}

La lista de Unidad Ciudadana reflejó los varios acuerdos a los que arribaron los diferentes grupos.

\section{Listado de candidatos 11}

\begin{tabular}{|c|c|}
\hline \multicolumn{2}{|c|}{ Diputados Provinciales de Unidad Ciudadana } \\
\hline Candidato/a & Organización \\
\hline \multicolumn{2}{|c|}{} \\
\hline Florencia Saintout & Unidos y Organizados (Frente) \\
\hline Guillermo Escudero & FRP-FPV \\
\hline Mirta Mariño & SOEME \\
\hline Juan Nieves & UPCN \\
\hline Elsa Huwiler & Soberanía Nacional \\
\hline Jorge Luis Carpinetti & Lalumna Alberti \\
\hline
\end{tabular}


Listado de candidatos 12

\begin{tabular}{|c|c|}
\hline \multicolumn{2}{|c|}{ Concejales de Unidad Ciudadana $^{232}$} \\
\hline Victoria Tolosa Paz & Casa Para la Victoria Peronista \\
\hline Aníbal Norberto Gomez & Frente Amplio Peronista \\
\hline Ana Castagneto & Kolina \\
\hline Cristian Vander & $\begin{array}{c}\text { Sindicato de Obreros, Especialistas y Empleados } \\
\text { de los Servicios e Industria de las } \\
\text { telecomunicaciones de La Plata }\end{array}$ \\
\hline Alejandra Marcela López & FRP-FPV \\
\hline Oscar Blanco & Por los Principios Sociales \\
\hline Julia Lucía Di Jorgi & Peronismo Militante \\
\hline Alberto Ramón Ramírez & Frente Político y Social Carlos Cajade \\
\hline Sabrina Noemí Rodríguez & Los Apóstoles de Perón \\
\hline Jorge Ignacio Malpeli & Vuelta de Obligado \\
\hline Gabriela Chaparro & La Walsh \\
\hline Ángel Clemente Ibáñez & John William Cooke \\
\hline
\end{tabular}

El criterio que primó, nuevamente, fue de tipo inclusivo de diferentes grupos, más que un criterio territorial o por sectores. Salvo los espacios que estuvieron vinculados a las listas del Frente Cumplir, casi todos los grupos con cierta relevancia en el entramado local del peronismo podían encontrar un o una referente en estas boletas ${ }^{233}$. Resulta más que significativo el hecho de que La Cámpora no obtuviera ninguna candidatura, como también que quienes ocuparon espacios de representación como Concejales en otros momentos ahora fueran relegados a lugares poco probables de ingreso. El caso de Mirta

\footnotetext{
232 En esta categoría se listan solo los titulares por una cuestión de espacio.

233 Cabe destacar que el grupo Octubres obtuvo la segunda candidata a Consejera Escolar -Silvina Kociancich. Además otros grupos, de los surgidos tras el ballottage, obtuvieron cargos testimoniales, como Hnatiuk Juan -de la agrupación 25 de Mayo- cuarto candidato a Concejal suplente y Sbattella Violeta -Vecinxs Unidos Contra el Neoliberalismo- que fuera primera candidata suplente a Concejera Escolar. Por su parte el MPU sostuvo que no quisieron tener candidaturas y que se sentían identificadas con la lista de UC.
} 
Mariño, del gremio de SOEME debe comprenderse también en la vinculación que dicha estructura gremial tiene con el diario Hoy.

\subsection{Construcción identitaria particular}

La estrategia comunicacional de UC de La Plata pasó principalmente por las redes sociales $^{234} \mathrm{y}$, como ya se comentó, por el matutino Hoy, como contrapartida a la fuerte disputa que la candidata Saintout sostuvo con el diario El Día -donde no se realizó ninguna publicidad de campaña ${ }^{235}$. El análisis de las formas de interpelación utilizadas para esta campaña permite recobrar algunos aspectos: en primer lugar se asiste a una suerte de vaciamiento de los símbolos del peronismo como identidad política. La simbología de UC no muestra conexiones entre una identidad y otra, salvo por las candidaturas. Esto pudo deberse al desplazamiento táctico respecto a la estructura del PJ y con ello, la imposibilidad jurídica de utilizar dichos símbolos. Sin embargo, tampoco aparecen elementos que vinculen simbólicamente la propuesta con los años del Kirchnerismo en el ejercicio del poder ejecutivo nacional -ver propaganda 36-. Esto, que para algunos medios nacionales, fue tomado como una forma de "camuflaje", refleja un posicionamiento político novedoso, principalmente hacia el peronismo como identidad en tanto expresa una postura inclusiva de diferentes identidades, situada en una posición progresista del arco ideológico ${ }^{236}$.

Otro elemento a tener en cuenta es el tipo de modulación discursiva en torno a las propuestas: la estrategia comunicacional en este punto se centró en el impacto que las políticas nacionales tuvieron sobre el distrito. Se trató de una agenda descendente en tanto comprendía que los problemas locales centrales resultaban de las malas decisiones del

\footnotetext{
${ }^{234}$ La propaganda política en redes es un fenómeno relativamente reciente -en términos de masividadque merece un estudio pormenorizado de los casos. En una rápida observación dos elementos saltan a la luz: en primer lugar hay cierto factor de desterritorialización en tanto las actividades locales -incluso barriales- se transforman en intervenciones con impacto des-localizado geográficamente. El otro elemento es que su ínfimo costo genera una superabundancia de intervenciones y una cierta fragmentación discursiva en tanto los materiales se generan desde diversos puntos del entramado militante.

${ }^{235}$ Salvo el caso de Victoria Tolosa Paz que visitó los estudios televisivos del diario en 2 ocasiones: el 11/08 (disponible en https://www.youtube.com/watch?v=T82Re1y DXo) y el 25/08 (disponible en https://www.youtube.com/watch?v=E8d3wX-Ds2Y) .

${ }^{236}$ En una entrevista concedida en Septiembre de dicho año Capitanich -Ex jefe de Gabinete nacional del gobierno del FPV- expresaba que "El kirchnerismo sin el resto del PJ no alcanza y el peronismo solo no gana" (Letra P, 02/09/2017)
} 
gobierno nacional. Parte de este tipo de modulación discursiva puede comprenderse a la luz de que la propaganda gráfica establecía como punto de acumulación política más importante la figura de Saintout -ver propaganda 35-. En los medios de comunicación gráficos, no apareció otra figura candidato/a destacada como dicha referente. Además, el voto que se buscó fue el de clase media, en tanto se desprende que los “costos" del ajuste tuvieron a estos como principal segmento poblacional sobre el que recaer.

Propaganda 36

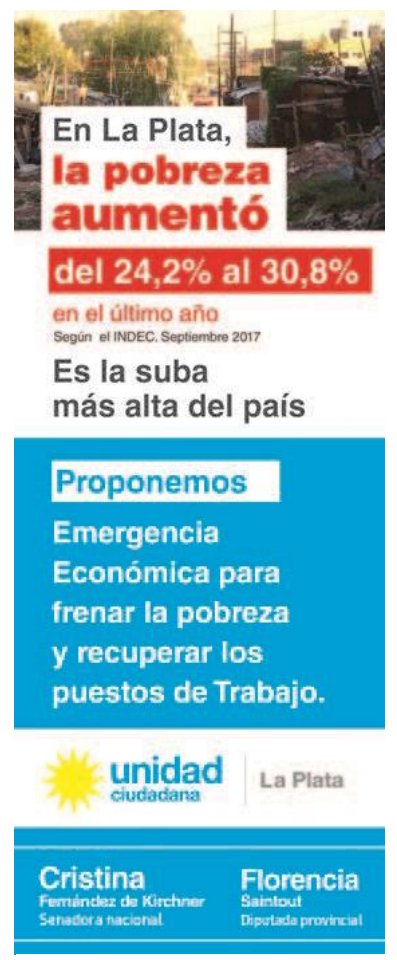

Fuente: Hoy,

01/10/2017, pág. 11

\section{Propaganda 35}

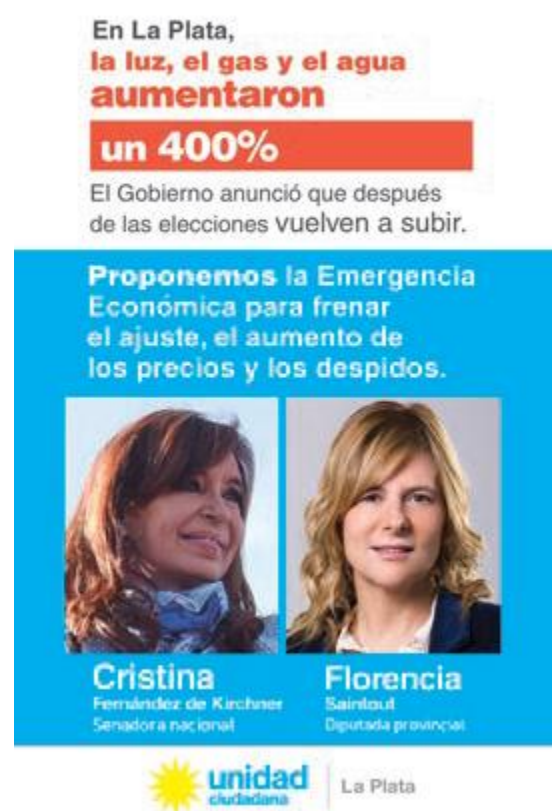

Fuente: Hoy, 02/10/2017, pág. 09 


\section{Actuación del Frente Cumplir}

La constitución del Frente Cumplir en los niveles municipales, se produjo sobre las bases de las mesas promotoras que se originaron en el 2015 cuando Randazzo intentó ser pre candidato a presidente. En particular, en la ciudad de La Plata, estas mesas se expandieron en los inicios del 2017 -además de las agrupaciones legítimamente identificadas con la propuesta de Randazzo- con la inclusión de diversas agrupaciones que ingresaron por acuerdos provinciales -como el Movimiento Evita- o lo hicieron en el marco de la dispersión por la imposibilidad de obtener espacios de referencia en lo que termino siendo la estructura de alianzas de UC.

A diferencia de otros espacios, en La Plata, este Frente fue a internas. A nivel de las categorías locales, existieron cerca de cierre de listas la disputa entre diversos sectores (E1 Día, 21/06/2017) que terminó con la conformación de dos propuestas en las categorías locales. La actuación de este espacio fue extraña y poco homogénea. Si bien en principio hubo reuniones e intentos de no llegar a internas (El Día, 24/06/2017) que fracasaron; lanzados a la competencia los espacios tuvieron intervenciones por separado y pocas estrategias comunes. Al respecto un referente contaba:

“Hubo una mesa común de todos y después obviamente había tantos referentes...porque la verdad es que el espacio fue un espacio muy rico de discusión. Era un espacio con tantos referentes que armar una sola lista implicaba resignar para muchos compañeros, muchos lugares. Yo era partidario de la lista única. Obviamente que en ese contexto no dio porque hubo intransigencias también. [...] Pero vos fijate que dentro de ese marco la interna fue sana. Con un debate de ideas regidas por un mismo eje, donde la premisa siempre fue la misma de ambas listas, y donde no hubo un daño ni físico ni moral. [...] Y al otro día dimos el ejemplo de peronismo, nos juntamos todos, hicimos una cena, nos pusimos de acuerdo para ver cómo empezábamos a construir una campaña entre todos." (Entrevista a Ramón Galache, septiembre 2017).

Ocurrió, además, que ambos espacios modularon un discurso para el cual la figura de Randazzo constituía el punto de acumulación más importante de las boletas. Ninguno de los dos espacios generó acciones masivas, por lo que las campañas se desarrollaron sobre la base de actividades de intervención puntual -caminatas, timbreados, acciones en comedores y copas de leche, etc.- además de la visita del candidato a Senador que se 
produjo en el marco de una caminata y un acto (El Día 10/09/2017).

Tras las PASO la distribución siguió la carta orgánica del $\mathrm{PJ}^{237}$ y la lista oficializada para la competencia de Octubre fue la lista 2 que sumó en cuarto lugar a Federico Martelli. En los meses que trascurrieron hasta Octubre, la campaña continuó siendo escasa en intervenciones y propagandas. Al igual que a nivel provincial, este espacio construyó una intervención pública que intentó polarizar tanto con CAMBIEMOS como con UC. La búsqueda de un votante de corte peronista pero crítico de la figura de la ex presidenta, resultaba un intento difícil de perforar el techo que la polarización establecida entre las dos grandes coaliciones. Esta quizás sea una de las explicaciones posibles de la baja en la competitividad electoral entre Agosto y Octubre.

\subsection{Estrategia electoral}

A nivel local la estrategia de ambos espacios se trazó sobre las cabeceras de las categorías: tanto los candidatos a Diputados Provinciales como a Concejales fueron los que tuvieron mayor nivel de exposición. En ambas listas, los candidatos a Diputados Provinciales, si bien no contaban con índices de reconocimiento público significativos, presentaban a cierta trayectoria electoral -el caso de Justo Chaves- o una organización importante con anclaje territorial y una trayectoria legislativa -como el caso de Di Marzio.

La instalación de los candidatos, además de ser un objetivo claramente identificable, iba acompañada de una estrategia de polarización doble: hacia la lista de CAMBIEMOS en términos de un discurso más de tipo peronista clásico, el cual trazaba la frontera entre formas de intereses de clase. Frente a la lista de U.C. la búsqueda era tratar de capitalizar el votante peronista no alineado con la figura de la Ex Presidenta, como también de aquellos que buscaban en la estructura partidaria una forma de modular la participación política.

${ }^{237}$ Al igual que ocurrió en 2015 . Ver apartado 4.3 cap. 5 de la presente tesis. 


\subsection{Marco de alianzas}

Tanto la lista 2 como la lista 4 se construyeron teniendo en cuenta la articulación de los lugares más accesibles a entrar en la legislatura, tanto a nivel de Diputados como de Concejales, en una hipotética buena performance electoral.

\section{Listado de candidatos 13}

\begin{tabular}{|c|c|}
\hline \multicolumn{2}{|c|}{ Diputados Provinciales Lista 2 Alianza Cumplir } \\
\hline Nombre & Agrupación \\
\hline Gustavo Di Marzio & Movimiento Evita \\
\hline Norma Antonia Benitez & Ateneo Eva Perón \\
\hline Roberto Daniel Prandini & Ateneo Eva Perón \\
\hline
\end{tabular}

\section{Listado de candidatos 14}

\begin{tabular}{|c|c|}
\hline \multicolumn{2}{|c|}{ Concejales Lista 2 Alianza Cumplir } \\
\hline Nombre & Agrupación \\
\hline Paula Lambertini & Agrupación Evita \\
\hline Diego Fernández Camillo & Movimiento Evita \\
\hline Gudalaupe Reboredo & CONAPLA \\
\hline Ramón Galache & La Cafiero \\
\hline
\end{tabular}

Este espacio utilizó un criterio muy similar al que se pudo observar en UC, por el cual se puso de manifiesto la importancia de los grupos por sobre otra forma de estructurar las listas. Si se leen de manera conjunta ambos listados -que constituyen los nombres más sobresalientes de candidatos- se puede observar que este marco de alianzas distribuyó teniendo en cuenta un criterio que priorizó, posiblemente, cierta horizontalidad entre los grupos que compusieron el espacio. Resulta importante resaltar para este caso dos situaciones: por un lado los lugares sobresalientes que obtuvo el Movimiento Evita, acorde a los acuerdos provinciales que habían trazado con Randazzo. Por otro lado, el 
hecho de que la lista contenga a las agrupaciones que estuvieron enfrentadas hasta el 2015, permite pensar que también este marco de alianzas fungió como un espacio de contención para aquellas agrupaciones que quedaron fuera del cierre de UC.

Por su parte, la lista 4 se conformó de la siguiente forma:

\section{Listado de candidatos 15}

\begin{tabular}{|c|c|}
\hline \multicolumn{2}{|c|}{ Diputados provinciales Lista 4 Alianza Cumplir } \\
\hline Nombre & Agrupación \\
\hline Guillermo Justo Chaves & Espacio Bicentenario \\
\hline Aranguren Marisol & MUP \\
\hline Claudio Carvalho & Corriente Peronista para la Victoria \\
\hline
\end{tabular}

\section{Listado de candidatos 16}

\begin{tabular}{|c|c|}
\hline \multicolumn{2}{|c|}{ Concejales Lista 4 Alianza Cumplir } \\
\hline Nombre & Agrupación \\
\hline Federico Martelli & MUP \\
\hline Antuña Gisela Martinez & MUP \\
\hline Pablo Acosta & Hermandad Peronista \\
\hline Cecilia Gómez Miranda & MUP \\
\hline
\end{tabular}

En este caso, el criterio que salta a la vista es mucho más restrictivo que el de la lista anterior. Sea por simplemente haber correspondido a un deseo de ir a internas por parte de estas agrupaciones ${ }^{238}$ o, posiblemente, por la inexistencia de lazos horizontales previos fuertemente consolidados, esta lista se compuso casi en su mayoría por una agrupación predominante -el MUP.

\footnotetext{
${ }^{238}$ La referencia a las intransigencias que sostuvo el entrevistado Ramón Galache.
} 


\subsection{Construcción Identitaria Particular}

La estrategia comunicacional del Frente Cumplir en sus dos listas y posteriormente de las PASO se basó en la instalación de los candidatos. Puesto que ninguno de los actores contaba por sí mismo con una proyección electoral propia, se trató de campañas gráficas que tenían como propósito la instalación de las figuras. La escasa campaña gráfica derivó en una campaña en redes sociales, que al igual que el caso de UC, presentaba el problema de la dispersión y la fragmentación.

Los elementos centrales de esta construcción discursiva estuvieron puestos en la apelación al peronismo como identidad fuerte y a la utilización del lema provincial del "valor de la palabra" -ver propagandas 37 y 38- que provenía de la figura de Randazzo y su accionar en 2015, cuando el mismo se negó a ser candidato a Gobernador por el FPV al renunciar a su precandidatura a Presidente. En el caso de la lista 2, donde el Movimiento Evita presentaba candidatos, la gráfica contó además con la apelación a la pobreza y la niñez -temáticas de trabajo propias de este espacio. 


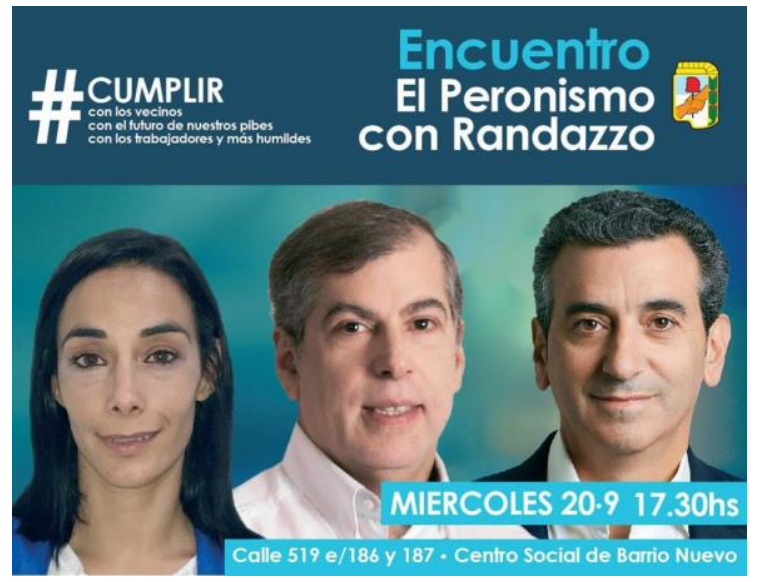

Propaganda 37

Fuente:

https://www.facebook.com/movimientoevi talp/

$18 / 09 / 2017$

Disponible en:

https://www.facebook.com/movimientoevi

talp/photos/rpp.279830725437183/147493

6032593307/?type=3\&theater

Propaganda 38

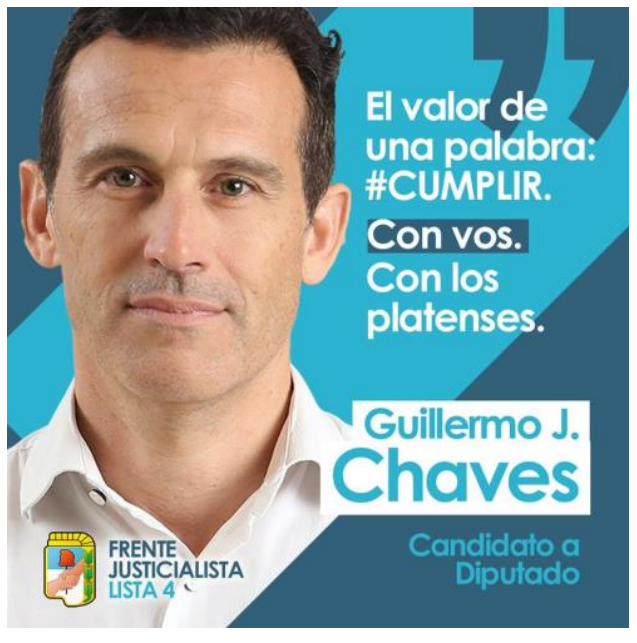

Fuente:

https://www.facebook.com/gjustoc haves

24/07/017

Disponible en:

https://www.facebook.com/Chaves

GJ/photos/ecnf.623991790/136056

9414057268/?type=3\&theater 


\section{Conclusiones}

El análisis de las interacciones entre agrupaciones peronistas en el FPV -Unidad Ciudadana, para ser más precisos- platense de cara a los comicios de 2017 presenta varios datos importantes para esta investigación. En primer lugar, la clave de la dispersión, originada tanto por la derrota electoral y la salida del peronismo del ejercicio del gobierno municipal, le permitió a las organizaciones con poca trascendencia hasta ese momento lograr posicionarse en el espacio público con cierta notoriedad. Claramente no todas las agrupaciones buscaban protagonizar la construcción de una nueva hegemonía, pero si al menos conducir y participar en un proceso de recambio de élites locales. Fue posible observar también cierto crecimiento por diferenciación que, aunque las causas de esa misma diferenciación resulten siempre particulares, en términos de efectos de una mirada global, aporta a la comprensión de la capacidad del peronismo local de incorporar sectores a la cotidianeidad política institucional. La constitución en torno a una demanda política como eje central de construcción -sea esta el caso del género, o la exigencia de un fortalecimiento de las reglas partidarias, o un recambio dirigencial- presenta un desafío analítico para la comprensión de la constitución de la agenda del peronismo a nivel local. Atravesadas por las formas coyunturales que adoptó esta identidad en los últimos años, el que sean agrupaciones y no líneas internas, pareciera indicar que la estructura partidaria continúa su derrotero simplemente como espacio de encuentro, más que como una forma institucionalizada de participación militante. Así también, los eventos multiorganizacionales observados, no solo traslucieron la gran cantidad de agrupamientos que participan en la ciudad - con un alto índice de fluidez interna- sino también los modos de articulación y crecimiento conjuntos en tanto construyeron agendas comunes.

También en relación con la dispersión, la rearticulación de los diferentes polos de agrupamientos mostró que la fractura existente -y analizada en el capítulo anterior- al interior de peronismo platense se debilitó frete al escenario de baja performance electoral, permitiendo una reunificación. Ciertamente esto implicó un cambio en la figura de la candidatura con proyección electoral, lo cual es, por lo analizado hasta este momento, central en las formas de articulación local. Pareciera ser que el polo de agrupaciones de UyO capitalizó el fenómeno de externalización iniciado en 2011 logrando establecerse como la renovación necesaria del peronismo a nivel local. Sin embargo, el costo de esta suerte de sutura, implicó el abandono de los mecanismos adoptados al interior del marco 
de alianzas para la distribución de cargos permitiendo que agrupaciones importantes como La Cámpora no obtuvieran candidatos con expectativas de ingreso al consejo Deliberante. Ciertamente en el marco de una reunificación como la observada y con un fenómeno de surgimiento de nuevos agrupamientos, se produjo un cuello de botella entre la cantidad de cargos existentes y la cantidad de espacios en disputa que terminó - también posibilitada por los movimientos de actores provinciales- por generar una nueva fractura. El conjunto de agrupaciones que se vincularon a la mesa promotora de la candidatura de Randazzo, dejando de lado aquellas que lo hicieron por acuerdos provinciales, bien podrían haber sido parte -al observar sus trayectorias en elecciones anteriores- del agrupamiento de Unidad Ciudadana, si no fuera por la escasa capacidad de este de contenerlas en el marco de una esperable baja performance electoral. 


\section{Conclusiones}

"Buscábamos probar, simplemente, que la realidad social había resultado distinta de lo pensado" Miguel Murmis y Juan Carlos Portantiero

La presente investigación partió de problematizar una cuestión que retorna como cuestión académica y política: la unidad del peronismo. La observación de las dinámicas de cooperación, competencia y acuerdos en el peronismo de la ciudad de La Plata permitió anclar esta cuestión en un nivel poco estudiado: lo local. Elegimos, entonces, poner el foco en el estudio de los diferentes factores que influyen en la dinámica del peronismo, que explican los diferentes posicionamientos de los actores y ayudan a comprender la unidad del peronismo, sus tensiones y sus rupturas.

Esta diversidad, agonística en muchos casos, tensionaba la compresión de la identidad peronista si esta solo se basaba en el fenómeno de la adscripción de los y las actoras. Y es que cada expresión que lograba articular una propuesta electoral expresaba fuertes contrastes con las otras, tanto en relación con un posicionamiento a nivel nacional o provincial, como también en relación a los modos de construcción colectiva y formas de negociación. Se trataba, entonces, de una complicación en la que claramente se articulaban dos preguntas distintas. Por un lado, ¿cómo era posible pensar la unidad de una fuerza política que mostraba una permanente diferenciación de sus términos? La suposición de que esta pregunta nos enfrentaba a un problema de investigación estaba dada por la imposibilidad de responderla apelando tanto a una unidad virtual que desde fuera del devenir histórico operaría como un lazo de comunión entre los militantes; cuestionamiento que tampoco encontraba respuesta inversa, apelando a una suerte de multiplicación incontenible que sostuviera la idea de que existían muchos peronismos. La unidad del peronismo estaba ahí, frente a los ojos de todos, pero de modo inasible.

La segunda pregunta, derivada quizás de la primera, de carácter más particular indagaba por la especificidad de lo local en ese problema de la unidad: ¿Qué papel jugaban los y las actoras del peronismo local en los procesos de construcción colectiva de esta fuerza política? ¿Se trataba solo de una inscripción de lo local en construcciones nacionales o provinciales? Ciertamente como se ha mencionado a lo largo de toda esta investigación, 
el caso del peronismo platense y su abigarrado universo de grupos y sectores, rápidamente precipitaba la sospecha de que era necesario atender las interacciones locales sin someterlas, ni derivarlas, de las interacciones nacionales y/o provinciales.

Estas dos preguntas animaron esta investigación de manera inter relacionada. Buscando una respuesta que satisficiera ambos interrogantes es que derivamos en el ejercicio de la representación, su especificidad en el estrato organizativo y los fenómenos de negociación asimétrico que estas entablaban con actores de otras dimensiones. A continuación, presentaremos entonces las conclusiones a las que arribamos.

A lo largo de los diferentes capítulos empíricos se pudo observar la existencia de dos lógicas de representación distintas a nivel municipal que disputaron el campo representacional del peronismo platense. Esta disputa atravesó diferentes escenarios sobre los que las posiciones de los polos de agrupamientos fueron modificándose teniendo en cuenta diversas variables, trazando trayectorias que acumulaban una experiencia y operaban sobre horizontes de posibilidades cambiantes. Además de esto, desde una mirada general, es posible sostener que fue esta misma tensión la que le permitió al peronismo en estos años tener una participación en la agenda pública de modo permanente y diferenciado ocupando gran parte del arco ideológico de enunciación pública.

Ahora bien, en lo que hace en particular a estas lógicas de representación, es importante marcar que, a diferencia de las agrupaciones locales, estas fueron más visible a nivel general y por ende, también las que permitieron establecer un registro histórico de la trayectoria del peronismo en el distrito. Aunque las mismas no se agotaron en las personas, claramente por estar signadas por el ejercicio de la disputa electoral las mismas se observaron por medio de los y las candidatas a Intendente. Es de remarcar que en este nivel la representación presentó tres movimientos además de la confrontación entre lógicas: uno hacia el marco de alianzas propio, otro hacia los votantes y un tercero hacia las élites partidarias extra-distritales. Así mismo, un punto se surge de la observación y que parece común a cualesquiera sean las modalidades que estas lógicas adoptaron en este nivel: es el que la figura del candidato/a a intendente fue considerada como un primus inter pares (Ollier, 2010), es decir que no se encontró investido con una legitimidad indiscutida por la que se aliviarían las presiones de las organizaciones de base. O, en otras palabras, aun cuando se trató de una figura que logró una acumulación de capital político 
que le permitía sobresalir del estrato de las organizaciones menores, su densidad política fue considerada siempre posible de ser disputada.

En el caso del FRP-FPV presentó una lógica fuertemente centralizada sobre la figura de Pablo Bruera que le permitió desarrollar hacia dentro del marco de alianzas un tipo de estrategia de negociación más inclusiva en los momentos de auge político -elecciones del 2011- y de fidelización en los momentos de baja performance electoral -elecciones del 2013. El desplazamiento de una estrategia a otra de modo continuo supuso esta “centralidad" como línea de continuidad. Esta modalidad, que le permitió a dicho espacio obtener un rápido reconocimiento público en un solo punto de acumulación de carácter local, le generó un margen de maniobra amplio entre las opciones de alianzas con sectores del peronismo que se presentaban como opciones externas al FPV en la ciudad. Como contracara de estos beneficios pueden contarse dos eventos: por un lado, fue imposible desligar el apellido Bruera de las acusaciones de negligencia tras el fenómeno de la inundación; por otro lado, la centralidad de dicha forma de representación le impidió generar un recambio de figuras con la celeridad necesaria para mantener el protagonismo. Ambos eventos refieren al mismo fenómeno: en la medida que el punto de acumulación de dicha lógica se solapa con una única figura pública o un apellido, no cabe espacio para la distribución de las responsabilidades como tampoco para la delegación en otro como garantía de cumplimiento de acuerdos internos. El que, tras el evento de la inundación, el FRP-FPV trazara una curva de crecimiento decreciente en su performance electoral, potenciada por estas dificultades, resulta explicativo del achicamiento de su marco de alianzas.

En relación al movimiento sobre la sociedad en general, la lógica de representación que estructuró el FRP-FPV tuvo siempre un carácter territorial, variando entre modalidades discursivas de tipo vecinalistas a otras de tipo provinciales - el proyecto de La Plata como "gran capital provincial"-, lo que le permitió construir como locus al "vecino" y, a través de dicha figura contener diversas -e incluso contradictorias- demandas. El sesgo territorial entendido en estos términos le proporcionó altos índices de estabilidad, al punto que le permitió a dicho espacio tener conflictos con la élite nacional del partido y aun así transitar un gobierno municipal casi sin sobresaltos hasta el evento de la inundación. Pero incluso más allá de la tragedia, el que dicho espacio mantuviera una capacidad de negociación para las elecciones del 2015 y una performance electoral que aun en su curva decreciente fuera competitiva, encuentra su causa en esta modalidad inclusiva de la 
representación. Como contracara de los beneficios derivados de esta modalidad se encuentra la dilación en la actualización de las agendas públicas, algo que como se vio, fue desarrollado por el otro polo organizacional con mayor capacidad.

En cuanto a la relación con las élites partidarias extra-locales, la modalidad centralizada de la representación permitió una flexibilidad en la búsqueda de acuerdos con diversos sectores del peronismo. En este sentido el fortalecimiento de la figura de Bruera como punto de acumulación más alto de este marco de alianzas devino en la definición de dicha figura como único nodo de acuerdos por fuera el distrito. Esta concentración de los acuerdos se realizaba desde una adscripción identitaria del peronismo muy general -o con márgenes muy flexibles- que, en tanto plataforma, le proporcionaba las opciones virtuales de un posible desplazamiento como capital político para las negociaciones asimétricas. Más allá de que en el transcurso del proceso político de dichos años, finalmente el FRP no se desligó del espacio del FPV, su perfil de armado local, concomitante a dicha "centralidad", le permitía fortalecerse solo con amagar con una posible mudanza de vinculación provincial y/o nacional. Así, el recorrido desde la participación en el "grupo de los 8"239, pasando luego a una alineación con la figura de CFK y por último terminar vinculado a la figura de Daniel Scioli, no significaron siempre una derrota total ni una victoria total, sino resultados mixtos donde ambos puntos de la negociación terminaron obteniendo ciertos beneficios de la misma.

La otra lógica de la representación fue la construida en el polo organizacional de UyO. En relación al marco de alianzas esta lógica estructuró acuerdos horizontales que fungieron como plataforma para quien luego ocupara la figura de la candidatura a jefe de la ciudad -en las elecciones del 2011- y, si bien luego fue mutando hacia una lógica más centralizada -elecciones del 2015-, nunca perdió su carácter asociativo. Esta modalidad tuvo su causa en los recursos políticos que presentaron algunas de las agrupaciones de base que conformaron su marco de alianzas, las cuales contaban con vinculaciones propias y particulares tanto con la élite nacional del partido o con organizaciones de carácter extra-municipal con volumen nacional. Todo lo cual les permitió disponer de múltiples objetivos electorales y, simultáneamente, lograr una cohesión interna por la cual se reglaba el ingreso de nuevos sectores. De hecho, aun cuando incorporaron la candidatura de Saintout y lograron trazar una curva ascendente de performance electoral,

${ }^{239}$ Ver apartado 3.1 del capítulo 3 de la presente tesis. 
el conjunto de acuerdos internos resultó tan fuerte que la forma de inclusión para otros grupos fue de "subordinación". Aun cuando este aspecto remite positivamente a la capacidad de establecer una disciplina organizacional, tuvo como contracara el hecho de un letargo en el crecimiento de dicho marco de alianzas. Ciertamente este fenómeno también se encontraba vinculado a las expectativas de los resultados, en tanto los lugares legislativos más seguros para ingresar en cada evento electoral resultaban escasos. Sin embargo, fue un rasgo distintivo de esta modalidad asociativa el que tendieran a cerrarse sobre los lugares más visibles.

En lo que hizo al movimiento sobre la sociedad en general, esta forma de representación tuvo un carácter de particularización identitaria sobre los contornos del FPV. Tratando de sobre ocupar el espacio de la imagen de la élite nacional en el distrito, lo que denominamos como el espacio delegativo, las diferentes intervenciones públicas fueron dirigidas a establecer un vínculo de identificación sin intermediación con estas referencias. Además, su narrativa varió entre modalidades discursivas de los tópicos de una agenda nacional y otras de tipo municipal adversativas, permitiéndole construir como locus al "vecino comprometido" y desde allí capturar y significar las demandas movilizadoras. Esta modalidad le proporcionó como ventaja la capacidad de protagonizar conflictos sociales, como también una velocidad en la actualización de las agendas coyunturales, observable en la disposición a la intervención pública permanente. Si se sigue el trayecto entre el 2011 y 2015 de las interpelaciones que esta lógica realizó se observa claramente estos sesgos confrontativos a nivel local que le permitieron acceder rápidamente a un reconocimiento público incluso por fuera de la utilización de los medios de comunicación tradicionales de la ciudad. La masividad de las intervenciones de tipo "Las mujeres con Florencia" - capítulo 5-, no solo expresaron un acierto en términos de la relación "masividad - actualización de la agenda política", sino que, por sobre todo, modelaron una relación vertical descendente que aparentaba una prescindencia de estructuras organizativas intermedias, basándose en la relación entre "representación contenciosa y vecino/a comprometido/a". Como contracara de esta modalidad, esta lógica de representación terminaba enfrentando una tensión entre su curva creciente de impacto público local con la característica particularista de su propia identificación. Salvo en el caso de las elecciones de 2017, que se analizaran más abajo, las elecciones de 2013 y 2015 mostraban que la impermeabilidad de sus límites parecía terminar, paradójicamente, siendo retardataria del crecimiento electoral. 
La relación con las élites nacionales la fidelización como modo de vinculación le permitió contar con la garantía de los recursos para la participación electoral, entre ellos la siempre mentada boleta electoral y espacios en las categorías legislativas provinciales. Así mismo, esta fidelización fue acompañada por una multiplicación de los interlocutores, observable en el hecho de que las organizaciones principales que formaban parte del marco de alianzas tenían sus propias terminales nacionales de discusión. Salvo en las elecciones de 2017, que como se verá se trató de una reorganización, esta táctica no presentó vinculaciones explícitas con la élite provincial del FPV ni con otros referentes municipales de la provincia. Como si hubieran delegado su interlocución provincial a la misma élite nacional, la fidelización peso más en las negociaciones asimétricas, que la posibilidad de contar con dichas interacciones provinciales como capital político. Esto derivo en dos grandes consecuencias negativas: por un lado, la escasa presencia de los candidatos extra-municipales en la elección 2015 acompañado esta propuesta. Por otro lado, permitirle ocupar al otro polo organizacional la posibilidad de usufructuar dichos vínculos.

El escenario abierto tras la derrota electoral del 2015 en términos de representación, operó como una apertura a la posibilidad de que las interacciones entre lógicas relajaran su carácter adversativo y propiciaran las relaciones colaborativas. Si bien la disputa no finalizó y no se trató de una articulación sino más bien de un ensamble, la participación electoral de 2017 estuvo signada por la unidad como táctica más beneficiosa para todos. Esta convergencia exigió una negociación donde ambas lógicas tuvieron que ceder ciertos elementos propios que parecían inamovibles. Por el lado del FRP-FPV se observó el recambio de referencia pública, y por el lado de UyO la permisibilidad a otros sectores de las candidaturas legislativas con "expectativas" -o blancas-. El contraste entre las curvas de performance electoral de una y otra lógica operó como catalizador para que UyO, a través de su referencia pública protagonizara el punto de acumulación más alto de la lista de la denominada Unidad Ciudadana en 2017.

Es necesario dedicar unas palabras al lugar que recibieron las organizaciones de base en esta experiencia electoral. Si bien no es posible referirse a las mismas como una proto lógica de representación, entre otras cosas porque no comparten un mismo marco de alianzas, fue la interacción horizontal entre ellas las que potenció su participación en las listas. Los eventos multiorganizacionales que ocurrieron entre el 2016 y el 2017 operaron como un símil de un marco de alianzas sin candidato/a. También para estas 
organizaciones, la clave del ensamble como modo de construcción les fue positivo.

La relación con el polo de agrupamientos que se denominó como Cumplir, consideramos que es una experiencia que debe ser entendida en términos de un modo de externalización o de desdoblamiento: al tratarse esta de una experiencia que no contaba con expectativas electorales, la misma operó como receptora de las agrupaciones que no pudieron ingresar, en un lugar expectante, al marco de alianzas de U.C. o que desarrollaban en el territorio los acuerdos provinciales que como organizaciones habían trazado.

En relación a la interpelación sobre la sociedad de ambas listas de Cumplir en general, la lógica de representación tuvo dos niveles de interpelación: uno marcado por la relocalización de la ciudad en el marco de la agenda nacional, en cuanto se buscó mostrar el impacto de las políticas nacionales en el territorio. Así, la apelación a la ciudadanía, solo reprodujo una estrategia comunicacional provincial. En un segundo nivel, se encontraron los discursos dispersos y multidireccionados de los distintos grupos que compusieron esta unidad. En este caso, la campaña expresó más un interés de acumulación de las partes (agrupaciones) por sobre el todo.

III

Las diferentes modalidades que transitaron las lógicas de representación en el nivel de los polos organizacionales le permitieron al peronismo el suficiente equilibrio para poder participar reiteradamente de los eventos electorales, proyectar candidaturas, establecer modos de crecimiento y acciones para intentar suplir deficiencias. Todos estos fenómenos no son posibles si no ocurren sobre la base de una secuencia temporal regular. Ante la escasa o nula gravitación de una estructura que contenga la tendencia expansiva observada para las organizaciones de base, es la representación política la que ocupa dicho lugar. De aquí que consideremos la acción de los polos organizacionales como una fuerza estabilizadora de los fenómenos que ocurren en las interacciones de las agrupaciones de base. Por contraposición, las tensiones y la multidireccionalidad que presentan las organizaciones de base, puede considerarse como una tendencia movilizadora que mantiene al peronismo inserto en los múltiples debates de la ciudadanía, pero que por sí misma no resulta conducente. Es en la articulación de estas dos tendencias donde la unidad cobra un sentido y una potencia. Una lógica de representación logra 
estabilizar y direccionar la movilización.

En vistas de una mirada general el peronismo platense parece haber constituido durante estos años un campo de tensiones contrapuestas. Por un lado, una tendencia que le permitió crecer -y también le significó decrecer-, intervenir de modos múltiples en el conjunto del campo social y renovarse de forma continua, pero que también le significó una disputa permanente y una fragilidad constante de cualquier construcción de unidad. Por el otro lado, una tendencia que con la que ganó en regularidad, estableció acuerdos políticos y protagonizó la disputa electoral, pero que también le implicó una selección y de las organizaciones de base y una restricción sobre los modos de crecimiento. Así, el peronismo platense fue, durante estos años, los distintos equilibrios generados entre estos dos sentidos. Desde esta perspectiva no resulta extraño el que esta misma fuerza política se encuentre en constante renovación, aun cuando este fenómeno baje en intensidad -sin desaparecer- los años en que la fuerza estabilizadora logra equilibrios más sólidos.

Tras la derrota electoral en 2015, mucho se ensayó la idea de una posible crisis interna del peronismo que podría haber derivado en su fragmentación y consecuente incapacidad de volver a formar una fórmula electoral competitiva. Ciertamente la derrota opera la interior del peronismo como un acontecimiento central. Sin embargo, la misma puede ser matizada a la vista de los resultados de esta investigación, puesto que en este caso, el peronismo siempre se encuentra tensionado internamente. La lectura de los eventos electorales permite observar estas tensiones en su momento más públicamente reconocibles, puesto que allí la identidad y la estrategia política convergen en un mismo escenario. Pero, quizás, lo más importante a destacar, es que es la aceptación por parte de los actores de esta misma tensión interna lo que diferencia al peronismo de los partidos de cuadros y lo vuelve un movimiento partidario en el que conviven diferentes mediaciones: más particulares como el kirchnerismo, más amplias como el peronismo y de carácter más universal como el movimiento nacional popular. Que todas las mediaciones operen bajo las reglas del sistema democrático, atendiendo a la regularidad institucional, como así también a sus reglas y requerimientos, explica su perfil partidario. Que se intente incorporar las contradicciones sociales en un campo identitario estable, y que las rearticule en torno a una nueva frontera antagónica, es lo que explica su perfil movimentista del peronismo. Sobre esos dos perfiles, se estructura una fuerza política que, desde abajo, se reinventa constantemente. Durante esta investigación se logró mostrar las dinámicas organizacionales internas del peronismo platense, estudiar sus 
interacciones locales y extra locales y reconstruir las trayectorias de diferentes lógicas de representación. Quedan abiertas diversas líneas de trabajo que, por cuestiones de tiempo o espacio, no hemos podido desarrollar: por un lado, un estudio desde una perspectiva general de las organizaciones de base, sus modos de interacción y sus dispositivos de reconocimiento como pares. Si algo pudo observarse a lo largo de nuestra investigación, es que en este estrato, las organizaciones de base componen un universo fragmentado y con altos índices de autonomía que merece ser analizado de modo global. Suponer que las mismas se sintetizan de manera espontánea en los marcos de alianzas es un grave error. Para la perspectiva de la empresa que pretenda estudiarlas, la negociación deberá constituir un concepto clave.

Por otro lado, tampoco pudimos profundizar el análisis sobre la notoria ausencia de la figura de la élite provincial del peronismo, en las discusiones políticas locales. Resulta extraña y enigmática esta situación a comparación con lo que, desde una mirada veloz, se podría postular de lo observable en otras provincias. También sería importante poder analizar, en la medida que la tendencia prosiga, las formas de la comunicación política. No tanto en lo que hace solo al formato, con el progresiva migración de los medios tradicionales como los periódicos a las redes sociales, sino también en la relación entre territorialidad de las prácticas políticas y mensajes desterritorializados.

Por último, la cuestión partidaria, principalmente en su escasa gravitación sobre las lógicas de organización merecería una investigación aparte. Aun cuando ya se ha estudiado la cuasi paradójica situación de una fuerza política sin partido, es posible advertir que la estructura del PJ opera en el cotidiano como una plataforma para los rictus políticos. En el desarrollo de nuestra investigación nos interesó tratar de aportar a la lectura crítica de esta fuerza política sin perder una mirada general de los fenómenos. De aquí que muchas de estas cuestiones no pudieron ser analizadas. Consideramos que en estos términos, lograríamos contribuir al debate general sobre partidos políticos en la medida que pudiéramos mostrar las variaciones de datos empíricos por sobre los contenidos constantes de los conceptos. Esperamos que estos objetivos hayan sido satisfechos. 


\section{Bibliografía}

Abbattista, M. L. y Tocho, F. (2012). "El verano caliente del '74: La Tendencia Revolucionaria del peronismo entre la asunción de Perón y el aniversario del 'triunfo popular'." Trabajo presentado en VII Jornadas de Sociología de la UNLP, 5 al 7 de diciembre de 2012, La Plata, Argentina. Disponible en: http://www.memoria.fahce.unlp.edu.ar/trab_eventos/ev.1658/ev.1658.pdf

Aboy Carlés, G. (2001). "Las dos fronteras de la democracia argentina: la reformulación de las identidades políticas de Alfonsin a Menem”, Homo Sapiens Ediciones, Bs. As.

Acha, O., \& Quiroga, N. (2009). "La normalización del primer peronismo en la historiografia argentina reciente." Estudios Interdisciplinarios De América Latina Y El Caribe, 20(2). Recuperado a partir de http://eial.tau.ac.il/index.php/eial/article/view/307

Aelo, O. H. (2006). "Formación y crisis de una elite dirigente en el peronismo bonaerense 1946-1951" en MELON PIRRO, Julio C. y QUIROGA, Nicolás (eds.), "El peronismo bonaerense: partido y prácticas políticas, 1946-1955”, Mar del Plata, Ed. Suárez, pp. 15-42.

Alma, A. y Lorenzo, P. (2009). "Mujeres que se encuentran" Feminaria editora, Bs. As.

Altamirano, C. (2001), "Peronismo y Cultura de Izquierda", Temas Grupo Editorial, Bs. As.

Archenti, N. (2007). "Estudio de caso/s", en Marradi, Archenti y Piovani, "Metodología de las ciencias sociales", Emecé Editores, Bs. As.

Arce, M. E. (2011). "El día que Bruera fue agosto: De la fractura de la hegemonía alakista al triunfo del frente renovador platense. Un análisis de las continuidades y transformaciones en la politica platense (2000-2007)." Tesis de grado. Universidad Nacional de La Plata. Facultad de Humanidades y Ciencias de la Educación. En Memoria Académica. Disponible en: http://www.memoria.fahce.unlp.edu.ar/tesis/te.692/te.692.pdf

Auyero, J. (2002). "Clientelismo Político en Argentina: doble vida y negación colectiva", Perfiles Latinoamericanos, junio, № 20, FLACSO, Distrito Federal, México, pp. 33-52.

Recalde, A. (2009). “El pensamiento de John W. Cooke en las cartas a Perón." Ed. Nuevos Tiempos, Bs. As.

Balbi, F. A. (2007). "La dudosa magia del carisma. Explicaciones totalizadoras y perspectiva etnográfica en los estudios sobre el peronismo". AVA (11), 11-38.

Balbi, F. A. (2009). “Explicar "el peronismo"? Apuntes para un debate pendiente”. Desarrollo Económico, Vol. 49, No. 193 (Apr. - Jun.), pp. 151-160

Barbosa, S. (2010). "Menemismo y kirchnerismo en Argentina: un análisis político discursivo de su construcción hegemónica." Pensamento Plural, (6), 11-34.

Barry, C. (2009). "Evita capitana: el partido peronista femenino, 1949-1955", EDUNTREF, Tres de febrero.

Becerra, M. (2015). “Transgresión, propaganda, convergencia, y concentración. El 
sistema de medios en el kirchnerismo", en Gervasoni, C. y Peruzzotti, E. (comp.) "¿Década ganada? Evaluando el legado del kirchnerismo”, DEBATE, Bs. As.

Besoky, J. L. (2016). “En la patria de Perón, ni judio ni masón”. Aproximaciones a la cultura política de la derecha peronista en los años setenta. Historia e Cultura, Vol. 5, $\mathrm{N}^{\mathrm{o}} 3$, pp. 199-223, diciembre.

Bozza, J. A. (2001). "El peronismo revolucionario. Itinerario y vertientes de la radicalización, 1959-1969.” Sociohistórica, (9-10).

Butler, J. (2007). "El género en disputa. El feminismo y la subversión de la identidad", Paidós, Barcelona.

Calvo, E. (2005). “Argentina, elecciones legislativas 2005: consolidación institucional del kirchnerismo y territorialización del voto." Rev. De Ciencias Política, Vol. 25, № 2, pp. 153-160.

Calvo, E. y Escolar, M. (2005). "La nueva política de partidos en la Argentina: Crisis política, Realineamientos partidarios y Reforma Electoral”, Ed. Prometo, Bs. As.

Calvo, E. y Murillo, M. V. (2012) Argentina: the persistence of peronismo, Journal of Democracy, Volume 23, No 2, April, pp. 148-161.

Calvo, E. (2013). "El peronismo y la sucesión permanente: mismos votos, distintas elites", Revista SAAP, Vol. 7, No 2, Bs. As.

Canelo, P. (2011). “"Son palabras de Perón” Continuidades y rupturas discursivas entre peronismo y menemismo", en Pucciarelli (ed.) "Los años de Menem, la construcción del orden neoliberal", Siglo XXI, Bs. As.

Carnagui, J. L. (2010). "La construcción de un sentido común sobre la "derecha peronista" de los años '70", Antíteses, vol. 3, N 6, julio-diciembre.

Carrizo, C. y Galván, C. (2012). "Partidos, Federalismo y Práctica Electoral: la provincialización de la política local en las elecciones de 2011 ”, FORJANDO, Bs. As., pp. 106-114.

Casullo, M. E. (2015). "Argentina: del bipartidismo a la democracia peronista", Nueva Sociedad, No 258 , pp. 16-28.

Casullo, M. E., Rodríguez, S. (2015). “Apogeo y Caída del Frente Renovador: un juego de mapas", Rev. El Estadista, Bs. As. Disponible en: http://elestadista.com.ar/?p=7003

Cavarozzi, M. y Casullo, M. (2002). "Los Partidos Políticos en América Latina Hoy: ¿Consolidación o Crisis?”, en Cavarozzi, M. y ABAL MEDINA, J. (ed.) “El Asedio a la Política: Los Partidos Latinoamericanos en la Era Neoliberal", Homo Sapiens Ediciones, Bs. As.

Cerrutti, M., y Grimson, A. (2004). “Buenos Aires, neoliberalismo y después. Cambios socioeconómicos y respuestas populares". Cuadernos del IDES, 5, 3-63.

Cherny, N. (2011). "Una mirada a las elecciones presidenciales argentinas de 2011", Iberoamericana (2001-), Nueva época, Año 11, No. 44 (Diciembre), pp. 135-139.

Cipponeri, M. et all (2014). "Vulnerabilidad de la población de la ciudad de La Plata (Argentina) a precipitaciones extraordinarias", Rev. Aqua-LAC - Vol. 6 - No 2 - 
Septiembre, pp. $11-20$.

Correa, R. y Quintana, S. (2013). "Las agencias del poder: Intervenciones partidarias y formación del partido peronista en Salta, 1949-1952”, en Tcach y Marcor (ed.) “La invención del peronismo en el interior del país", Tomo II, Universidad Nacional del Litoral, Santa Fe.

De Ipola, E. (1989). "Ruptura y continuidad. Claves parciales para un balance de las interpretaciones del peronismo", Desarrollo Económico, Vol. 29, Núm 115, México.

De Riz, L. (1987). "Retorno y Derrumbe. El último gobierno peronista." Ed. Hyspamérica, Bs. As.

Dell'Unti, J. C. (2017). "Si 18 años no es nada: análisis de la construcción de la propuesta electoral del FREJULI en el municipio de La Plata para las elecciones del 11 de marzo de 1973". Actas de las XVI Jornadas Interescuelas Mar del Plata. Universidad Nacional de Mar del Plata. Disponible en: https://interescuelasmardelplata.wordpress.com/actas/

Dip, N. (2012). "La universidad en un mundo de tensiones: Una aproximación al itinerario político-universitario de las organizaciones de estudiantes y docentes peronistas de los años sesenta a través del estudio del proyecto de Universidad NacionalPopular propuesto en la revista Envido." (En línea). Trabajo presentado en VII Jornadas de Sociología de la UNLP, 5 al 7 de diciembre de 2012, La Plata, Argentina. Disponible en: http://www.memoria.fahce.unlp.edu.ar/trab_eventos/ev.1836/ev.1836.pdf

Di Paola, M. y Oliver, M. (2002). “Autonomía Municipal y participación pública. Propuestas para la Provincia de Buenos Aires. Fundación ambiente y Recursos Naturales". Disponible en http://www.farn.org.ar/docs/libros.html

Di Tella, T. (1973). "Populismo y reformismo", en Germani, G., Di Tela, T. y Ianni, O. "Populismo y contradicciones de clase en argentina", Ediciones Era S.A., México.

Di Tella, G. (1983). “Perón-Perón 1973-1976”, Hyspamerica, Bs. As.

Eidelman, A. (2004). "Militancia e Historia en el peronismo revolucionario de los años 60: Ortega Peña y Duhalde", Cuaderno de trabajo n 31 , Ediciones del Instituto Movilizador de Fondos Cooperativos, Bs. As.

Eryszewicz, L. (2015). “ ¿Localización de la Política? EL protagonismo de los intendentes argentinos en la escena nacional", en Rocío Annunziata (coord.) "Pensar las elecciones: democracia, líderes y ciudadanos", CLACSO, Buenos Aires.

Feinmann, J. P. (1974). “El peronismo y la primacía de la política”, Ed. Cimarrón, Bs. As.

Ferrari, M. (2009). "Entre la reorganización y la derrota. El peronismo bonaerense en vísperas de las elecciones de 1983”, Estudios Sociales, Nº 37, año XIX, pp. 97-126.

Ferrari, M (2016). "La Provincia de Buenos Aires" en Ferrari M. y Mellado V. "La renovación Peronista. Organización partidaria, liderazgos y dirigentes, 1983-1991", EDUNTREF, Tres de Febrero.

Ferraudi Curto, M. (2011). “ ¿Estás nervioso? Las elecciones desde una villa del Gran 
Buenos Aires." Athenea Digital. Revista de Pensamiento e Investigación Social, Noviembre-Sin mes, 99-118.

Fraga, R. (2011). "Análisis del resultado de las elecciones 2011”, Academia Nacional de Ciencias Morales y Políticas, Bs. As.

Freidenberg, F. y Sánchez López, F. (2001). "Partidos políticos y métodos de selección de candidatos en América Latina: Una discusión sobre reglas y prácticas.", en Trabajo preparado para su discusión en el XXIII Encuentro Internacional de la Asociación de Estudios Latinoamericanos. Washington, D.C., 6 al 8 de septiembre de 2001. Disponible en: http://lasa.international.pitt.edu/Lasa2001/FreidenbergFlavia.pdf Revisado el 20/03/2019.

Freidenberg, F. (2003). "Selección de candidatos y democracia interna en los partidos de América Latina". Asociación Civil Transparencia e International IDEA, Lima. Disponible en:

http://americo.usal.es/oir/opal/pdfs/Flavia freidenberg/Libro Seleccion\%20CandidatosAL03.p $\underline{\mathrm{df}}$

Foucault, M. (1979). “La arqueología del saber” Siglo XXI Editores, México.

Gamallo, L. (2012). "Entre paros y cacerolazos: Apuntes sobre la conflictividad social en la Argentina reciente." Revista Anuario del Conflicto Social, Universidad de Barcelona, España, pp. 877-908.

Gamsom, W. y Meyer, D. (1999). "Marcos Interpretativos de la oportunidad politica", en McAdam, D., McCarthy, J. D., \& Zald, M. "Movimientos sociales, perspectivas comparadas: oportunidades políticas, estructuras de movilización y marcos interpretativos culturales". Ediciones Istmo S.A., Madrid.

Garatergaray, M (2013). “Entre Perón y Alfonsín: notas sobre la Renovación peronista (1983, 1989)", Temas y Debates No 25, año 17, Enero- Julio.

Germani, G. (1965). "Política y sociedad en una época de transición”, Paidós, Buenos Aires.

Germani, G. (1973a). "El surgimiento del Peronismo: el rol de los obreros y los migrantes internos”, Desarrollo Económico, Vol. 13, № 51 (Oct. - Dic.), pp. 435-488.

Germani, G. (1973b). "Democracia representativa y clases populares", en Germani, G., Di Tela, T. y Ianni, O. "Populismo y contradicciones de clase en argentina", Ediciones Era S.A., México.

González Canosa, M. (2012). "Las Fuerzas Armadas Revolucionarias: Orígenes y desarrollo de una particular conjunción entre marxismo, peronismo y lucha armada" (Tesis de posgrado). Presentada en Universidad Nacional de La Plata. Facultad de Humanidades y Ciencias de la Educación para optar al grado de Doctora en Ciencias Sociales. Disponible en: http://www.memoria.fahce.unlp.edu.ar/tesis/te.808/te.808.pdf

Gonzalez, H. (2019) “Ser peronista”, La Tecl@ Eñe, Revista digital. Disponible en https://lateclaenerevista.com/ser-peronista-por-horacio-gonzalez/

González, L. M. (2012). “Historia y memoria de ex militantes de las FAP PB en la ciudad de La Plata." VII Jornadas de sociología de la UNLP, La Plata. 
Grimson, A. (2011). "Los límites de la cultura”, Siglo XXI, Bs. As.

Gutiérrez, R. (2003). "Entre movimiento y partido: un análisis de las transformaciones organizativas del peronismo", Política y gestión, $\mathrm{N}^{0}$ 5, Bs As.

Gutierrez, R. (2001). “La desindicalización del peronismo", Política y Gestión, No 2, 2001, pp. 93-112.

Gimenez, G. (1996) "La identidad social o el retorno del sujeto en sociología", en Méndez L. (coord.), "Identidad: análisis y teoría, simbolismo, sociedades complejas, nacionalismo y etnicidad”. III Coloquio Paul Kirchhoff, México, UNAM, pp. 11- 24.

Hirschman, A. (1977). “Salida, Voz y Lealtad”, FCE, México D.F.

Horowicz A. (1986) “Los cuatro peronismos”, ed. Hyspamerica, Bs. AS.

James, D. (1990). "Resistencia e Integración, el peronismo y la clase trabajadora argentina.” Siglo XXI, Avellaneda.

Kröll, H. G. (2000). "El método de los estudios de caso", en Tarrés, M. L. (comp.) "Observar, escuchar y comprender. Sobre la tradición cualitativa en la investigación social", FLACSO, México.

Laclau, E. (2006). “La razón populista”, Fondo de Cultura Económica, México.

Ladeuix, J. I. (2008). "Entre la institucionalización y la práctica. La normalización del Partido Justicialista en la Provincia de Buenos Aires. 1972-1973." Programa Buenos Aires de Historia Política del siglo XX.

Lenarduzzi, J. (2010). "Identidades renovadas: las transformaciones del vínculo representativo en el conurbano bonaerense", V Congreso Latinoamericano de Ciencia Política, organizado por la Asociación Latinoamericana de Ciencia Política (ALACIP). Buenos Aires, 28 a 30 de julio de 2010.

Lenarduzzi, J. (2012a). " "Permanecer y trasncurrir": los discursos de la renovación política en la democracia argentina (1983-2011)", tesis de Maestría. Disponible en http://ri.unsam.edu.ar/greenstone/collect/coltesis/index/assoc/HASH015d/eacea1d6.dir/TMAG \%20IDAES\%202012\%20LJ.pdf

Lenarduzzi, J. (2012b). "Como si el poder estuviera en otro lugar: reflexiones en torno a la "renovación" y la "nueva política" en la Argentina contemporánea" en Cheresky y Dabene (comp.) "Ciudadania y representación política”, Ed. ECOS MINCYT, Bs. As.

Lenci, L. (1999). “Cámpora al gobierno, Perón al poder. La Tendencia Revolucionaria del peronismo ante las elecciones del 11 de marzo de 1973”, en Pucciarelli A. (Ed.) La Primacía de la política, Ed. Eudeba, Bs. As.

Levitsky, S. (2004) La transformación de los vínculos partido-sindicato en el peronismo, 1983-1999, Desarrollo económico, Vol. 44, Núm. 173, México.

Levitsky, S. (2005). "La transformación del Justicialismo: del partido sindical al partido clientelista: 1993-1999.”, Siglo XXI, Buenos Aires.

Linz, J.J. (1997). "Democracia presidencial o parlamentaria: Qué diferencia implica?" en Linz J. y Valenzuela A. (comp.) "La crisis del presidencialismo", Alianza Editorial, 
Madrid, pp. 25-143.

López, M. (2013). “Acciones y estrategias en lo público. Algunas reflexiones sobre (y en) la catástrofe". Question, 38-57. Recuperado a partir de https://perio.unlp.edu.ar/ojs/index.php/question/article/view/1853

Mackinnon, M. (2002). “Los años formativos del partido peronista (1946-1950)”, Siglo XXI, Bs. As.

McAdam, D., Tarrow, S. y Tilly, C. (2005). “Dinámica de la contienda política”, Hacer Editorial, Barcelona.

Michel, R. (1979). “Los Partidos políticos”, Ed. Amorrortu, Bs. As.

Melon Pirro, J. (2009). “EL peronismo después del peronismo. Resistencia, sindicalismo y politica luego del 55”, Siglo XXI, Bs. As.

Montero, A. M. y Vincent, L. (2013) Del "peronismo impuro" al "kirchnerismo puro": la construcción de una nueva identidad política durante la presidencia de Néstor Kirchner en Argentina (2003-2007), Rev. Post Data 18, No 1, Abril, pp. 123-157.

Murmis, M. y Portantiero, J. (1969): Estudios sobre los orígenes del peronismo, Siglo XXI Eds., Buenos Aires, 1969.

Mustapic, A. (2002). "Del partido peronista al partido justicialista. Las transformaciones de un partido carismático", en Cavarozzi, Marcelo y Juan Manuel Abal Medina (h) (comps.), "El asedio a la política. Los partidos latinoamericanos en la era neoliberal", Rosario, Ediciones Homo Sapiens.

Mustapic, A. (2005). "Inestabilidad sin colapso. La renuncia de los presidentes: Argentina en el año 2001", Desarrollo Económico, Vol. 45, N. 178 (Jul. - Sep.), pp. 263280.

Natalucci, A. y Schuttenberg, M. (2012). "Los Movimientos Populares en la Argentina Reciente”, FORJANDO, Bs. As., pp. 118-128.

Natalucci, A. (2012). "El kirchnerismo y su estatuto como movimiento político", Apuntes de Investigación del CECYP, año XVI, núm. 21, Bs. As.

Natalucci, A. (2014). "La cultura política en el kirchnerismo: dos hipótesis sobre la politización." Sudamérica: Revista de Ciencias Sociales, (3), 155-172.

Novaro, M. (1999). "Crisis y renovación de los partidos. Una perspectiva comparada sobre los años del menemismo", en Novaro, Torre, et all, "Entre el abismo y la ilusión. Peronismo, democracia y mercado." Norma, Bs. As.

Ollier, M. (2010). "El liderazgo político en democracias de baja intitucionalización (el caso del peronismo en la Argentina)”, Revista de Sociología, No. 24, pp. 127-150.

Ortiz, R. y M. Schorr (2006). "La economía politica del gobierno de Alfonsín: creciente subordinación al poder económico durante la década perdida", en Alfredo Pucciarelli (coord.) "Los años de Alfonsín. El poder de la democracia o la democracia del poder". Ed. Siglo XXI, Bs. As.

Palacio, J. M. (2010). “El primer peronismo en la historiografia reciente: nuevas 
perspectivas de análisis", Rev. Iberoamericana (2001-), Nueva época, Año 10, No. 39, pp. $255-265$

Panebianco, A. (1990). "Modelos de partido", Alianza Editorial, Madrid.

Pérez, G. y Natalucci, A. (2010). "La Matriz Movimentista de Acción Colectiva en Argentina: La Experiencia Militante del Kirchnerismo", América Latina Hoy, 54, pp. 97112.

Perez, G. y Natalucci, A. (2012). "El kirchnerismo como problema sociológico", en Pérez, G y Natalucci, A. "Vamos las Bandas, organización y militancia kirchnerista", Nueva Trilce Editorial, Bs. As.

Pucciarelli, A. (1999). “La primacía de la política. Lanusse, Perón y la Nueva Izquierda en tiempos de GAN”, EUDEBA, Bs. As.

Pucciarelli, A. (2011). "Menemismo: la construcción política del peronismo neoliberal", en Pucciarelli (ed.) "Los años de Menem, la construcción del orden neoliberal", Siglo XXI, Bs. As.

Pugliese, A., Pereyra, F. y Blanco, J. (2008). "Historia Electoral Argentina (19122007)", Ministerio del Interior, Subsecretaría de Asuntos Políticos, Bs. As.

Quiroga, N. (2008). “Las Unidades Básicas durante el primer peronismo. Cuatro notas sobre el Partido Peronista a nivel local", Nuevo Mundo Mundos Nuevos [En línea], Debates, Puesto en línea el 16 abril 2008. URL: http://nuevomundo.revues.org/30565

Quiroz, J. (2008). "Piqueteros y peronistas en la lucha del Gran Buenos Aires. Por una visión no instrumental de la política popular", Cuadernos de antropología social, sin mes, 113-131.

Retamozo, M. (2006). "El Movimiento de Trabajadores Desocupados en Argentina: Subjetividad y acción en la disputa por el orden social" (Doctoral dissertation, Facultad Latinoamericana de Ciencias Sociales. Sede Académica de México).

Robles, H. (2008). "La Juventud Peronista platense. Desde los orígenes hasta la primera etapa barrial (1957/69)", ponencia a $3^{\circ}$ Jornadas sobre la política en Buenos Aires en el siglo XX, CISH, Facultad de Humanidades y Educación, UNLP, La Plata, 28 y 29 de agosto.

Robles, H. (2011). "Radicalización política y sectores populares en la Argentina de los '70: La juventud peronista y su articulación con Montoneros en los barrios periféricos de la ciudad de La Plata" (Tesis de posgrado). Presentada en Universidad Nacional de La Plata. Facultad de Humanidades y Ciencias de la Educación para optar al grado de Magíster en Ciencias $\quad$ Sociales. $\quad$ Disponible en: http://www.memoria.fahce.unlp.edu.ar/tesis/te.437/te.437.pdf

Sartori, G. (1994). "Partidos y sistemas de partidos. Marcos para un análisis", Alianza Editorial, Madrid.

Satta, P. (2015). "El Movimiento Villero Peronista: Una experiencia de radicalización" (Tesis de grado). Presentada en Universidad Nacional de La Plata. Facultad de Humanidades y Ciencias de la Educación. Disponible en: 
Schuttenberg, M. (2014). "Las Identidades Nacional-Populares. De la resistencia noventista a los años kirchneristas." Ed. Universitaria Villa María, Villa María.

Sidicaro, R. (2008). “Los tres peronismos”, Siglo XXI, Bs. As.

Sidicaro, R. (2011). "El partido peronista y los gobiernos kirchneristas", Revista Nueva Sociedad No 234, pp. 74-94.

Sigal, S. (2008). “Del peronismo como promesa", Desarrollo Económico, Vol. 48, No. 190/191 (Jul. - Dec.), pp. 269-286.

Stavale, M. (2012). "Las Fuerzas Armadas Peronistas y su experiencia alternativa (19641979)." Universidad Nacional de La Plata. Facultad de Humanidades y Ciencias de la Educación. En Memoria Académica. Disponible en:

http://www.memoria.fahce.unlp.edu.ar/tesis/te.705/te.705.pdf

Stokes, S., Dunning, T., Nazareno, M. y Brusco, V. (2013). "Brokers, Voters, and Clientelism. The Puzzle of Distributive Politics", Cambridge University Press [Kindle 1.15.04 version] recuperado de Amazón.com.

Svampa, M y Martuccelli, D. (1997). “La Plaza Vacía. Las transformaciones del peronismo." Ed. Losada, Bs. As.

Svampa, M. (2011). “Argentina, una década después: del "que se vayan todos" a la exacerbación de lo nacional-popular", Nueva Sociedad, No 235, septiembre-octubre, pp. 17-34.

Tagina, M. L. (2013). "Elecciones 2009 y 2011 en Argentina: ocaso y resurgimiento del gobierno de Cristina Kirchner". En Alcántara, M., y Tagina, M. L. (2013). "Elecciones y política en América Latina 2009-2011”. México: Instituto Federal Electoral. México D. F.

Tarrow, S (1997). "El Poder en Movimiento", Alianza Editorial, Madrid.

Tcach, C. (2002). “El enigma peronista: la lucha por su interpretación”, Historia Social, No. 43, pp. 129-139.

Tcach, C. y Macor, D. (2003). "La invención del peronismo en el interior del país", Tomo I, Universidad Nacional del Litoral, Santa Fe.

Tcach, C. y Macor, D. (2013). "La invención del peronismo en el interior del país", Tomo II, Universidad Nacional del Litoral, Santa Fe.

Tocho, F. (2014). "Los otros "setenta": Un recorrido por la experiencia de la Tendencia Revolucionaria del Peronismo en la gobernación bonaerense (1973-1974)." Aletheia, 4(8): 17.

Tocho, F. (2015). "El desafío institucional : Las prácticas políticas no armadas de la Tendencia Revolucionaria del Peronismo en el Ministerio de Asuntos Agrarios de la provincia de Buenos Aires (1973-1974)." Sociohistórica (35).

Torre, J. (1999). "El peronismo como solución y como problema", en Novaro, Torre, et all, "Entre el abismo y la ilusión. Peronismo, democracia y mercado." Norma, Bs. As. 
Torre, J (2011). “La vieja Guardia Sindical y Perón”, Ediciones ryr, Buenos Aires.

Unamuno, M. (1984). "El Perón de la lucha, no el de la leyenda" en Unamuno, Bárbaro, Cafiero y Otros, "El peronismo de la derrota", Centro Editor de América Latina, Bs. As.

Valle Bethencourt, P. (2014) "La cuestión femenina en el peronismo: sufragio femenino, hijos ilegítimos y divorcio”, Ed. FLACSO, México D.F.

Vázquez, M. y Vommaro, P. (2009). "Sentidos y prácticas de la política entre la juventud organizada de los barrios populares en la Argentina reciente." Cuadernos del CENDES, Enero-Abril, 47-68.

Viguera, A. (1993) “Populismo" y "Neo populismo" en América Latina, Revista Mexicana de Sociología, Vol. 55, No. 3, (Jul. - Sep.), pp. 49-66.

Vincent, L. (2011). "La disputa por la mediación durante el kirchnerismo en la Argentina”, CONfines de relaciones internacionales y ciencia política, 7(13), pp. 49-81.

Weber, M. (2008) “Economía y Sociedad”, FCE, México.

Zaremberg, G. (2009). “Mujeres, votos y asistencia social en el México priista y la Argentina peronista”, Ed. FLACSO, México D.F.

\section{Fuentes Hemerográficas}

\section{$\underline{\text { Ámbito Financiero }}$}

22-09-2010. “Un intendente díscolo descartó sumarse al peronismo federal” Sección: Política.

Clarin

09/06/2015. Ortelli, Ignacio. "Florencio Randazzo lanzó su candidatura sin hablar de Cristina Kirchner y apuntó contra Mauricio Macri”. Sección: Política.

\section{Crónica TV}

25-08-2010. "Pablo Bruera en el Luna Park” Crónica TV. Subido por: Frente Renovador Peronista. Dirección: https://www.youtube.com/watch? $\mathrm{v}=\mathrm{cK}$ Ba5XdbRY Revisado el 20/06/2019.

\section{Diagonales}

18-01-2011. "Pérsico: "Bruera prefirió a TN antes que acompañar el proyecto $K$ "”. Sección: La Ciudad.

El Día:

04-02-1999. “Anuncian mejoras en algunas delegaciones” Sección: La Ciudad. 05/09/1999. “El PJ platense le cedió un concejal al cavallismo”. Sección: La Ciudad. 01/08/2000. “"Bruera es agosto”: primer lanzamiento en el PJ local”. Sección: La ciudad. 
19/12/2000. "Reacomodamientos, movidas y acuerdos en la UCR Platense". Sección: El País.

15-10-2001. "La elección municipal: Ganó el PJ y el voto bronca quedó segundo con el $26 \%$ \%. Sección: El País.

01-07-2005. “Fractura y dos nóminas en el alakismo” Sección: El País.

18-11-2005. "Lanzaron en la Provincia nuevo espacio kirchnerista" Sección: La Provincia.

29-05-2007. "El Movimiento Evita se suma al proyecto de Bruera intendente" Sección: La Provincia.

02-09-2007. “Denuncian una campaña sucia contra Bruera” Sección: elecciones 2007.

23-09-2007. “Las listas “espejo”, la nueva moda electoral”. Sección: La Provincia.

08-10-2007. “Auge del vecinalismo y el fenómeno de las tijeras” Sección: La Provincia.

17/10/2008. "Concejal desembarca en el registro de la propiedad”. Sección: La Provincia.

23-12-2008. “Asumió la presidencia del PJ local”, Sección: La Ciudad.

09/05/2009. "Funcionarios e intendentes confirmaron sus candidaturas "testimoniales"”,. Sección: La Provincia.

17/05/2009. “EN La Plata competirán 18 listas de candidatos”. Sección: la Provincia.

07-06-2009. "Radicales califican de "operativo" el resultado de las últimas encuestas" Sección: La Provincia.

25/06/2009. “Kirchner, de caminata por los Hornos". Sección: La Ciudad.

“Audio: Las Palabras de Tereza Razzari”, 29-06-2009. Sección: La Ciudad. Disponible en: http://pasado.eldia.com/edis/20090629/20090629121910.htm

Revisado el 22-05-2016.

03-06-2011. “Acuerdo con Massa y sin competencia en la interna”, Sección: La Provincia

04-06-2011. "Ya con la interna por la gobernación despejada, se reúne el congreso del PJ', Sección: La Provincia

17/06/2011. "Pablo debe tener las manos libres para armar la lista" Sección: La Provincia.

26-06-2011. “Avanzada K y máxima tensión en el peronismo bonaerense” Sección: La Provincia.

29-06-2011. “Intrigas y conjuras tras el cierre de listas del PJ' Autor: Mariano Pérez de Eulate. Sección: Opinión.

01/07/2013. "Insaurralde: "Hoy no está en agenda reformar la Constitución”." Sección: El País. 
11-04-2013. "Reclamos y debate en Plaza Moreno" Sección: La Ciudad.

20/06/2013. "Alicia jugaría por Santa Cruz y crece el rol de los Intendentes". Sección: La Provincia

23-06-2013. "En La Plata, variada oferta para la renovación de Diputados y Concejales" Sección: La Provincia.

03-07-2013. "La campaña bonaerense con Scioli de protagonista”. Autor: Mariano Pérez de Eulate. Sección: Opinión.

23/07/2013. "Gabriel Bruera en el Barrio San Carlos” Sección: Apuntes de campaña.

27/07/2013. "Error en información sobre la lista del Frente Social" Sección: La Provincia.

28/07/2013. "Las visitas a los barrios, el signo de la campaña”. Sección: Opinión.

09/08/2013. “Nueva reunión con vecinos inundados.” Sección: La Ciudad.

24/10/2013. "Candidatos locales del FPV cerraron la campaña electoral en el bosque". Sección: La Ciudad

"Scioli confirmó sus aspiraciones a la presidencia" 12-07-2013. Sección: La Provincia.

20-12-2013. “Nuevo integrante en el bloque del FPV” Sección: La Provincia.

09/06/2015. "Scioli: “Los massistas que vuelven son peronistas que quieren ganar"”. Sección: La Provincia.

22/06/2015. "La ciudad elegirá tres senadores provinciales: se anotaron 17 listas". Sección: La Provincia.

03/07/2015. "Máximo Kirchner en un acto en Santa Cruz junto a Scioli y Zannini”. Sección: El País.

10/07/2015. “Bruera suma apoyos de gremios y randazzistas”. Sección: La Provincia.

25/07/2015. "Nuevos respaldos a la candidatura de Pablo Bruera". Sección La Provincia.

03/08/2015. "Bruera cerró su campaña con Scioli y los precandidatos a gobernador". Sección: La Provincia.

30/08/2015. “Apoyo a Bruera del Movimiento Evita”. Sección: apuntes de campaña.

02/09/2015. “Apoyo a Bruera de sectores peronistas". Sección: apuntes de campaña.

03/09/2015. "Fuertes tironeos en el massismo platense por la lista de Concejales". Sección: La Provincia.

08/09/2015. "Pacharotti confirmó su alejamiento del Frente Renovador". Sección: Breves.

09/09/2015. “El peronismo platense dio otra muestra de unidad”. Sección: apuntes de campaña. 
27/09/2015. "Bruera, de campaña junto a Sabbatella”. Sección: apuntes de campaña.

07/10/2015. “Otra mudanza al FPV desde el massismo platense”. Sección: La Provincia.

09/10/2015. “Otro pase del massismo platense al Frente Para la Victoria”. Sección: La Provincia.

15/10/2015. “Bruera, junto al ex defensor del Pueblo". Sección: apuntes de campaña.

21/10/2015. “Denarvaez ahora vota a Scioli y recibe un aluvión de críticas". Sección: La Provincia.

01/11/2015. “Militantes por Scioli”. Sección La Provincia.

15/11/2015. “Movida local en respaldo a Scioli”. Sección: La Provincia.

01-03-2016. "Lista de asistentes" Sección: La Ciudad.

26/06/2016. “Caravana por la vuelta del tren”. Sección: La Ciudad.

21/09/2016. "Cristina encabezó un acto en La Plata junto a la FULP”. Sección: La Ciudad.

05/06/2017. “Del peronismo y... ¿cuatro listas en La Plata?” Sección: Visto y Oido.

09/06/2017. "Cristina deja afuera el sello del PJ para no darle PASO a Randazzo". Sección: La Provincia.

15/06/2017. “El randazzismo ¿Con más de una lista?”. Sección: La Provincia.

19/06/2017. “Las mil posibilidades del PJ y los K”. Sección: La Provincia.

21/06/2017. "Pujas y posible interna en el peronismo local”. Sección: La Provincia.

24/06/2017. "Intensas negociaciones para la unidad en el peronismo platense”. Sección: La Provincia.

30/08/2017. "“Gano Unidad Ciudadana y perdió el gobierno” dijo Cristina en el relanzamiento de su campaña en La Plata”. Sección: El País.

10/09/2017. “Randazzo juntó a su tropa platense”. Sección: La Provincia.

$\underline{\mathrm{HOY}}$

10/06/2017. "El peronismo se movilizó contra el ajuste”. Sección: Política.

27/07/2017. “Emotivo homenaje a Evita en La Plata”. Sección: Política.

02/08/2017. “DE caprichosas y mejicanos”. Sección: Editorial.

15/09/2017. "Entregaron petitorio con firmas para pedir por la excarcelación de Mariano Bruera". Sección: Política

\section{INFOBAE:}

15-07-2013. "Scioli: "Como dice el paisano, no hay que cambiar de caballo en el medio del río" Sección: Elecciones 2013. 


\section{$\underline{\text { INFOCIELO }}$}

04/03/2017. "Saintout Movilizó 1900 mujeres en SOSBA para respaldar a Cristina". Sección: Política.

11/06/2017. "Magario y Alak compartieron un acto en La Plata: "el gobierno se ha olvidado de los bonaerenses "”.'. Sección: Política.

09/08/2017. "Taiana dijo que hay una situación social "en deterioro" y pidió el voto para Unidad Ciudadana”. Sección: Política

\section{INFOPLATENSE}

28/06/2017. "Es una locura que no se pongan de acuerdo en La Plata: van a malgastar la imagen de nuestro candidato Randazzo". Disponible en: http://www.infoplatense.com.ar/nota/2017-6-28-14-18-0--es-una-locura-que-no-se-pongan-de-acuerdoen-la-plata-van-a-malgastar-la-imagen-de-\%E2\%80\%A61/5 Revisado el 02/03/2018.

\section{La Nación:}

18-11-2005. “Integrar la militancia al Estado”. Sección: Política.

26/03/2011. “Otorgan en La Plata un premio periodístico a Hugo Chávez” Sección: Cultura.

22-06-2011. Mariano Obarrio. "Preocupación en el gobierno por la fuga en el conurbano". Sección: Política.

27-06-2011. Sebastián Lalaurette "La Cámpora se impuso en la lista bonaerense". Sección: Política.

13-05-2012. Pablo Morosi. "Scioli dice que en 2015 quiere ser presidente y crece la pelea". Sección: Política. Internas en el PJ bonaerense.

09-05-2013. "Cristina Kirchner instó a que se investigue el número real de muertos en la tragedia de La Plata" Sección: Política.

07-07-2013. "Apatía electoral y buena imagen de gestión para Cristina y para Scioli" Sección: Política.

26/06/2015. "El secreto detrás de la popularidad de Cristina Kirchner". Sección: Política.

La Política Online

19/08/2017. "Un sector del randazzismo platense anunció que apoyará la lista de Cristina". Sección: Elecciones $2017 . \quad$ Disponible en: http://www.lapoliticaonline.com/nota/107881/ Revisado el 05/03/2019.

\section{$\underline{\text { Letra } \mathrm{P}}$}

15/09/2017. “"EL kirchnerismo sin el resto del PJ no alcanza y el peronismo solo no gana,"'. Sección: Política.

Página 12: 
30-08-2005. "Nuevo escenario, la misma pelea" Sección: El País.

18-04-2012. “"Un gran acto de apoyo” ” Autor: Nicolás Lantos. Sección: El País.

21-06-2014. "La corte ordenó”. Autor: Sergio Kiernan. Sección: M2.

08-05-2015. “Esto no es para blandos ni para tibios” Sección: El País.

$\underline{\text { Perfil }}$

16/07/2014. "Escándalo por coimas en La Plata envuelve al hermano de Bruera". Sección: Política

$\underline{\text { Télam }}$

14/04/2013. "Con una masiva concentración, culminó la jornada de ayuda a los damnificados por el temporal”. Sección: Política.

21/03/2015. "Candidatos del FPV a la gobernación de la Provincia de Buenos Aires intensifican la campaña electoral”. Sección: elecciones 2015.

Todo Noticias:

04-04-2013. "Pablo Bruera y un "error" de su equipo de comunicación" Sección: Sociedad. Disponible en: http://tn.com.ar/sociedad/el-intendente-de-la-plata-y-un-polemicotweet 380877

\section{Documentos Oficiales}

Leyes

Constitución Nacional de la República Argentina, 15 de Diciembre de 1994. Disponible en: http://infoleg.mecon.gov.ar/infolegInternet/anexos/0-4999/804/norma.htm

Constitución de la Provincia de Buenos Aires. 1994. Disponible en: http://www.gob.gba.gov.ar/dijl/constitucion.php

Nacionales:

Decreto Ley nacional $\mathrm{N}^{\mathrm{o}}$ 4161. Boletín Oficial del Poder Ejecutivo de la Nación Argentina, 9 de marzo de 1956. Disponible en: http://www.elortiba.org/pdf/proscripcion.pdf

Ley nacional No 19945, Boletín Oficial de la República Argentina, 19 de diciembre de 1972. Disponible en: http://www.infoleg.gob.ar/infolegInternet/verNorma.do?id=19442

Ley nacional No 23298, Boletín Oficial de la República Argentina, 25 de octubre de 1985. Disponible en: http://www.infoleg.gob.ar/infolegInternet/verNorma.do?id=23893

Ley nacional No 24012, Boletín Oficial de la República Argentina, 3 de diciembre de 1991. Disponible en: http://www.infoleg.gob.ar/infolegInternet/verNorma.do?id=411

Ley nacional № 26215, Boletín Oficial de la República Argentina, 17 de enero de 2007. Disponible en: http://www.infoleg.gob.ar/infolegInternet/verNorma.do?id=124231

Ley nacional No 23522, Boletín Oficial de la República Argentina, 10 de octubre de 
2009. Disponible en: http://www.infoleg.gob.ar/infolegInternet/verNorma.do?id=158649

Ley nacional No 26571, Boletín Oficial de la República Argentina, 11 de diciembre de 2009. Disponible en: http://www.infoleg.gob.ar/infolegInternet/anexos/160000164999/161453/texact.htm

Ley nacional Nº 27412, Boletín Oficial de la República Argentina, 15 de Diciembre de 2017. Disponible

en:http://servicios.infoleg.gob.ar/infolegInternet/verNorma.do?id=304794

De la Provincia de Buenos Aires:

Ley provincial № 5109 (y modificatorias), Boletín Oficial de la Provincia de Buenos Aires, 9 de noviembre de 1946. Disponible en:

http://www.gob.gba.gov.ar/dijl/\#/DIJL_buscador.php?tipo=

Ley provincial No 6769 (y modificatorias), Boletín Oficial de la Provincia de Buenos Aires, 30 de abril de 1958. Disponible en:

http://www.gob.gba.gov.ar/dijl/\#/DIJL buscador.php?tipo=

Ley provincial $\mathrm{N}^{\mathrm{0}}$ 13482, Boletín Oficial de la Provincia de Buenos Aires, 28 de junio de 2006. Disponible en: http://www.gob.gba.gov.ar/dijl///DIJL buscador.php?tipo $=$

Ley provincial No 14086, Boletín Oficial de la Provincia de Buenos Aires, 23 de diciembre de 2009. Disponible en:

http://www.gob.gba.gov.ar/dijl/\#/DIJL buscador.php?tipo $=$

Ley provincial No 14848, Boletín Oficial de la Provincia de Buenos Aires, 19 de Octubre de 2016. Disponible en:

http://www.gob.gba.gov.ar/dijl/\#/DIJL_buscador.php?tipo=01

Documentos oficiales de la Municipalidad de La Plata: Diario de Sesiones del Concejo Deliberante de la Municipalidad de La Plata. 